PROPUESTA DE TESIS PARA OPTAR AL TÍTULO DE
MAGISTER SCIENTIAE EN MANEJO INTEGRAL DE CUENCAS HIDROGRÁFICAS

Tesis

Maestría en Manejo Integral de Cuencas Hidrográficas.

\title{
TÍTULO:
}

\section{ALTERNATIVAS DE MANEJO SUSTENTABLE DE LA SUBCUENCA DEL RÍO PITURA, PROVINCIA DE IMBABURA, ECUADOR.}

Alternatives to a Sustainable Management of the Subwatershed of the Pitura River, Imbabura Province, Ecuador.

Tesista: Ing. Jorge Luis Ramírez López

Secretaría Nacional de Educación Superior, Ciencia, Tecnología e Innovación del Ecuador (SENESCYT).

Sánchez y Cifuentes y Velasco, edificio La Previsora. Ibarra, Ecuador. jorgechula@hotmail.com

Director: Mg. Sci. Gerardo Denegri

Universidad Nacional de La Plata, Facultad de Ciencias Agrarias y Forestales 


\section{INDICE}

1. INTRODUCCIÓN 10

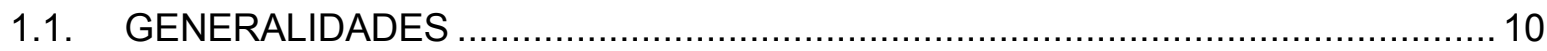

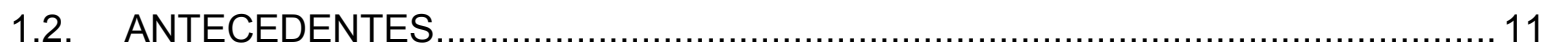

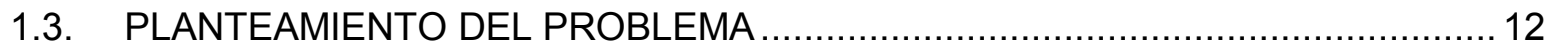

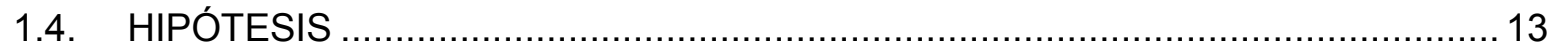

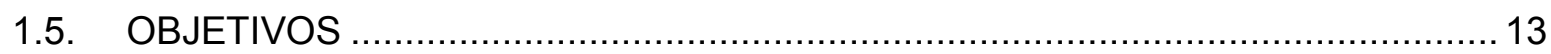

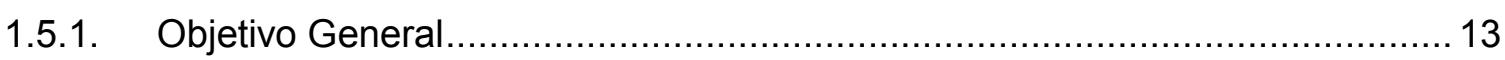

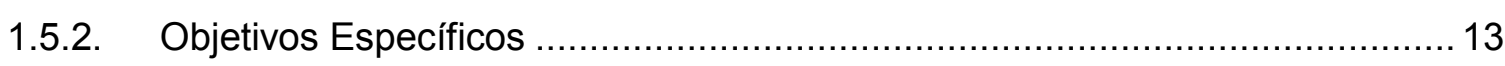

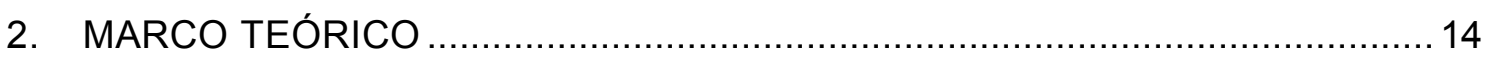

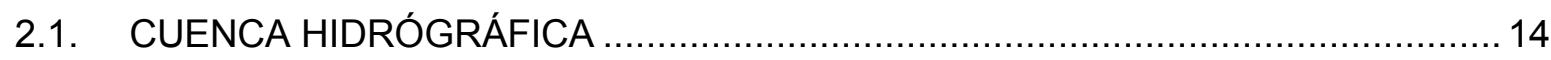

2.1.1. Características morfológicas de la cuenca............................................. 15

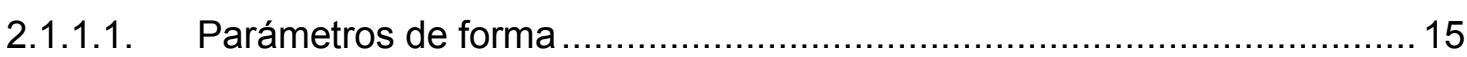

2.1.1.2. Parámetros de relieve ................................................................. 17

2.1.1.3. Parámetros relativos a la red hidrográfica......................................... 18

2.2. EL MANEJO INTEGRAL DE CUENCAS HIDROGRÁFICAS ............................... 19

2.2.1. Definición de Manejo Integral de Cuencas Hidrográficas .............................. 19

2.2.2. Objetivo del Manejo Integral de Cuencas Hidrográficas................................. 19

2.2.3. Planificación de Cuencas Hidrográficas ..................................................... 20

2.2.4. Ordenación de Cuencas Hidrográficas ...................................................... 21

2.2.5. Limitantes del Manejo Integral de Cuencas Hidrográficas............................. 22

2.3. EL MANEJO DE CUENCAS EN EL ECUADOR …........................................ 22

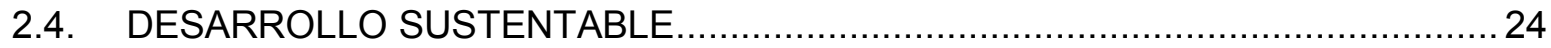

2.4.1. Definición y Alcance del Desarrollo Sustentable ........................................... 24

2.4.2. Dimensiones de la Sustentabilidad .................................................... 25

2.4.2.1. La Dimensión Ecológica o Ambiental................................................ 25

2.4.2.2. La Dimensión Socio-Cultural ..................................................... 25

2.4.2.3. La Dimensión Económica ..................................................................... 26

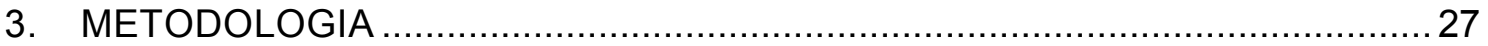

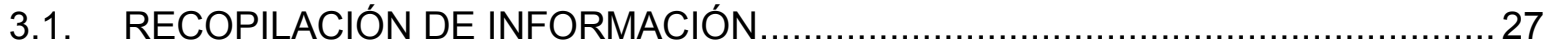

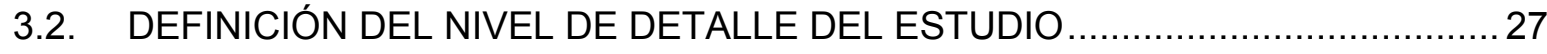

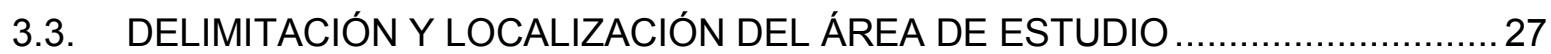


3.4. CARACTERIZACIÓN MORFOMÉTRICA DE LA CUENCA ............................... 28

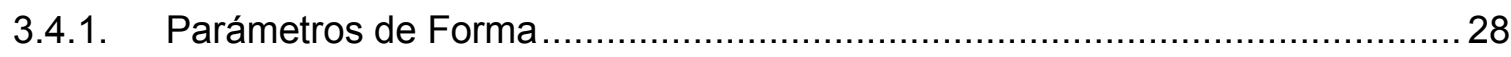

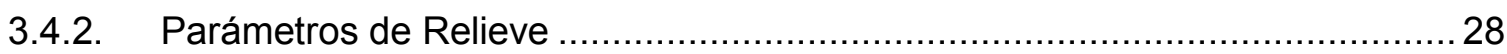

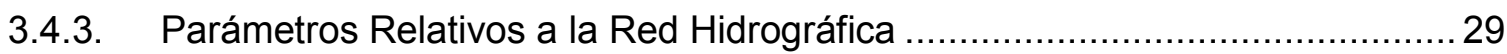

3.5. CARACTERIZACIÓN BIOFÍSICA DE LA CUENCA ........................................ 30

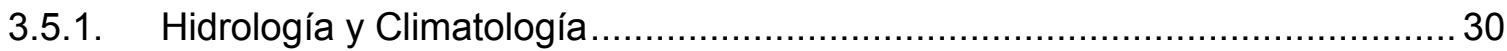

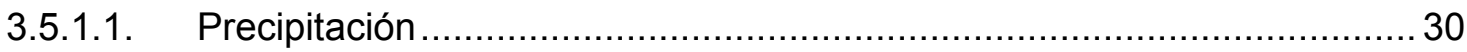

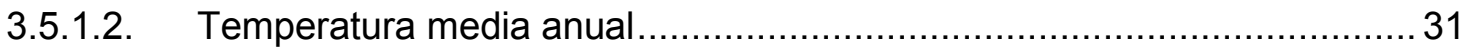

3.5.1.3. Determinación de zonas climáticas.............................................. 31

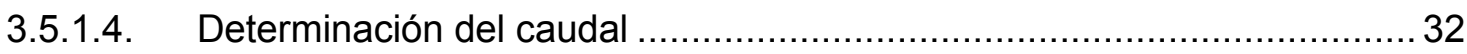

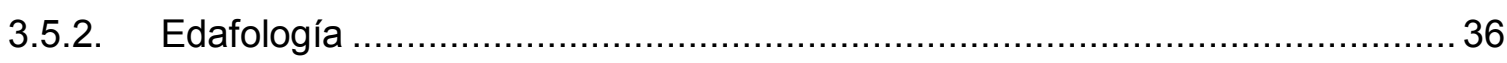

3.5.2.1. Determinación de tipos de suelos .................................................. 36

3.5.2.2. Determinación de pendientes del suelo ............................................... 36

3.5.2.3. Determinación del uso actual del suelo y cobertura vegetal.................... 37

3.5.2.4. Determinación de uso potencial del suelo........................................... 37

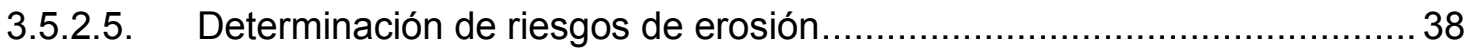

3.5.2.6. Determinación del cambio de uso del suelo..................................... 38

3.5.2.7. Determinación de la pérdida del suelo ............................................. 40

3.6. CARACTERIACIÓN SOCIO-CULTURAL DE LA CUENCA .............................. 44

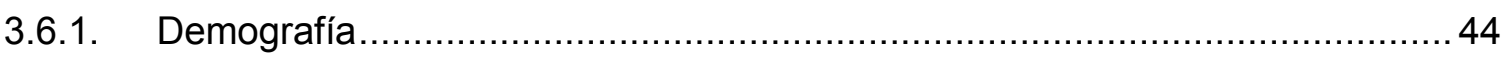

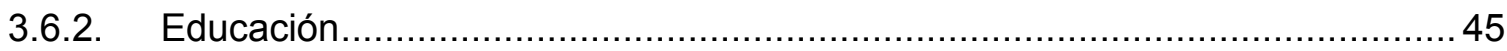

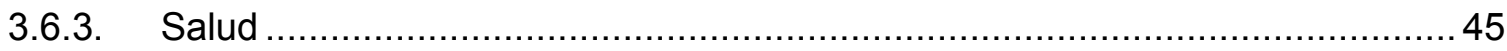

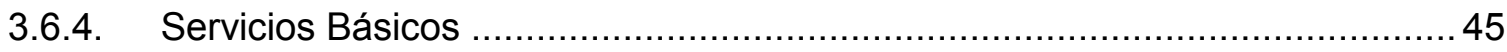

3.7. CARACTERIZAZCIÓN ECONÓMICO - PRODUCTIVA .................................. 45

3.7.1. Principales Actividades Económicas...................................................... 45

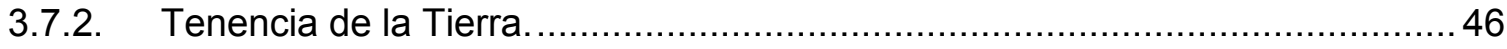

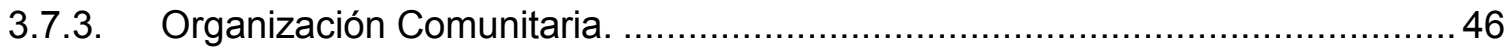

3.8. EVALUACIÓN DE IMPACTOS DENTRO DE LA CUENCA ….............................46

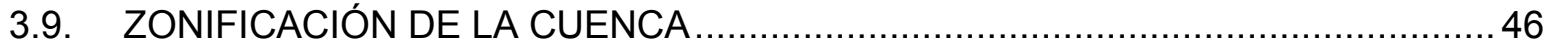

3.10. Elaboración de la Propuesta de Manejo de la Cuenca........................................ 47

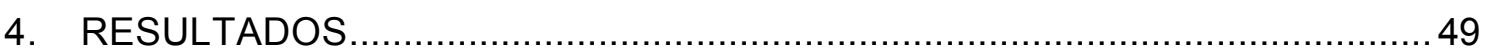

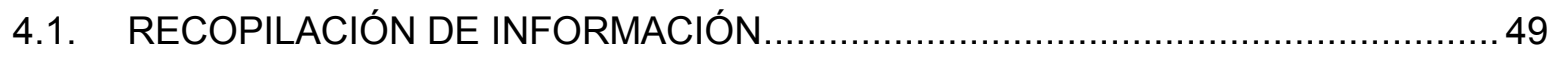

4.2. DEFINICIÓN DEL NIVEL DE DETALLE DEL ESTUDIO .................................. 49

4.3. DELIMITACIÓN Y LOCALIZACIÓN DEL ÁREA DE ESTUDIO ............................. 50 
4.3.1. Delimitación de la Subcuenca del río Pitura................................................. 50

4.3.2. Ubicación Geográfica de la Subcuenca del río Pitura. .................................... 51

4.4. CARACTERIZACIÓN MORFOMÉTRICA DE LA CUENCA ............................... 52

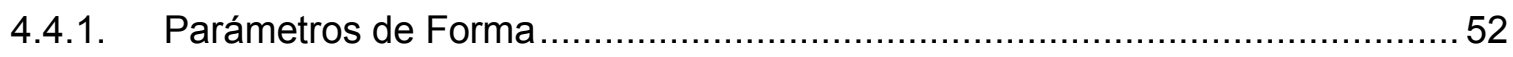

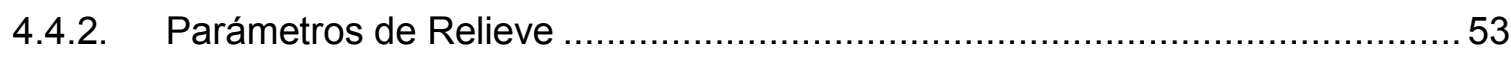

4.4.3. Parámetros Relativos a la Red Hidrográfica ............................................. 54

4.5. CARACTERIZACIÓN BIOFÍSICA DE LA CUENCA ...................................... 55

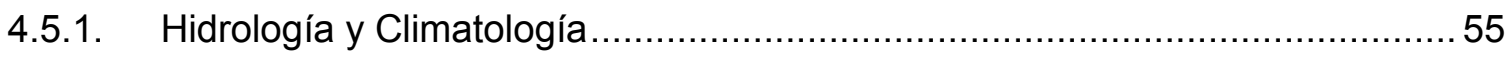

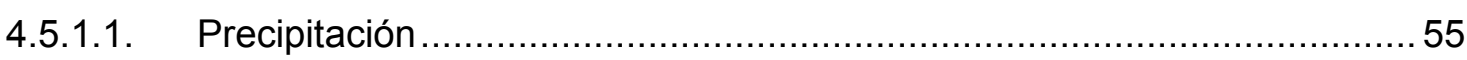

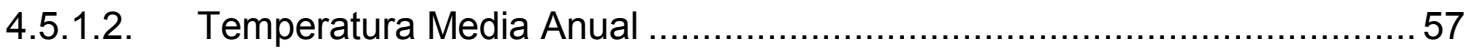

4.5.1.3. Determinación de zonas climáticas................................................. 58

4.5.1.4. Determinación del Caudal......................................................... 60

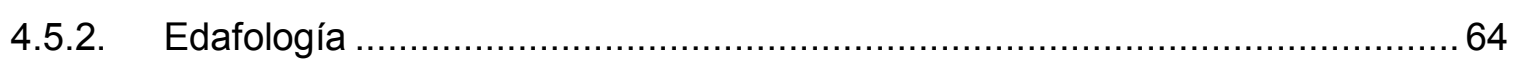

4.5.2.1. Determinación de Tipos de Suelos .............................................. 64

4.5.2.2. Determinación de Pendientes del Suelo ............................................66

4.5.2.3. Determinación del Uso Actual y Cobertura Vegetal del Suelo..................69 69

4.5.2.4. Determinación de Uso Potencial del Suelo.......................................... 73

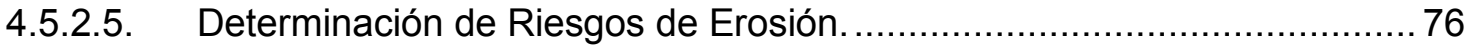

4.5.2.6. Determinación de Cambio de Uso del Suelo. ..................................... 79

4.5.2.7. Determinación de la Pérdida del Suelo.................................................. 87

4.6. CARACTERIACIÓN SOCIO-CULTURAL DE LA CUENCA .............................. 93

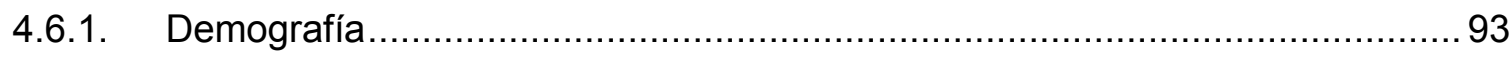

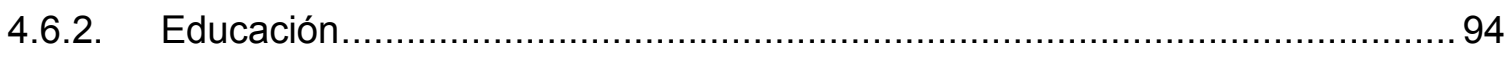

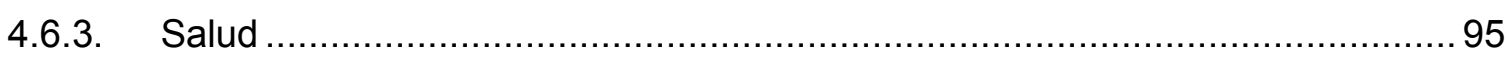

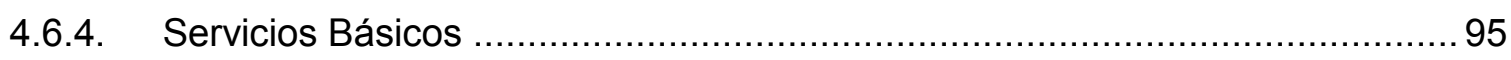

4.7. CARACTERIZAZCIÓN ECONÓMICO - PRODUCTIVA ................................ 96

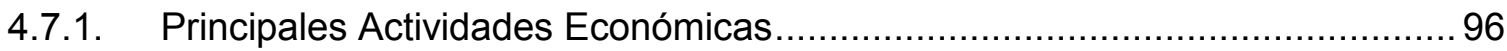

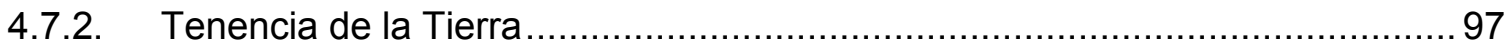

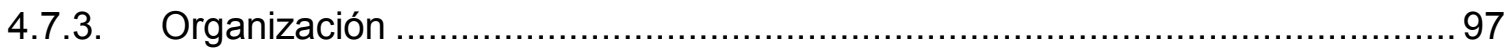

4.8. EVALUACIÓN DE IMPACTOS DENTRO DE LA CUENCA ..............................98

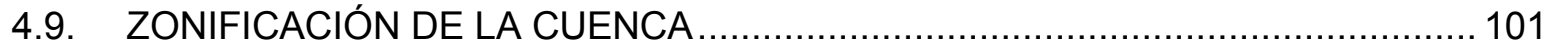

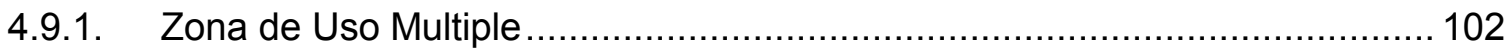

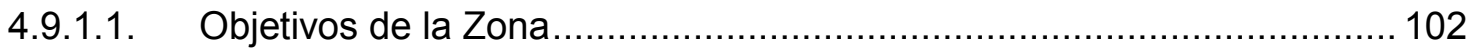

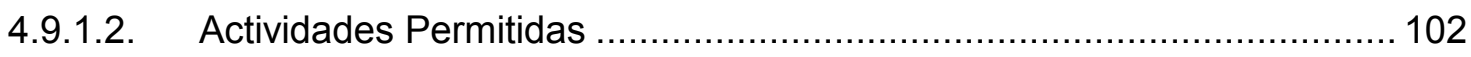

4.9.2. Zona de Manejo y Recuperación de Suelos ............................................ 103 


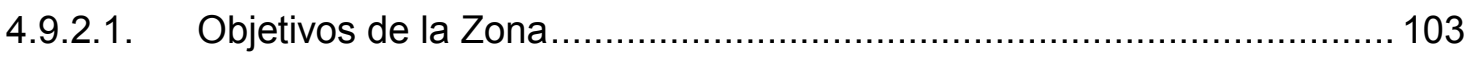

4.9.2.2. Actividades Permitidas ............................................................. 103

4.9.3. Zona de Conseravción y Ecoturismo .......................................................... 104

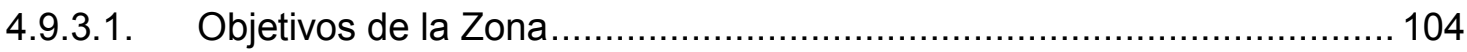

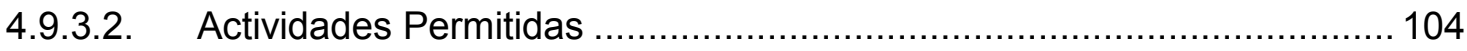

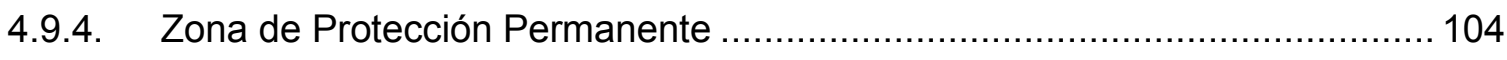

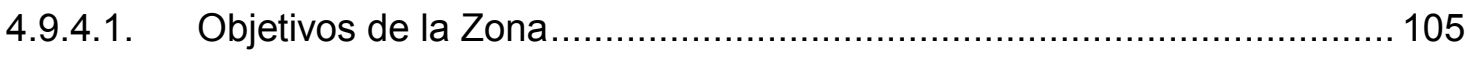

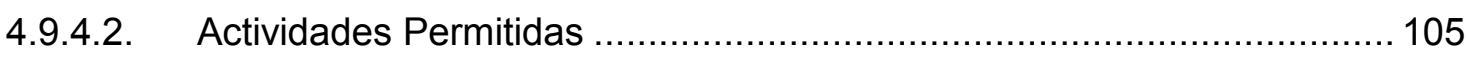

5. PROPUESTA DE PLAN DE MANEJO …................................................. 106

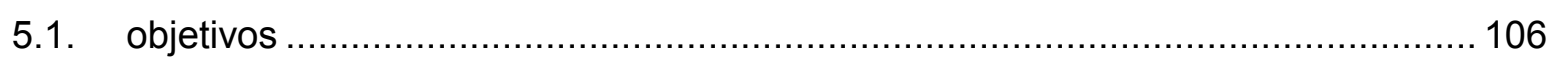

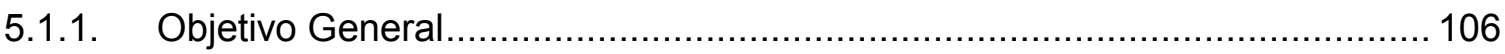

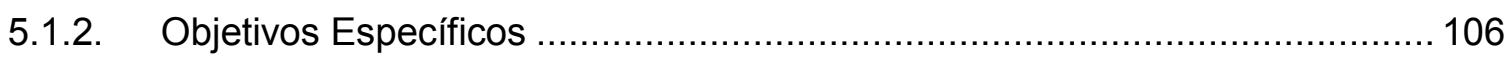

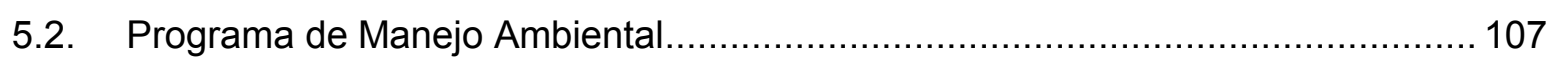

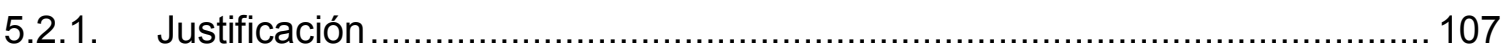

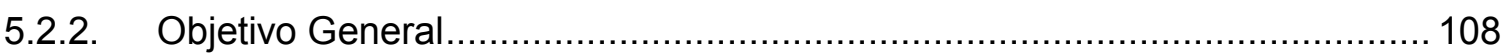

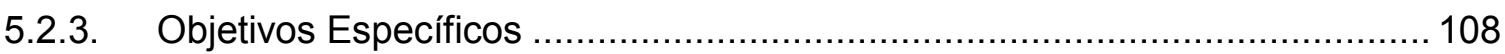

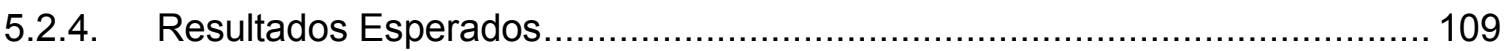

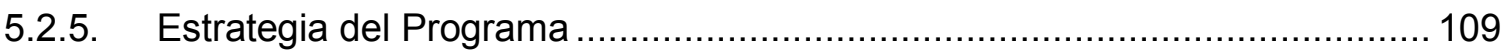

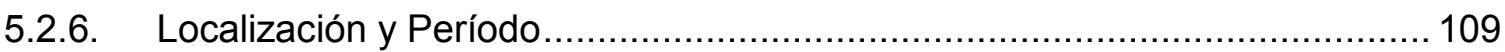

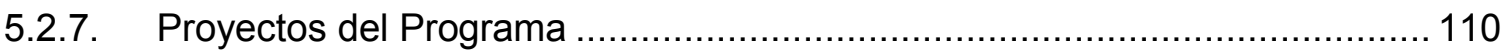

5.3. Programa de Gestión Productiva ..................................................................... 110

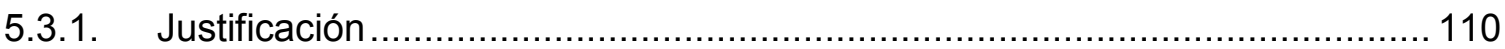

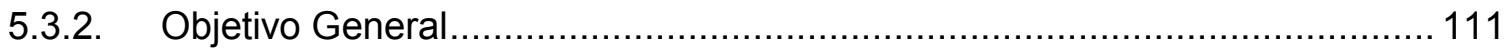

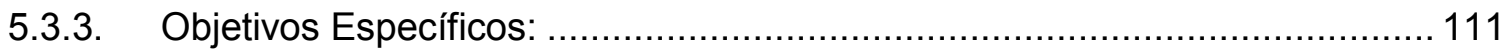

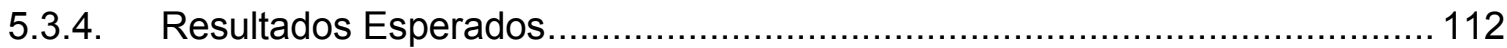

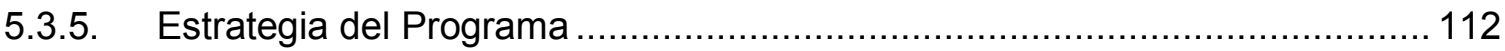

5.3.6. Localización y Período para la Ejecución del Programa .............................. 113

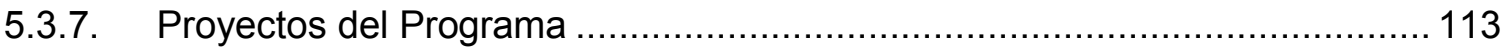

5.4. Programa de Desarrollo Comunitario.......................................................... 113

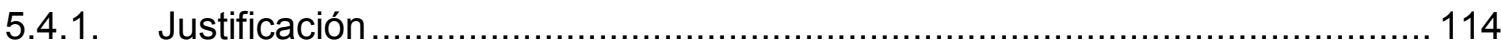

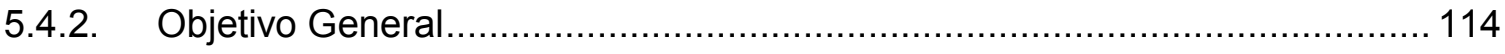

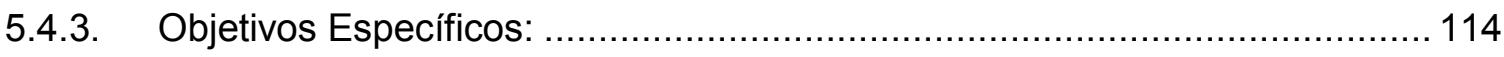

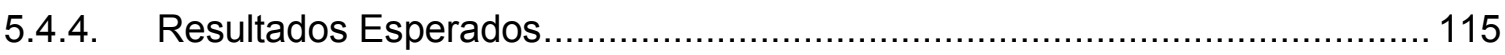

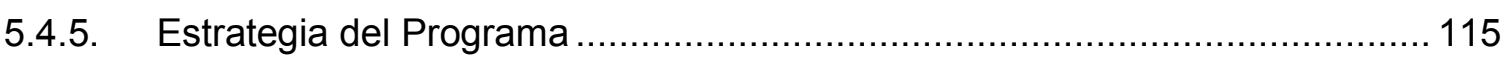

5.4.6. Localización y Período para la Ejecución del Programa .............................. 115 


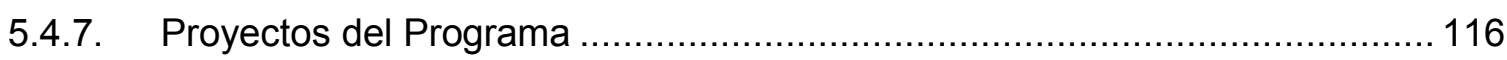

5.5. Programa de Capacitación y Organización Comunitaria ................................... 116

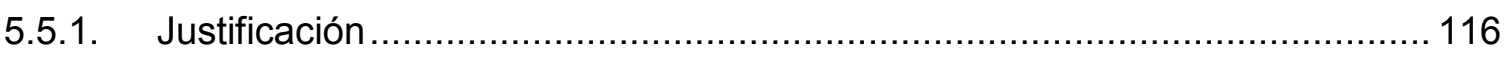

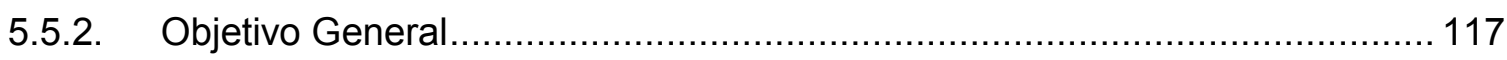

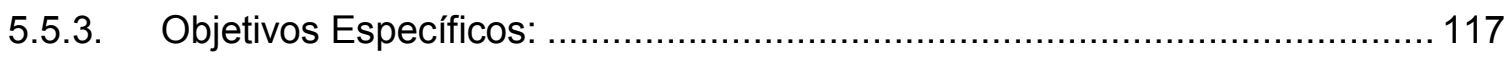

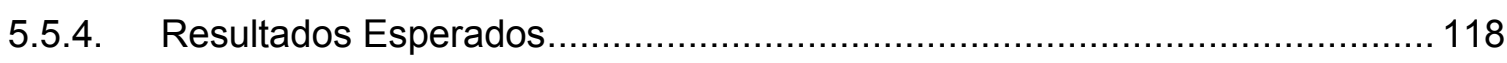

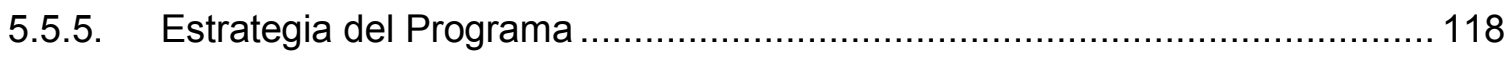

5.5.6. Localización y Período para la Ejecución del Programa ............................... 119

5.5.7. Proyectos del Programa .................................................................... 119

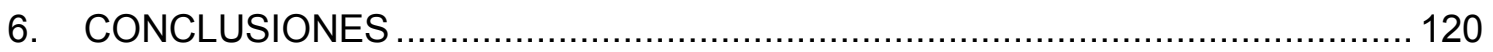

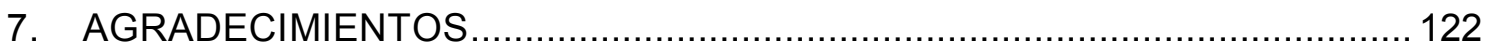

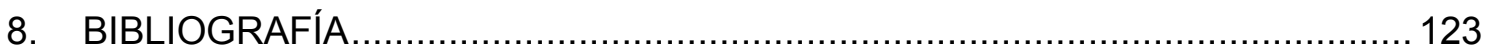

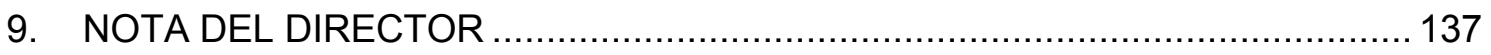

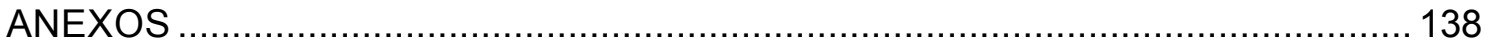

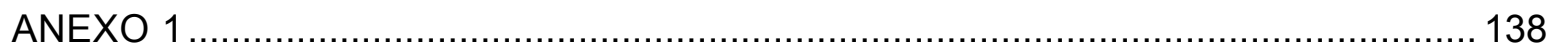

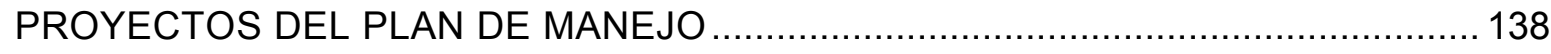

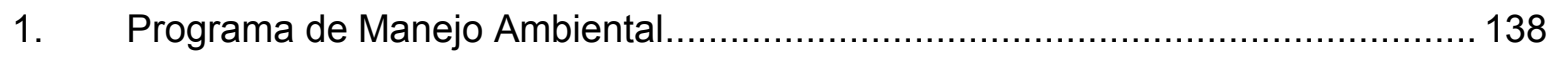

1.1. Proyecto de Conservación y Manejo de los Recursos Naturales..................... 138

1.1.1. Componente de Manejo de Recursos Naturales .................................. 138

1.1.2. Componente de Fortalecimiento de las Zonas de Protección y Conservación 140

1.1.3. Componente Fomento del Ecoturismo ............................................. 141

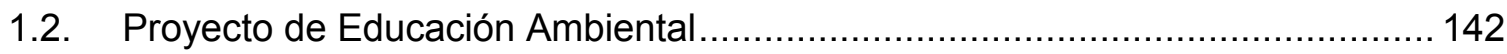

1.2.1. Componente de Formación Ambiental Comunitaria ............................... 143

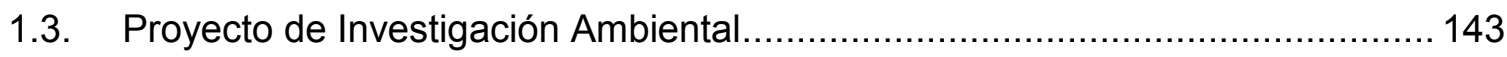

1.3.1. Componente de Investigación Básica ............................................... 143

1.3.2. Componente Uso Apropiado de los Recursos ..................................... 144

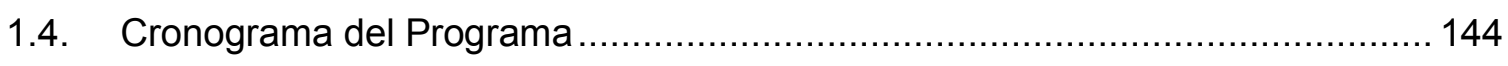

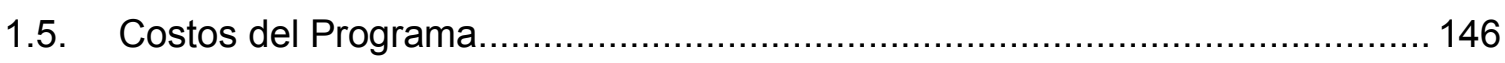

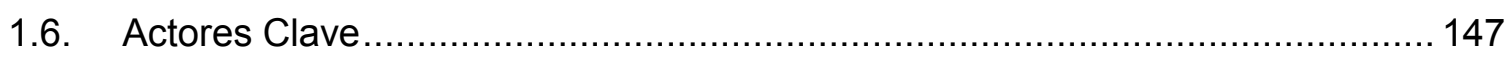

2. Proyectos del Programa de Gestión Productiva........................................ 148

2.1. Proyecto de Mejoramiento de la Producción Agrícola .................................... 148

2.2. Proyecto de Mejoramiento de la Producción Ganadera.................................. 149

2.3. Proyecto de Capacitación y Asistencia Técnica ........................................... 150

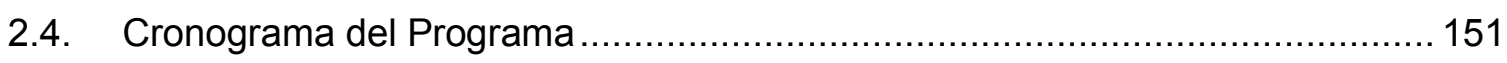

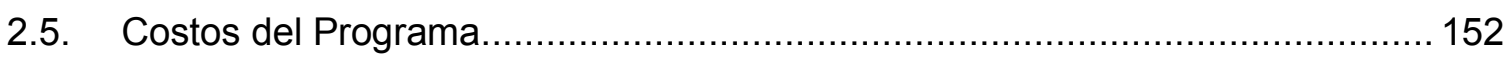




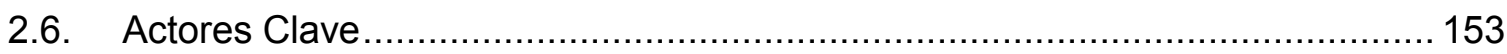

3. Proyectos del Programa de Desarrollo Comunitario. ...................................... 153

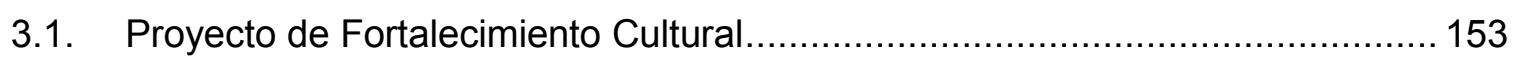

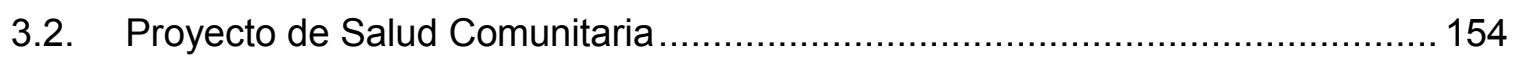

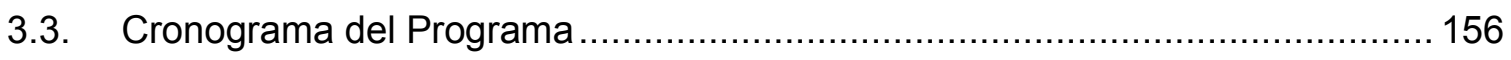

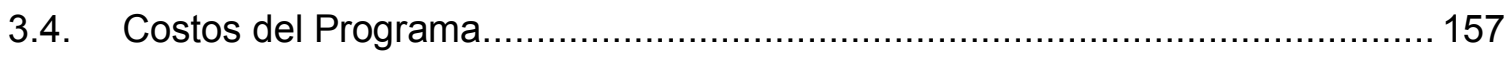

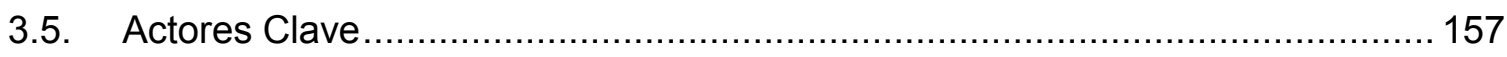

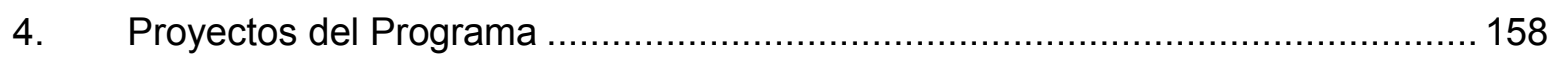

4.1. Proyecto de Capacitación para el Fortalecimiento de Organizaciones ............. 158

4.2. Proyecto de Desarrollo Integral de la Mujer Comunitaria................................... 159

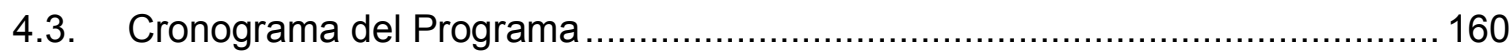

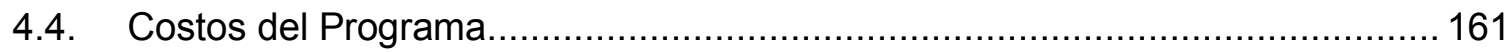

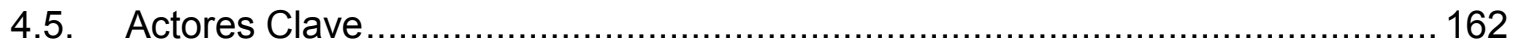




\section{TITULO}

Alternativas de Manejo Sustentable de la Subcuenca del Río Pitura, Provincia de Imbabura, Ecuador.

\section{RESUMEN}

El presente trabajo propone alternativas para alcanzar un manejo sustentable de la subcuenca del río Pitura. Se realizó una caracterización biofísica y socioeconómica para determinar las características y principales problemas que enfrenta el área de estudio; y mediante el análisis de impactos y zonificación, se construyó los diferentes programas y proyectos del plan de manejo de la subcuenca.

Los principales problemas encontrados, son la falta de planificación en el ordenamiento y uso del suelo, provocando un incremento del área de intervención y una disminución de los ecosistemas naturales; acompañado de la falta de manejo en las actividades productivas y una dependencia económica hacia la ganadería por parte de los pobladores. Los diferentes programas elaborados contribuirán a la solución de los problemas presentes en la subcuenca, generando una propuesta de conservación integral de los recursos, mejoramiento de la administración, manejo y protección de los ecosistemas, y el desarrollo de las comunidades.

\section{PALABRAS CLAVE}

Caracterización biofísica y socioeconómica, zonificación, evaluación de impactos, plan de manejo.

\section{TíTULO ABREVIADO}

Manejo Sustentable de la Subcuenca del Pitura 


\section{TITLE}

Alternatives to a Sustainable Management of the Subwatershed of the Pitura River, Imbabura Province, Ecuador.

\section{ABSTRACT}

This paper proposes alternatives to achieve a sustainable management of subwatershed of Pitura river. A biophysical and socioeconomic characterization was performed to determine characteristics and main problems facing the study area; and by analyzing impacts and zoning, different programs and projects for management plan of subwatershed were built.

Main concerns are the lack of planning in the system and land use, causing an increase in the intervention area and a decrease in natural ecosystems; accompanied by a lack of management in productive activities and an economic dependence on livestock by settlers. some elaborated programs will contribute in solving problems of the subwatershed, generating a comprehensive conservation of resources proposal, ecosystems administration, management and protection, and the development of communities.

\section{KEYWORDS}

Biophysical and socioeconomic characterization, zoning, impact assessment, management plan.

\section{SHORT TITLE}

Sustainable Management of the Subwatershed of the Pitura. 


\section{INTRODUCCIÓN}

\subsection{GENERALIDADES}

Imbabura, conocida también como la provincia de los lagos, se encuentra ubicada en la sierra norte del Ecuador; limita al norte con las provincias de Carchi y de Esmeraldas, al sur con la provincia de Pichincha, al este con las provincias de Sucumbíos y Napo y al oeste con la provincia de Esmeraldas; dentro de las coordenadas: $00^{\circ} 07$ y $00^{\circ} 52$ latitud norte; $77^{\circ} 48^{\prime}$ y $79^{\circ} 12^{\prime}$ longitud oeste. (IGM, 2013).

La capital de esta provincia es la ciudad de Ibarra y los cantones que la conforman son: Ibarra, Antonio Ante, Otavalo, Cotacachi, Pimampiro y San Miguel de Urcuquí, los cuales se asientan en una extensión de 4353 km² aproximadamente (IGM, 2013), con una población de 398244 habitantes según el último Censo de Población y Vivienda realizado en el 2010 (INEC, 2010).

El sistema hidrológico de la provincia está constituido por las cuencas, de los ríos Chota-Mira, Ambi, Tahuando, Intag, Pitura y Lita, entre los más importantes, por su superficie, los recursos disponibles, y la población que albergan (Flores, 2010). Alberga en su superficie pisos climáticos desde el meso térmico húmedo hasta el páramo (Flores, 2010), con temperaturas que oscilan entre $7^{\circ} \mathrm{C}$ y $28^{\circ} \mathrm{C}$ y precipitaciones entre los 340 y 3000 m.m. anuales (INAMHI, 2012).

Uno de los ecosistemas más afectados en Imbabura y toda la sierra norte ecuatoriana es el páramo (Ramsay \& Oxley, 2001), caracterizado por una vegetación herbácea y arbustiva con alta biodiversidad y endemismo (Monasterio \& Molinillo, 2003), que cubre 1337119 hectáreas de las cordilleras Oriental y Occidental del Ecuador (Beltrán, et. al., 2009). Es de gran importancia para el abastecimiento de agua de casi la totalidad de las ciudades y poblados de las partes bajas de los andes al tener características que le permiten almacenar este recurso en el suelo y su vegetación (Beltrán, et. al., 2009). Sin embargo los campesinos y hacendados que ocupan el ecosistema lo ven como el territorio en el que desarrollan sus actividades productivas (Hofstede, et. al., 2014), bajo este concepto se han destinado grandes extensiones al desarrollo de la ganadería extensiva, como principal actividad de generación de ingresos económicas (Ramsay \& Oxley, 2001). La ganadería está acompañada de constantes quemas para la generación de pastos nuevos y nutritivos (Ramsay, 1999), provocando procesos adversos en la funcionalidad del páramo como el desequilibrio hidrológico. Pese a que los productores tienen conocimiento del efecto negativo de las prácticas utilizadas, no se ha realizado mayores cambios en su accionar (Hofstede, et. al., 2014). 
El cambio de cobertura vegetal ocasiona inestabilidad en todos los componentes del ecosistema, siendo el suelo uno de los más afectados (Zapata, 2002), su deterioro es más acelerado en las partes altas de las cordilleras que lo observado en las partes bajas. La erosión en algunas áreas es tan severa que generan una alta producción de sedimentos (IICAPROCIANDINO, 1995), los suelos de las cadenas montañosas con pendientes muy pronunciadas, muestran signos de afloramiento de cangahua ${ }^{1}$ y la pérdida total del suelo fértil (Córdova \& Novoa, 1997).

El estudio de alternativas para llegar a un manejo Sustentable de los recursos naturales, está conceptualizado como un instrumento de planificación que tiene a la cuenca hidrográfica como unidad de gestión, siendo un apoyo para la toma de decisiones de pobladores y organismos encargados de su administración.

\subsection{ANTECEDENTES}

La subcuenca del río Pitura, se encuentra dentro del área de influencia del "Proyecto Multipropósito Tumbabiro", que inicio entre los años 1970 y 1980 como el proyecto "PiñanTumbabiro" con los estudios realizados por el ex Instituto Nacional de Recursos Hídricos (INERHI) (Cando, 2014), posteriormente se realizaron nuevos estudios entre los cuales se pueden mencionar al Estudio de Factibilidad del Proyecto de Irrigación Tumbabiro o los realizados por la Consultora Japonesa Pacific Consultans International Naigai Engineering Co.Ltda, que concluyeron en el año 1994, sin poder finalizar el proyecto (Cando, 2014).

Finalmente el proyecto es retomado por la Secretaría Nacional del Agua (SENAGUA), como un proyecto prioritario de riego, consumo humano y generación hidroeléctrica, que beneficiará a las poblaciones de Ibarra, Ambuquí, Pimampiro, Carpuela, Juncal, Chota y San Alfonso (Innovativa-ESPE, 2014a). La Universidad Técnica del Norte mediante concurso público se adjudica la fiscalización del proyecto (Cando, 2014) y proporciona datos de la zona de influencia del "Proyecto Multipropósito Tumbabiro", a alumnos, egresados y graduados de este centro de estudio, para la realización de distintas investigaciones, entre ellos el presente trabajo.

\footnotetext{
${ }_{1}^{1}$ Material fino endurecido. Que se puede encontrar en posición aflorante o cubierto por formaciones. en el primer caso se puede tener una superficie dura aflorante (duripan) o un suelo (durustoll y durandept) que es el resultado del ablandamiento de dicha superficie dura por el hombre. (Custode, E., 1.992)
} 
Los resultados expuestos en los estudios del proyecto, muestran la gran importancia de la subcuenca del río Pitura para el abastecimiento de agua de las poblaciones ubicadas en las partes bajas de las parroquias de Imantag, Apuela, Cahuasquí, San Blas, Urcuquí y la nueva Ciudad del Conocimiento "Yachay" (Innovativa-ESPE, 2014a). Sin embargo esta subcuenca cubierta en su mayor parte por páramo andino, se está viendo afectada por la actividad ganadera, que transforma grandes extensiones de ecosistemas naturales en potreros y pastizales en donde los animales son liberados sin ninguna clase de control. (InnovativaESPE, 2014a).

\subsection{PLANTEAMIENTO DEL PROBLEMA}

Los problemas que afronta la subcuenca del río Pitura están derivados fundamentalmente de la actividad antrópica, que durante las últimas décadas ha ido intensificándose, contribuyendo a una acelerada degradación y contaminación de los ecosistemas de la subcuenca (Cando, 2014).

Las actividades agropecuarias son la principal fuente de ingreso de las comunidades asentadas dentro de la subcuenca; sin embargo, sus prácticas no cuentan con lineamientos de manejo técnico, lo que las convierte también en una de las principales causas de degradación ambiental (Innovativa-ESPE, 2014a). Esta situación se ve agravada por la topografía de la subcuenca que presenta pendientes muy pronunciadas, y por la vulnerabilidad del páramo andino, ecosistema que cubre la mayor parte de la zona de estudio. Los suelos de los páramos por su estructura y porosidad presentan condiciones favorables para las actividades agropecuarias, incluso en pendientes pronunciadas, lo que ha causado incesantes cambios de uso de suelo (Podwojewski, \& Poulenard, 2000), generando problemas ambientales tales como erosión, cambios en los cursos del agua, producción de aguas residuales, desechos de las cosechas, desechos de animales, entre otros (Sarandón et.al., 2014). El deterioro descrito afecta la provisión de servicios ecosistémicos como procesos de producción y regulación hídrica, biodiversidad, paisajes y retención de suelos (Caballero, 2014).

Al atravesar diferentes unidades político-administrativas con diferentes intereses ambientales, económicos y sociales, no se ha podido realizar una verdadera planificación en el uso de los recursos naturales y territorio de la subcuenca, por lo que la generación de alternativas para alcanzar el desarrollo sustentable, a través de la aplicación de un plan de manejo integral se 
presenta como una herramienta inicial para enfrentar el deterioro de los ecosistemas naturales de la subcuenca y satisfacer las necesidades de sus habitantes.

\subsection{HIPÓTESIS}

Los ecosistemas encontrados dentro de la subcuenca del río Pitura, están degradados principalmente por las actividades agropecuarias, una planificación integradora en el manejo de los recursos de la subcuenca del río Pitura constituye una etapa inicial en su recuperación.

\subsection{OBJETIVOS}

\subsubsection{Objetivo General}

Proponer una alternativa de manejo sustentable de la subcuenca del río Pitura, mediante la formulación de un plan de manejo integral.

\subsubsection{Objetivos Específicos}

- Describir la red hidrológica de la subcuenca del río Pitura, mediante parámetros morfométricos.

- Diagnosticar el estado biofísico de la subcuenca del río Pitura.

- Diagnosticar el estado socioeconómico de la subcuenca del río Pitura.

- Proponer alternativas de manejo sustentable, aplicables a la subcuenca del río Pitura. 


\section{MARCO TEÓRICO}

\subsection{CUENCA HIDRÓGRÁFICA}

Una cuenca hidrográfica es el área físico-geográfica delimitada por divisorias topográficas o edáficas en donde las aguas superficiales y subterráneas desembocan en una red natural mediante vertientes que confluyen a su vez en un río principal, en un depósito natural de aguas, en un pantano o directamente en el mar (Valderrama Plata, 1985).

También se puede definir a una cuenca hidrográfica como el área natural en donde se acumula el agua proveniente de las precipitaciones formando un cauce principal, las divisorias de agua son formadas naturalmente por los puntos más altos que encierran el río principal y los sistemas de cursos de agua que desembocan en él, formando así una unidad fisiográfica (Ramakrishna, 1997).

En la actualidad el concepto de cuenca hidrográfica abarca más allá de sus límites naturales y sus características biofísicas, agregándole las diferentes relaciones que se generan entre los recursos naturales y los habitantes de la cuenca, que cambian de una cuenca a otra por las condiciones físicas, biológicas, económicas, sociales y culturales particulares de cada una (Aguilar, 2007). Los componentes biofísicos, biológicos y antropológicos que interrelacionan dentro de la cuenca deben estar en equilibrio, ya que al afectarse uno de ellos pone en peligro todo el sistema (Ramakrishna, 1997).

Es así que una cuenca es una fuente natural de captación de agua, con una realidad social propia establecida por las relaciones económicas, culturales, sociales y políticas que se establecen entre los diferentes grupos sociales (Aguilar, 2007). Transformándose en un sistema en el que interactúan sus componentes en el tiempo y el espacio, siendo el recurso hídrico el eje integrador (Gonzales, et. al., 2013). En la cuenca se denota el desarrollo histórico de las poblaciones, intereses y hábitos, que definen la forma como se organiza el territorio y las diferentes prácticas productivas que se realizan (Aguilar, 2007).

Por lo tanto las cuencas hidrográficas deben ser tratadas como unidades de planificación ordenamiento territorial y gestión, para el manejo de los recursos naturales, ya que la conservación de estos recursos no está circunscrita a límites geográficos o políticos, sino más bien al accionar y características sociales, culturales y económicas de la población asentada dentro de la cuenca y el deterioro ambiental que generan sus prácticas de producción (Gaspari, et. al., 2010). 


\subsubsection{Características morfológicas de la cuenca}

Las características fisiográficas de una cuenca hidrográfica pueden ser explicados, mediante el procesamiento de la información cartográfica y topográfica de la zona de estudio (Gaspari, et. al., 2010). Estos parámetros morfométricos se obtienen mediante un conjunto de estimaciones realizadas al emprender un estudio de tipo hidrológico, para determinar las condiciones hidrológicas básicas (Aguirre, 2007).

El análisis morfométrico permite conocer las características físicas de una cuenca mediante el estudio de las particularidades de superficie, relieve e hidrografía, que permite realizar comparaciones con otras cuencas y ayuda a entender el complejo de su funcionamiento hidrológico y las consideraciones necesarias para su manejo. (Aguirre, 2007).

Los parámetros morfométricos se clasifican en:

\subsubsection{Parámetros de forma}

\section{- Perímetro (P)}

Es la medición del contorno que encierra el área de la cuenca hidrográfica, por la divisoria de aguas (Gaspari, et. al., 2010).

\section{- Longitud Axial (La)}

Es la distancia entre el desagüe y el punto más lejano de la cuenca. Es el eje de la cuenca (Beltrán, 2010). Es decir es la mayor distancia medida en kilómetros, desde la parte más alta de la cuenca hasta su desembocadura, en sentido del cauce principal (Fierro \& Jiménez, 2011).

\section{- Área (A).}

Es la superficie encerrada por la divisoria de aguas medida en kilómetros, que permite definir el tamaño y el nombre para la caracterización de la cuenca (Gaspari, et. al., 2010).

\section{- Ancho promedio (Ap).}

Es la relación entre la superficie de la cuenca con su longitud axial obtenida en kilómetros (Burbano, 1989). 


\section{- Factor de forma (IF).}

Este es un indicador que nos permite aproximar la forma de la cuenca a una forma geométrica, a fin de poder determinar la velocidad con la que el agua llega al río principal de la cuenca (Fierro \& Jiménez, 2011). Por este motivo es importante conocerlo para tener referencias en las crecientes de la red hidrográfica; una cuenca alargada es menos susceptible a crecidas de gran magnitud que una redondeada (Beltrán, 2010).

Cuando IF es similar a 1, se está ante una cuenca de forma redondeada, y en los casos en que IF es menor a 1, se caracteriza por ser una cuenca alargada (Gaspari, et. al., 2010: 7).

\section{- Coeficiente de compacidad de Gravelius (Kc).}

Es un índice adimensional que relaciona el perímetro de la cuenca con el perímetro de un círculo de área equivalente al de la cuenca (Burbano, 1989).

El valor de este parámetro varía entre 1 y 1,75 , este valor será mayor a medida de que aumente la irregularidad de la forma de la cuenca. Cuando el valor es más cercano a 1 la cuenca se asemeja a una circunferencia y el tiempo de concentración es menor, haciéndola más susceptible a las crecidas (Gaspari, et. al., 2010).

TABLA 1: Rangos del coeficiente de Gravelius (Kc), (Gaspari et. al., 2010).

\begin{tabular}{ll}
\hline Valor Kc & Forma de la cuenca \\
\hline $\mathrm{Kc}=1,00$ & Redonda \\
$\mathrm{Kc}=1,25$ & Oval redonda \\
$\mathrm{Kc}=1,50$ & Oblonga \\
$\mathrm{Kc}=1,75$ & Rectangular oblonga \\
\hline
\end{tabular}

Kc: Coeficiente de Graveluis

\section{- Índice de alargamiento (lal).}

Es el cociente entre el recorrido más largo del agua y el ancho promedio del área dr4nada de la cuenca (Fierro \& Jiménez, 2011). Cuando este índice tiene un valor alto, se asemeja a un rectángulo de iguales dimensiones que las de la cuenca, tomando una forma alargada y formando un pequeño ángulo entre el cauce principal y los afluentes de la red 
hidrográfica. (Gaspari, et. al., 2010). Este se relaciona con el tiempo de concentración de la cuenca (Yaguachi, 2013).

\section{- Índice de homogeneidad (Ih).}

Se define como la relación que existe entre el área de la cuenca y un rectángulo de igual superficie, complementario al índice de alargamiento (Gaspari, et. al., 2010).

\subsubsection{Parámetros de relieve}

\section{- Curva hipsométrica (CH)}

Es la distribución del área de las áreas parciales de la cuenca de acuerdo a un rango de elevación. Permite obtener la relación hipsométrica mediante el análisis altitudinal con el límite de la cuenca, el intervalo de altitud seleccionado debe ser una equidistancia para todas las áreas parciales de la cuenca (Gaspari, et. al., 2010).

\section{- $\quad$ Altura Media (h)}

Este factor expresa la altura definida por el volumen de la cuenca en relación a la superficie de la misma (Gaspari, et. al., 2010: 12).

\section{- Pendiente media de la cuenca (PM).}

Este parámetro es la media ponderada de todas las pendientes de las áreas elementales en las que se considera constante la máxima pendiente. Es decir muestra el grado de rugosidad que tiene el suelo de la cuenca expresado en porcentaje (Beltrán, 2010).

\section{- Coeficiente de rugosidad (Ra).}

Se define como la relación entre el desnivel de la cuenca y su densidad de drenaje, este factor es adimensional (Gaspari, et. al., 2010). 


\subsubsection{Parámetros relativos a la red hidrográfica}

\section{- Número de orden de los cursos de agua:}

Es un valor asignado en base al número de ramificaciones que presenta la red hidrográfica, si esta llega a tener un numero de orden mayor que otra cuenca de área similar, indica que la cuenca estudiada es mayor el potencial erosivo, el transporte de sedimentos y el escurrimiento directo (Gaspari, et. al., 2010). Para determinar el número de orden de drenaje de una cuenca, se puede recurrir a los criterios de Schumn y Horton (Burbano, 1989). Schumn asigna el primer orden 1 a todos los cauces que no tienen tributarios y, en general la unión de dos cauces de igual orden originan un orden inmediatamente superior y la unión de dos de diferente orden dan origen a otro conservando el orden mayor entre los dos, así se repite el proceso hasta determinar el orden de la cuenca, que es el orden que obtendrá el cauce principal (Beltrán, 2010). Horton en cambio asigna el orden 1 a uno de los tributarios simples confluyentes, siendo el otro inmediatamente de orden superior, sucesivamente se repite el proceso hasta llegar al número de orden de la cuenca (Gaspari, et. al., 2010).

\section{- Densidad de drenaje (Dd):}

Se define como el grado de dificultad que presenta una cuenca hidrográfica para evacuar el agua de las precipitaciones por su red hidrográfica (Yaguachi, 2013). La red hidrográfica es el drenaje natural, permanente o temporal, por el que el escurrimiento superficial (Rosero, 2014).

\section{- Pendiente media del cauce $(\mathrm{J})$ :}

La pendiente media del cauce se obtiene a partir del desnivel topográfico que se presenta sobre el cauce principal y su longitud (Beltrán, 2010). Al aumentar la pendiente aumenta la velocidad del agua por la red hidrográfica, haciendo más susceptible a la cuenca a procesos erosivos y al arrastre de materiales (Yaguachi, 2013).

\section{- Tiempo de concentración (Tc)}

Es el tiempo que le toma llegar a la última gota de agua caída en la parte más lejana de la cuenca al desagüe (Beltrán, 2007). Para realizar esta determinación el tiempo de 
duración de la precipitación es por lo menos igual al tiempo de concentración y que se distribuye uniformemente en toda la cuenca (Gaspari, et. al., 2010).

\subsection{EL MANEJO INTEGRAL DE CUENCAS HIDROGRÁFICAS}

\subsubsection{Definición de Manejo Integral de Cuencas Hidrográficas}

El manejo integral de las cuencas hidrográficas es una parte fundamental de las acciones de gestión ambiental, que busca contrarrestar efectos ambientales negativos y alcanzar efectos ambientales positivos, los cuales puedan ser evaluados por la cantidad, calidad, de los recursos de una cuenca (Bahamondes, 2007). Busca satisfacer las necesidades del hombre, conservando los recursos naturales encontrados dentro de la cuenca, a fin de poder elevar su calidad de vida en armonía con el medio en el que se desarrollan (Ramakrishna, 1997), mediante la implementación de acciones que permitan lograr un desarrollo sustentable, tanto en la cuenca alta, media y baja (Tetreault, 2015). Se trata de alcanzar el bienestar de la población mediante el uso sostenible de los recursos naturales, conservándolos para que los mismos sean aprovechados por las generaciones futuras (Ramakrishna, 1997).

Es necesario realizar un conjunto de acciones y técnicas, ajustadas a las características socioeconómicas y legales de la zona, que se muestren como una solución a los problemas ambientales, económicos y sociales, a fin de mejorar la calidad de vida de su población (Francke, 2001).

Se convierte en una tarea difícil, ya que este debe garantizar la conservación de los recursos naturales, sin descuidar las necesidades de los habitantes (Ramakrishna, 1997). Es fundamental tener la capacidad para solucionar los problemas y conflictos que nacen en el desarrollo de la interacción entre el ser humano y la naturaleza, encontrando una propuesta viable que promueva la protección de la naturaleza y no afecte beneficios que la población obtiene de ella (Flores, 2010).

\subsubsection{Objetivo del Manejo Integral de Cuencas Hidrográficas}

Definido de una manera sencilla el objetivo principal del manejo integral de las cuencas es la consecución de un uso verdaderamente racional de los recursos naturales, en donde el hombre es el principal agente de destrucción o conservación (Ramakrishna, 1997). 
Si bien la conservación de los ecosistemas naturales sobresale en esta concepción, alcanzarla necesita del mejoramiento de las condiciones socioeconómicas de los pobladores asentados dentro de la cuenca (Aguirre, 2007), para lo cual es necesario definir y analizar los sistemas de producción predominantes en la zona, a fin de determinar los limitantes socioeconómicos y bilógicos que enfrenta la población (Fraile, 1993). Y de esta manera efectivizar los modelos de producción, mediante prácticas y tecnicas que permitan recuperar, rehabilitar y restaurar las áreas degradadas, como nuevas alternativas para un desarrollo armonioso con el medio, bajo el marco jurídico que regula las actividades de protección y producción en el país (Aguirre, 2007).

Para alcanzar esto es necesario incorporar en la población una filosofía de desarrollo sustentable, en una realidad de restricciones económicas abiertas al mercado, así se hace necesario un proceso de fortalecimiento en las áreas de educación, capacitación, planificación, concientización, participación y financiamiento (Hernández, 1997).

\subsubsection{Planificación de Cuencas Hidrográficas}

La planificación dentro del manejo integral de las cuenca hidrográficas, busca establecer las mejores alternativas de aprovechamiento, manejo y conservación de los recursos naturales, en base a los problemas y la situación actual en la que se desenvuelve la cuenca; en este proceso la sociedad es participe de la toma de decisiones (Rada, 2000).

Las características biofísicas de una cuenca, forman sistemas ambientales coherentes, por lo que se transforman en unidades de planificación para el desarrollo (Exhibición \& del Río Bermejo, 1978). Pese a que la planificación de las cuencas tienen numerosas implicaciones, el manejo de los recursos hídricos ha sido considerado como el punto más importante; lo que en sus inicios hizo que la planificación de las cuencas se encargue de temas específicos, hasta que se implementó el concepto de planificación por propósito, que buscaba dividir el agua existente en una estructura en todos sus posibles usos, sin embargo ya que los diferentes usos pueden ser competitivos se presentaba un problema con esta conceptualización de planificación (Exhibición \& del Río Bermejo, 1978).

Es así como nace el concepto de planificación integrada de cuencas hidrográficas como una respuesta a este problema, ya que dentro de esta conceptualización se busca coordinar y desarrollar armónicamente los usos de agua conjuntamente con los distintos procesos que se generan dentro y fuera de la cuenca (Exhibición \& del Río Bermejo, 1978). En este sentido, la planificación es un instrumento para la gestión que debe basarse en la búsqueda de 
equilibrios y la consecución de metas prefijadas (Rada, 2000). Tomando en cuenta que la planificación integrada va más allá del manejo de los recursos hídricos y es necesario la incorporación de aspectos ambientales, sociales y económicos (Forbes \& Hodges, 1971).

Para alcanzar los objetivos de la planificación integral, la participación de los habitantes es un componente esencial, ya que el modo más eficaz de conservar los recursos, es que las comunidades asentadas dentro de la cuenca participen dentro de su ordenación y puedan beneficiarse del aprovechamiento racional de los bienes y servicios que ofrece la cuenca.

\subsubsection{Ordenación de Cuencas Hidrográficas}

Aguirre (2007), sobre el ordenamiento de cuencas hidrográficas indica: "Es el proceso de formulación y ejecución de un sistema de acción, que incluye el manejo de los recursos de una cuenca para la obtención de bienes y servicios, sin afectar los recursos de suelo e hídricos".

Se considera al ordenamiento de las cuencas como la mejor repartición geográfica generada por el hombre en base a las actividades socioeconómicas y a las características de los recursos naturales (Rodríguez, 2003). También se lo considera como una disciplina científica, técnica y político-administrativa (CEMAT, 1983), cuyo objetivo es alcanzar un desarrollo equilibrado mediante la organización racional del espacio geográfico, en base a la capacidad de uso y valorización de los recursos y el desarrollo de los habitantes (Rodríguez, 2009).

El ordenamiento territorial necesita de la participación, dialogo, consenso y sobre todo la colaboración de los habitantes de la zona y el resto de actores inmersos en el manejo y uso de los recursos naturales. Las personas que viven dentro de la cuenca son las que mejor conocen el territorio y las que se verán afectadas o beneficiadas directamente con las decisiones tomadas, por lo que es necesario que involucrarlos para evitar conflictos. Al estar involucrados se logra la pertenencia de los proyectos y se evitan los conflictos (Vega, 2008).

En conclusión podemos considerar al ordenamiento de las cuencas como un instrumento de planificación, que busca organizar el uso y ocupación del suelo, en base a las potencialidades y limitaciones que establecen las características biofísicas y las necesidades, expectativas y aspiraciones de la población, a fin de alcanzar un desarrollo sustentable (Valencia, 2013). 


\subsubsection{Limitantes del Manejo Integral de Cuencas Hidrográficas.}

Para lograr un manejo integral de las cuencas hidrográficas es necesario realizar estudios detallados de la relación entre el hombre y el uso que este le da a los recursos, y el marco legal que ampara esta relación (Aguirre, 2007). Es necesario la capacitación de los actores inmersos en el territorio sobre prácticas y técnicas de producción y conservación de los recursos, los cuales en la mayoría de los casos son desconocidos (Aguirre, 2007). El desconocimiento de prácticas ajustadas a las características del territorio es una de las principales limitantes para alcanzar un manejo integral de las cuencas. Más aún si se toma en cuenta que la pérdida de vegetación natural, conlleva a procesos de degradación del suelo, biodiversidad y recursos hídricos (Ramakrishna, 1997). Este fenómeno se debe principalmente a prácticas de producción agropecuaria y de extracción forestal de alto impacto, que erosionan el suelo y contaminas los ríos con sedimentos y otras sustancias toxicas (Ramakrishna, 1997).

Otra de las limitantes que se presenta es el desconocimiento de la vocación de las cuencas, lo que no permite valorar la degradación a la que se ve afectada la cuenca, ni tampoco permite definir las estrategias de intervención, esto acompañado de una desvalorización del conocimiento ancestral y de la percepción que el individuo y la familia tiene de los problemas ambientales que enfrentan (Ramakrishna, 1997).

Dentro de las limitaciones naturales que se tiene que enfrentar están la topografía, el difícil acceso, las variaciones climáticas, los rangos altitudinales que se manejan en las cuencas de los andes, y la gran variabilidad en cantidad y calidad de la producción dada por características de los pisos ecológicos que cambian en áreas relativamente pequeñas (CATIE, 1986).

De igual manera hay que enfrentar la problemática de llegar a un consenso político que beneficie a todos los habitantes de la zona y la aplicación de regulaciones legales generalizadas que no toman en cuenta la particularidad de cada zona (CATIE, 1986). Acompañado de los problemas de la administración y trámites burocráticos, que dificultan el acceso a recursos económicos para la realización de los proyectos (CATIE, 1986).

\subsection{EL MANEJO DE CUENCAS EN EL ECUADOR}

En el Ecuador el sistema hidrográfico natural está determinado por la cordillera de los Andes formando 31 Sistemas Hidrográficos de los cuales 24 pertenecen a la vertiente del Pacifico, con una superficie total de $124644 \mathrm{Km}^{2}$ y 7 a la vertiente del Amazonas con una superficie de $131726 \mathrm{Km}^{2}$, correspondiendo respectivamente al $49 \%$ y $51 \%$ del total de la 
superficie del país (Valencia, 2013).Hasta hace pocos años el manejo de las cuencas estaba dirigido a solucionar los problemas enfocados al recurso hídrico; sin darle importancia al manejo integrado de los recursos de la cuenca, acciones que han ocasionado un sinnúmero de problemas sociales y ambientales (Aguirre, 2007).

La diversidad de ecosistemas y condiciones ambientales que presenta el Ecuador, se han convertido en uno de los principales problemas en el manejo integral de cuencas, ya que es necesario realizar varios estudios individualizados para cada cuenca. (Aguirre, 2007). Sin embargo se ha establecido como uno de los objetivos de desarrollo del país establecer mecanismos integrales y participativos que permitan conservar, preservar y restaurar la funcionalidad de las cuencas hidrográficas, con conceptos de equidad, a fin de alcanzar el desarrollo sustentable (SENPLADES, 2014). Para alcanzar este objetivo los diferentes actores involucrados en todos los niveles de gobierno y organización social, integraran las actividades de gestión basadas en los lineamientos de la política nacional y sectorial considerando las necesidades sociales y ambientales (SENPLADES, 2014).

Con la finalidad de poder cumplir con este objetivo se ha puesto en marcha el desarrollo e implementación de un sistema hídrico nacional, para caracterizar y cuantificar los usos que se le da al agua por cuenca hidrográfica (SENPLADES, 2013). Visto el grave problema de explotación de los ecosistemas de alta montaña que afecta a las reservas naturales de agua, se ha implementado mecanismos para detener el deterioro del ambiente e incentivar la reforestación en áreas erosionadas para la recuperación de los suelos y la protección de las cuencas hidrográficas (SENPLADES, 2013).

Dentro del manejo de las cuencas hidrográficas en el Ecuador es fundamental tener en cuenta al ecosistema páramo, ya que por su capacidad de retención garantiza la calidad y cantidad de agua que alimenta a las cuencas (Heinz, 2014). Este ecosistema en cierta medida ha sido protegido por la altura en el que se desarrolla, sus condiciones climáticas y el difícil acceso, sin embargo, los efectos antrópicos son considerables, al igual que sobre los otros ecosistemas presentes en el país (Heinz, 2014).

Finalmente, mencionar que La Ley Orgánica de Recursos Hídricos, Usos y Aprovechamiento del Agua del año 2014 establece en su Artículo 35 que: "La cuenca hidrográfica constituirá la unidad de planificación y gestión integrada de los recursos hídricos en el Ecuador". Concepto fundamental para la realización de proyectos de manejo y conservación de recursos naturales, que complementa a uno de los principales objetivos del Plan Nacional del Buen Vivir, que establece: "Garantizar la gestión integral de cuencas hidrográficas, su regulación, su uso y una educación ambiental que incentive la cultura del agua y privilegie el ahorro y el uso 
racional de la misma en los ámbitos doméstico, industrial y agrícola de acuerdo con la propuesta de cambio de matriz productiva y eficiencia energética".

\subsection{DESARROLLO SUSTENTABLE}

\subsubsection{Definición y Alcance del Desarrollo Sustentable}

La definición de Desarrollo Sustentable se ha ido ajustando a través de un proceso gradual de aproximaciones y acuerdos (Tetreault, 2015). Sin embargo, a pesar de los notables avances de reflexión y análisis, se considera que todavía subsisten las generalidades por encima de los criterios prácticos que faciliten su aplicación y evaluación (Tetreault, 2015: 4).

El desarrollo sustentable es un concepto innovador que propone la protección de la naturaleza y la equidad social presente y futura, sin poner en discusión los diferentes modelos económicos y políticos; en cambio toma a la naturaleza como punto de partida para una transformación social gradual y sin problemáticas (Treviño, 2003). Sin embargo, la conceptualización necesita todavía de análisis, ya que al ser tan amplia dificulta ponerla en práctica y genera varias interpretaciones (Treviño, 2003).

La necesidad de una nueva visión de desarrollo nace de la problemática ambiental y social que sufre el planeta y la posibilidad del colapso de los sistemas que dan soporte a la vida del ser humano (Segura \& Arriaga, 2003). Se necesita implementar el desarrollo desde un contexto social más amplio y visualizándolo a largo plazo, concibiendo que el deterioro de los ecosistemas y los desechos producidos también se transforman en el capital natural heredado a las generaciones futuras (Segura \& Arriaga, 2003).

Hay que entender que el desarrollo sustentable no solo debe estar encaminado a aspectos ambientales, sociales y económicos; sino que se trata también de la sobrevivencia de la cultura de los individuos, transformándose en una lucha por la diversidad (Segura \& Arriaga, 2003).

Para alcanzar el desarrollo sustentable es necesario la participación activa de todos los actores sociales, garantizar la distribución equitativa de la riqueza y evitar el deterioro y uso irracional de los recursos naturales; mediante el desarrollo e implementación de tecnologías que brinden soluciones limpias, eficiencia en la administración y respeto a la diversidad y heterogeneidad (Tetreault, 2015), lo que permitirá mantener en el tiempo un flujo de bienes y servicios que satisfagan las necesidades socioeconómicas y culturales de la población, dentro 
de los límites biofísicos que establecen el correcto funcionamiento de los sistemas naturales que lo soportan (Sarandón, et. al., 2002).

\subsubsection{Dimensiones de la Sustentabilidad}

\subsubsection{La Dimensión Ecológica o Ambiental}

Busca la protección de la naturaleza, sin dejar de lado los requerimientos de la población (Tetreault, 2015). Se enfatiza el concepto de que el hombre se desarrolla en un planeta finito, y que la magnitud de los sistemas económicos y productivos deben estar acordes con la capacidad de carga de la naturaleza, atribuyendo la degradación de los ecosistemas al crecimiento de la producción y el consumo (Treviño, 2003).

Esta dimensión deja claro que los recursos naturales no pueden ser sustituidos por bienes elaborados por el hombre, y que es necesario una conducta de solidaridad con la tierra y sus formas de vida (Gallopín, 2003). Los sistemas productivos deben ser capaces de utilizar fuentes renovables y eliminar la producción de residuos que vuelven a la naturaleza (Artaraz, 2002).

La dimensión ecológica de la sustentabilidad está condicionada por la provisión de recursos naturales y de servicios ambientales de un espacio geográfico (Tetreault, 2015: 9).

\subsubsection{La Dimensión Socio-Cultural}

Implica un modelo de desarrollo en el cual se favorece el uso y acceso a los recursos naturales, contemplando la conservación de la biodiversidad, la justicia y equidad social, la conservación de valores, prácticas y símbolos de identidad cultural; y garantiza la participación del mayor número de actores sociales en la toma de decisiones (Tetreault, 2015).

Este nuevo estilo de desarrollo tiene como norte una nueva ética del desarrollo, una ética en la cual los objetivos económicos del progreso estén subordinados a las leyes de funcionamiento de los sistemas naturales y a los criterios de respeto a la dignidad humana y de mejoría de la calidad de vida de las personas (Altvater, 2004: 100). 


\subsubsection{La Dimensión Económica}

Busca el logro de un beneficio que permita cubrir las necesidades económicas de los pobladores y la disminución de los riesgos asociados a los factores de producción, el mercado, los insumos y la baja diversificación y falta de valor agregado a los productos desde su origen (Tetreault, 2015). En la evaluación económica se debe tener en cuenta todos los factores que interactúan dentro de las actividades económicas y no sólo aquellos que pueden expresarse en unidades monetarias (Tetreault, 2015). 


\section{METODOLOGIA}

\subsection{RECOPILACIÓN DE INFORMACIÓN}

La recopilación de información se realizó mediante la búsqueda, compilación, análisis y clasificación de bibliografía, estudios anteriores y publicaciones tanto del tema como del área de estudio; complementada con la información proporcionada por las instituciones involucradas en la gestión de los recursos naturales.

El proceso de sistematización de la información se realizó de la siguiente manera:

- Se realizó una lista de las posibles fuentes de información como: Universidades y centros de investigación, instituciones públicas y privadas, bibliotecas, páginas especializadas de internet.

- Una vez recolectada la información se realizó el proceso de análisis y clasificación de la información, en base a la aplicación de la misma para cumplir con los objetivos planteados en el trabajo.

- Se comparó la información de las diferentes fuentes y se procedió a estandarizar la misma.

\subsection{DEFINICIÓN DEL NIVEL DE DETALLE DEL ESTUDIO}

Para definir el detalle de estudio del presente trabajo se analizó la información cartográfica y temática disponible, aplicando la metodología recomendada para planificación regional del uso de la tierra, estudio de cuencas hidrográficas, evaluación de tierras y planes de manejo (SENPLADES, 2012).

\subsection{DELIMITACIÓN Y LOCALIZACIÓN DEL ÁREA DE ESTUDIO}

La subcuenca del río Pitura fue delimitada utilizando el el software ArcGis $10 \AA$, utilizando como cartografía base la información topográfica digital del Instituto Geográfico Militar a escala 1:50000 con el Datum WGS 1984 UTM Zona 17S (IGM, 2013), disponible en el Sistema Nacional de Información del Ecuador (SIN, 2014). 


\subsection{CARACTERIZACIÓN MORFOMÉTRICA DE LA CUENCA}

\subsubsection{Parámetros de Forma}

Para el cálculo de los parámetros de forma se utilizó el archivo shapefile del límite de la subcuenca (obtenido en el proceso anterior) y la información topográfica de base. Esta información fue procesada mediante el empleo del software ArcGis $10 \AA$ y su herramienta "Calculate Geometry", con la cual se obtuvieron los valores de estos parámetros (Beltrán \& Rosales, 2012).

\subsubsection{Parámetros de Relieve}

Los parámetros de relieve se obtuvieron mediante el análisis topográfico de la subcuenca; para lo cual se realizó un Modelo de Elevación Digital (MED) empleando el software ArcGis $10 \circledR$. Se calcularon las áreas de los polígonos formadas entre las cotas principales de la información topográfica de base (equidistancia $200 \mathrm{~m}$ ) y el límite de la subcuenca (Beltrán \& Rosales, 2012); y se realizó la gráfica de la curva hipsométrica utilizando el software Excel $2013 \AA$.

A continuación se determinó la altura media de la subcuenca utilizando el "Método de Áreas Elementales", el cual determina que la altura media es la medida ponderada de todas las alturas correspondientes a áreas elementales (Beltrán \& Rosales, 2012). Para llevar a cabo este proceso se usó la ecuación 1 (Ec.1) (Burbano, 1.989):

$$
H=\frac{\sum_{i=1}^{n}(h i . x . A i)}{A}
$$

Donde:

$\mathrm{H}=$ Altura media de la cuenca $(\mathrm{m})$.

$A_{i}=$ Área parcial entre curvas de nivel sucesivas $\left(\mathrm{Km}^{2}\right)$.

$h_{i}=$ Altitud media entre curvas de nivel sucesivas $(m)$

$A=$ Área total de la cuenca $\left(\mathrm{Km}^{2}\right)$

Finalmente se calculó la pendiente media y se clasifico su valor según el criterio de López Cadenas de Llano (1998), expuesto en la Tabla 2. 
TABLA 2: Rangos y tipos de pendiente media, (Gaspari, et. al., 2010).

\begin{tabular}{ll}
\hline Pendientes medias (\%) & Tipo de relieve \\
\hline$\geq 0<0,5$ & Muy Plano \\
$\geq 0,5<1$ & Plano \\
$\geq 1<3$ & Suave \\
$\geq 3<12$ & Lomadas \\
$\geq 12<20$ & Accidentado \\
$\geq 35<50$ & Muy fuerte \\
$\geq 50<75$ & Escarpado \\
$\geq 75$ & Muy escarpado \\
\hline
\end{tabular}

\subsubsection{Parámetros Relativos a la Red Hidrográfica}

Para el cálculo de estos parámetros se extrajo de la información base (IGM, 2013), la red hidrográfica de la subcuenca; con esta información se determinaron los números de orden de cursos de agua según el criterio de Schumn (Gaspari, et. al., 2010). Posteriormente se calcularon los siguientes parámetros:

- La densidad de drenaje mediante la ecuación 2 (Ec.2) establecida por Horton (Gaspari, et. al., 2010).

$$
\mathrm{Dd}=\operatorname{Ln} / \mathrm{A}
$$

Ec. 2

Donde:

$\mathrm{Dd}=$ Densidad de drenaje $\left(\mathrm{Dd}\right.$, en $\left.\mathrm{km} \cdot \mathrm{km}^{-2}\right)$.

Ln: Sumatoria de las longitudes de todos los cursos de agua que drenan por la cuenca $(\mathrm{km})$.

A: Área total de la cuenca $\left(\mathrm{km}^{2}\right)$.

- La pendiente media del cauce mediante la ecuación 3 (Ec.3) (Gaspari, et. al., 2010):

$$
J=\frac{H \max -H \min }{L} x 100
$$


Donde:

$\mathrm{J}=\quad$ Pendiente media del cauce $(\%)$.

Hmax= Cota máxima sobre el curso de agua $(\mathrm{m})$.

Hmin= Cota mínima sobre el curso de agua $(m)$.

$\mathrm{L}=\quad$ Longitud del río más largo $(\mathrm{m})$.

- El tiempo de concentración mediante la ecuación 4 (Ec.4) (Gaspari, et. al., 2010):

$$
T c=0.3\left(\frac{L}{J / 4}\right)^{0.76}
$$

Donde:

Tc= Tiempo de concentración (en horas)

$\mathrm{L}=$ Longitud de cauce $(\mathrm{km})$

$\mathrm{J}=$ Pendiente media del cauce $(\%)$

\subsection{CARACTERIZACIÓN BIOFÍSICA DE LA CUENCA}

\subsubsection{Hidrología y Climatología}

\subsubsection{Precipitación}

Para determinar la precipitación en el área de estudio se tomaron en cuenta los datos de las estaciones meteorológicas del Instituto Nacional de Meteorología e Hidrología del Ecuador (INAMHI, 2012) cercanas al área de estudio, como elemento para determinar la climatología de la subcuenca. Las estaciones meteorológicas se detallan en la tabla 3.

TABLA 3: Estaciones meteorológicas de las zonas de estudio, (INAMHI, 2012).

\begin{tabular}{|c|c|c|c|c|c|c|c|c|}
\hline $\mathbf{N}^{\circ}$ & CÓDIGO & ESTACION & $\begin{array}{l}\text { ALTITUD } \\
\text { (m.s.n.m.) }\end{array}$ & $\mathbf{x}$ & $\mathbf{Y}$ & $\begin{array}{c}\text { PRECIPITACIÓN } \\
\text { (mm/año) }\end{array}$ & $\begin{array}{c}\text { T MEDIA } \\
\left({ }^{\circ} \mathrm{C}\right)\end{array}$ & PERIODO \\
\hline 1 & M001 & INGUINCHO & 3140 & 789113,9 & 10028800 & 1373 & 10 & $1977-2010$ \\
\hline 2 & M021 & ATUNTAQUI & 2400 & 809319,1 & 10036890 & 686 & 16 & $1965-1987$ \\
\hline 3 & M100 & TUMBABIRO INE & 2100 & 811696,4 & 10052570 & 742 & 16 & 1969-1992 \\
\hline 4 & M107 & CAHUASQUI FAO & 2335 & 810456,5 & 10057330 & 606 & 17 & $1980-1988$ \\
\hline
\end{tabular}




\begin{tabular}{|c|c|c|c|c|c|c|c|c|}
\hline $\mathbf{N}^{\circ}$ & CÓDIGO & ESTACION & $\begin{array}{l}\text { ALTITUD } \\
\text { (m.s.n.m.) }\end{array}$ & $x$ & $\mathbf{Y}$ & $\begin{array}{l}\text { PRECIPITACIÓN } \\
\text { (mm/año) }\end{array}$ & $\begin{array}{l}\text { T MEDIA } \\
\left({ }^{\circ} \mathrm{C}\right)\end{array}$ & PERIODO \\
\hline 5 & M311 & CAHUASQUI & 2380 & 810239,9 & 10057420 & 784 & 17 & $1964-1985$ \\
\hline 6 & M312 & PABLO ARENAS & 2340 & 813397,2 & 10055790 & 760 & 15 & $1964-1989$ \\
\hline 7 & M313 & COPIHUE & 1900 & 812902,8 & 10053860 & 528 & 17 & 1964-1984 \\
\hline 8 & M317 & СОTACACHI HDA & 2410 & 804796,4 & 10034540 & 1270 & 14 & $1964-1989$ \\
\hline 9 & M318 & APUELA & 1620 & 777070,4 & 10039680 & 1687 & 20 & $1964-2008$ \\
\hline 10 & M322 & CAMBUGAN & 3120 & 789561,2 & 10029610 & 1372 & 10 & $1966-1987$ \\
\hline 11 & M323 & ACHUPALLAS I & 3200 & 792155,1 & 10031660 & 1229 & 9 & $1966-1989$ \\
\hline 12 & M328 & HDA LA MARIA ANEXAS & 2600 & 805882,3 & 10042140 & 1097 & 14 & $1971-1989$ \\
\hline 13 & M329 & INGUINCHO G & 3180 & 789268,7 & 10028490 & 1599 & 10 & $1965-1987$ \\
\hline 14 & M571 & TUMBABIRO & 2120 & 812656,1 & 10051740 & 648 & 16 & 1976-1995 \\
\hline 15 & M621 & CUELLAJE & 1890 & 775489,8 & 10044320 & 1764 & 17 & 1976-1981 \\
\hline 16 & M693 & BUENOS AIRES I & 2200 & 798714,1 & 10068790 & 1453 & 15 & 1986-1991 \\
\hline 17 & M875 & INGUINCHO 6 & 3400 & 788278,5 & 10028800 & 1344 & 8 & 1971-1989 \\
\hline 18 & M910 & MORASPUGRO & 2860 & 795890,3 & 10029940 & 1312 & 13 & $1964-1985$ \\
\hline
\end{tabular}

Con estos datos se determinó la intensidad de precipitación en la subcuenca mediante el método de las isoyetas, que establece líneas de igual precipitación (Gutiérrez, 2014). Para la elaboración de las isoyetas se utilizó la herramienta "Kriging" del software ArcGis $10 \AA$, obteniendo los rangos de intensidad de precipitación sobre la subcuenca, representado en un mapa de isoyetas (Beltrán \& Rosales, 2012).

\subsubsection{Temperatura media anual}

Para determinar la temperatura media de la cuenca se realizó un mapa de isotermas utilizando el criterio de la correlación entre la temperatura y la altitud (Fries, et. al., 2012). Para la construcción del mapa de isotermas se utilizó el MED y los datos de temperatura de las estaciones meteorológicas expuestos en la tabla 4 (Beltrán \& Rosales, 2012). Este parametro nos servira como elemento para detrminar la climatología del área de estudio.

\subsubsection{Determinación de zonas climáticas}

Para determinar las zonas climáticas dentro de la subcuenca, se realizó un cruce entre los polígonos de Isoyetas e Isotermas empleando la herramienta "Union" del software ArcGis $10 \circledR$. En el polígono obtenido se identificaron las diferentes zonas climáticas utilizando el criterio de clasificación de Pourrut (1983), está información fue plasmada en un mapa de zonas climáticas. 


\subsubsection{Determinación del caudal}

\section{a) Determinación del número de curva}

Para determinar el caudal de la subcuenca se realizó el cálculo del factor denominado Número de la Curva (NC), método desarrollado en el año de 1972, por el Servicio de Conservación de Suelos de los Estados Unidos (Soil Conservation Service-S.C.S.), este depende del tipo de suelo, la cobertura vegetal, la pendiente del terreno y la precipitación antecedente (Gaspari, et. al., 2010).

Para obtener el Número de Curva de la subcuenca, se realizó un mapa en el que se cruzó la información de tipo de suelo (textura, adaptado a la tabla 4) y de uso actual del suelo (adaptado de la tabla 5), empleando el software ArcGis $10 \AA$; detrminando el NC correspondiente a cada área; finalmente se realizó la ponderación de los NC obtenidos en cada una de las unidades de tipo y uso de suelo, para obtener un NC representativo para toda la subcuenca.

En la tabla 4 se muestra el tipo de suelo según la textura para la determinación del número de curva de la subcuenca.

TABLA 4: Tipo de suelo para clasificación de número de la curva. (Gaspari, et. al., 2010)

\begin{tabular}{cl}
\hline Tipo de Suelo & \multicolumn{1}{c}{ Textura de suelo } \\
\hline A & Arenas con poco limo y arcilla; suelos muy permeables \\
B & Arenas finas y limos \\
C & Arenas muy finas, limos, suelos con alto contenido de arcilla \\
D & Arcillas en grandes cantidades; suelos poco profundos con \\
& subhorizontes de roca sana; suelos muy impermeables \\
\hline
\end{tabular}

En la tabla 5 se muestra el número de curva según la cobertura vegetal, para la determinación de este factor en la subcuenca.

TABLA 5: Tabla uso del suelo para determinar número de la curva. (Gaspari, et. al., 2010)

\begin{tabular}{llllcrr}
\hline \multirow{2}{*}{ Usos de la tierra y cobertura } & \multirow{2}{*}{ Tratamientos de suelo } & Pendiente del terreno & \multicolumn{4}{c}{ Tipo de suelo } \\
& & (\%) & A & B & C & D \\
\hline Sin cultivo & Surcos rectos & - & 77 & 81 & 88 & 94 \\
& Surcos rectos & $>1$ & 72 & 78 & 85 & 91 \\
Cultivo en Surcos & Surcos rectos & $<1$ & 67 & 79 & 84 & 89 \\
& Contorneo & $>1$ & 70 & 75 & 82 & 88 \\
\hline
\end{tabular}

Continúa en la página siguiente 


\begin{tabular}{|c|c|c|c|c|c|c|}
\hline \multirow{2}{*}{ Usos de la tierra y cobertura } & \multirow{2}{*}{ Tratamientos de suelo } & \multirow{2}{*}{$\begin{array}{c}\text { Pendiente del terreno } \\
(\%)\end{array}$} & \multicolumn{4}{|c|}{ Tipo de suelo } \\
\hline & & & A & B & C & D \\
\hline \multirow{3}{*}{ Cultivo en Surcos } & Contorneo & $<1$ & 65 & 74 & 80 & 86 \\
\hline & Terrazas & $>1$ & 66 & 71 & 78 & 82 \\
\hline & Terrazas & $<1$ & 62 & 76 & 84 & 81 \\
\hline \multirow{6}{*}{ Cereales } & Surcos rectos & $>1$ & 65 & 75 & 83 & 88 \\
\hline & Surcos rectos & $<1$ & 63 & 74 & 82 & 87 \\
\hline & Contorneo & $>1$ & 63 & 73 & 81 & 85 \\
\hline & Contorneo & $<1$ & 61 & 72 & 79 & 84 \\
\hline & Terrazas & $>1$ & 59 & 70 & 78 & 82 \\
\hline & Terrazas & $<1$ & 66 & 77 & 85 & 81 \\
\hline \multirow{6}{*}{$\begin{array}{l}\text { Leguminosas o praderas con } \\
\text { rotación }\end{array}$} & Surcos rectos & $>1$ & 58 & 72 & 81 & 89 \\
\hline & Surcos rectos & $<1$ & 64 & 75 & 83 & 85 \\
\hline & Contorneo & $>1$ & 55 & 69 & 78 & 85 \\
\hline & Contorneo & $<1$ & 63 & 73 & 80 & 83 \\
\hline & Terrazas & $>1$ & 51 & 67 & 76 & 83 \\
\hline & Terrazas & $<1$ & 68 & 79 & 86 & 80 \\
\hline \multirow{4}{*}{ Pastizales } & - & $>1$ & 39 & 61 & 74 & 89 \\
\hline & - & $<1$ & 47 & 67 & 81 & 80 \\
\hline & Contorneo & $>1$ & 6 & 35 & 70 & 88 \\
\hline & Contorneo & $<1$ & 30 & 58 & 71 & 79 \\
\hline Bosque muy ralo & - & - & 56 & 75 & 86 & 78 \\
\hline Bosque ralo & - & - & 46 & 68 & 78 & 91 \\
\hline Bosque normal & - & - & 36 & 60 & 70 & 84 \\
\hline Bosque espeso & - & - & 26 & 52 & 62 & 77 \\
\hline Bosque muy espeso & - & - & 15 & 44 & 54 & 69 \\
\hline Camino de terracería & - & - & 72 & 82 & 87 & 89 \\
\hline Camino duro & - & - & 74 & 84 & 90 & 89 \\
\hline
\end{tabular}

\section{b) Elección de los datos de precipitación}

Para realizar el cálculo del caudal se analizaron los datos pluviométricos de la estación ESPE, ubicada en la comunidad de Piñán, coordenadas WGS 1984 UTM ZONA 17S E787787 N10056767, a una altitud de 3084 m.s.n.m. (Innovativa-ESPE, 2014b); se escogió esta estación por estar ubicada dentro de la subcuenca, lo que brindó datos representativos de las precipitaciones en el área de estudio y por ser la única estación que cuenta con datos de precipitación en intervalos de 30 minutos. Los datos recolectados por la estación corresponden al periodo 12/10/2013 - 02/12/2014, de estos datos se seleccionaron las menores y mayores precipitaciones registradas. 


\section{c) Cálculo del caudal}

Para realizar el cálculo del caudal de la cuenca se recurrió al método racional modificado, el cual se basa en la formulación propuesta por Témez (1987). Este método permite estimar caudales máximos en cuencas de drenaje naturales con áreas menores de $770 \mathrm{~km}^{2}$ y con tiempos de concentración (Tc) de entre 0,25 y 24 horas (Ministerio de Transporte y Comunicaciones del Perú, 2008), representado en la ecuación 5 (Ec. 5) (Ministerio de Transporte y Comunicaciones del Perú, 2008):

$$
Q=0,278 . C . I . A . K
$$

Donde:

$\mathrm{Q}=$ Caudal $\left(\mathrm{m}^{3} / \mathrm{s}\right)$.

$\mathrm{C}=$ Coeficiente de escorrentía para el intervalo en el que se produce I.

$\mathrm{I}=$ Intensidad de precipitación máxima horaria $(\mathrm{mm} / \mathrm{h})$.

$\mathrm{A}=$ Área de la cuenca $\left(\mathrm{Km}^{2}\right)$.

$\mathrm{K}=$ Coeficiente de Uniformidad.

\section{- Determinación del Coeficiente de Escorrentía (C)}

El coeficiente de escorrentía fue calculado mediante la ecuación 6 (Ec. 6) (Ministerio de Transporte y Comunicaciones del Perú, 2008):

$$
C=\left(\frac{\left(P_{d}-P_{o}\right) \cdot\left(P_{d}+23 P_{o}\right)}{\left(P_{d}+23 P_{o}\right)^{2}}\right)
$$

Donde:

$P_{d}=$ Precipitación máxima diaria $(\mathrm{mm})$

$\mathrm{P}_{\mathrm{o}}=$ Umbral de escorrentía 
El Umbral de Escorrentía $\left(P_{\circ}\right)$, fue calculado mediante la ecuación 7 (Ec.7) (Ministerio de Transporte y Comunicaciones del Perú, 2008):

$$
P_{o}=\left(\frac{5000}{C N}\right)
$$

Ec.7

Donde:

$\mathrm{CN}=$ Número de Curva

\section{- Determinación de la Intensidad de Precipitación (I)}

La Intensidad de precipitación fue calculada mediante la ecuación 8 (Ec. 8) (Ministerio de Transporte y Comunicaciones del Perú, 2008):

$$
I=\left(\frac{P}{24}\right) \cdot(11)^{\frac{28^{0.1}-T c^{0.1}}{28^{0.1}-1}}
$$

Donde:

$\mathrm{P}=$ Precipitación máxima corregida $(\mathrm{mm})$

Tc $=$ Tiempo de concentración (horas)

Para determinar la precipitación máxima corregida sobre la cuenca $(P)$, se utilizó la ecuación 9 (Ec. 9) (Ministerio de Transporte y Comunicaciones del Perú, 2008):

$$
P=K_{A} \cdot P_{d}
$$

Donde:

$\mathrm{K}_{\mathrm{A}}=$ Factor reductor .

$P_{d}=$ Precipitación máxima diaria $(\mathrm{mm})$. 
El Factor reductor $\left(\mathrm{K}_{\mathrm{A}}\right)$, fue calculado mediante la ecuación 10 (Ec. 10) (Ministerio de Transporte y Comunicaciones del Perú, 2008):

$$
K_{A}=1-\left(\log _{10}(A / 15)\right) \quad \text { Ec. } 10
$$

Donde:

$\mathrm{A}=$ Área de la cuenca $\left(\mathrm{Km}^{2}\right)$

\section{- Determinación del Coeficiente de Uniformidad (K)}

El cálculo del Coeficiente de Uniformidad $(\mathrm{K})$ se lo realizó mediante la aplicación de la ecuación 11 (Ec. 11).

$$
K=1+\left(\frac{T c^{1.25}}{T c^{1.25}+14}\right)
$$

Donde:

Tc= Tiempo de concentración (horas)

\subsubsection{Edafología}

\subsubsection{Determinación de tipos de suelos}

El tipo de suelos de la subcuenca se determinó utilizando la cobertura digital de tipos de suelos de Imbabura a escala 1:50000 (SNI, 2014), obteniendose un mapa de tipos de suelo en base al Sistema de Clasificación del Departamento de Agricultura de los Estados Unidos (USDA-2006) utilizado en la información base (SNI, 2014), a fin de que proporcione los datos de las unidades de suelo y su distribución espacial en el área de estudio (Beltrán, 2010).

\subsubsection{Determinación de pendientes del suelo}

Para realizar el mapa de pendientes de la subcuenca se usó el MED, el cual se reclasifico porcentualmente en base a la clasificación de la tabla 6 empleando el software 
ArcGis $10 \AA$, este mapa brindara información para determinar alternativas de manejo para la zona y minimizar la erosión.

Para la clasificación de pendientes por rango porcentual se utilizó el criterio del Catálogo de Objetos elaborado por el Centro de Levantamientos Integrados de Recursos Naturales por Sensores Remotos (CLIRSEN) y el Ministerio de Agricultura, Ganadería, Acuacultura y Pesca (MAGAP) elaborado en 2011. (SENPLADES, et. al., 2012).

TABLA 6: Tipos de Pendiente según el porcentaje. (SENPLADES, et. al., 2012)

\begin{tabular}{ll}
\hline Pendiente (\%) & Relieve \\
\hline$\geq 0<2$ & Plana \\
$\geq 2<5$ & Muy suave \\
$\geq 5<12$ & Suave \\
$\geq 12<25$ & Media \\
$\geq 25<40$ & Media a fuerte \\
$\geq 40<70$ & Fuerte \\
$\geq 70<100$ & Muy Fuerte \\
$\geq 100<150$ & Escarpada \\
$\geq 150<200$ & Muy Escarpada \\
$\geq 200$ & Abrupta \\
\hline
\end{tabular}

\subsubsection{Determinación del uso actual del suelo y cobertura vegetal}

Utilizando la cobertura digital de cobertura y uso actual del suelo de Imbabura a escala 1:50000 (SNI, 2014), se realizó un mapa empleando el software ArcGis $10 \AA$, a fin de determinar la distribución espacial de los diferentes tipos de cobertura vegetal existentes en la subcuenca (Beltrán, 2010).

\subsubsection{Determinación de uso potencial del suelo}

Utilizando la cobertura digital de capacidad de uso del suelo de Imbabura a escala 1:50000 (SNI, 2014), se realizó un mapa en base al criterio de "Clasificación de la Capacidad Agrológica de los Suelos" (USDA, 1961); a fin de delimitar las unidades de terreno en donde las condiciones ambientales se presentan de una manera homogenea, destacar las caracteísticas agrológicas y su distribución geografica en el territorio, señalar las tierras que requieren control de erosión y finalmente de que sirva como una herramienta para proponer actividades en base a las potencialoidades del suelo (INEGI, 2005). 
Las clases de suelo de este sistema se detallan a continuación (SENPLADES, et. al., 2012):

Tierras adecuadas para cultivos y otros

- Clase I.- Tierras con muy ligeras limitaciones

- Clase II.- Tierras con algunas limitaciones

- Clase III.- Tierras con severas limitaciones

- Clase IV.- Tierras con muy severas limitaciones

Tierras de uso limitado o no adecuados para cultivos

- Clase V.- Tierras para pastos o bosques

- Clase VI.- Tierras con limitaciones ligeras para pastos y bosques

- Clase VII.- Tierras con severas limitaciones para pastos y bosques

- Clase VIII.- Tierras con muy severas limitaciones para cualquier uso

Las subclases de capacidad de uso están determinadas de acuerdo con las limitaciones y en función de los siguientes factores: erosión (e), suelo (s), humedad (h) y clima (c). La metodología plantea la utilización de subíndices con letras minúsculas en el siguiente orden e, $\mathrm{s}, \mathrm{h}$ y $\mathrm{c}$ que identifica las subclases de acuerdo al factor o los factores limitantes (SENPLADES, et. al., 2012).

\subsubsection{Determinación de riesgos de erosión}

Utilizando la cobertura digital de riesgos de erosión a escala 1:50000 (SNI, 2014) se realizó un mapa susceptibilidad a la erosión presentes en la subcuenca (Beltrán, 2010). A fin de detrminar la zonas que presentan características más propensas a este fenómeno y como herramienta para calcular la pérdida de suelo.

\subsubsection{Determinación del cambio de uso del suelo.}

Para determinar el cambio de uso de suelo se realizó un análisis multitemporal, empleado imágenes satelitales LANDSAT multiespectrales. Las imágenes fueron descargadas de la página web del Global Land Cover Facility (GLCF, 2015) y del U.S. Geological Survery (USGS/EROS, 2015); para la elección de las fotografías se tomó en cuenta la nubosidad y la época del año en que fueron capturadas. 
Las imágenes descargadas corresponden a los años 1999, 2010 y 2014. La descarga de las imágenes se las realiza por bandas separadas, por lo que se utilizó el software ArcGis $10 \AA$ para unir las bandas y obtener una imagen final del área de estudio. Una vez unidas las bandas se cálculo el Índice de Vegetación de Diferencia Normalizada (NDVI), aplicando la ecuación 12 (Ec. 12) (ESRI, 2013):

$$
N D V I=((I R-R) /(I R+R)) \times 100+100 \quad \text { Ec. } 12
$$

Donde:

IR = valores de píxel de la banda infrarroja

$\mathrm{R}=$ valores de píxel de la banda roja

Este índice genera valores entre $-1,0$ y 1,0 que básicamente representan el verdor y donde cualquier valor negativo corresponde principalmente a las nubes, el agua y la nieve y los valores cercanos a cero corresponden principalmente a las rocas y al terreno desnudo. Los valores muy bajos de NDVI (por debajo de 0,1 ) corresponden a áreas yermas de rocas, arena o nieve. Los valores moderados representan terrenos con arbustos y prados $(0,2$ a 0,3$)$, mientras que los valores altos indican bosques de zonas templadas y tropicales $(0,6$ a 0,8$)$ (ESRI, 2013). Los resultados obtenidos en formato raster fueron transformados a formato vectorial para el cálculo de las áreas correspondientes a cada rango de NDVI y su cobertura correspondiente.

Finalmente para determinar el cambio de uso de suelo se utilizará la ecuación 13 (Ec.13) establecida por Puyravaud, 2003 (Ministerio del Ambiente, 2012a):

$$
R=\frac{A 1-A 2}{T 2-T 1}
$$

Donde:

$R=$ Perdida de cobertura vegetal total anual promedio para el período determinado.

$A 1=$ Área inicial de la cobertura vegetal.

A2= Área final de la cobertura vegetal.

$T 1=$ Tiempo inicial.

$T 2=$ Tiempo final . 


\subsubsection{Determinación de la pérdida del suelo}

Para determinar la degradación del suelo se aplicó el modelo U.S.L.E. o Ecuación Universal de Pérdida de suelo, el cual es un modelo paramétrico creado por Wischmeir y Smith (1965), con el fin de estimar la perdida promedio anual de suelo (Gaspari, et. al., 2010).

El modelo U.S.L.E. permite obtener tasas de erosión para varios sistemas de uso y manejo de suelo. Cuando los valores obtenidos se comparan con la tolerancia, se puede determinar el nivel de erosión que presentan los suelos y las prácticas ecesarias para su conservación (Gaspari, et. al., 2010).

La expresión para el cálculo del modelo U.S.L.E. se expresa en la ecuación 14 (Ec.14) (Gaspari, et. al., 2010).

$$
A=\text { R. K. LS. C. } P \quad \text { Ec. } 14
$$

Donde:

$A=$ Pérdida de suelo por erosión pluvial (Mg/ha.año).

$\mathrm{R}=$ Índice de erosión pluvial o de erosionabilidad del aguacero (Mj.mm/ha.h.año).

K= Erodabilidad del suelo (Mg.ha.h/ha.MJ.mm).

LS= Topográfico, L: Longitud de pendiente; S: Gradiente de pendiente.

C= Ordenación de cultivos.

$\mathrm{P}=$ Control de erosión mediante prácticas de cultivo.

En el presente estudio, se decidió no utilizar el factor de control de erosión mediante prácticas de cultivo $(P)$, ya que dentro de la zona de este tipo de prácticas son casi inexistentes, por lo que el valor de esta factor se considera despreciable (Vásconez \& Hofstede, 2006); por lo que el cálculo de las tasas de erosión hídrica dentro de la subcuenca se calculará en base solo a los factores R, K, LS, y C; generando un mapa de la tasa de pérdida de suelo de la subcuenca del río Pitura, con la ayuda del software ArcGis $10 \AA$.

A continuación se describe el procedimiento para determinar cada uno de los factores antes mencionados: 


\section{a) Factor de índice de erosión pluvial (R):}

Este factor establecido por Wischmeier (1959) representa la potencia del aguacero para erosionar superficialmente el suelo, por lo que se lo considera un índice de su torrencialidad. (Gaspari, et. al., 2010).

Al existir poca disponibilidad de estaciones meteorológicas que cuenten con registros continuos de pluviosidad, se determinó el factor "R" utilizando el Índice Modificado de Fournier (IMF) (Mancilla, 2008), el cual es aplicable para la información disponible. Este factor se obtiene con la ecuación 15 (Ec. 15):

$$
I M F=\sum_{1}^{12} \frac{P i^{2}}{P}
$$

Donde:

IMF = Índice Modificado de Fournier.

$\mathrm{P}$ i= Precipitación mensual del mes "i” $(\mathrm{mm})$

$\mathrm{P}=$ Precipitación media anual $(\mathrm{mm})$

El Índice Modificado de Fournier es empleado como un reemplazo directo del factor $\mathrm{R}$ para cálculos en donde no existen muchos datos, entregando índices comparativos y soluciones prácticas a la falta de datos (Mancilla, 2008).

La estimación del factor "R" se realizó para cada una de las estaciones meteorológicas detalladas en la tabla 3. Empleando el software ArcGis $10 \circledast$ se realizó un mapa de variación espacial de la erosión pluvial en la subcuenca del río Pitura.

\section{b) Factor de erodabilidad del suelo (K):}

Este factor representa la susceptibilidad de un suelo a ser erosionado; al estar relacionado con la estructura del suelo este factor se calcula a partir del porcentaje de las distintas fracciones granulométricas, porcentaje de materia orgánica, permeabilidad y estructura del suelo (Gaspari, et. al., 2010).

Para determinar el factor de erodabilidad del suelo $(K)$, se utilizaron los rangos establecidos por la USDA (Santos \& Gonzáles, 1999), los cuales fueron asignados según su descripción a la cobertura de riesgos de erosión de la subcuenca. Establecidos los valores se procedió a 
construir un mapa de distribución espacial de la erodabilidad del suelo, empleando el software ArcGis $10 \circledR$.

TABLA 7: Clasificación de los grados de erodabilidad USDA. (Santos \& Gonzales, 1999).

\begin{tabular}{ll}
\hline \multicolumn{1}{c}{$\begin{array}{c}\text { Valor de K } \\
\text { (Mg.ha.h/ha.MJ.mm) }\end{array}$} & \multicolumn{1}{c}{ Clasificación } \\
\hline$<0,0079$ & Poco erodable \\
$\geq 0,079<0,0171$ & Debilmente erodable \\
$\geq 0,0171<0,0329$ & Medianamente erodable \\
$\geq 0,0329<0,0691$ & Fuertemente erodable \\
$\geq 0,0691<0,1019$ & Extremadamente erodable \\
\hline
\end{tabular}

\section{c) Factor topográfico (LS):}

El factor LS está conformado por la longitud y la pendiente del terreno, constituyéndose en el factor topográfico para el cálculo de la perdida de suelo (Clérici \& García, 2001). Para determinar los valores del factor "LS", se utilizó la cobertura de pendientes de la subcuenca, y se asignó los valores de "LS" correspondientes a cada rango de la pendiente en base a los valores propuestos por Mintegui Arregui (1.988). La tabla 8 muestra los valores de "LS" según la pendiente (Gaspari, et. al., 2010).

TABLA 8: Valores de LS según rangos de pendiente, (Gaspari, et. al., 2010)

\begin{tabular}{|c|c|}
\hline PENDIENTE (\%) & LS \\
\hline$\geq 0<3$ & 0,3 \\
\hline$\geq 3<12$ & 1,5 \\
\hline$\geq 12<18$ & 3,4 \\
\hline$\geq 18<24$ & 5,6 \\
\hline$\geq 24<30$ & 8,7 \\
\hline$\geq 30$ & 14,6 \\
\hline
\end{tabular}

\section{d) Factor de ordenación de cultivos (C):}

El factor $C$ es definido como la relación entre el valor medio de pérdida de suelo con un determinado sistema de uso y manejo (Clérici \& García, 2001). Considerando fundamental la función de la cobertura vegetal en la protección y conservación del suelo. Para determinar los valores de este factor, se utilizó la información digital de cobertura vegetal y uso actual del suelo generada para la subcuenca y se asignó los valores de "C", en base a lo propuesto por Gómez (2001), los valores asignados se muestran en la tabla 9. 
TABLA 9: Factor de ordenación de cultivos de la subcuenca del río Pitura (adaptado de Gómez, 2001).

\begin{tabular}{lr}
\hline \multicolumn{1}{c}{ USO DEL SUELO } & \multicolumn{1}{c}{ FACTOR C } \\
\hline Bosque siempreverde montano alto de & 0,0346 \\
Cordillera Occidental de los Andes & 0,0346 \\
Herbazal del Páramo & 0,09 \\
Herbazal inundable del Páramo & 0,0346 \\
Arbustal siempreverde y Herbazal del & \\
Páramo & 0,225 \\
Intervención & \\
\hline
\end{tabular}

Finalmente se realizó el mapa de distribución espacial de este factor empleando el software ArcGis $10 \circledR$.

\section{e) Estimación de pérdida de suelo (A):}

Para la estimación de la pérdida de suelo en la subcuenca se realizó el producto de los factores R, K, LS y C con la herramienta "Raster Calculator" del software ArcGis 10 ®; el resultante fue una capa raster con la distribución espacial del factor " $A$ " expresados en Mg.ha/año. El raster fue transformado a formato vectorial para el cálculo del área que ocupa cada grado de erosión, los cuales fueron representados en un mapa de perdida de suelo. Los los rangos de erosión hídrica para la U.S.L.E están expuestos en la tabla 10 (SENPLADES, et. al., 2014).

TABLA 10: Clasificación en grado de erosión hídrica superficial. (SENPLADES, et. al., 2014).

\begin{tabular}{|c|c|}
\hline $\begin{array}{l}\text { Pérdida de suelo } \\
\left.\text { (Mg.ha }^{-1} \cdot a_{n} o^{-1}\right)\end{array}$ & Grados de Erosión Hídrica \\
\hline$<10$ & Leve \\
\hline$\geq 10<50$ & Moderado \\
\hline$\geq 50<200$ & Alto \\
\hline$\geq 200$ & Muy Alto \\
\hline
\end{tabular}




\subsection{CARACTERIACIÓN SOCIO-CULTURAL DE LA CUENCA}

\subsubsection{Demografía}

Para determinar la población de la subcuenca se identificaron los centros poblados existentes en el área de estudio y el sector censal al que corresponden, mediante la codificación del Instituto Nacional de estadísticas y Censos (INEC, 2010). Se realizó una proyección con un horizonte de 10 años, con lo cual se determinó la población de la subcuenca para 2015, y su evolución en los próximos 5 años, periodo para el cual generalmente se realizan los planes de manejo (Aguirre, 2007). La proyección de la población se realizó mediante la metodología de los componentes, esta se describe en la ecuación 16 (Ec. 16) (INEC, 2012):

$$
N(t+5)=N(t)+B(t ; t+5)-D(t ; t+5)+I(t ; t+5)-E(t ; t+5)
$$

Donde:

$N(t+5)$ : Representa la población estimada por el modelo en el punto final de un periodo quinquenal.

$N(t)$ : Corresponde a la población estimada en el punto inicial del período de proyección.

$B(t, t+5)$ : nacimientos en el período.

$D(t, t+5)$ : Defunciones en el período.

I $(t, t+5)$ : Inmigrantes en el período.

$E(t, t+5)$ : Emigrantes en el período.

Este método contempla que las tasas de frecuencia anual de cada componente permanecerán constantes a lo largo del periodo de proyección (Argote, 2015).

Se determinó la distribución de la población por etnias y la migración mediante el procesamiento de la información a nivel parroquial del último censo de población y vivienda (INEC, 2010). Para definir esta distribución se estableció las proporciones de cada sector censal empleando la ecuación 17 (Ec. 17) (Aguirre, 2010): 
Donde:

Pcs: Población del sector censal.

Pp: Población parroquial

\subsubsection{Educación}

Para determinar el índice de educación dentro del área de estudio Se determinó la el índice de analfabetismo de la población, mediante el procesamiento de la información a nivel parroquial del último censo de población y vivienda (INEC, 2010). Para definir esta distribución se empleó la ecuación 17 (Ec. 17). De igual manera se determinó el número de instituciones educativas cercanas a la población.

\subsubsection{Salud}

Para determinar este indicador social, se estableció el número de centros de salud existentes a nivel parroquial y los principales problemas de salud registrados en la zona.

\subsubsection{Servicios Básicos}

Para identificar la cobertura de servicios básicos en el área de estudio se recurrió a la información a nivel parroquial del último censo de población y vivienda (INEC, 2010). Con la cual se determinó el número de viviendas que poseen energía eléctrica, el tipo de abastecimiento de agua para consumo humano y la eliminación de desechos.

\subsection{CARACTERIZAZCIÓN ECONÓMICO - PRODUCTIVA}

\subsubsection{Principales Actividades Económicas}

Para determinar las principales actividades económicas dentro de la subcuenca se realizó un análisis de los factores que intervienen en los sistemas y cadenas de producción, economía integral y procesos socio productivo de los habitantes del área de estudio. Esta información se obtuvo del último Censo Nacional Económico (INEC, 2010) y de los planes de ordenamiento territorial de las parroquias Apuela e Imantag. 


\subsubsection{Tenencia de la Tierra.}

Las características de la tenencia de la tierra fueron determinadas en base a la información de los Planes de Ordenamiento Territorial de las parroquias Imantag y Apuela.

\subsubsection{Organización Comunitaria.}

La organización de las comunidades dentro de las subcuencas fue determinada en base a la información de los Planes de Ordenamiento Territorial de las parroquias Imantag y Apuela.

\subsection{EVALUACIÓN DE IMPACTOS DENTRO DE LA CUENCA}

Para la evaluación de impactos dentro de la subcuenca del río Pitura se utilizó una matriz Leopold, que es una matriz de doble entrada, en la cual se coloca en las filas los factores que son afectados y en las columnas los factores causantes de los posibles impactos (Fernández, 2009). Cada cuadricula formada se dividió con una diagonal, colocando en la parte superior los valores de la magnitud del impacto utilizando una escala del 1 al 10 y precedido del signo + o - según corresponda si el efecto es negativo o positivo; y en la parte inferior se colocó el valor de la intensidad del impacto usando la misma escala; finalmente la sumatoria de las filas nos indicará el efecto que cada factor produce sobre el medio. (García, 2007). Para el análisis de impactos se escogieron 10 componentes del desarrollo económico productivo y cultural de la población, estos componentes fueron cotejados con 16 factores agrupados como: ambientales, económicos y sociales. El proceso permitió evaluar la interacción entre las actividades antrópicas generan y los elementos del medio biofísico y socioeconómico de la subcuenca.

\subsection{ZONIFICACIÓN DE LA CUENCA}

Para realizar la zonificación de la subcuenca se utilizó el criterio de zonificación ecológico-económica, que es una forma de planificar el uso de tierras teniendo en cuenta los elementos bio-físicos y prestando atención a las condicionantes socio-económicas, a fin de alcanzar un uso óptimo de los recursos (Vergara et.al., 1997). Esta zonificación considera a los ecosistemas como unidades estructurales, funcionales y temporales, que se distinguen espacialmente por la relación de las actividades humanas y los factores ambientales que los conforman (Carranza, 2000). 
La información temática utilizada en este proceso fue las coberturas de: Pendientes, Cobertura Vegetal y Uso Potencial del Suelo, obtenidos en los procesos anteriores. Las capas seleccionadas permitieron tomar en cuenta los aspectos más importantes para la conservación de los recursos naturales y las actividades económico-productivas de la población (Beltrán \& Rosales, 2012). La elaboración del mapa de zonificación se realizó con el software ArcGis $10 \AA$. En primera instancia se utilizó la herramienta "Select" para asignar rangos a cada una de las capas utilizadas en base a sus características; posteriormente se empleó la herramienta "Intersect" para unificar los rangos de las capas y finalmente se utilizó la herramienta "Unión" para la determinación de cada una de las zonas. El resultado final fue la zonificación de la subcuenca en formato vectorial (Beltrán \& Rosales, 2012).

Las zonas obtenidas en este proceso están sujetas a un manejo y uso específico, por lo que cada zona fue descrita. Se detallaron sus objetivos y las actividades permitidas dentro cada una, como marco regulatorio del ordenamiento territorial de la subcuenca.

\subsection{ELABORACIÓN DE LA PROPUESTA DE MANEJO DE LA CUENCA}

El plan de manejo integral es un documento técnico que se realizó en base a la evaluación de impactos de la subcuenca, en él se describen y analizan las características ambientales, sociales y económicas del área. Detalla las acciones a efectuarse en los siguientes años (Rosero, 2014), con el fin de conservar los recursos naturales y promover el desarrollo de las poblaciones asentadas en el área (Soria \& Chebez, 2001).

Está estructurado según lo contemplado en el Texto Unificado de Legislación Ambiental Secundaria del Ecuador (Ministerio del Ambiente, 2015), estableciéndose las medidas de corrección, mitigación, eliminación, modificación, prevención, contingencia y estimulación; en un conjunto Programas que las describen cronológicamente (Ministerio del Ambiente, 2015).

Cada Programa contiene una justificación, objetivos generales y específicos, resultados esperados, estrategias, localización dentro del área y el periodo en el que se efectuará. Además cuenta con distintos proyectos estructurados por un conjunto de acciones encaminadas a contrarrestar los impactos negativos vinculadas al aprovechamiento y al manejo de los recursos naturales, a fin de alcanzar el equilibrio entre el crecimiento económico, la equidad social y la sostenibilidad ambiental (Ferrando, 2015).

Para este proceso fue necesario analizar el nivel de detalle con el que debe ser atendido cada impacto detectado y la coherencia con aspectos políticos, sociales, económicos y técnicos. Para definir los programas se analizaron las generalidades de los impactos, mientras que para 
estructurar los proyectos se analizaron las particularidades de los impactos encontrados (Cámara, 2005). 


\section{RESULTADOS}

\subsection{RECOPILACIÓN DE INFORMACIÓN}

Como resultado de la recolección de información para el presente trabajo se consultó y compilo información de 62 libros, 62 artículos científicos en revistas, 8 documentos técnicos, 13 tesis, 17 artículos en libros, 8 recursos digitales e información cartográfica de base. Las fuentes de esta información fueron: bibliotecas de dos Universidades y tres instituciones públicas relacionadas; el repositorio digital de 9 universidades, 3 escuelas politécnicas y 8 instituciones públicas y 56 revistas especializadas.

\subsection{DEFINICIÓN DEL NIVEL DE DETALLE DEL ESTUDIO}

En el presente estudio se usó un nivel de detalle a escala 1:50000, esta escala es considerada como de semidetalle, y es utilizada en el análisis y estudio de áreas menores a $10.000 \mathrm{Km}^{2}$, y es aplicada en los procesos de planificación regional del uso de la tierra, el estudio de cuencas hidrográficas, evaluación de tierras semi-cuantitativa o planes de manejo (SENPLADES, 2012).

También fue importante para la elección de esta escala la existencia de cartografía e información digital descargable en las páginas oficiales del Instituto Geográfico Militar (IGM, 2013), y el Sistema Nacional de Información (SIN, 2014) a escala 1:50000 proyectada en el sistema de coordenadas WGS 1984 UTM, Zona 17S. La elección un escala es de suma importancia para lograr un manejo de los recursos naturales, más aun cuando la unidad de planificación es una cuenca hidrográfica cuya superficie puede llegar a cientos o miles de $\mathrm{Km}^{2}$ (Wilcox, et. al., 2003); cada ecosistema adquiere un nivel jerárquico en base a la escala con la cual se trabaje (Ceballos, et. al., 1998), por lo que hay que tener en cuenta que los ecosistemas son sistemas jerarquizados y complejos con funcionamiento diferente uno del otro (Bergkamp, 1995), las precipitaciones, vientos, temperatura y otros fenómenos atmosféricos también tienen un comportamiento diferente de acuerdo a la escala con la que se los examine (Yilmaz, et. al., 2015). Para trabajos relacionados con el manejo de los recursos naturales a nivel de subcuencas hidrográficas es recomendable utilizar la escala seleccionada, ya que permite llegar a conclusiones valederas optimizando recursos (Tibaldi, 1995). 


\subsection{DELIMITACIÓN Y LOCALIZACIÓN DEL ÁREA DE ESTUDIO}

\subsubsection{Delimitación de la Subcuenca del río Pitura.}

Para el presente estudio se delimito la subcuenca del río Pitura, formada por los ríos Piñán, Pantaví y la quebrada Gualoto, que alimentan al cauce principal.

Sin embargo, se decidió incorporar a la microcuenca de la laguna Tobar Donoso más conocida como la laguna de Piñán al estudio, debido a que es el principal atractivo turístico de aventura en la zona y genera un importante ingreso económico a la población de Piñán ubicada a 800 $\mathrm{m}$ de la laguna (Araque, 2012). La microcuenca de tipo endorreica está formada por un conjunto lacustre de origen glaciar, compuesto por las lagunas Tobar Donoso y Yanacocha, sin embargo en época lluviosa se llegan a contabilizar hasta 35 lagunillas (Araque, 2012).

El manejo y conservación del conjunto lacustre es fundamental para alcanzar un desarrollo sustentable de la subcuenca del río Pitura, por este motivo en el estudio se tratara a las dos cuencas como una sola unidad de manejo y planificación. En la figura 1 se observa las dos cuencas que forman el área de estudio.

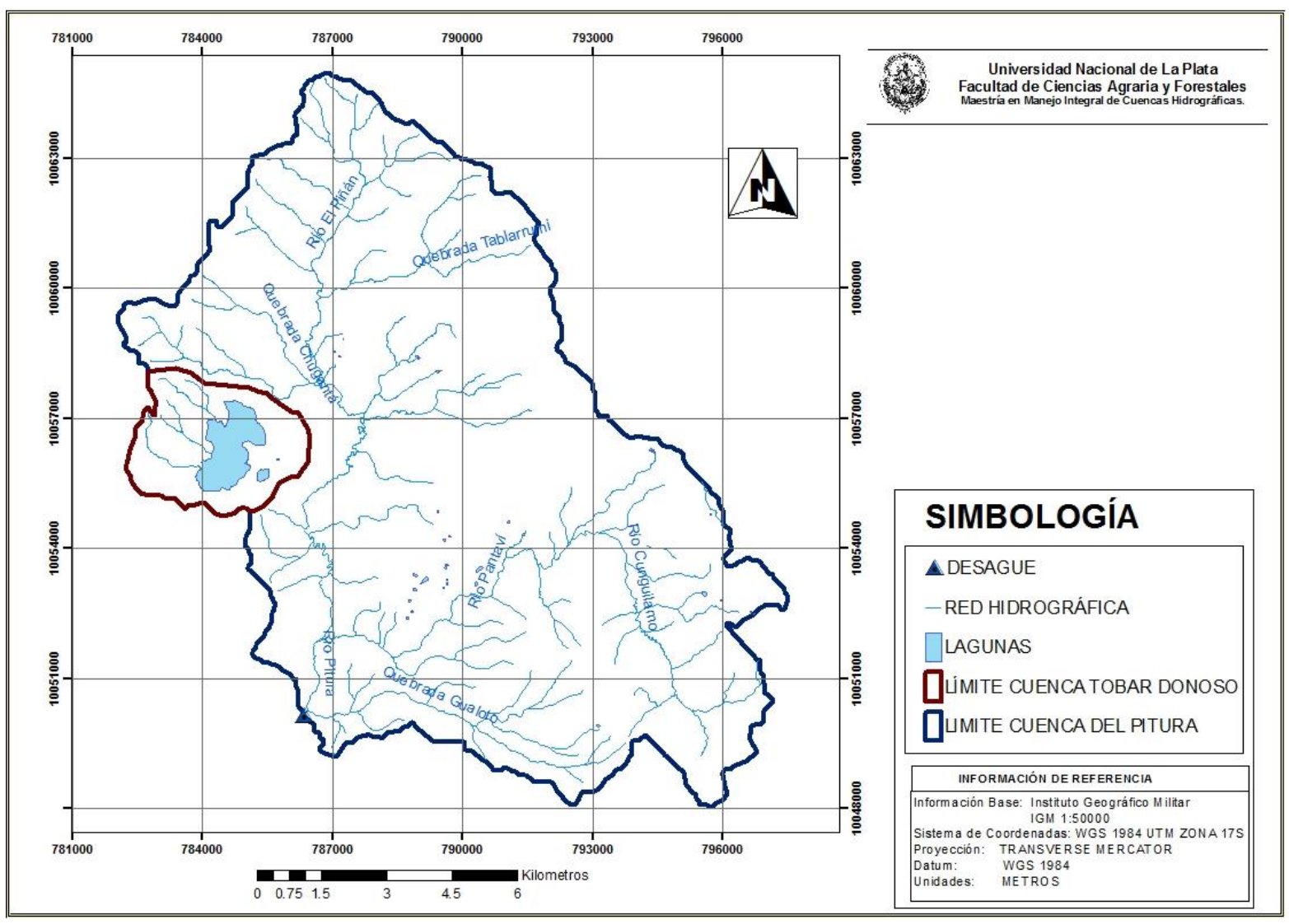

FIGURA 1: Delimitación de las cuencas en estudio. Escala: 1:200000. 


\subsubsection{Ubicación Geográfica de la Subcuenca del río Pitura.}

La subcuenca del río Pitura se encuentra ubicada íntegramente en la provincia de Imbabura, dentro de las siguientes coordenadas geográficas:

- Desde: $00^{\circ} 25^{\prime} 30^{\prime \prime}$ Hasta $00^{\circ} 35^{\prime} 00^{\prime \prime}$ Latitud Norte.

- Desde: $78^{\circ} 19^{\prime} 30^{\prime \prime}$ Hasta $78^{\circ} 28^{\prime} 00^{\prime \prime}$ Longitud Occidental.

Y limitado por las siguientes cuencas:

- Norte: Cuenca del río Lita.

- Sur: Cuencas de los ríos Apuela y Ambi

- Este: Cuenca del río Pablo

- Oeste: Cuenca del río Cristopamba

En la figura 2 se muestra la ubicación general de la subcuenca del río Pitura.

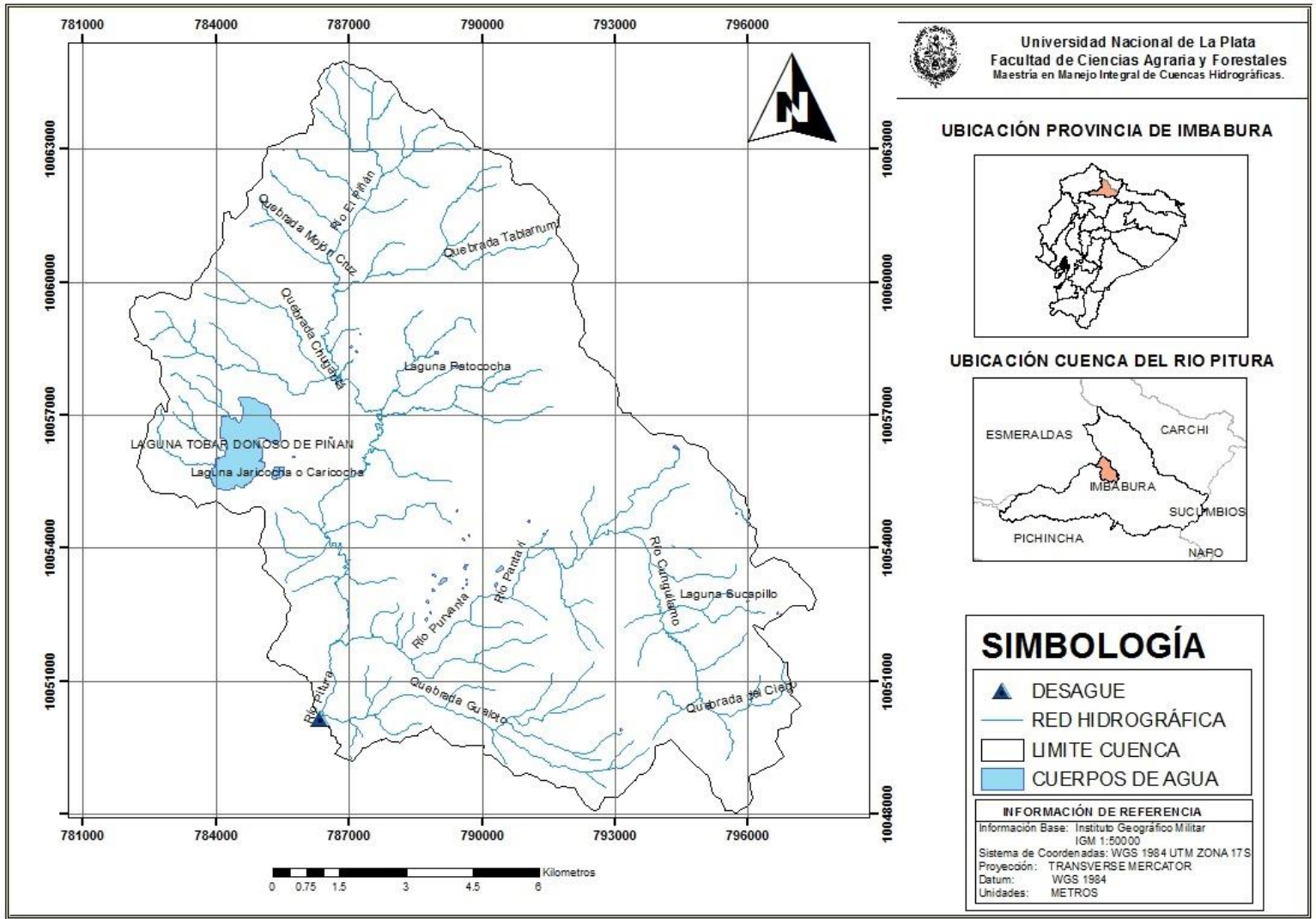

FIGURA 2: Localización general del área de estudio. Escala: 1:200000. 
Dentro del área de la subcuenca se encuentran las parroquias Imantag y Apuela, pertenecientes al cantón Cotacachi y una pequeña parte de la parroquia de La Merced de Buenos Aires perteneciente al cantón Urcuquí. La figura 3 muestra el mapa base del área de estudio.

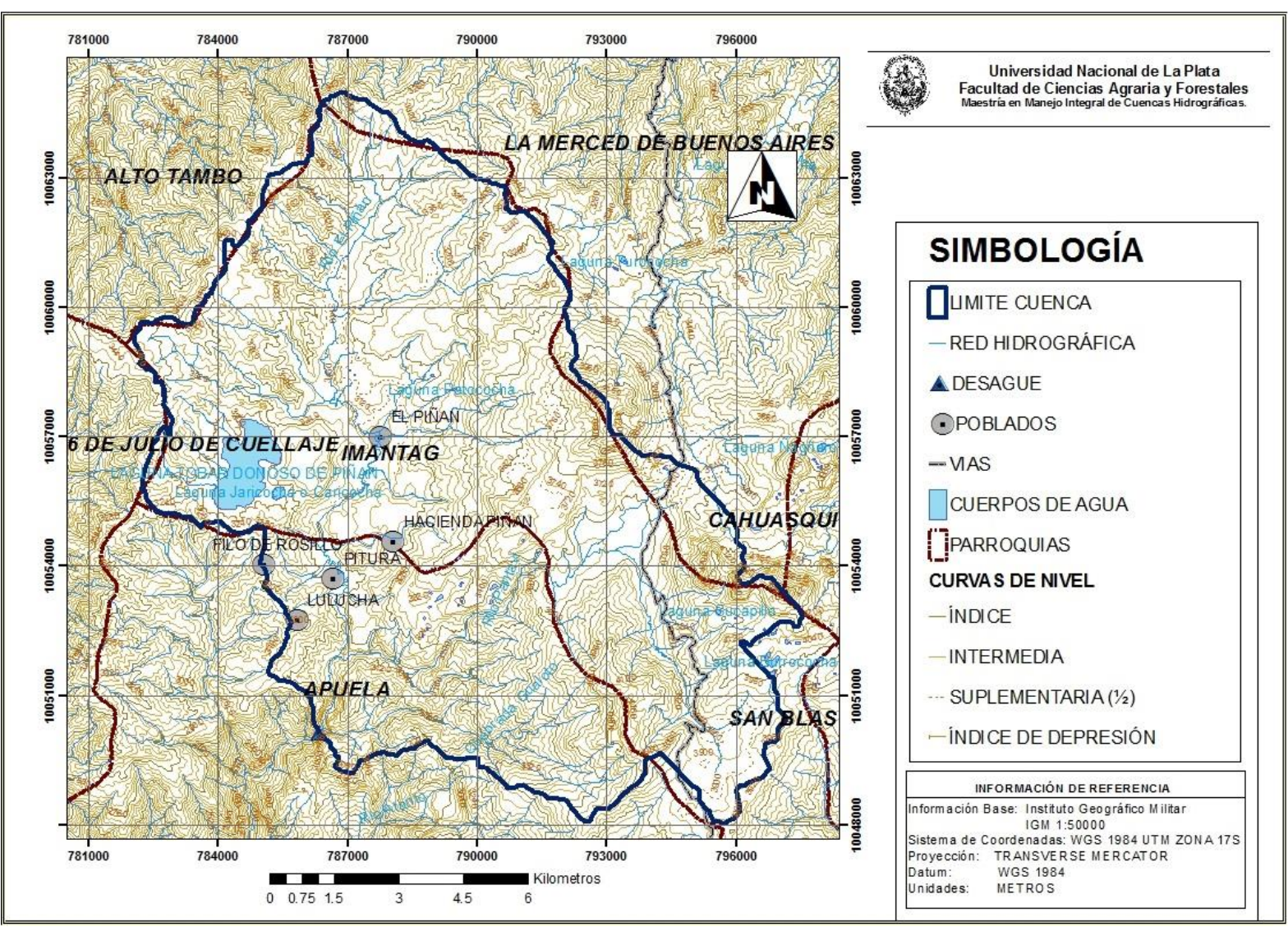

FIGURA 3: Mapa base del área de estudio. Escala: 1:200000.

\subsection{CARACTERIZACIÓN MORFOMÉTRICA DE LA CUENCA}

\subsubsection{Parámetros de Forma}

El área de la subcuenca del río Pitura es de 13574,25 ha, mientras que el área de la microcuenca de la laguna Tobar Donoso tiene una extensión de 1012,75 ha, con una superficie total en estudio de 14587 ha. El factor de forma de la cuenca principal es de 0,36, siendo de forma alargada con crecidas de menor magnitud y susceptibilidad baja a la erosión; la microcuenca muestra un valor de factor de forma igual a 0,97 , siendo una cuenca redondeada. Según el coeficiente de compacidad de Gravelius la cuenca principal es de forma 
oblonga, con un valor de 1,56 , lo que disminuye el riesgo de crecidas, la cuenca endorreica es de forma redonda con un valor de 1,18.

\subsubsection{Parámetros de Relieve}

El área en estudio se encuentra entre los 2680 y 4520 m.s.n.m; esta distribución altitudinal se observa en la figura 4, detallándose los polígonos de las áreas parciales formadas por el límite de la cuenca y las cotas principales con una equidistancia de $200 \mathrm{~m}$.

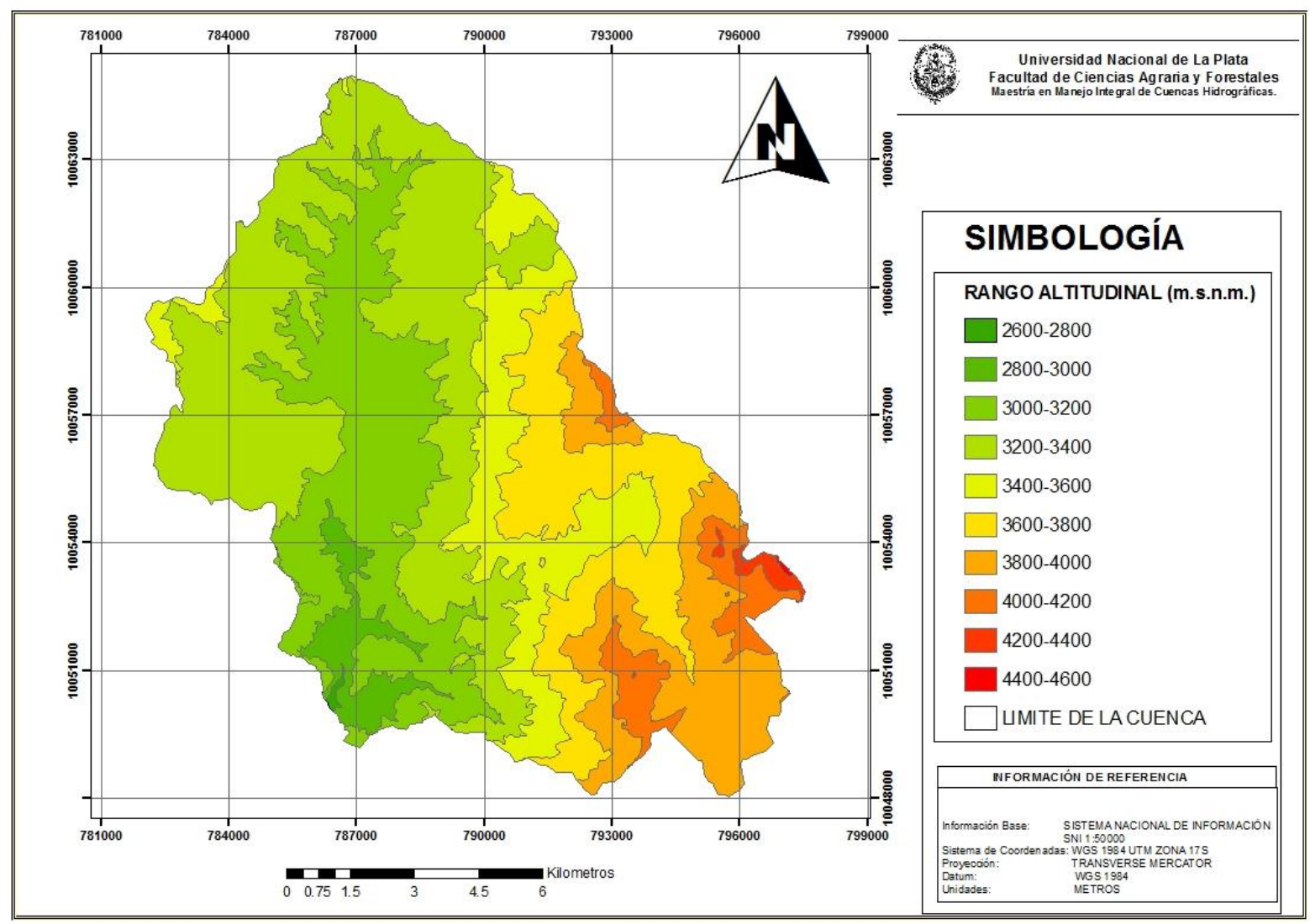

FIGURA 4: Poligonos parciales del área de estudio a intervalos de 200 metros. Escala: $1: 200000$.

La curva hipsométrica de la subcuenca del río Pitura, representada en la figura 5; muestra que la subcuenca en fase de madurez y equilibrio; con una altura media de 3.431,89 m.s.n.m. 


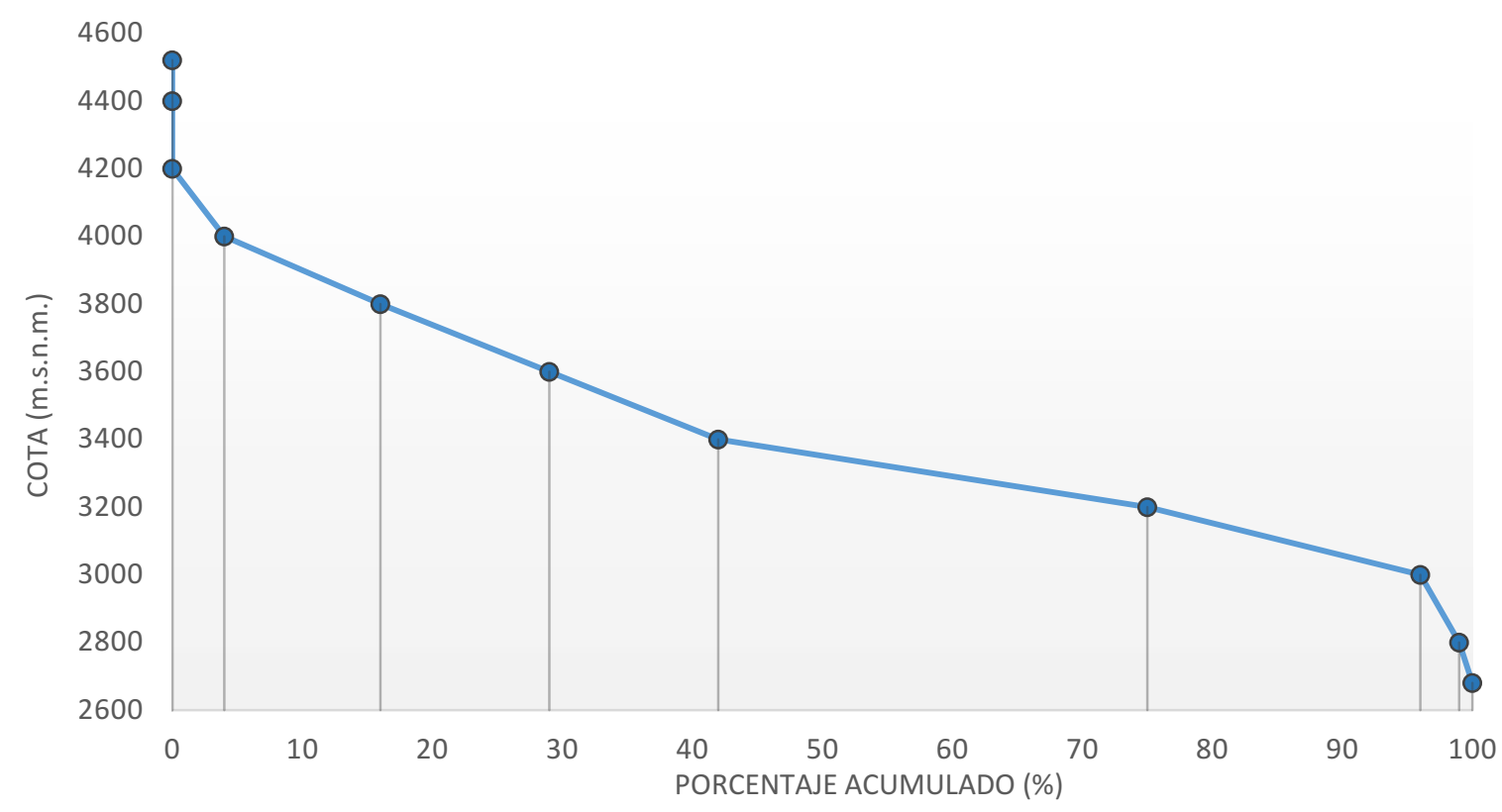

FIGURA 5: Curva Hipsométrica de la subcuenca del río Pitura

La distribución altitudinal de la subcuenca permitió determinar que su pendiente media tiene un valor de $25,54 \%$, siendo un relieve que se considera entre accidentado y muy fuerte, con una alta rugosidad topográfica y un alto riesgo a la erosión.

\subsubsection{Parámetros Relativos a la Red Hidrográfica}

La topografía accidentada de la subcuenca forma cursos de agua pequeños en las partes altas, los cuales confluyen en áreas pequeñas haciendo que el cauce principal de la subcuenca tenga un orden de drenaje de 5 según el criterio de Schumn (1956). Su densidad de drenaje es de $1,41 \mathrm{~km} / \mathrm{km}^{2}$, con un tiempo de concentración de 2,21 horas y una pendiente del cauce principal del $3,48 \%$. Estos valores en una cuenca de esta superficie son considerados altos, por lo que es mayor el potencial erosivo y el transporte de sedimentos. La distribución del orden de los cursos de agua se puede observar en la figura 6. 


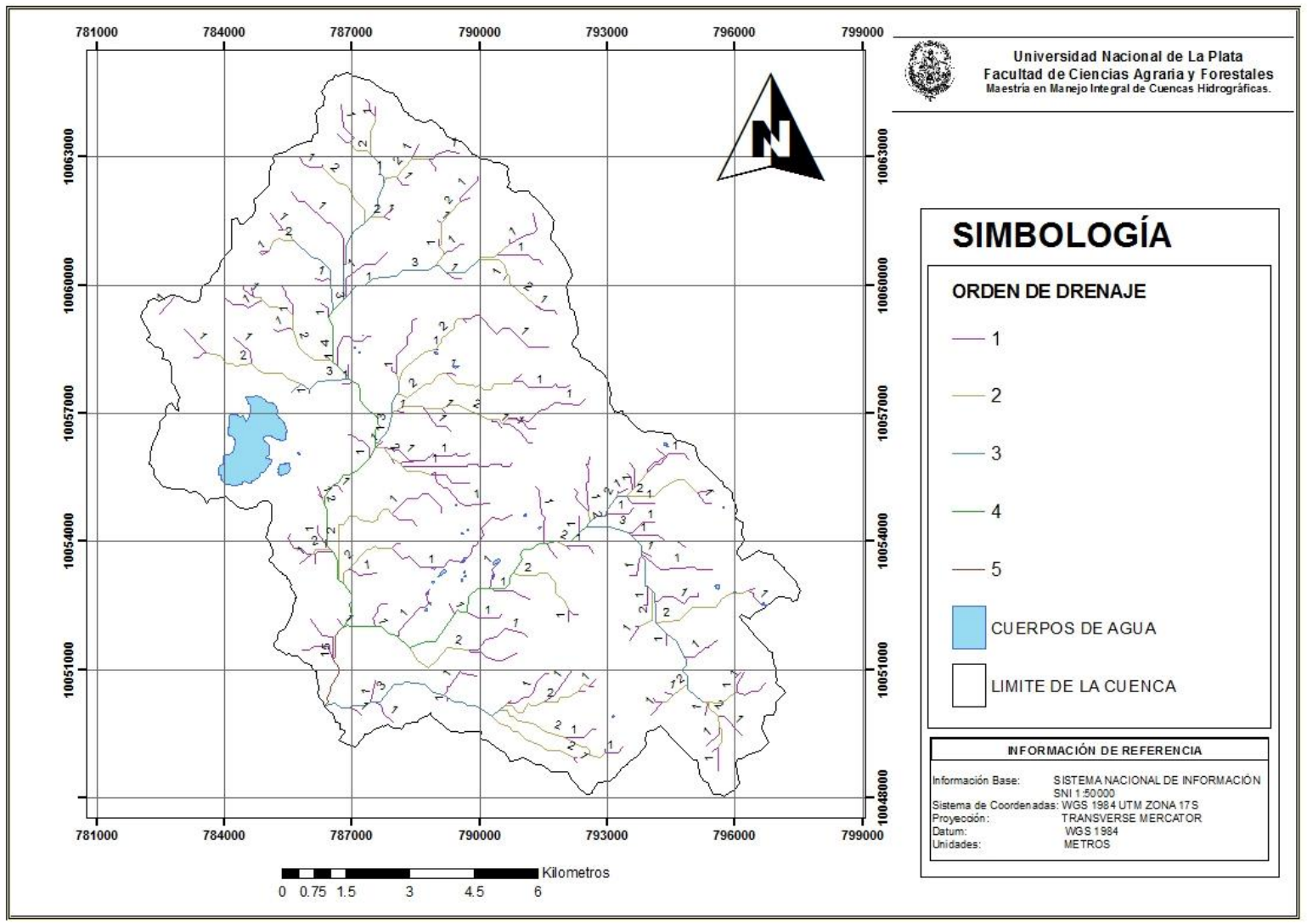

FIGURA 6: Número de órdenes de drenaje del área de estudio. Escala: 1:200000.

\subsection{CARACTERIZACIÓN BIOFÍSICA DE LA CUENCA}

\subsubsection{Hidrología y Climatología}

\subsubsection{Precipitación}

La subcuenca del río Pitura registra precipitaciones mayores a $1.200 \mathrm{~mm}$ anuales, estos valores son normales en los rangos altitudinales que está asentada ya que la mayor parte de la misma este cubierta por páramo andino, en este tipo de ecosistemas las precipitaciones pueden variar desde los 800 hasta por encima de los $3000 \mathrm{~mm}$ (Buyteart, et. al., 2006), la variación en las precipitaciones ocurre por los límites altitudinales de este ecosistema que van variando de acuerdo a la distribución latitudinal en la región andina del Ecuador. Si bien la precipitación es uniforme durante todo el año, se observan que entre los meses de agosto y septiembre existe una disminución en las precipitaciones, mientras que entre los meses de diciembre y febrero las precipitaciones aumentan (Buytaert, et. al., 2005), este fenómeno ocurre debido a la influencia que el régimen del Pacífico y los aires 
continentales provenientes del Atlántico tienen sobre los andes ecuatorianos (Vuille, et. al., 2000). La distribución espacial de las precipitaciones se muestra en la figura 7.

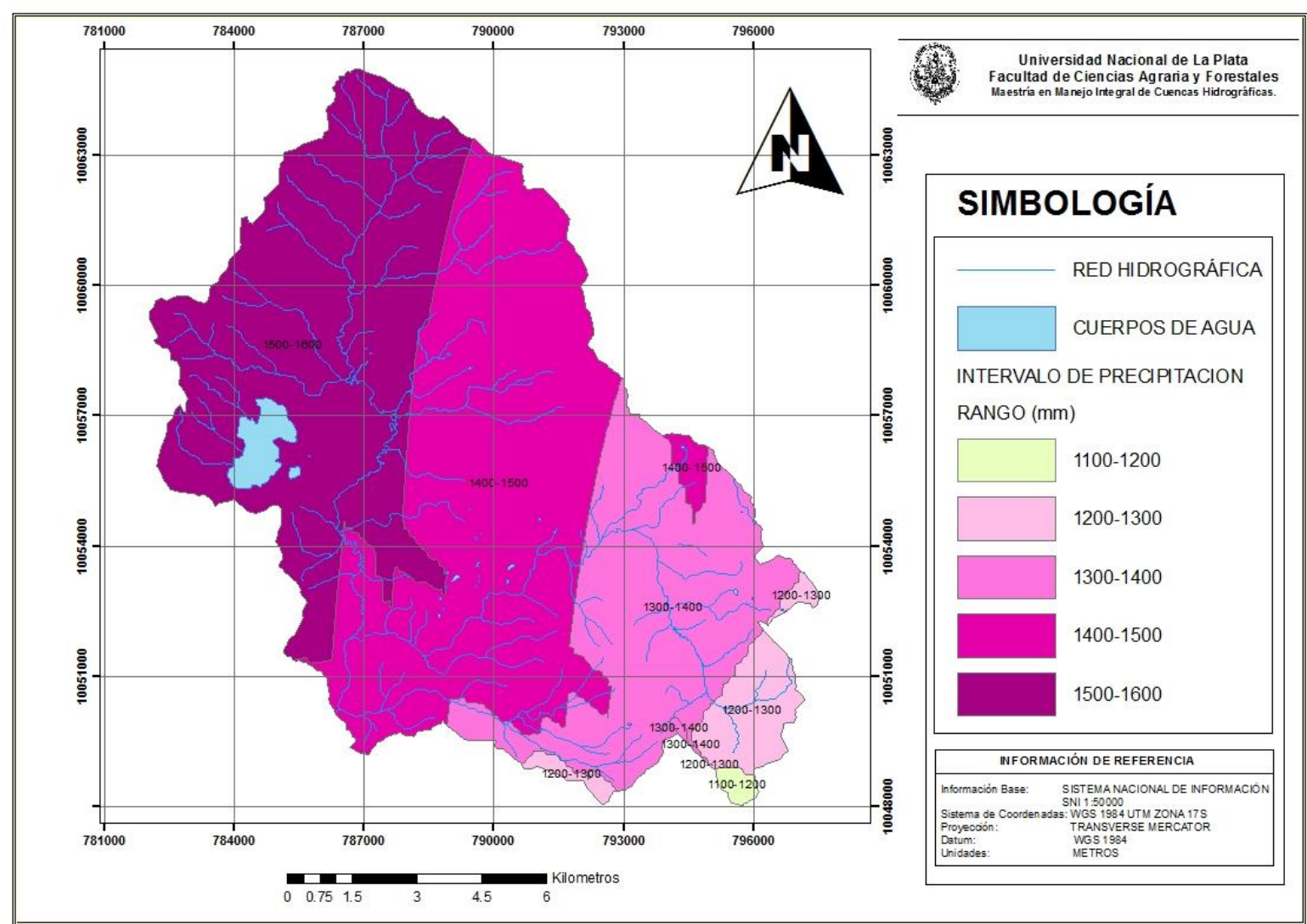

FIGURA 7: Distribución de la precipitación media anual del área de estudio. Escala: 1:200000.

En la tabla 11 se presenta los datos de superficie y porcentaje de la precipitación anual en el área de estudio.

TABLA 11: Cálculo de la precipitación media anual del área de estudio.

\begin{tabular}{ccrrr}
\hline $\begin{array}{c}\text { Intervalo de } \\
\text { Isoyetas }\end{array}$ & $\begin{array}{c}\text { Pp media del } \\
\text { intervalo }(\mathbf{m m})\end{array}$ & \multicolumn{1}{c}{ Área (ha) } & Porcentaje (\%) & $\begin{array}{c}\text { Pp media de la } \\
\text { cuenca }(\mathbf{m m})\end{array}$ \\
\hline$\geq 1100<1200$ & 1150 & 59,41 & 0,41 & \\
$\geq 1200<1300$ & 1250 & 617,31 & 4,23 & 1456,68 \\
$\geq 1300<1400$ & 1350 & 2924,00 & 20,05 & \\
$\geq 1400<1500$ & 1450 & 5675,04 & 38,90 & \\
$\geq 1500<1600$ & 1550 & 5311,35 & 36,41 & \\
\hline
\end{tabular}

Pp: Precipitación 


\subsubsection{Temperatura Media Anual}

La temperatura dentro del área de estudio como en todo el territorio ecuatoriano es constante durante todo el año, en la región interandina se registran variaciones de hasta 10 ${ }^{\circ} \mathrm{C}$ en el día (Crespo, et. al., 2014), la temperatura media es de aproximadamente $8{ }^{\circ} \mathrm{C}$ a 3500 m de altitud (Buytaert, 2006), lo que concuerda con los valores obtenidos en el estudio, también se puede comprobar la relación directamente proporcional entre la altitud y la temperatura, que disminuye entre 0,5 y $0,7^{\circ} \mathrm{C}$ por cada $100 \mathrm{~m}$ de asenso (Castaño 2002).

El mapa de isotermas de la subcuenca del río Pitura se representa en la figura 8 , con un intervalo entre isolineas de $1^{\circ} \mathrm{C}$.

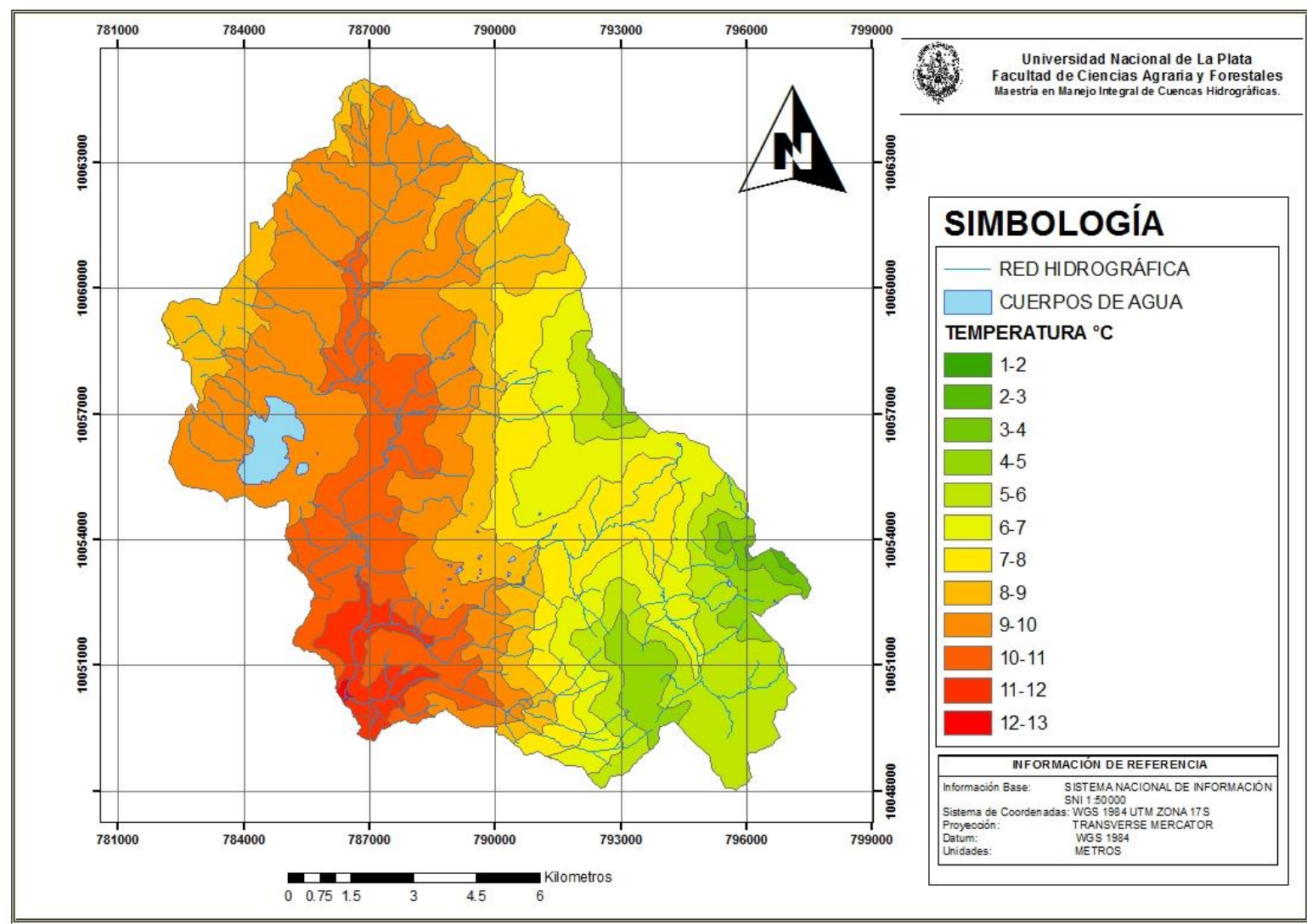

FIGURA 8: Mapa de isotermas de la subcuenca del área de estudio. Escala: 1:200000.

En la tabla 12 se presenta los valores de superficie y porcentaje de la temperatura en el área de estudio y la temperatura media anual calculada para el área de estudio. 
TABLA 12: Cálculo de la Temperatura media anual del área de estudio.

\begin{tabular}{ccrrr}
\hline $\begin{array}{c}\text { Intervalo de } \\
\text { Isotermas }\end{array}$ & $\begin{array}{c}\text { T media del } \\
\text { intervalo }\left({ }^{\circ} \mathbf{C}\right)\end{array}$ & \multicolumn{1}{c}{ Área (ha) } & \multicolumn{1}{c}{ Porcentaje (\%) } & $\begin{array}{c}\text { T media de la } \\
\text { cuenca }\left({ }^{\circ} \mathbf{C}\right)\end{array}$ \\
\hline $1-2$ & 1,5 & 0,02 & 0,00 & \\
$2-3$ & 2,5 & 19,33 & 0,13 & \\
$3-4$ & 3,5 & 102,53 & 0,70 & \\
$4-5$ & 4,5 & 644,25 & 4,42 & \\
$5-6$ & 5,5 & 1538,81 & 10,55 & \\
$6-7$ & 6,5 & 1555,60 & 10,66 & 8,32 \\
$7-8$ & 7,5 & 1664,38 & 11,41 & \\
$8-9$ & 8,5 & 2051,01 & 14,06 & \\
$9-10$ & 9,5 & 4548,35 & 31,18 & \\
$10-11$ & 10,5 & 2027,06 & 13,90 & \\
$11-12$ & 11,5 & 423,16 & 2,90 & \\
$12-13$ & 12,5 & 12,59 & 0,09 & \\
\hline
\end{tabular}

$T:$ Temperatura

\subsubsection{Determinación de zonas climáticas}

De acuerdo a la clasificación de zonas climáticas de Pourrut (1983), en la mayor parte de la subcuenca predominan los climas subtemperado Per-húmedo y Frío Súperhúmedo. Estas zonas son caracterizadas por lluvias orográficas y lloviznas constantes (Cortez, 2015), con presencia de alta irradiación solar y bajas temperaturas, lo que ha desarrollado una biodiversidad con sistemas de adaptaciones específicos (Mena \& Hofstede, 2006), y abundante microclimas que se forman por la fuerte topografía de los andes ecuatorianos (Llambi, et. al., 2013), que también origina la presencia de vientos muy fuertes (Buytaert, et. al., 2006). No se observa caída de nieve y las heladas son inusuales, sin embargo en los días con precipitación existe una gran nubosidad que aumenta considerablemente la humedad relativa (Buytaert, et. al., 2012).

Por lo general se describe al clima de los páramos como frío y húmedos, con alta irradación, sin embargo existe una variabilidad climática muy grande dependiendo de la latitud en la que se encuentre el ecosistema (Hofstede, 2014), la diversidad de la vegetación presente en distintos páramos es muestra de estas variaciones climáticas (Llambi, et. al., 2013). Otro factor importante en el clima de la sierra ecuatoriana es la humedad relativa del aire, siendo las regiones con mayor humedad relativa del aire las que presentan menor variación de la temperatura (Smith \& Young, 1987). El de la zona hace que las heladas sean muy pocas y que se generen tan solo en las horas de la madrugada, la temperatura en el día es lo suficientemente alta para evitar la acumulación de hielo en los pajonales por debajo de los 4000 m.s.n.m. (Buytaert, et. al., 2006). En la sierra norte los páramos se clasifican como húmedos y superhúmedos, por la humedad que acarrea la las masas de aire provenientes del 
pacífico (Hofstede, et. al., 2014). Las zonas climáticas según la clasificación de Pourrut (1983), se muestran en la figura 9.

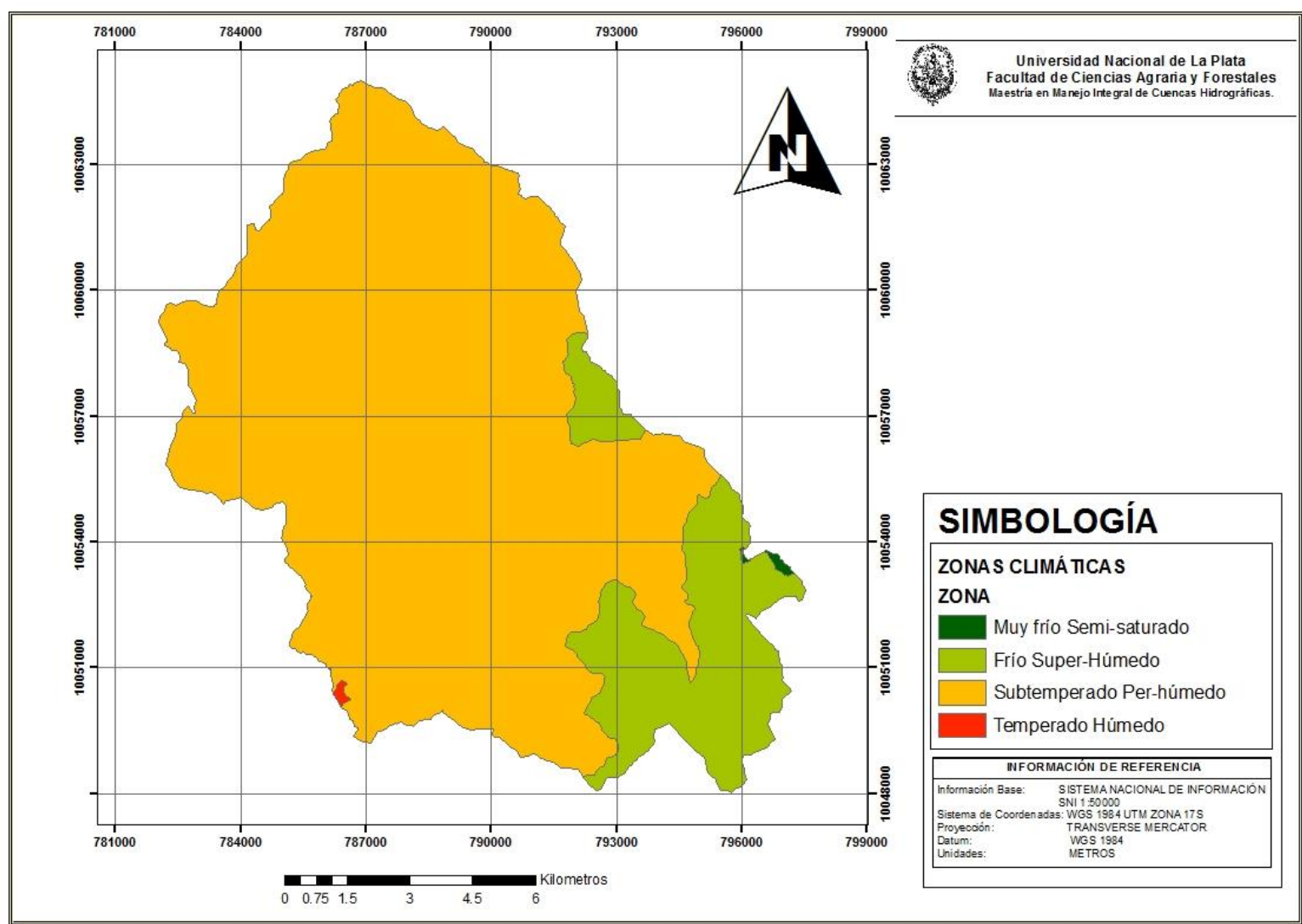

FIGURA 9: Mapa de zonas climáticas del área de estudio. Escala: 1:200000.

En la tabla 13 se detallan los rangos de precipitación y temperatura media anual de cada una de las zonas climáticas, su y el porcentaje.

TABLA 2: Zonas climáticas del área de estudio

\begin{tabular}{lccrr}
\hline \multicolumn{1}{c}{ Tipo de Clima } & $\begin{array}{c}\text { Rango Pp } \\
(\mathbf{m m})\end{array}$ & $\begin{array}{c}\text { Rango T } \\
\left({ }^{\circ} \mathbf{C}\right)\end{array}$ & Área (ha) & $\begin{array}{r}\text { Porcentaje } \\
(\%)\end{array}$ \\
\hline Muy frío Semi-saturado & $1000-2000$ & $1,5-3$ & 19,35 & 0,13 \\
Frío Súper-Húmedo & $1000-2000$ & $3-6$ & 2285,58 & 15,67 \\
Subtemperado Perhúmedo & $1000-2000$ & $6-12$ & 12269,59 & 84,11 \\
Temperado Húmedo & $1000-2000$ & $12-17$ & 12,59 & 0,09 \\
\hline
\end{tabular}

T: Temperatura; Pp: Precipitación 


\subsubsection{Determinación del Caudal}

a) Determinación del número de curva de la subcuenca

La figura 10 muestra el mapa de tipo de suelo para la determinación del número de curva en el área de estudio.

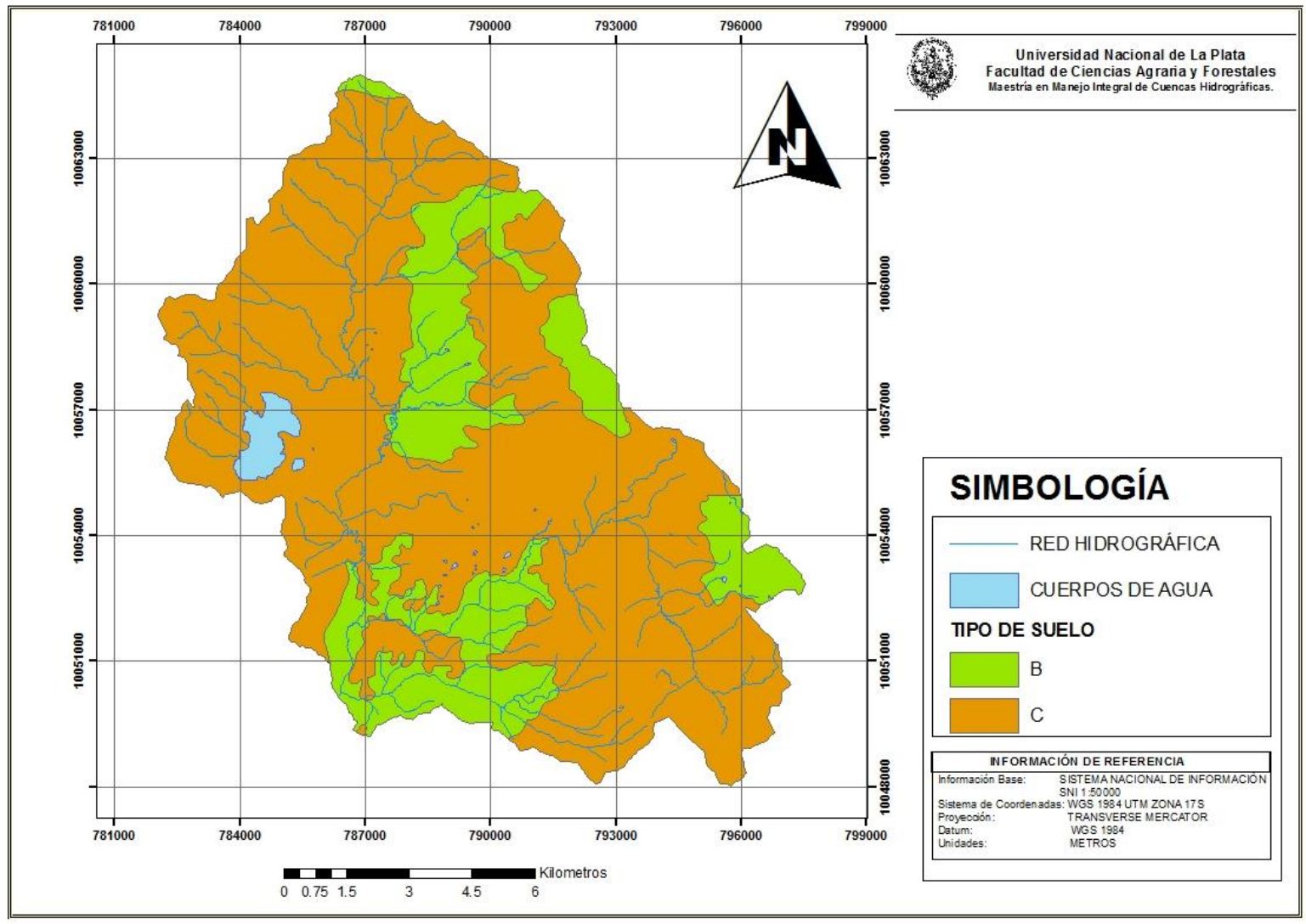

$B$ : Suelos con arenas finas y limos; $C$ : suelos con arenas muy finas, limos, suelos con presencia de arcilla.

FIGURA 10: Mapa de tipo de suelos del área de estudio. Escala: 1:200000.

En la tabla 14 se detallan el área, el porcentaje y la descripción de los tipos de suelo encontrados en la subcuenca del río Pitura, a fin de determinar el número de curva de la cuenca.

TABLA 3: Tipos de suelo del área de estudio

\begin{tabular}{clrr}
\hline Tipo de Suelo & \multicolumn{1}{c}{ Descripción } & \multicolumn{1}{c}{$\begin{array}{c}\text { Área } \\
\text { (ha) }\end{array}$} & $\begin{array}{c}\text { Porcentaje } \\
\text { (\%) }\end{array}$ \\
\hline B & Arenas finas y limos & 3324,59 & 22,79 \\
C & $\begin{array}{l}\text { Arenas muy finas, limos, suelos con presencia de } \\
\text { arcilla }\end{array}$ & 11262,53 & 77,21 \\
\hline
\end{tabular}


El área de estudio está cubierta por Inseptisoles de origen volcánico, las texturas dominantes en este tipo de suelo franco arcillosa, franco arcillo arenosa y arcillosa (Chinchilla, 2011), sin embargo en los páramos andinos la descomposición lenta de la materia orgánica hace que se generen arenas y limos (Quichimbo, et. al., 2012), lo que concuerda con la textura del suelo en la subcuenca y la elección del tipo de suelo para el cálculo del NC.

La figura 11 muestra el mapa de la distribución del Número de Curva en el área de estudio con una condición de humedad antecedente del suelo, el tipo II, ya que el estudio no se realizó para una época específica de estudio sino para un estudio global del sector.

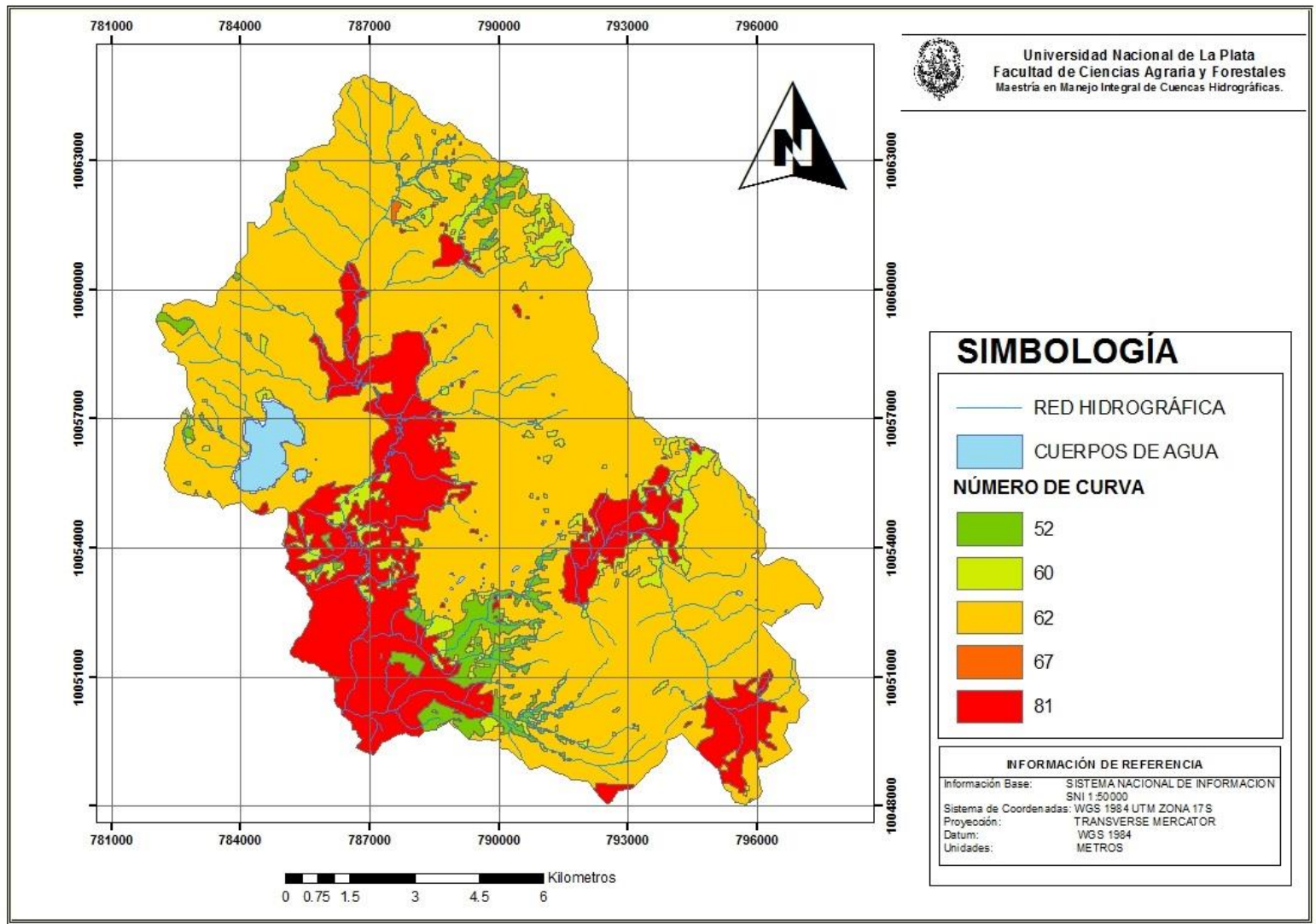

FIGURA 11: Mapa de Número de Curva del área de estudio. Escala: 1:200000.

En la tabla 15 se puede observar el área y porcentaje que ocupa cada Número de Curva en el área de estudio y el valor del Número de Curva Ponderado. 
TABLA 154: NC Ponderada y NC Parciales encontrados en la subcuenca del río Pitura.

\begin{tabular}{crrr}
\hline NC & \multicolumn{1}{c}{ ÁREA (ha) } & \multicolumn{2}{c}{ PORCENTAJE (\%) } \\
\hline 0 & 213,12 & & 1,46 \\
52 & 167,42 & & 1,15 \\
60 & 710,60 & & 4,87 \\
62 & 10148,21 & & 69,59 \\
67 & 7,29 & & 0,05 \\
81 & 3336.63 & & 22,88 \\
NC PONDERADA & $\mathbf{6 6}$ & \\
\hline
\end{tabular}

NC: Número de Curva

El número de curva obtenido en el área de estudio es bajo, esto se debe en gran medida al ecosistema predominante en el área, en el cual debido al clima frío, la alta humedad relativa y la baja presión atmosférica favorecen a la acumulación de materia orgánica y una alta capacidad de retención de agua (Crespo, et. al., 2014). Igualmente importante es la cobertura vegetal, la cual está compuesta principalmente por pajonal, almohadillas y bosque de Polylepis sp. (Mosquera, et. al., 2012), sin embargo también se puede observar una gran extensión con un valor de numero de curva elevado en el área de intervención, que ha transformado el páramo original en pastizales, mediante el pastoreo extensivo (Mosquera, et. al., 2012) y las quemas constantes que se realizan cada dos o tres años (Harden, et. al. 2015).

\section{b) Elección de los datos de precipitación}

En la tabla 16 se detallan los datos de precipitación utilizados en la estimación del caudal medio de la subcuenca del río Pitura, obtenidos de la estación Pluviométrica ESPE.

TABLA 16: Datos de precipitaciones para cálculo del caudal de la subcuenca del río Pitura

\begin{tabular}{lcc}
\hline $\begin{array}{c}\text { Fecha de la } \\
\text { precipitación }\end{array}$ & $\begin{array}{c}\text { Duración de la lluvia } \\
\text { (horas) }\end{array}$ & $\begin{array}{c}\text { Precipitación } \\
(\mathbf{m m})\end{array}$ \\
\hline $25 / 12 / 2013$ & 1 & 0,60 \\
$04 / 02 / 2014$ & 8 & 33 \\
\hline
\end{tabular}




\section{c) Cálculo del caudal}

En la tabla 17 se resumen los diferentes factores calculados para determinar el caudal de la subcuenca.

TABLA 175: Resultados cálculo del caudal de la subcuenca del río Pitura.

\begin{tabular}{lcr}
\hline \multicolumn{1}{c}{ Parámetros } & Unidades & Resultado \\
& & \\
\hline Tiempo de concentración & horas & 2,21 \\
Coeficiente de Uniformidad & Adimensional & 1,703 \\
Coeficiente de simultaneidad o Factor reductor & Adimensional & 0,899 \\
Precipitación máxima corregida sobre la cuenca & Adimensional & 29,680 \\
Intensidad de Precipitación & $\mathrm{mm} / \mathrm{hora}$ & 8,246 \\
Coeficiente de Escorrentía & Adimensional & 0,020 \\
Caudal Base & $\mathrm{m}^{3} / \mathrm{s}$ & 1,76 \\
Caudal Calculado para un P de 0,6 mm & $\mathrm{m}^{3} / \mathrm{s}$ & 2,03 \\
Caudal Calculado para un P de 33 mm & $\mathrm{m}^{3} / \mathrm{s}$ & 3,26 \\
Caudal Promedio (Q) & $\mathrm{m}^{3} / \mathrm{s}$ & $\mathbf{2 , 6 5}$ \\
\hline
\end{tabular}

P: Precipitación

En el Ecuador como en todos los países andinos las cuencas hidrográficas nacen de los páramos, el caudal de estas cuencas depende principalmente de la capacidad de regulación hídrica de este ecosistema (Podwojewski \& Poulenard, 2000), los sistemas hidrológicos están determinadas por las precipitaciones que pueden variar de moderadas a altas (Hofstede, et. al., 2014), en el caso del área de estudio estas precipitación son moderadas. Otro factor que influye en la generación de los caudales de las cuencas andinas en el Ecuador son los suelos, los cuales al tener gran cantidad de materia orgánica retienen mucha humedad, la misma que van aportando a las vertientes de manera prolongada y continua (Buytaert, et. al., 2006). Al igual que el suelo la vegetación también juega un papel importante en la generación hidrológica de estas cuencas, aportan humedad de la neblina y su consumo de agua es mínimo (Buytaert, et. al., 2006). En algunas cuencas cubiertas por páramo en el Ecuador se han registrado hasta $1000 \mathrm{~mm} / a n ̃ o$, lo que equivale a las dos terceras partes de la precipitación promedio sobre estas áreas (Buytaert, et. al. 2006). Estos caudales son indispensables en el abastecimiento de agua para las ciudades y en la generación de energía hidroeléctrica (Hofstede, et. al., 2014). 


\subsubsection{Edafología}

\subsubsection{Determinación de Tipos de Suelos}

El mapa base de tipos de suelos según Soil Taxonomy se muestra en la figura 12.

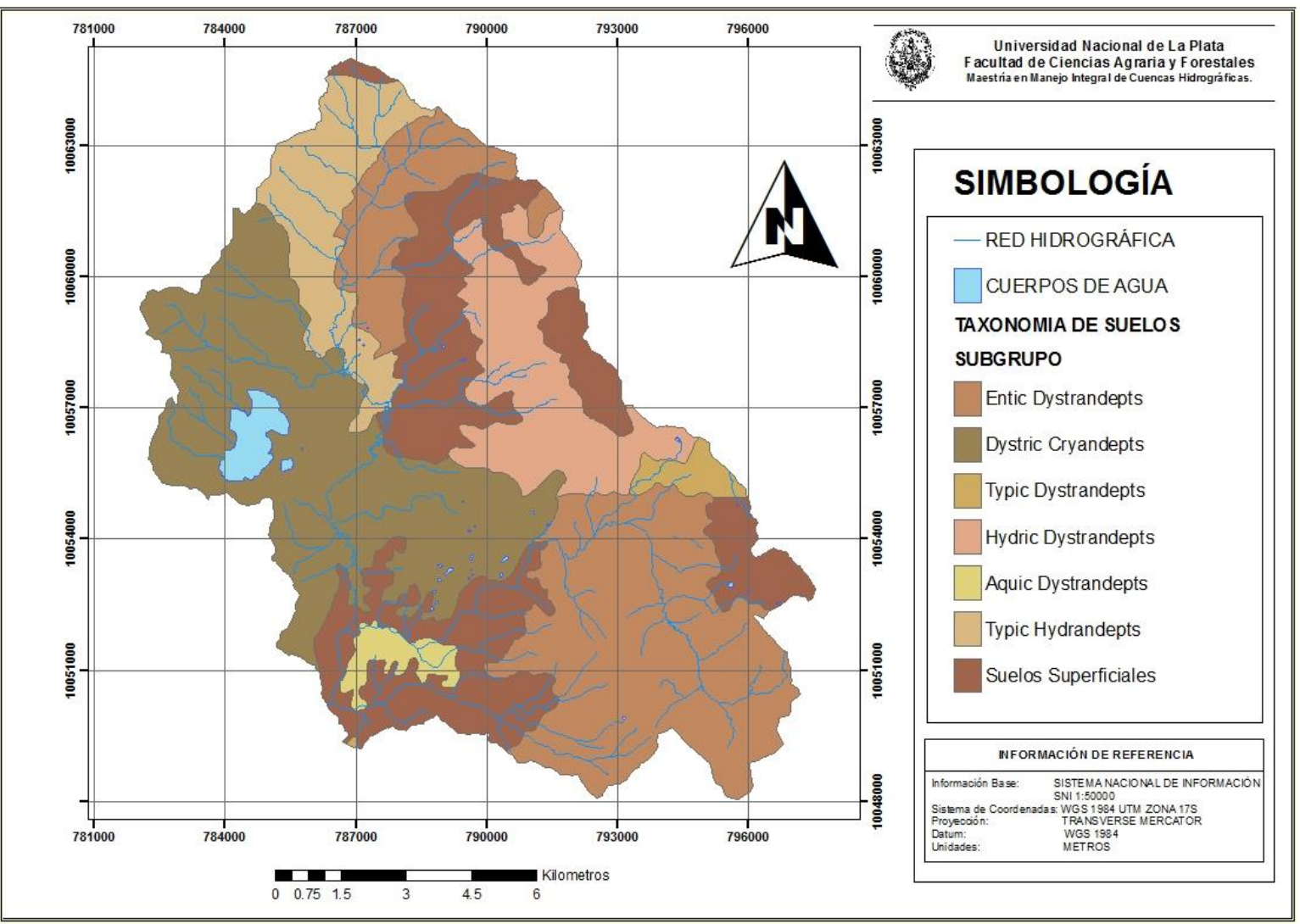

FIGURA 12: Mapa de tipo de suelos del área de estudio. Escala: 1:200000.

A continuación se detallan en la tabla 18 las áreas y porcentajes de cada uno de los tipos de suelos encontrados en la subcuenca.

TABLA 6: Tipos de suelos encontrados en el área de estudio

\begin{tabular}{|c|c|c|c|c|c|}
\hline ORDEN & SUBORDEN & GRAN GRUPO & SUBGRUPO & $\begin{array}{l}\text { ÁREA } \\
\text { (ha) }\end{array}$ & $\begin{array}{c}\text { PORCENTAJE } \\
(\%)\end{array}$ \\
\hline INCEPTISOLES & ANDEPTS & DYSTRANDEPTS & Entic Dystrandepts & 4088,10 & 28,03 \\
\hline INCEPTISOLES & ANDEPTS & CRYANDEPTS & Dystric Cryandepts & 3960,81 & 27,15 \\
\hline INCEPTISOLES & ANDEPTS & DYSTRANDEPTS & Typic Dystrandepts & 196,52 & 1,35 \\
\hline INCEPTISOLES & ANDEPTS & DYSTRANDEPTS & Hydric Dystrandepts & 1569,38 & 10,76 \\
\hline INCEPTISOLES & ANDEPTS & DYSTRANDEPTS & Aquic Dystrandepts & 241,39 & 1,65 \\
\hline INCEPTISOLES & ANDEPTS & HYDRANDEPTS & Typic Hydrandepts & 1206,33 & 8,27 \\
\hline $\begin{array}{l}\text { Suelo } \\
\text { Superficial }\end{array}$ & $\begin{array}{l}\text { Suelo } \\
\text { Superficial }\end{array}$ & Suelo Superficial & Suelo Superficial & 3324,59 & 22,79 \\
\hline
\end{tabular}


Las características de los tipos de suelos señalados en la tabla 18 se detallan a continuación:

- Entic Dystrandepts (Db): Son suelos encontrados en la sierra volcánica alta (hasta 3.600 m.s.n.m.), con relieves ligeros o moderadamente ondulados; se presentan como suelos limosos muy negro con más de $50 \%$ de agua a $\mathrm{pF}^{2}$, sobre muestra sin desecación y menos de 80\% (SENPLADES, et. al., 2012).

- Dystric Cryandepts (Dcy): Son suelos que no tienen moteados, con croma de 2 o menos dentro del metro de la superficie del suelo, no son tixotrópicos ${ }^{3}$ en la mitad o más del espesor de todos los horizontes entre las profundidades de $25 \mathrm{~cm}$ y $1 \mathrm{~m}$, y el promedio ponderado de retención de agua a 15 bares es inferior al $20 \%$ entre los $25 \mathrm{~cm}$ y $1 \mathrm{~m}$ (SENPLADES, et. al., 2012).

- Typic Dystrandepts (Df): Son suelos encontrados en la sierra volcánica alta (hasta 3.600 m.s.n.m.), con relieves ligeros o moderadamente ondulados; se muestra como un suelo limoso negro. Con retención de agua a pF3 20 a 50 \% sobre muestra sin desecación (SENPLADES, et. al., 2012).

- Aquic Dystrandepts (Dn): Son suelos encontrados en la sierra volcánica alta (hasta 3.600 m.s.n.m.), con relieves ligeros o moderadamente ondulados; se muestra como un suelo limoso o limo-arenoso, muy negro, con retención de agua 20 a 50 \% a pF 3 sobremuestra sin desecación (SENPLADES, et. al., 2012).

- Hydric Dystrandepts (Dh/R): Son suelos encontrados en la sierra volcánica alta (3200 a 4000 m.s.n.m.) estribaciones occidentales y orientales de la sierra con relieves fuertemente ondulados; se muestra como un suelo muy negro, limoso muy suave, untuoso, esponjoso (SENPLADES, et. al., 2012).

- Typic Hydrandepts (Dt): Son suelos encontrados en vertientes de las cordilleras con suaves o fuertes pendientes. En la sierra altitudes entre 1.500 a 4.000 m.s.n.m., con un relieve fuertemente ondulado; se muestran como un suelo negro, generalmente profundo, limo muy suave, untuoso, esponjoso, retención de agua a pF3 sobre muestra sin desecación de 100 a 200 gramos de agua por 100 gramos de suelo seco (SENPLADES, et. al., 2012).

\footnotetext{
${ }^{2}$ Logaritmo decimal que expresa la tensión de la humedad igual a la atmosfera en el suelo.

${ }^{3}$ Suelos tixotrópicos.-Son aquellos que pierden resistencia tras el arado, para luego recuperar una parte de ésta con el tiempo (Pliego de prescripciones técnicas generales de materiales ferroviarios, 2006).
} 
- Suelos Superficiales: Son suelos que tienen una profundidad de $30 \mathrm{~cm}$., aunque normalmente son muy superficiales (menos de $10 \mathrm{~cm}$.). Son de textura franco limosa a franco arcillosa, con gravillas de basalto en todo el perfil y bien drenados. La fertilidad natural es media a alta (SENPLADES, et. al., 2012).

Los suelos presentes en el área de estudio pertenecen al orden de los Inceptisoles, los cuales son comunes en las zonas de páramo (Crespo, et. al., 2014.), estos suelos son considerados jóvenes debido al proceso lento de su formación, la ceniza volcánica de los cuales se originan (Hofstede, et. al., 2014) y la baja temperatura que letarga la mineralización de los suelos (Llambi, et. al., 2012). El clima húmedo de la subcuenca contribuye a la gran cantidad de materia orgánica presente en el suelo (Malagón \& Pulido, 2000), ya que la vegetación se descompone muy lentamente por la poca actividad microbiana existente en bajas temperaturas (Hofstede, et. al., 2014), con lo que se acumula este material en proceso de descomposición y forma horizontes superficiales profundos de color oscuro (Malagón \& Pulido. 2000), con altos contenidos de carbono y bastante profundos (Buytaert, et. al. 2002). El potencial de acumulación de carbono de estos suelos en zonas muy húmedas como el área de estudio, es mucho mayor al que presentan las selvas tropicales (Hofstede, et. al., 2014).

\subsubsection{Determinación de Pendientes del Suelo}

Para el presente estudio la pendiente se clasificó de acuerdo a 10 rangos, comprendidos en un intervalo de plana a abrupta; cerca del $45 \%$ del área en estudio presenta pendientes mayores al $25 \%$, lo que muestra la topografía accidentada del área de estudio y las graves limitaciones para realizar actividades agropecuarias en algunas zonas de la subcuenca. Estas pendientes son normales en los andes ecuatorianos (Josse, et. al., 2009), que se caracteriza por pendientes empinadas, quebradas profundas y picos escarpados, llegando en algunos lugares a darse cambios altimétricos de $4000 \mathrm{~m}$ en distancia horizontales de tan solo 50 o $100 \mathrm{Km}$ (Josse, et. al., 2009). Las zonas que tienen este tipo de pendientes elevadas son propensas a la inestabilidad de los suelos, este fenómeno es más evidente cerca de la red hidrográfica donde las pendientes son aún más pronunciadas, consecuentemente estos suelos generan gran cantidad y arrastre de sedimentos (Rodríguez \& Gordón, 2015). Estos suelos si son despojados de la cobertura vegetal son muy susceptibles a la erosión, por lo que es recomendable implementar sistemas de protección como la agroforestería (Winters, et. al., 1998). La distribución espacial de las pendientes del área de estudio se muestra en la figura 13 . 


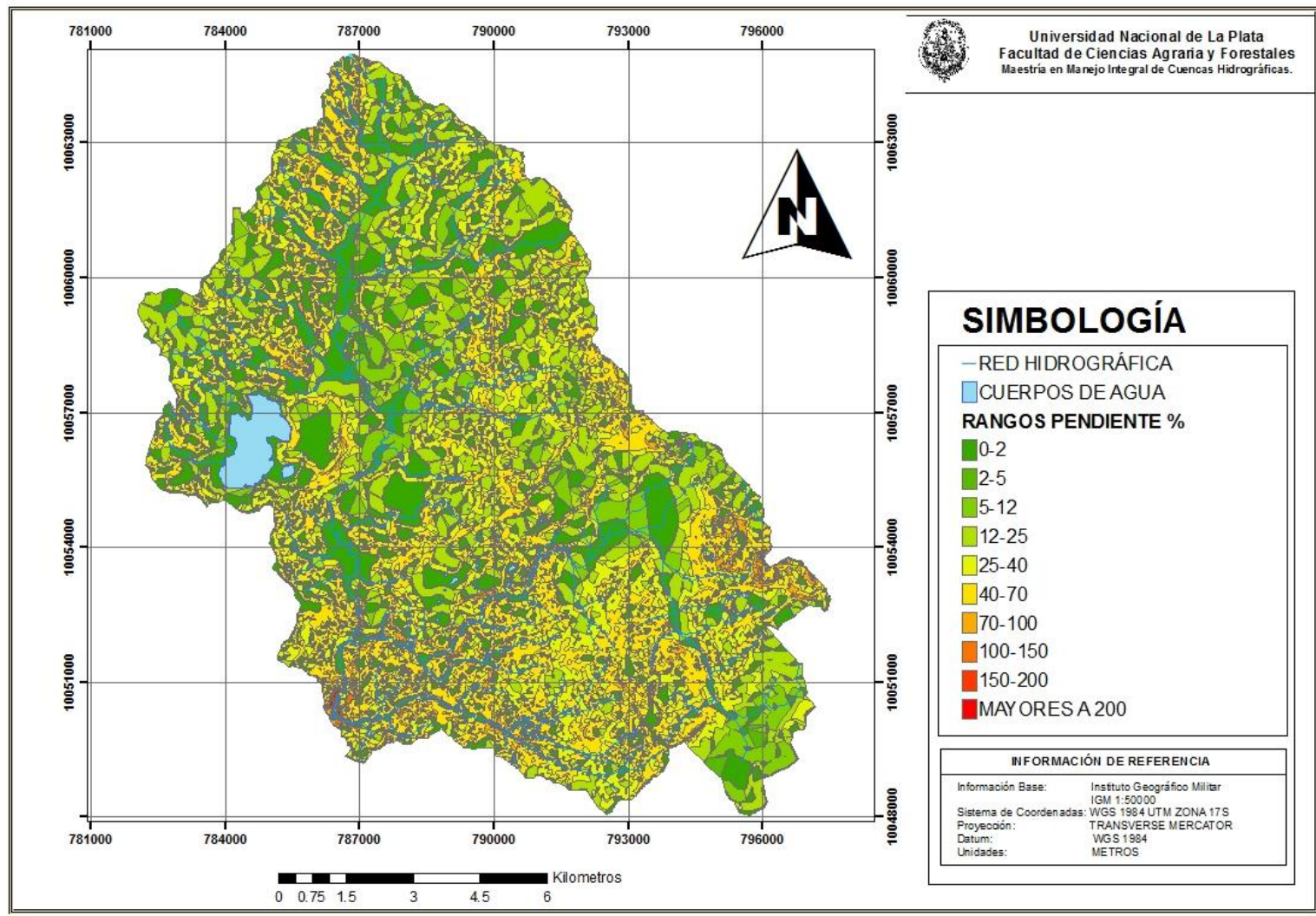

FIGURA 13: Mapa de pendientes del área de estudio. Escala: 1:200000.

En la Tabla 19, se presentan las clasificaciones de pendientes y relieves de la subcuenca del río Pitura.

TABLA 19: Clasificación de pendientes y relieve en área y porcentaje del área de estudio

\begin{tabular}{llrr}
\hline GRADO (\%) & RELIEVE & ÁREA (ha) & PORCENTAJE (\%) \\
& & & 21,88 \\
\hline $0-2$ & Plana & 3192,92 & 1,78 \\
$2-5$ & Muy suave & 259,04 & 7,38 \\
$5-12$ & Suave & 1076,24 & 20,40 \\
$12-25$ & Media & 2977,07 & 22,96 \\
$25-40$ & Media a fuerte & 3350,27 & 21,93 \\
$40-70$ & Fuerte & 3199,09 & 3,05 \\
$70-100$ & Muy Fuerte & 444,94 & 0,53 \\
$100-150$ & Escarpada & 77,84 & 0,06 \\
$150-200$ & Muy Escarpada & 8,08 & 0,03 \\
Mayores a 200 & Abrupta & 4,59 & \\
\hline
\end{tabular}


El detalle de los relieves, se presenta a continuación:

- Plana: Son relieves totalmente planas que tienen un porcentaje de inclinación que va del $0 \%$ al $2 \%$, dentro de este rango de pendiente se pueden realizar cualquier actividad agropecuaria (SENPLADES, et. al., 2012).

- Muy suave: Estos son relieves poco inclinados, que se encuentran dentro de un intervalo de porcentaje que va del $2 \%$ al $5 \%$, permite realizar actividades agropecuarias, con ligeras limitaciones (SENPLADES, et. al., 2012).

- Suave: Estos son relieves ligeramente ondulados, estos se encuentran en un rango que va del $5 \%$ al $12 \%$, permite realizar actividades agropecuarias con limitaciones, por lo que es ya necesario el empleo de criterios técnicos para la aplicación de las distintas prácticas agropecuarias (SENPLADES, et. al., 2012).

- Media: Son relieves medianamente ondulados, que se encuentran dentro de un rango que va desde $12 \%$ al $25 \%$, encontramos fuertes limitaciones en cuanto a las actividades agropecuarias, ya que son suelos más vulnerables a los efectos de la erosión hídrica y eólica (SENPLADES, et. al., 2012).

- Media a fuerte: Son relieves mediana a fuertemente colinados, con severas limitaciones para la realización de actividades agropecuarias, estos se encuentran en un rango que va del $25 \%$ al $40 \%$ (SENPLADES, et. al., 2012).

- Fuerte: Son relieves fuertemente disectados, que están dentro de un rango que va desde $40 \%$ al $70 \%$, en estos suelos no son aptos para realizar actividades agropecuarias; es recomendable realizar actividades forestales (SENPLADES, et. al., 2012).

- Muy Fuerte: Son relieves muy fuertemente disectados, que van en un rango de $70 \%$ a $100 \%$, con limitaciones para actividades forestales productivas (SENPLADES, et. al., 2012).

- Escarpada: Son relieves fuertemente desnivelada que dificulta el acceso, que van en un rango de $100 \%$ a $150 \%$, en las que al igual que en la anterior categoría es recomendable realizar actividades con objetivos de conservación y restauración (SENPLADES, et. al., 2012).

- Muy Escarpada: Son relieves que se encuentran dentro de un rango que va desde $150 \%$ a $200 \%$, presenta muy severas limitaciones (SENPLADES, et. al., 2012). 
- Abrupta: son relieves con una inclinación mayor a $200 \%$, en donde no se recomienda realizar ninguna actividad productiva, sino la regeneración natural y actividades de protección y conservación (SENPLADES, et. al., 2012).

\subsubsection{Determinación del Uso Actual y Cobertura Vegetal del Suelo}

Dentro el área de estudio la cobertura vegetal que ocupa la mayor superficie es el herbazal de páramo, ecosistema frágil que es característico en los rangos altitudinales en los que se encuentra la subcuenca (Hofstede, et. al., 2014), Sin embargo también se puede observar una gran superficie de intervención en la que la ganadería ha sido la actividad predominante, con lo que los suelos de esta zona estén cubiertos por pastizales. La figura 14 muestra el mapa de uso de suelo y cobertura vegetal del área de estudio.

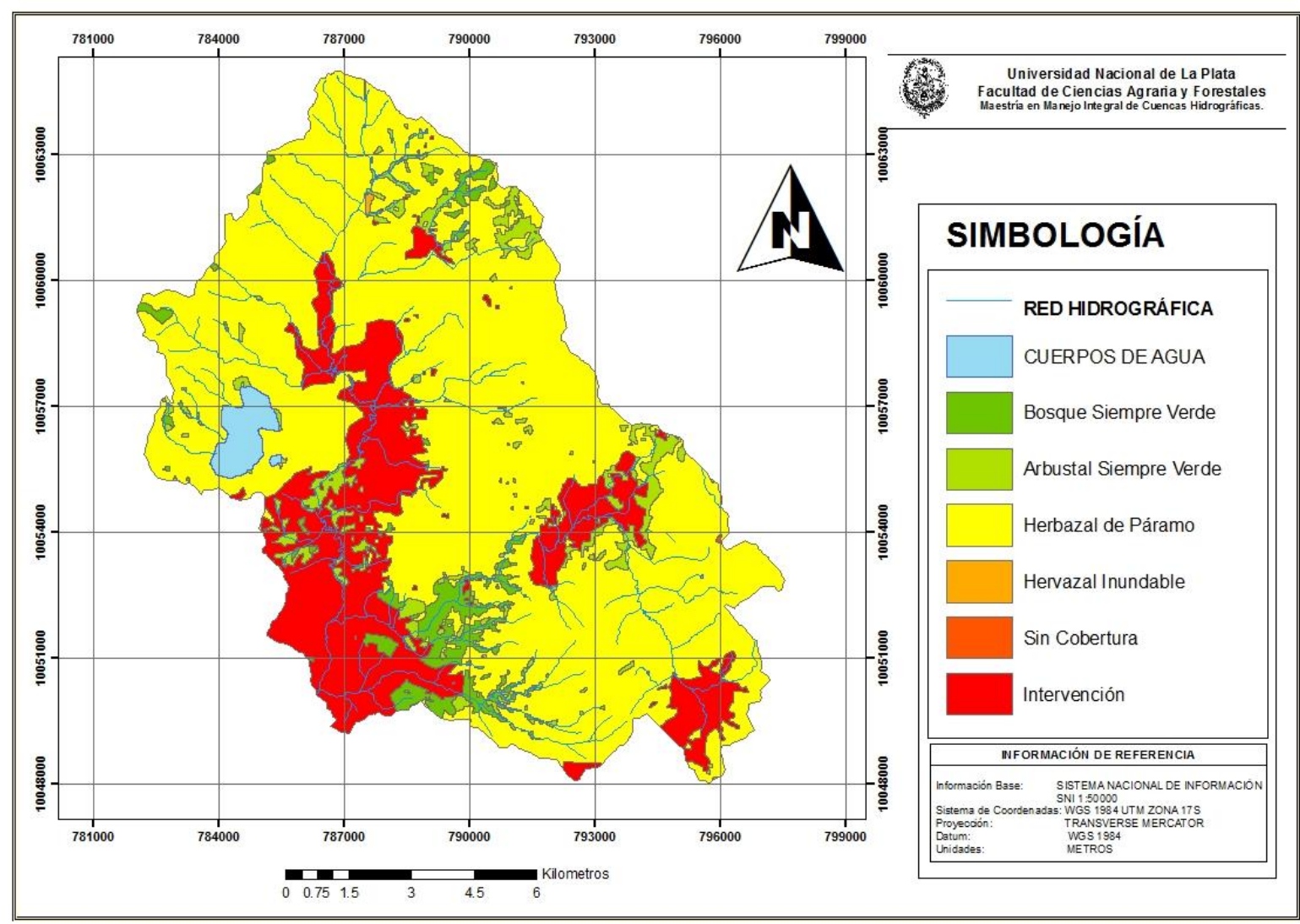

FIGURA 14: Mapa de uso actual del área de estudio. Escala: 1:200000. 
En la tabla 20 se muestran el área y porcentaje de las coberturas vegetales definidas para este trabajo.

TABLA 20: Tipos de uso de suelos del área de estudio.

\begin{tabular}{lrr}
\hline \multicolumn{1}{c}{ COBERTURA VEGETAL } & AREA (ha) & PORCENTAJE (\%) \\
\hline Agua & 213,12 & 1,46 \\
Intervención & 3336,63 & 22,88 \\
Sin Cobertura & 1,62 & 0,01 \\
Herbazal inundable del Páramo & 7,29 & 0,05 \\
Herbazal del Páramo & 10148,21 & 69,59 \\
Arbustal siempreverde y Herbazal del & 710,60 & 4,87 \\
Páramo & & 1,14 \\
Bosque siempreverde montano alto de & 165,80 & \\
Cordillera Occidental de los Andes & &
\end{tabular}

- Intervención corresponde a zonas en donde los ecosistemas nativos fueron sometidos a un cambio de uso de suelo que superó el $70 \%$, con el objetivo de destinarlo fundamentalmente a las actividades agropecuarias, con cultivos de ciclo corto (maíz, cebada, papa y haba) y pasto cultivado para el pastoreo de ganado (Ministerio del Ambiente, 2013).

- Herbazal inundable del Páramo se genera en donde las precipitaciones son mayores que la infiltración y evaporación (Bosman, et. al. 1993), esto ocasiona que la producción primaria sea mucho mayor que la descomposición de la materia orgánica por las condiciones anaeróbicas presentes (Cleef, et. al., 2005), el cambio de alguna de estas condiciones provocaría que el ecosistema se altere convirtiéndose en un ecosistema diferente (Cleef \& Rangel, 1984). Las especies identificadas para este ecosistema son: Agrostis boyacensis,, Azorella aretioides, Castilleja fissifolia, Cortaderia sericantha, Distichia muscoides, Eryngium humile, Geranium sibbaldioides, Huperzia crassa, Hydrocotyle pusilla, Hypericum aciculare, H. decandrum, Hypochaeris sonchoides, Hypsela reniformis, Juncus arctitus, Lachemilla fulvescens, L. orbiculata, Myrteola phylicoides, Oreobolus ecuadorensis, Oreobolus goeppingeri, Oreobolus obtusangulus, Oritrophium limnophilum, Plantago rigida, Schoenoplectus californicus, Sphagnum magellanicum, Werneria pygmaea, Xyris subulata (Cuesta, et. al., 2013). 
- Herbazal del Páramo: Este ecosistema está constituido por gramíneas de una altura mayor a $50 \mathrm{~cm}$ y se extiende por toda la sierra ecuatoriana (Beltrán, et. al. 2009), las características climáticas en donde se desarrolla genera una gran capacidad de retención y regulación hídrica (Buytaert, et. al., 2006). La vegetación de este ecosistema es fuertemente afectado por la ganadería (Lægaard, 1992). Las especies identificadas en el ecosistema son las siguientes: Agrostis breviculmis, Calamagrostis intermedia, Calamagrostis recta, Calamagrostis effusa, Chrysactinium acaule, Festuca asplundii, Gnaphalium pensylvanicum, Oreomyrrhis andicola, Pteridium arachnoideum, Puya lanata, Puya eryngioides, Puya pygmaea, Paspalum tuberosum, Stipa ichu, Viola humboldtii, Baccharis genistelloides, Bartsia pedicularoides, Bidens andicola, Bromus lanatus, Castilleja fissifolia, Calamagrostis effusa, Clinopodium nubigenum, Eryngiumhumile, Festuca asplundii, Festuca sublimis, Geranium sibbaldioides, Huperzia crassa, Hypochaeris sessiliflora, Hypochaeris sonchoides, Niphogeton dissecta, Orthrosanthus chimboracensis, Pedicularis incurva, Puya glomerifera, Valeriana bracteata, V. clematitis, V. microphylla, Werneria nubigena, Baccharis, Brachyotum, Diplostephium, Gaultheria, Pentacalia, Pernettya (Salgado, et. al., 2013a).

- Arbustal siempreverde y Herbazal del Páramo es considerado como una franja que limita al bosque montano alto (Cleef, 1981), está compuesto por arbustales de hasta $3 \mathrm{~m}$ de altura conbinados con pajonales, dispuestos en parches (Salgado, et. al., 2013b). Las especies identificadas para este ecosistema son las siguientes: Arcytophyllum vernicosum, Berberis grandiflora, Berberis hallii, Berberis lutea, Diplostephium rupestre, Escallonia myrtilloides, Hesperomeles obtusifolia, Miconia salicifolia, Monnina obtusifolia, Pernettya prostrata, Pentacalia arbutifolia, Pentacalia andicola, Pentacalia vaccinioides, Ribes andicola, Vaccinium floribundum. Bomarea glaucescens, Tristerix longebracteatus (Salgado, et. al., 2013b).

- Bosque siempreverde montano alto de Cordillera Occidental de los Andes, son bosques que no pierden sus hojas y llegan a una altura máxima de $20 \mathrm{~m}$ (Josse, et. al. 2003), los árboles que crecen en este ecosistema son irregulares y ramificados y el suelo suele estar cubierto con musgo (Valencia, et. al.1999), este fenómeno ocurre por las bajas temperaturas que hacen y la poca descomposición de materia orgánica (Hofstede, et. al. 1998). Los remanentes de este bosque están dispersos en su mayoría en zonas con pendientes pronunciadas (Suárez 2008). Las especies identificadas en este ecosistema son las siguientes: Aegiphila monticola, Clethra revoluta, Clethra fimbriata, Clusia flaviflora, Desfontainia spinosa, Escallonia myrtilloides, Freziera canescens, Gaiadendron 
punctatum, Hesperomeles ferruginea, Hesperomeles obtusifolia, Miconia andina, Miconia corymbosa, Miconia pustulata, Miconia theaezans, Morella pubescens, Myrsine dependens, Oreopanax ecuadorensis, Persea brevipes, Roupala pachypoda, Schefflera sodiroi, Symplocos carmencitae, Symplocos quitensis, Vallea stipularis, Viburnum triphyllum, Weinmannia latifolia, Weinmannia pinnata, Aristeguietia glutinosa, Badilloa salicina, Berberis halli, Boehmeria celtidifolia, Citharexylum ilicifolium. Clematis haenkeana (Iglesias \& Santiana, 2013).

La descripción de cada una de las coberturas vegetales dentro de la zona muestra la gran biodiversidad presente en los ecosistemas, en estudios realizados dentro del páramo ecuatoriano se han podido identificar 1524 especies de las cuales 14 son endémicas de los páramos de la sierra norte del Ecuador (Sklenar, 2005), por lo que el endemismo especifico encontrado en la zona es alto (Luteyn, 2000). Estas especies están distribuidas principalmente en las familias Asteraceae, Orchidaceae, Poaceae, Melastomataceae y Bromeliaceae (Hofstede, et. al., 2014), la biodiversidad es producto de la combinación de las diferentes condiciones ecológicas de la zona que generan un gran número de asociaciones vegetales (Rangel, 2000), sin embargo esta diversidad disminuye a medida de que la altitud aumenta (Beltrán, et. al., 2009).

La zona de transición entre el Bosque y el páramo está compuesta por árboles, arbustos y pajonales, esta zona está bastante afectada por la actividad antrópica, especialmente en las vertientes de las partes altas (Hofstede, et. al., 2014). En las zonas con condiciones climáticas más extremas se encuentran especies especializadas, adaptadas a las condiciones que el medio presenta (Sklenar. 2005). La flora encontrada en estos ecosistemas frágiles representan el $15 \%$ de las plantas endémicas del Ecuador y el $4 \%$ de toda la vegetación del país (Hofstede, et. al., 2014), sin embargo el $75 \%$ de las mismas están amenazadas y tan solo el 48 \% están dentro del Sistema Nacional de Áreas Protegidas (León, 2011).

La riqueza de diversidad en vegetación contrasta con la diversidad de la fauna presente en estos ecosistemas, siendo la mayor parte de los animales propios de las áreas circundantes más bajas (Monasterio \& Molinillo. 2003). Sin embargo dentro de estas zonas se encuentra las especies más representativas de los Andes: el condor (Vultur gryphus), el oso de anteojos (Tremarctos ornatus), la danta de montaña (Tapirus pinchaque) y el puma (Puma concolor) (Hofstede, et. al., 2014). Estudios han mostrado que parte de la fauna propia de esta zona ha desaparecido (Mena \& Medina, 2001) y es notoria la introducción de fauna exótica que representan ingresos económicos para los pobladores, entre ellos están los bobino y ovinos 
en los páramos y las truchas (Salmo trutta y S. gardnierii) en los ríos y lagunas (Hofstede, 2014).

En la zona de intervención y parte de los pajonales, se han destinado las mayores superficies a la ganadería combinada con quemas, en menor escala están los cultivos propios de las alturas como la papa (Solanum sp.), habas (Vicia faba), frejol (Phaseolus vulgaris L.), maíz (Zea mays L.) y otros cereales (Hofstede, et. al., 2014). Otra de las actividades realizadas aunque en una escala mucho menor son las plantaciones forestales; todas estas actividades han transformado el páramo en un mosaico de paisajes (Hofstede, et. al., 2014), amenazando a la integralidad de los ecosistemas naturales de la zona (Monasterio \& Molinillo. 2003), con el uso de agroquímicos que afectan la regeneración apropiada de la vegetación (Hofstede, et. al., 2014).

\subsubsection{Determinación de Uso Potencial del Suelo.}

El mapa de uso potencial de suelo muestra de ocho clases en base al aumento progresivo de las limitaciones para desarrollar las diferentes actividades agrosilvopastoriles; estas clases están representadas en la figura 15.

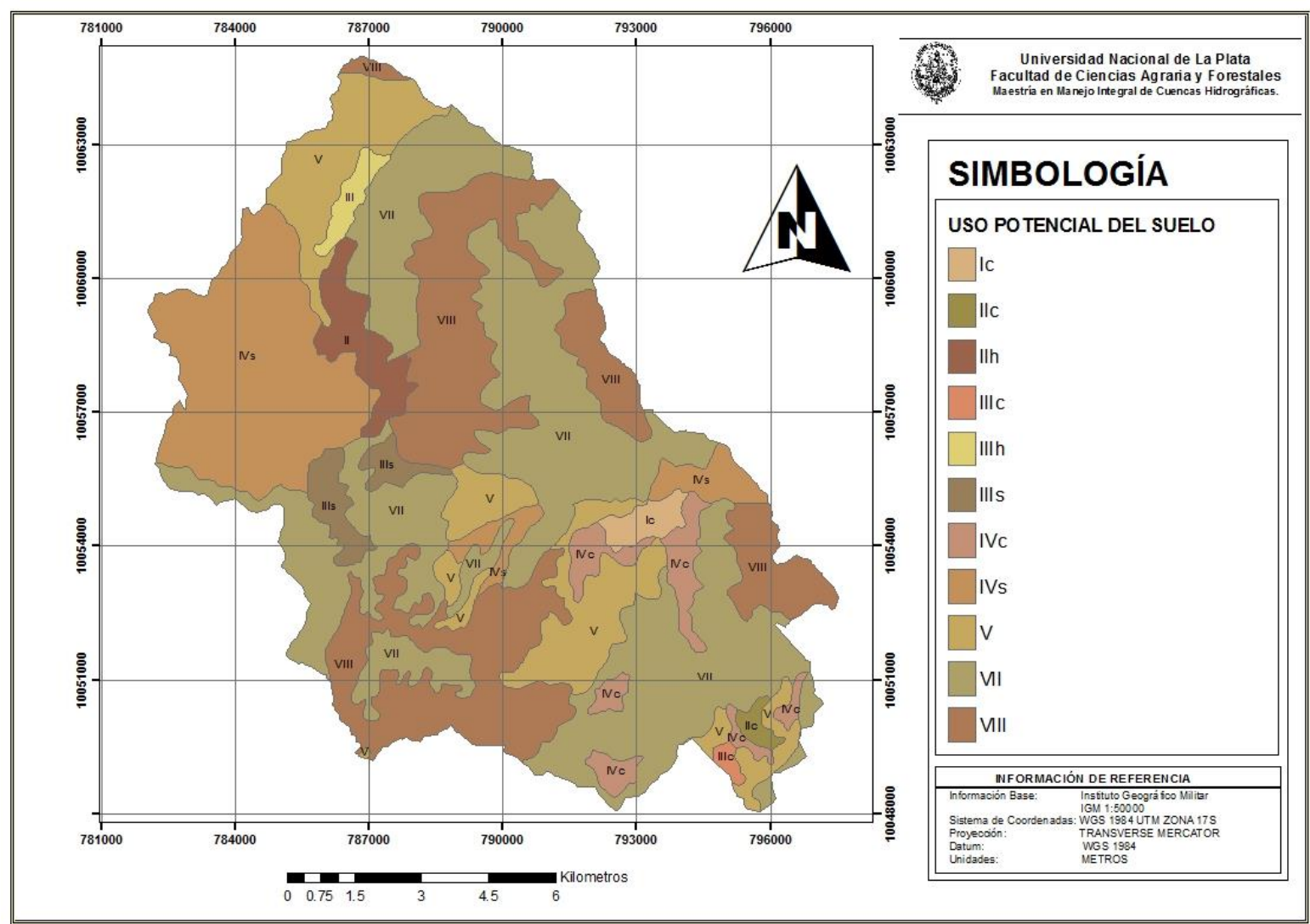


FIGURA 15: Mapa de uso potencial del suelo del área de estudio. Escala: 1:200.000

En la tabla 21 se encuentra el resumen de las áreas y porcentajes que ocupan cada una de las clases agroecológicas encontradas en la subcuenca del río Pitura.

TABLA 21: Clases de capacidad de uso de suelo del área de estudio.

\begin{tabular}{ccrr}
\hline CLASE & SUBCLASE & ÁREA (ha) & PORCENTAJE (\%) \\
\hline I & Ic & 142.02 & 0.97 \\
II & IIh & 371.67 & 2.55 \\
& Ilc & 60.87 & 0.42 \\
III & IIIc & 124.46 & 0.85 \\
& IIIh & 37.85 & 0.26 \\
IV & IIIs & 290.21 & 1.99 \\
V & IVc & 490.09 & 3.36 \\
VII & IVs & 2259.88 & 15.49 \\
VIII & V & 1824.51 & 12.51 \\
& VII & 5660.98 & 38.81 \\
& VIII & 3324.59 & 22.79 \\
\hline
\end{tabular}

- Clase I: Las tierras de esta clase pueden ser utilizadas para el desarrollo de actividades agrícolas, pecuarias o forestales adaptadas ecológicamente a la zona. Son tierras sin o muy pocas limitaciones, de pendiente plana hasta $2 \%$, sin evidencias de erosión, suelos profundos y fácilmente trabajables, sin o muy pocas piedras es decir que no interfiere en las labores de maquinaria, con fertilidad alta y no tóxicos, suelos con drenaje bueno, no salinos (SENPLADES, et. al., 2012).

- Clase II: Las tierras de esta clase pueden ser utilizadas para el desarrollo de actividades agrícolas, pecuarias o forestales adaptadas ecológicamente a la zona. Son tierras con leves limitaciones, con pendientes menores al $5 \%$, con erosión ligera o sin evidencia, moderadamente profundos y profundos, con poca pedregosidad que no limitan o imposibilitan las labores de maquinaria, fertilidad de mediana a alta, tienen drenaje natural bueno a moderado. Incluyen a suelos ligeramente salinos y no salinos, con toxicidad ligera o nula. Requieren prácticas de manejo más cuidadoso que los suelos de la Clase I, como drenajes simples (SENPLADES, et. al., 2012).

- Clase III: En esta clase se reduce la posibilidad de elección de cultivos anuales a desarrollar o se incrementan los costos de producción debido a la necesidad de usar prácticas de manejo de suelo y agua. En esta clase de tierras se presentan ligeras limitaciones, solas o combinadas, se encuentran en pendientes menores al $12 \%$, pueden o no presentar evidencia de erosión pudiendo ser ligera y moderada, son poco profundos 
a profundos, tienen poca pedregosidad que no limitan o imposibilitan las labores de maquinaria, poseen fertilidad alta, media o baja, tienen drenaje excesivo, bueno y moderado; incluyen a suelos salinos, ligeramente salinos y no salinos; presentan toxicidad nula, ligera y media (SENPLADES, et. al., 2012).

- Clase IV: Estas tierras requieren un tratamiento especial en cuanto a las labores de maquinaria o permiten un laboreo ocasional. Se restringe el establecimiento de cultivos intensivos y admite cultivos siempre y cuando se realicen prácticas de manejo y conservación. Son tierras que presentan moderadas limitaciones, se encuentran en pendientes menores al $25 \%$; pueden o no presentar erosión actual pudiendo ser ligera y moderada; son poco profundos a profundos, y tienen poca o ninguna pedregosidad; son de textura y drenaje variable. Incluyen a suelos desde no salinos a muy salinos y no tóxicos hasta altamente tóxicos (SENPLADES, et. al., 2012).

- Clase V: Las tierras de esta clase requieren de un tratamiento muy especial en cuanto a las labores con maquinaria ya que presentan limitaciones difíciles de eliminar en la práctica, se limita el uso de cultivos anuales, permanentes y semipermanentes. Son tierras con limitaciones fuertes a muy fuertes, se encuentran en pendientes mayores al $25 \% \%$, generalmente son suelos poco profundos, incluyendo suelos con mayor profundidad; con textura y drenaje variable; y ocasionalmente con limitaciones de pedregosidad; pueden presentar fertilidad desde baja hasta muy alta; incluyen a suelos desde no salinos a muy salinos y de no tóxicos hasta altamente tóxicos (SENPLADES, et. al., 2012).

- Clase VII: Estos suelos presentan fuertes limitaciones para el laboreo, especialmente por la pendiente. Muestran condiciones para uso forestal, pastoreo, confines de conservación. Son tierras ubicadas en pendientes de hasta el $70 \%$; con suelos poco profundos a profundos; con pedregosidad menor al $50 \%$; en cuanto a la textura, drenaje y fertilidad éstas pueden ser variables; incluyen suelos desde no salinos a muy salinos y de no tóxicos hasta altamente tóxicos (SENPLADES, et. al., 2012).

- Clase VIII: Son áreas que deben mantenerse con vegetación arbustiva y/o arbórea con fines de protección para evitar la erosión y mantenimiento de la vida silvestre y fuentes de agua. Son tierras con las más severas limitaciones; corresponden generalmente a pendientes superiores a los $70 \%$, superficiales a profundos, sin piedras o pedregosos que impiden cualquier tipo de actividad agrícola, pecuaria o forestal (SENPLADES, et. al., 2012). 
La capacidad de uso potencial del suelo puede clasificarse de muchas maneras, sin embargo ninguna clasificación puede utilizarse en su totalidad, debido a las diferencias físicas, sociales económicas y políticas de cada región, por lo que es necesario hacer adaptaciones para obtener datos representativos (Cuello, 2003). En la zona de estudio la mayor parte de los suelos se encuentran en las categorías agrológicas V, VII y VIII, las cuales no son aptas para realizar actividades agrícolas, sin embargo las condiciones socioeconómicas de los pobladores hacen que vayan aumentando las superficies destinadas a actividades productivas, sin tener en cuenta el potencial y las limitaciones del terreno. Los deslizamientos de tierra en pendientes pronunciadas aumentan con la remoción de la cobertura vegetal (Podwojewsky, 1999), además el suelo pierde su dinámica y nutrientes con la introducción de pastos y otros cultivos exóticos (Hofstede, et. al., 2014).

La clasificación de suelos por sus características agrológicas permite conocer sus capacidades agroproductivas (Zambrano \& González 2003), determinar el uso más conveniente y prácticas para reducir la erosión (Díaz, et. al., 2014). Se evitan los errores que se producen con la aplicación de sistemas paramétricos ya que los resultados concuerdan con las características físicas del área (Año, et. al., 1997). Esta valoración permite determinar rápidamente las tierras aptas para la producción, convirtiéndose en un instrumento valioso de planificación en el uso y manejo del suelo (Antón, et. al., 2014).

\subsubsection{Determinación de Riesgos de Erosión.}

Los procesos de erosión están presentes naturalmente en pequeñas áreas, sin embargo estos riesgos aumentan con la eliminación de la cobertura vegetal por actividades antrópicas, produciendo gran cantidad de sedimentos que terminan en la red hidrográfica de las cuencas (Vanacker, et. al., 2014). Los ecosistemas del norte de los andes ecuatorianos son muy sensibles a estos procesos (Jandl, et. al., 2009), por lo que los cambios inducidos por el hombre son de gran impacto en los servicios ambientales que brindan los ecosistemas (Foley, et. al., 2005). En las cuencas hidrográficas con presencia de erosión se observa un alto rendimiento hídrico, sin embargo su regulación es casi nula, con lo que no se realiza el almacenamiento de agua en sus poros y se pierde caudales en época seca (Hofstede, et. al., 2014).

El área de estudio pese a tener pendientes bastante fuertes, muestra una susceptibilidad baja a la erosión en la mayor parte de su superficie, esto se atribuye a la cobertura vegetal que le proporciona el páramo, por lo que es fundamental para el manejo integral de la cuenca, 
prevenir las actividades antrópicas que deterioren este ecosistema. La figura 16 muestra la distribución espacial de los riesgos de erosión en la subcuenca.

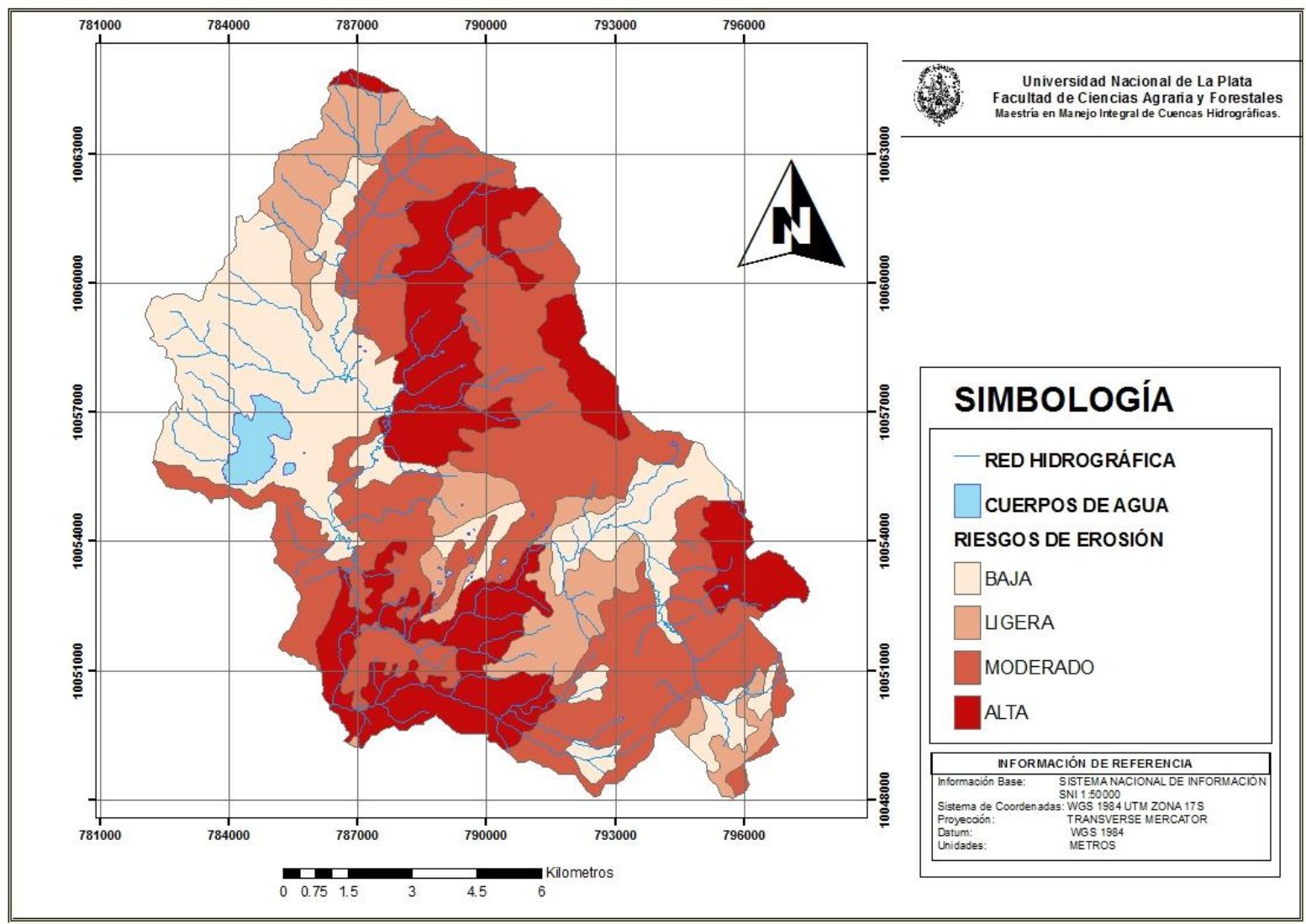

FIGURA 16: Mapa de riesgo de erosión hídrica del área de estudio. Escala: 1:200000.

En la tabla 22 se encuentra el resumen de las áreas y porcentajes que ocupan cada uno de los riesgos de erosión encontradas en la subcuenca del río Pitura.

TABLA 22: Riesgo de erosión de la subcuenca del río Pitura

\begin{tabular}{lrr}
\hline \multicolumn{1}{c}{ RIESGO } & AREA (ha) & PORCENTAJE (\%) \\
\hline Zonas Con Susceptibilidad Alta a La Erosión & 3324,59 & 22,79 \\
Zonas Con Susceptibilidad Moderada a La Erosión & 5660,98 & 38,81 \\
Zonas Con Susceptibilidad Ligera a La Erosión & 1824,51 & 12,51 \\
Zonas Con Susceptibilidad Baja a La Erosión & 3777,04 & 25,89 \\
\hline
\end{tabular}


Zonas Con Susceptibilidad Baja a La Erosión: Son aquellas unidades de estudio donde por la combinación de sus características morfométricas (rango de pendiente y longitud de vertiente), morfológicas (forma de vertiente), físico-químicas de suelo (textura superficial, profundidad efectiva y materia orgánica) y su grado de protección vegetal presentan un muy bajo índice de susceptibilidad a erosión y al ser analizada con los tres primeros índices de agresividad pluvial, presenta la más baja amenaza a erosión hídrica (SENPLADES, et. al., 2012).

Zonas Con Susceptibilidad Ligera a La Erosión: Son aquellas unidades de estudio que se presentan bajo tres condiciones: la primera es que a pesar de que el análisis de los factores en estudio califiquen a la unidad con una susceptibilidad baja a la erosión hídrica al momento de combinarla con el índice más alto de agresividad pluvial pasa a tener una condición ligera; por otro lado cuando la combinación de sus características morfométricas (rango de pendiente y longitud de vertiente), morfológicas (forma de vertiente), físicoquímicas de suelo (textura superficial, profundidad efectiva y materia orgánica) y su grado de protección vegetal presentan un moderado índice de susceptibilidad a erosión y al ser analizada con los índices intermedios de agresividad pluvial mantiene una amenaza ligera a erosión hídrica y por último a pesar de que la combinación de los factores muestre una susceptibilidad moderada al combinarla con el índice más bajo de agresividad pluvial su calificación de amenaza a erosión hídrica desciende a ligera (SENPLADES, et. al., 2012).

Zonas Con Susceptibilidad Moderada a La Erosión: Las unidades de estudio de esta clase se presentan bajo tres condiciones: la primera es que a pesar de que el análisis de los factores en estudio califiquen a la unidad con una susceptibilidad ligera a la erosión hídrica al momento de combinarla con el índice más alto de agresividad pluvial pasa a tener una condición moderada; por otro lado cuando la combinación de sus características morfométricas (rango de pendiente y longitud de vertiente), morfológicas (forma de vertiente), físico-químicas de suelo (textura superficial, profundidad efectiva y materia orgánica) y su grado de protección vegetal presentan un índice moderado de susceptibilidad a erosión y al ser analizada con los índice intermedios de agresividad pluvial mantiene una amenaza moderada a erosión hídrica y por último a pesar de que la combinación de los factores nos dé una susceptibilidad alta al combinarla con el índice más bajo de agresividad pluvial su calificación de amenaza a erosión hídrica desciende a moderada (SENPLADES, et. al., 2012).

Zonas Con Susceptibilidad Alta a La Erosión: Las unidades de estudio de esta clase se presentan bajo dos condiciones: la primera es que a pesar de que el análisis de los factores en estudio califiquen a la unidad con una susceptibilidad moderda a la erosión hídrica al 
momento de combinarla con el índice más alto de agresividad pluvial pasa a tener una calificación alta y por otro lado cuando la combinación de sus características morfométricas (rango de pendiente y longitud de vertiente), morfológicas (forma de vertiente), físico-químicas de suelo (textura superficial, profundidad efectiva y materia orgánica) y su grado de protección vegetal presentan un índice alto de susceptibilidad a erosión y al ser analizada con los tres últimos índices de agresividad pluvial mantiene una amenaza alta a erosión hídrica (SENPLADES, et. al., 2012).

\subsubsection{Determinación de Cambio de Uso del Suelo.}

La figura 17 muestra los valores de NDVI en formato raster del área de estudio para el año 1999.

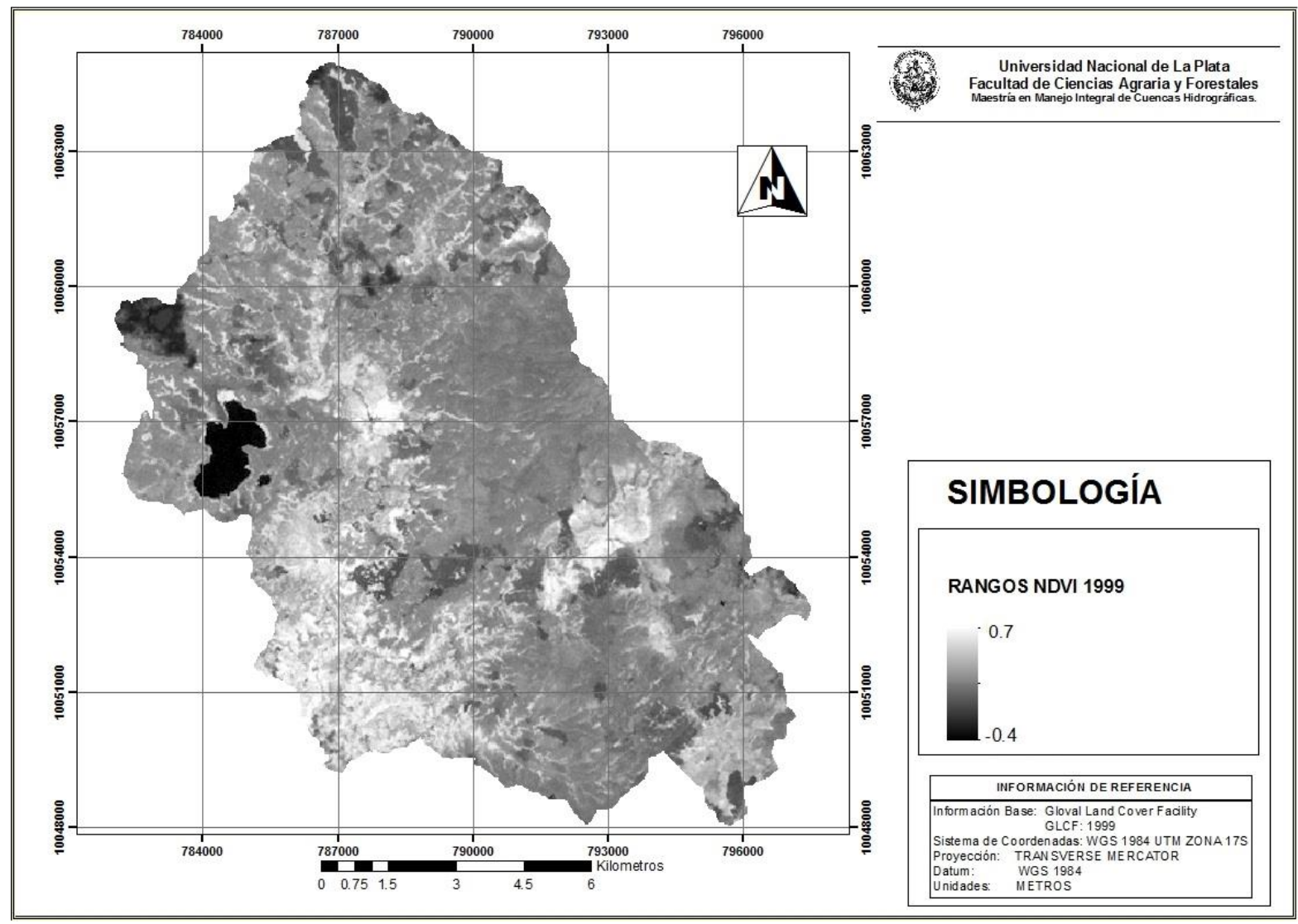

NDVI: Índice de Vegetación de Diferencia Normalizada

FIGURA 17: Determinación del NDVI del área de estudio para el año 1999. Escala: 1:200000. 
La figura 18 muestra la distribución espacial de los rangos de NDVI en formato vectorial con para el año 1999.

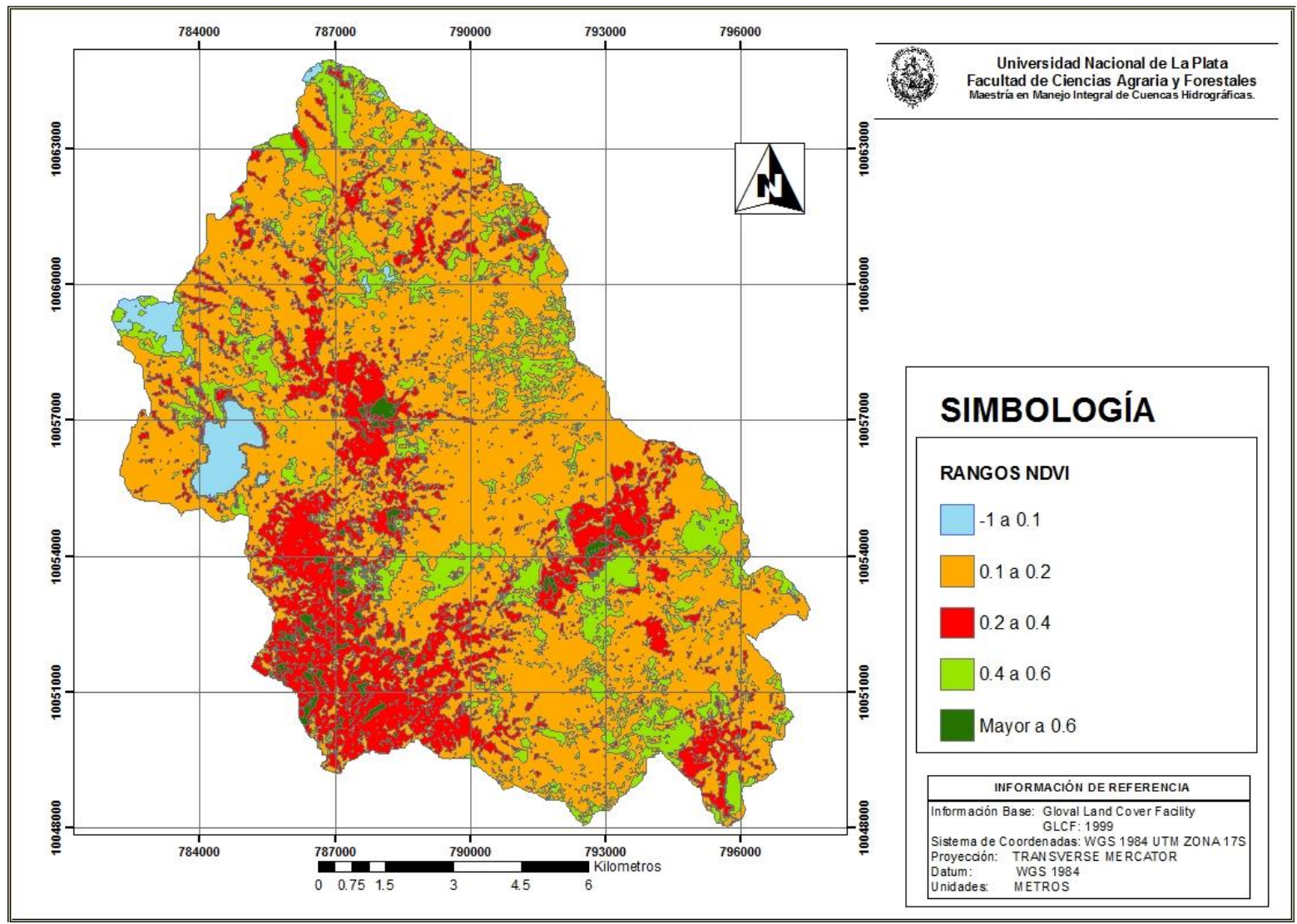

NDVI: Índice de Vegetación de Diferencia Normalizada

FIGURA 18: Valores del NDVI del área de estudio 1999. Escala: 1:200000. 
La figura 19 muestra los valores de NDVI en formato raster del área de estudio para el año 2010.

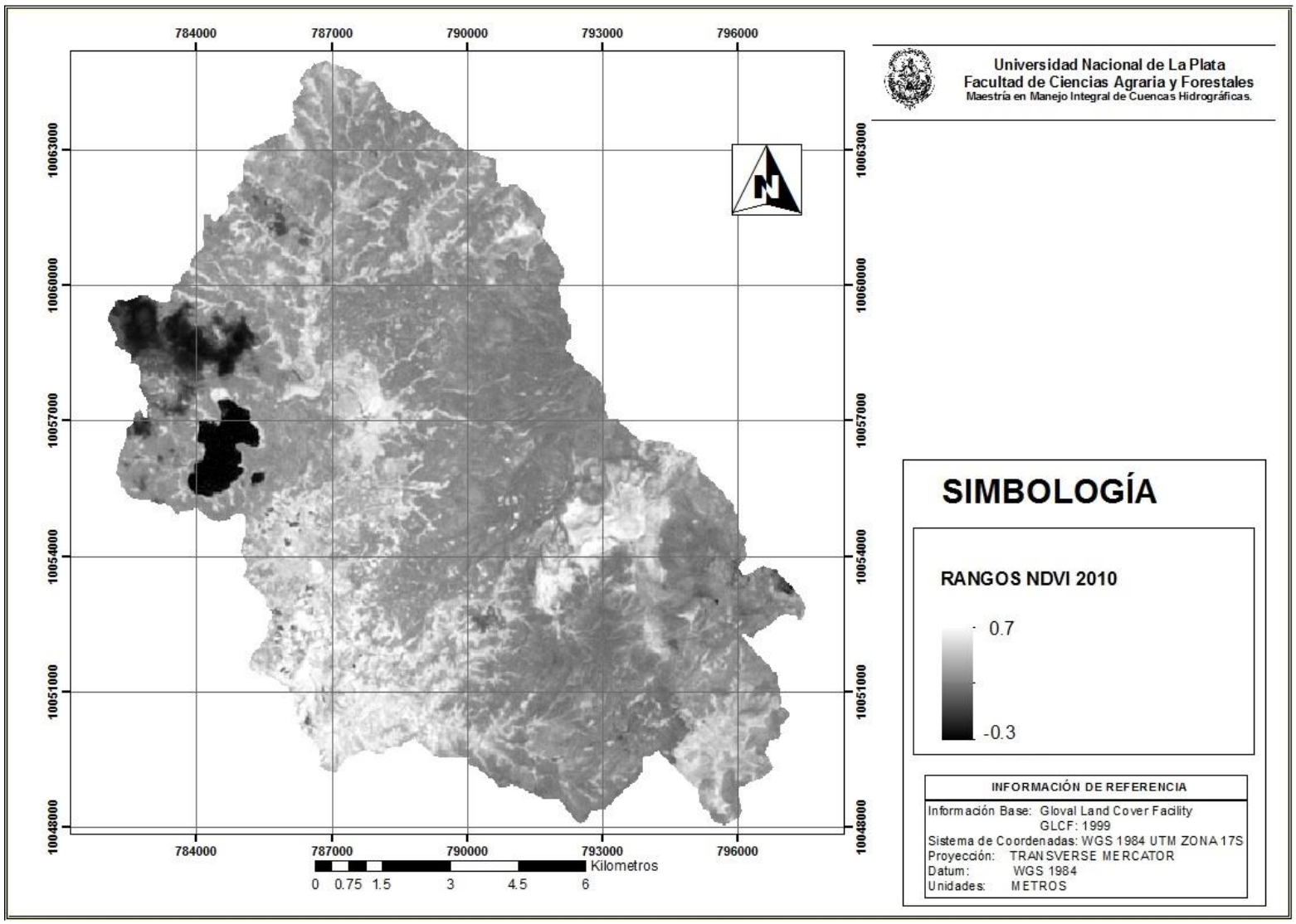

NDVI: Índice de Vegetación de Diferencia Normalizada

FIGURA 19: Determinación del NDVI de la Subcuenca del río Pitura para el año 2010. Escala: $1: 200000$. 
La figura 20 muestra la distribución espacial de los rangos de NDVI en formato vectorial con para el año 2010

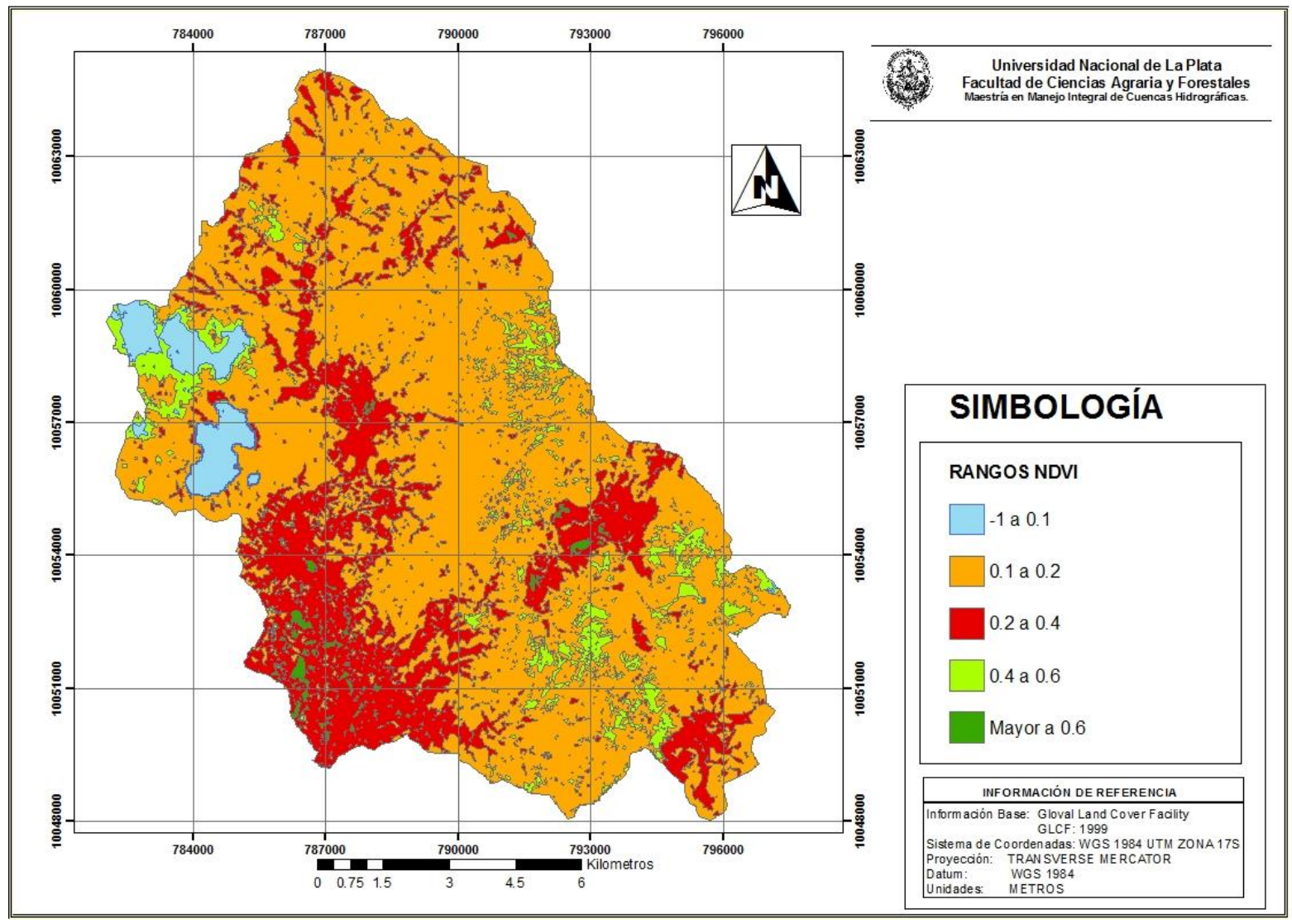

NDVI: Índice de Vegetación de Diferencia Normalizada

FIGURA 20: Valores del NDVI del área de estudio para el año 2010. Escala: 1:200000. 
La figura 21 muestra los valores de NDVI en formato raster del área de estudio para el año 2014.

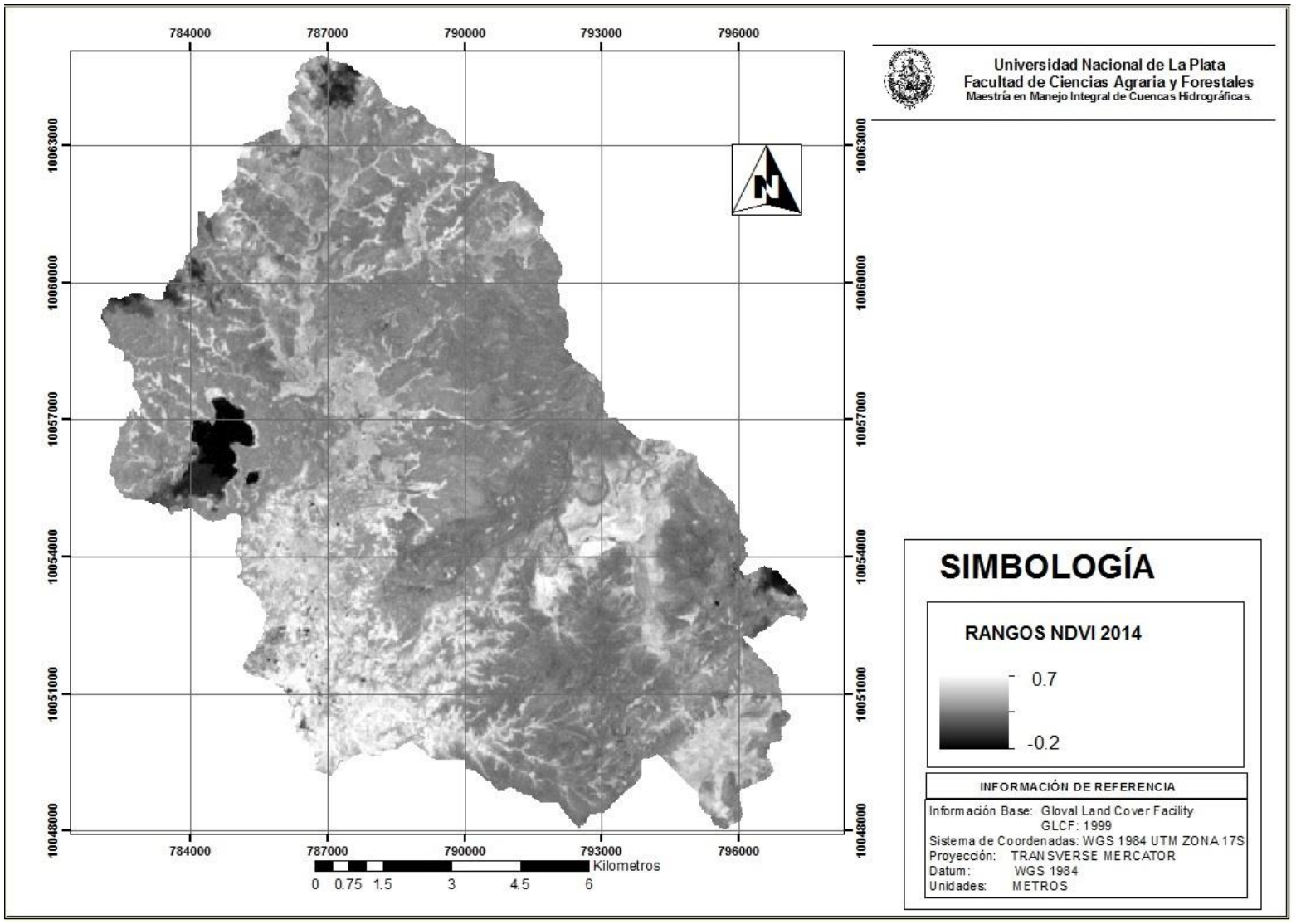

NDVI: Índice de Vegetación de Diferencia Normalizada

FIGURA 21: Determinación del NDVI de la Subcuenca del río Pitura para el año 2014. Escala: $1: 200000$. 
La figura 22 muestra la distribución espacial de los rangos de NDVI en formato vectorial con para el año 2014

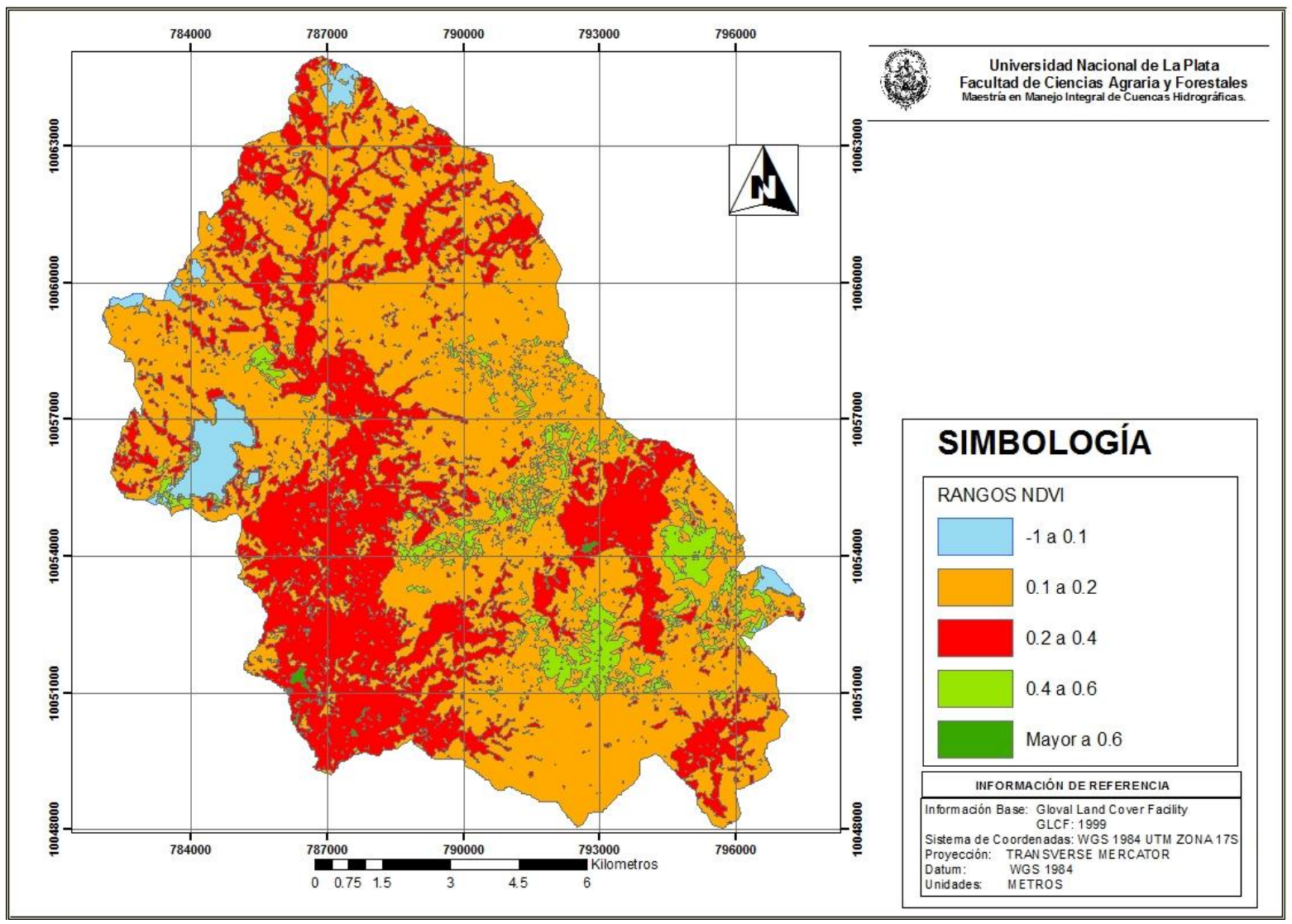

NDVI: Índice de Vegetación de Diferencia Normalizada

FIGURA 22: Valores del NDVI de la subcuenca del río Pitura para el año 2014. Escala: $1: 200000$. 
La figura 23 muestra la variación que han tenido las diferentes coberturas presentes dentro del área en estudio en los periodos seleccionados:

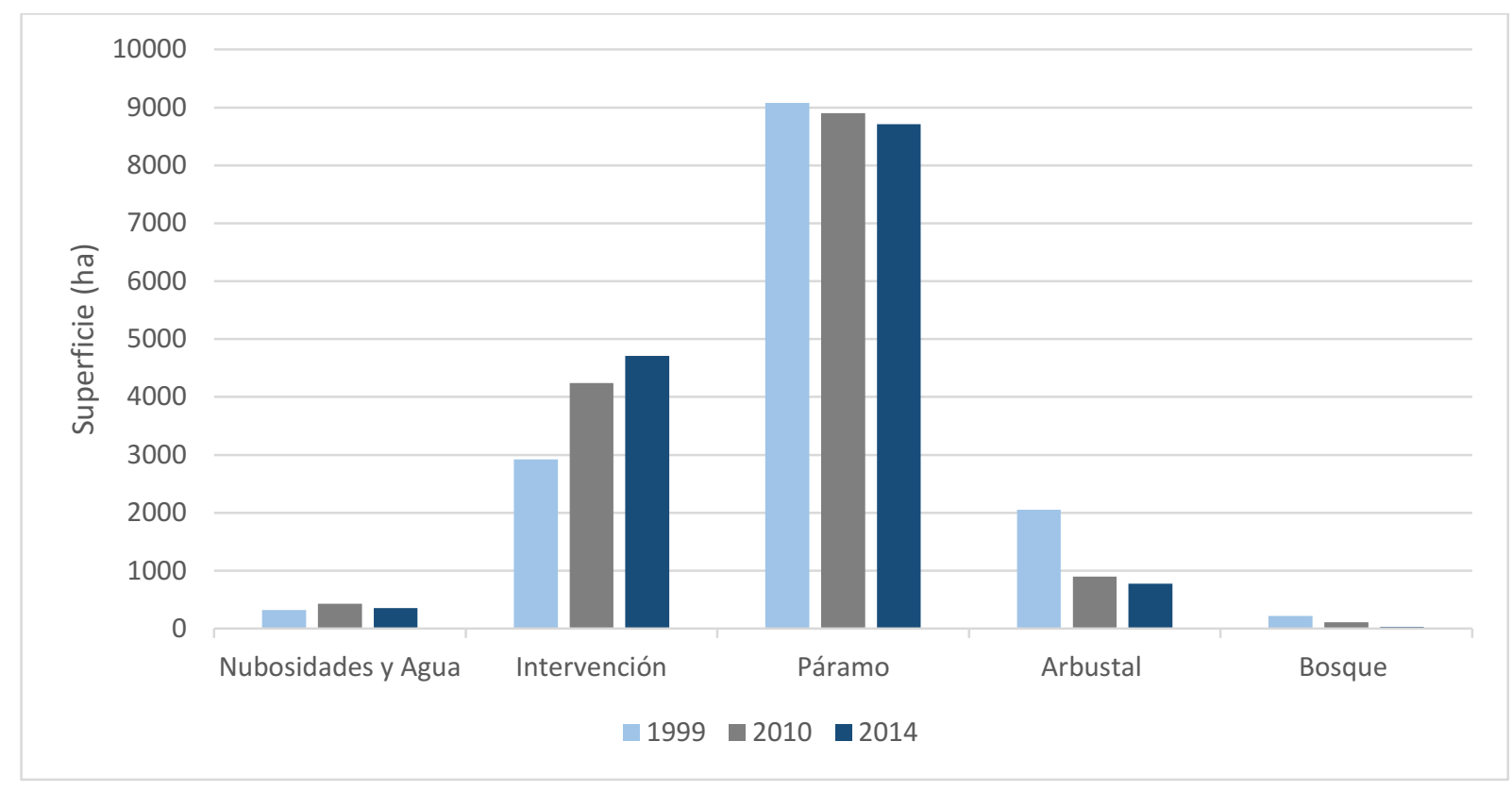

FIGURA 23: Variación de la cobertura vegetal en el área de estudio.

El análisis multitemporal de la subcuenca del río Pitura muestra un incremento acelerado de la zona de intervención, esto en merma de los ecosistemas naturales existentes. Porcentualmente la cobertura boscosa es la más afectada ante este aumento de la actividad antrópica; de igual manera el resto de coberturas que conforman el ecosistema páramo se han visto afectadas por las actividades productivas de la zona. Es así que en los últimos 15 años se registra un incremento del $62 \%$ de las áreas intervenidas. El cambio de la cobertura del páramo implica una pérdida de importante de biodiversidad endémica y pone en riesgo el abastecimiento de agua para las poblaciones asentadas en las partes bajas de las cuencas (Buytaert, et. al., 2011). De acuerdo al rango de NDVI utilizado para el estudio se observa que el cambio de uso de suelo fundamentalmente es para dar paso a pastizales, en los cuales los animales son liberados sin ningún control llegando al sobrepastoreo que afecta las características de los suelos y las funciones de regulación hidrológica que cumple el páramo (Buytaert, et. al., 2007). Al no haber existido grandes manadas de herbívoros en estos ecosistemas, la vegetación no está adaptada al pisoteo constante ni la herbívora, que en estas condiciones ambientales es alta por la necesidad de energía de los animales en climas fríos y el bajo valor nutritivo de la follaje (Hofstede, et. al., 2014); generando un cambio de la 
estructura natural evidente, más aún cuando se incorporan especies de pastos exóticos (Vargas, et. al. 2002). Los animales mayormente propagados en la zona poseen pezuñas que dejan espacios de suelo abierto propenso a la erosión, así la destrucción de la cobertura vegetal y la compactación del suelo son los impactos más importantes que genera el pastoreo extensivo (Hofstede, et. al., 2014).

Los efectos de la ganadería no se limitan al suelo, también tienen un impacto en la hidrología de las cuencas, al compactar los suelos la capacidad de retención y almacenamiento de agua es menor, con lo que se reduce el aporte a los caudales y en presencia de precipitaciones fuertes se incrementa el riesgo de crecidas (Buytaert, et. al. 2006). Las quemas que acompañan la actividad ganadera afectan muy seriamente al ecosistema, debido a que no existe una fertilización por parte de las ceniza (Vargas, et. al. 2002) y más bien se genera un impacto contrario en el crecimiento de la vegetación nativa (Hofstede, et. al., 2014). El ecosistema necesita de varios años para poder recuperarse de una quema (Vargas \& Velazco, 2011).

Si bien en el área de estudio la agricultura no se ha expandido en la misma proporción que la ganadería, los efectos que esta causa son importantes, al existir la necesidad de incrementar la producción los pobladores recurren a agroquímicos y a la eliminación total de la vegetación nativa para la preparación del suelo (Hofstede, et. al., 2014).

En el análisis de las imágenes en el estudio se observaron variaciones en el límite inferior del NDVI ocasionado por la presencia de nubosidades, sin embargo esta diferencia no afecta el análisis ya que las coberturas analizadas se reflejan en el rango de 0,1 hasta 0,7 , valores donde se refleja el verdor de la vegetación y que son constantes en todas las imágenes analizadas. 


\subsubsection{Determinación de la Pérdida del Suelo.}

a) Factor de Índice de erosión pluvial (R):

El mapa del índice de erosividad pluvial del área de estudio, muestra en la figura 24.

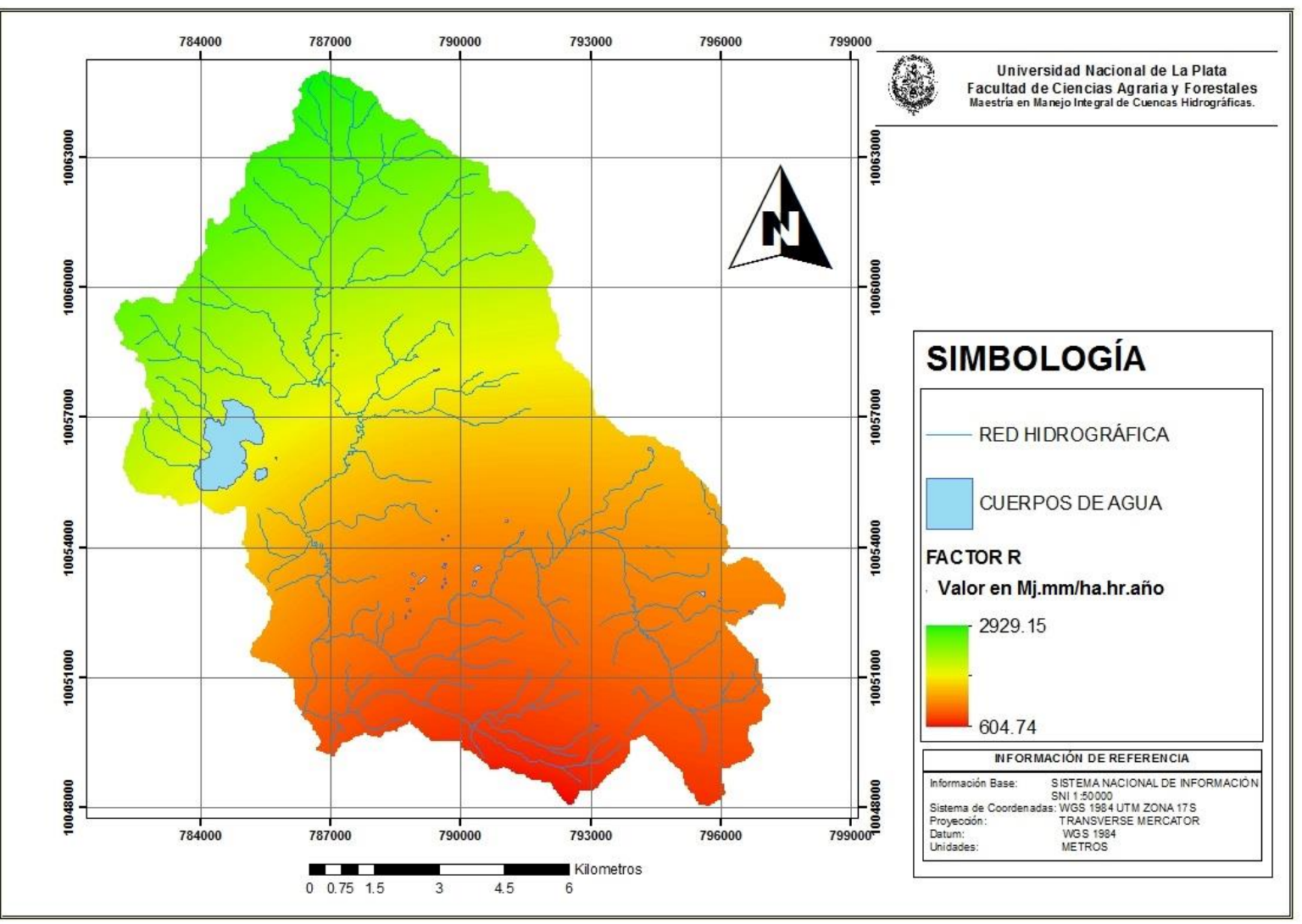

FIGURA 24: Mapa de índice de erosividad pluvial (R) (Mj.mm/ha.hr.año) del área de estudio. Escala: 1:200000.

El mapa del índice de erosividad pluvial muestra valores dentro de la cuenca que oscilan entre 604,74 Mj.mm/ha.h.año como mínimo y 2.929,15 Mj.mm/ha.h.año como máximo; lo que evidencia que la subcuenca está sometida a tormentas de medio y bajo poder erosivo, también se puede observar que el potencial erosivo disminuye en la parte baja de la subcuenca.

\section{b) Factor de erodabilidad del suelo (K):}

El mapa del factor de erodabilidad del suelo $(K)$ de la subcuenca del río Pitura (figura 25), muestra la distribución espacial de este factor dentro de la cuenca. El mismo muestra cuatro diferentes valores de K, los que se presentan a continuación: 


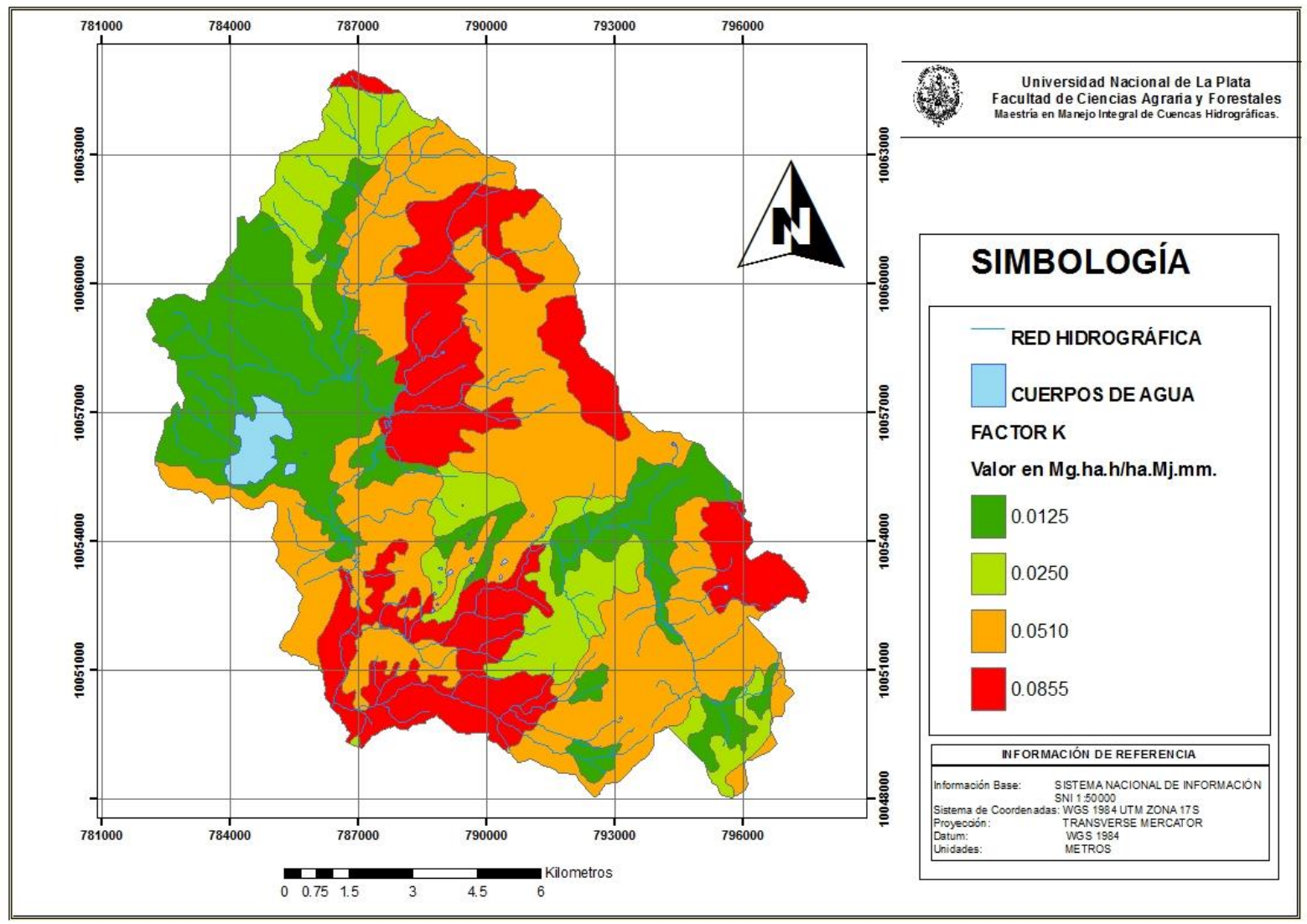

FIGURA 25: Mapa de erodabilidad del suelo (K) del área de estudio. Escala: 1:200000.

El factor de erodabilidad del suelo en el área de estudio, toma cuatro valores diferentes, siendo el menor valor el de 0,0125 Mg.ha.h/ha.Mj.mm, que abarca un 25,89 \% del total de la superficie de la subcuenca. El valor de 0.0250 Mg.ha.h/ha.Mj.mm, abarca un $12,51 \%$ del total de la superficie de la subcuenca. El valor de 0.0510 Mg.ha.h/ha.Mj.mm, abarca un 38.81 $\%$ del total de la superficie de la subcuenca. Finalmente el valor de 0.0855 Mg.ha.h/ha.Mj.mm, abarca un $22.79 \%$ del total de la superficie de la subcuenca. Estos resultados se deben al tipo de cobertura vegetal existente en el área de estudio y las pendientes del terreno fundamentalmente.

\section{c) Factor topográfico (LS):}

La figura 26 muestra la distribución espacial de este factor dentro de la cuenca, el mismo muestra los valores del factor LS, 


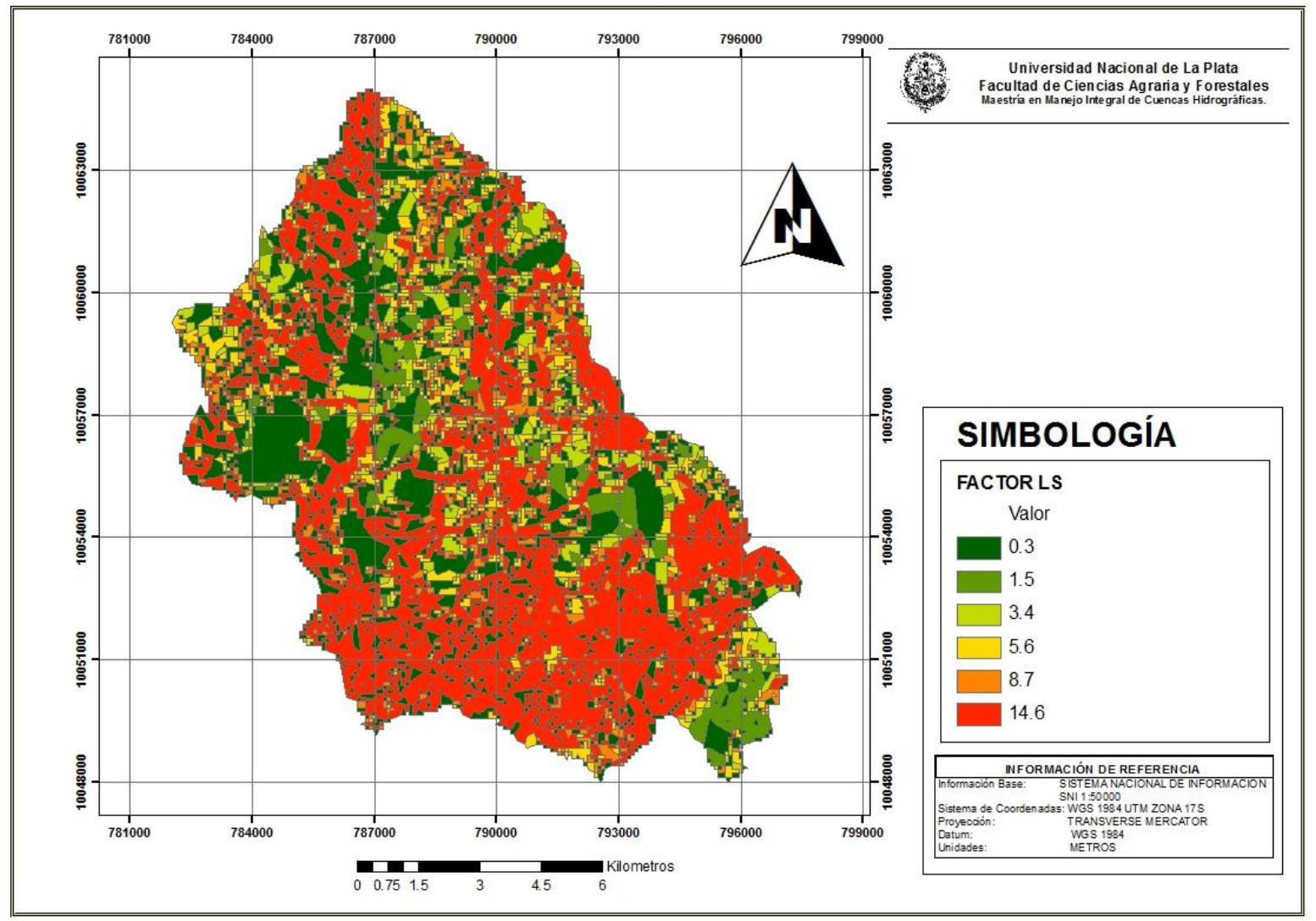

FIGURA 26: Mapa del factor topográfico (LS) según rangos topográficos del área de estudio. Escala: 1:200000.

En la figura 24 se muestra la distribución espacial del factor topográfico de la subcuenca del río Pitura, en este mapa se puede observar que los valores altos de este factor abarcan una gran superficie dentro de la subcuenca, esto debido a la relación entre las pendientes y el gradiente de las mismas; según los rangos de pendiente (LS), evidencia que el área de estudio presenta pendientes muy fuertes mayores al $30 \%$ de pendientes en la mayor parte de la superficie, lo cual se refleja en los valores obtenidos de este factor; teniendo que el valor de 14,6, que es el mayor en la escala establecida por Mintegui Aguirre (1988), ocupa una superficie de $6.426,09$ ha, lo que corresponde a un $44,09 \%$ del total de la superficie de la cuenca. 


\section{d) Factor de ordenación de cultivos (C):}

El mapa del factor de ordenación de cultivos (C) de la subcuenca del río Pitura (figura 27), muestra la distribución espacial de este factor dentro del área de estudio, este mapa muestra los valores de C adaptados de Gómez (2001).

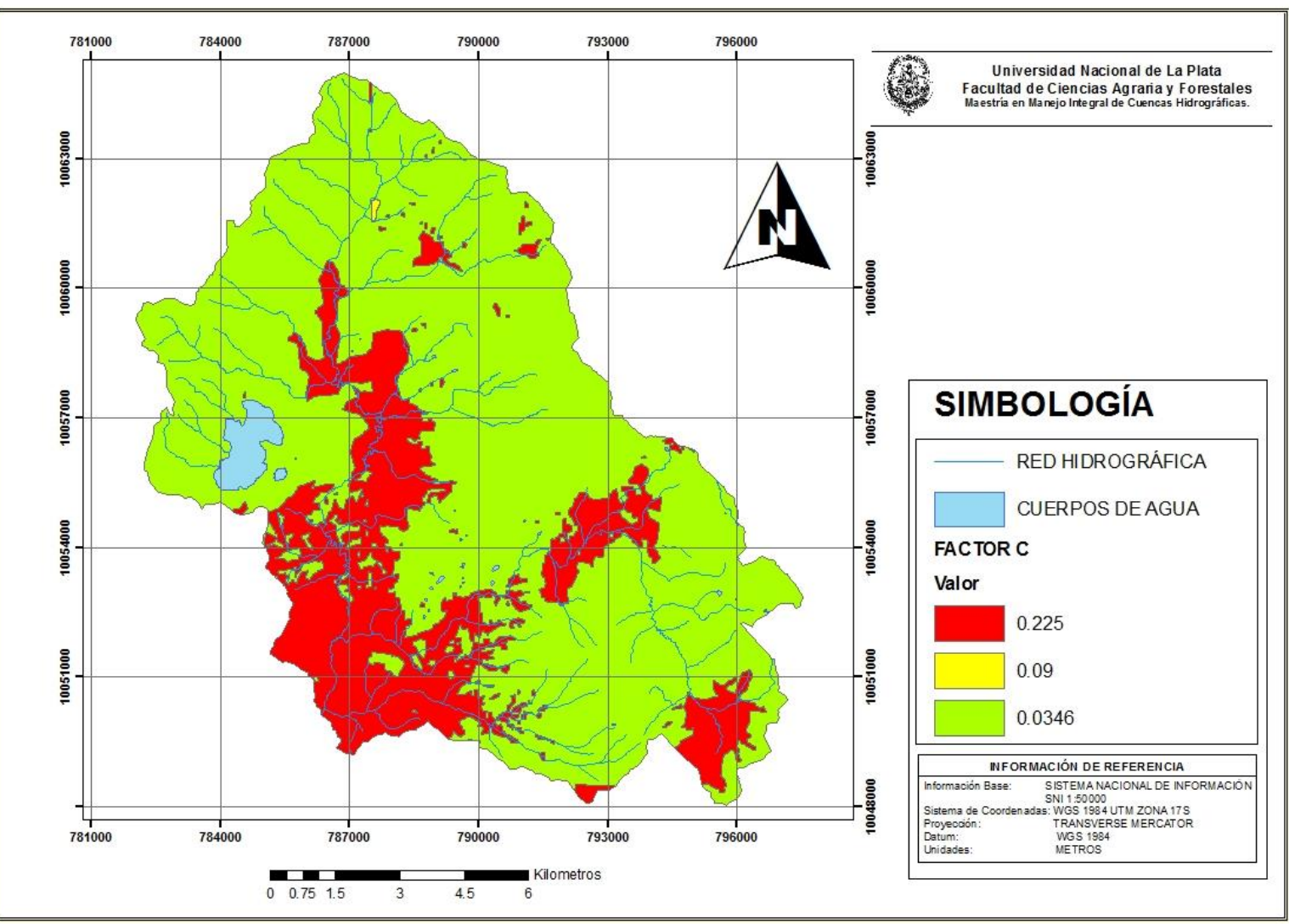

FIGURA 27: Mapa del Factor de Ordenación de Cultivos (C) de la subcuenca del río Pitura. Escala: 1:200000.

En el mapa se observa que en la mayor parte de la cuenca se encuentra el valor más bajo del factor de ordenación de cultivos, $C=0,0346$, esto debido a que la mayor parte del área en estudio está cubierta por páramo andino y sus combinaciones con pastos y vegetación arbustiva. De igual manera podemos observar una superficie importante cubierta por el valor más alto de este factor, $\mathrm{C}=0,225$, que corresponde $\mathrm{a}$ áreas donde se practican intensamente la ganadería, pastos introducidos y cultivos de ciclo corto, según la información del SIN (2013). 


\section{e) Estimación de pérdidas de suelo (A):}

El mapa de distribución de la pérdida de suelo de la subcuenca del Río Pitura, se muestra en la figura 28:

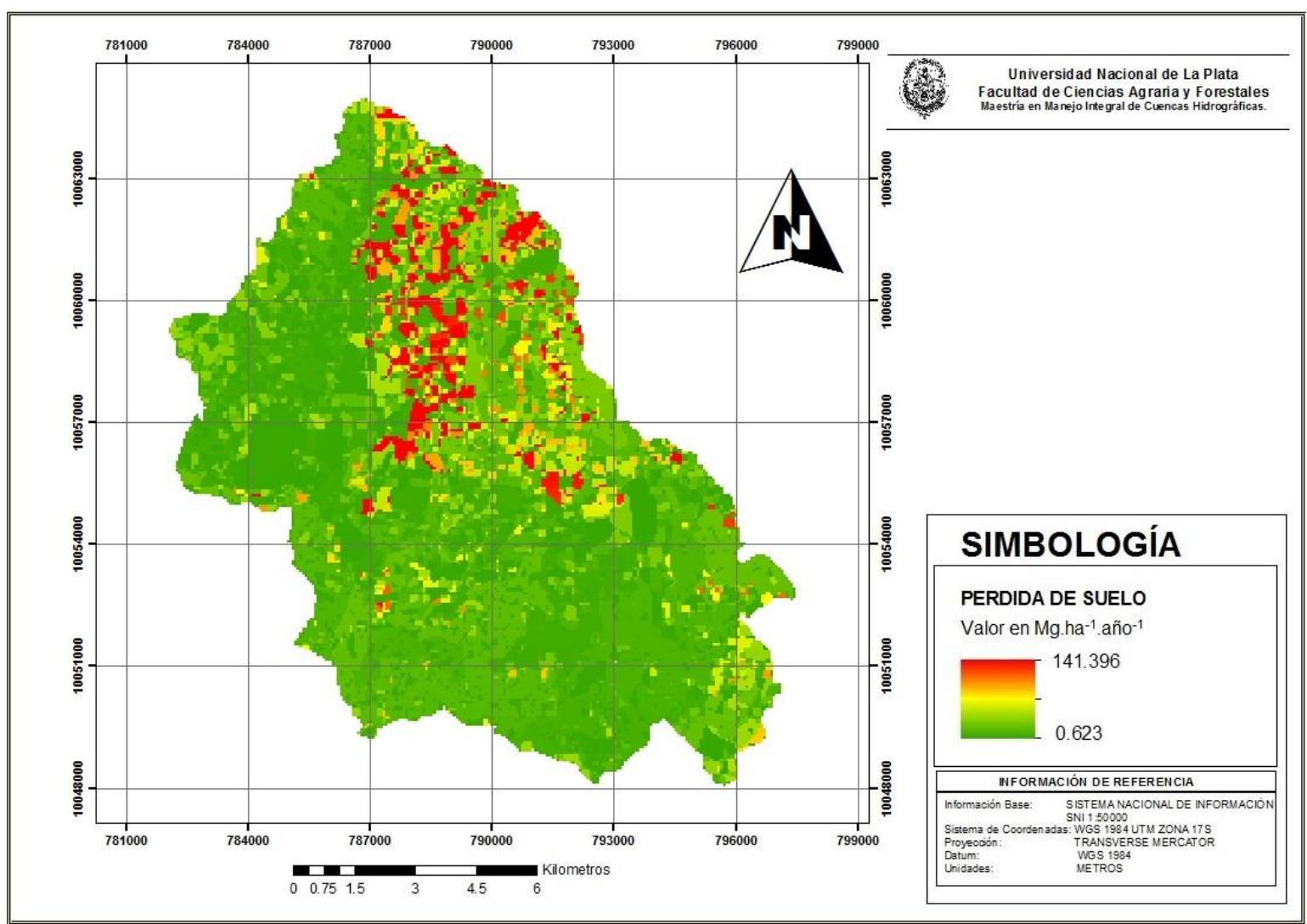

FIGURA 28: Estimación de la perdida de suelo $(\mathrm{A})$ de la subcuenca del río Pitura. Escala: $1: 200000$.

En la figura 28 se puede observar que la pérdida de suelo promedio anual de la subcuenca del río Pitura varía entre 0,623 Mg.ha-1.año-1 y 141,396 Mg.ha- $\mathrm{M}^{-1} \cdot \mathrm{año}^{-1}$, observándose que la mayor parte de la cuenca muestra valores bajos de pérdida de suelo, pese a que en muchas partes de la misma se encuentran pendientes bastante fuertes, esto dado por la cobertura vegetal dentro de la cuenca. 
En la figura 29 se muestra el mapa de grado de erosión hídrica de la subcuenca del río Pitura.

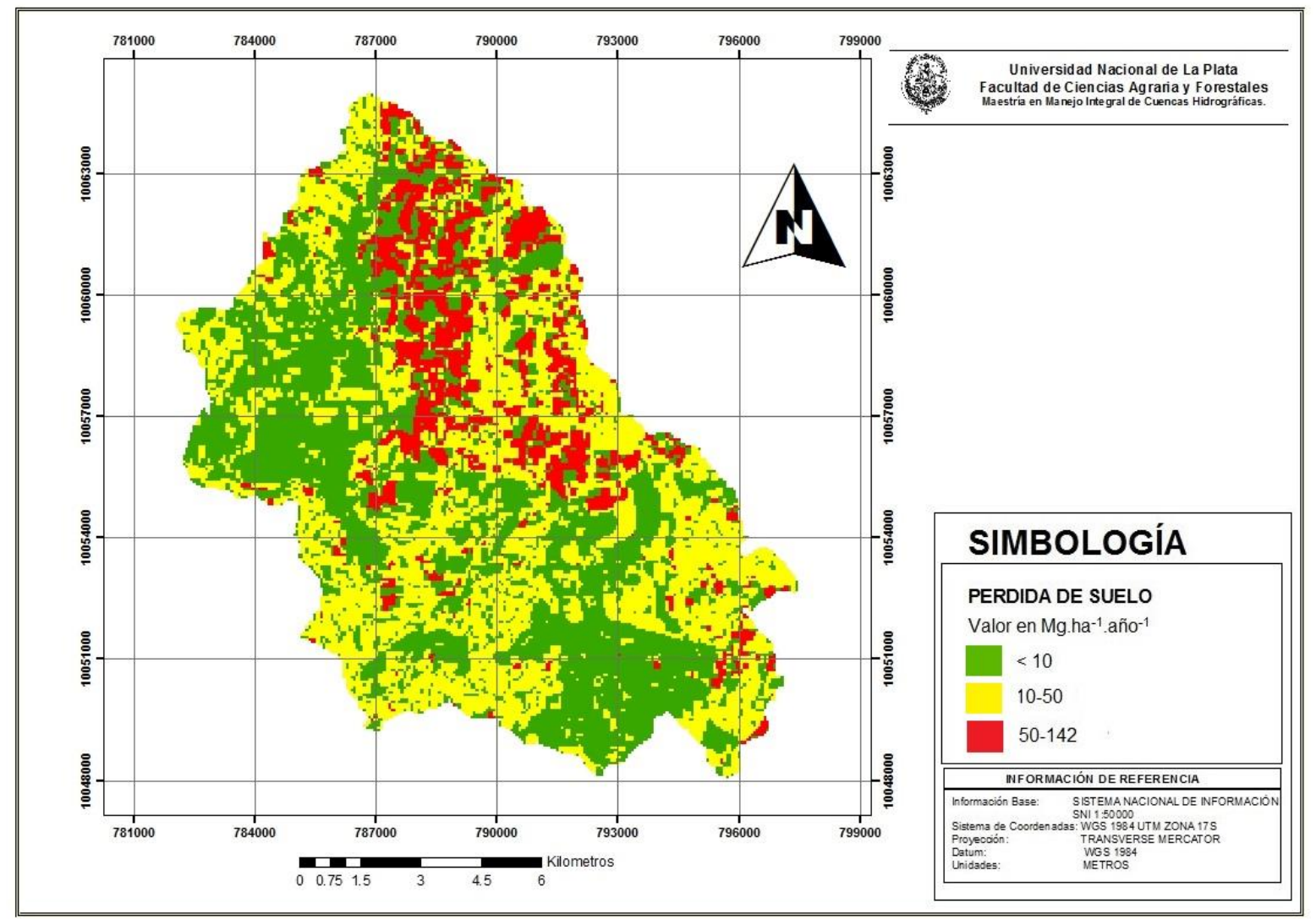

FIGURA 29: mapa de Grados de Erosión Hídrica de la subcuenca del río Pitura. Escala: $1: 200000$.

En la figura 29, se observa el mapa de pérdida de suelo de la subcuenca del río Pitura, según los grados de erosión hídrica establecidos en la tabla 12, observándose que dentro de la subcuenca están presentes los tres primeros grados de erosión. El 47,14\% de la superficie en estudio presenta un grado de erosión leve (menor a $10 \mathrm{Mg} \cdot \mathrm{ha}^{-1} \cdot \mathrm{año}^{-1}$ ), en donde la cobertura vegetal juega un papel fundamental, ya que es la que protege al suelo de los factor ambientales y genera la estructura de los suelos cubiertos por páramo (Hofstede, et. al., 2014).

Sin embargo el 39,45 \% de la superficie muestra un grado de erosión moderado (10-50 Mg.ha${ }^{1}$.año $\mathrm{o}^{-1}$ ), y un $13,38 \%$ presenta un grado de erosión alto (>50 Mg.ha- ${ }^{-1}$.año ${ }^{-1}$ ), estos rangos se pueden observar en las zonas con pendientes fuertes y en la zonas en las que las actividades agroproductivas se desarrollan, la eliminación de la cobertura vegetal para dar paso a áreas de grandes potreros y campos cultivados hacen más propenso al suelo a los procesos de erosión (Jandl, et. al., 2009), lo que se puede evidenciar en los resultados obtenidos en el 
estudio. La posibilidad de estimar cuantitativamente la erosión presente en los suelos, se transforma en una herramienta de planificación y toma de decisiones, encaminada al mantenimiento de los niveles productivos del suelo, la conservación de la biodiversidad y la reducción de los sedimentos transportados por los cauces (Clérici \& García Préchac, 2001).

\subsection{CARACTERIACIÓN SOCIO-CULTURAL DE LA CUENCA}

\subsubsection{Demografía}

La población del área de estudio está distribuida en los centros poblados de las parroquias rurales Imantag y Apuela (INEC, 2010), observándose que el existe una mayor población de hombres y cuyo crecimiento en el primer quinquenio fue del $6 \%$ para los poblados pertenecientes a la parroquia Apuela y de un $7 \%$ para la población de la parroquia de Imantag, mientras que para el segundo quinquenio el crecimiento poblacional en las dos parroquias fue del $10 \%$.

TABLA 23: Distribución de la población dentro del área de estudio. (INEC, 2010).

\begin{tabular}{|c|c|c|c|c|c|c|c|c|c|c|c|}
\hline \multirow[t]{2}{*}{ PARROQUIA } & \multirow[t]{2}{*}{ POBLADO } & \multirow[t]{2}{*}{ c.s.c. } & \multicolumn{2}{|c|}{ P.C.S. 2010} & \multirow[t]{2}{*}{ TOTAL } & \multicolumn{2}{|c|}{ P.P. 2015} & \multirow[t]{2}{*}{ TOTAL } & \multicolumn{2}{|c|}{ P.P. 2020} & \multirow[t]{2}{*}{ TOTAL } \\
\hline & & & $\mathrm{H}$ & M & & $\mathrm{H}$ & $\mathrm{M}$ & & $\mathrm{H}$ & M & \\
\hline & Pitura & & & & & & & & & & \\
\hline \multirow[t]{2}{*}{ Apuela } & Filo de Rosillo & 100351999001 & 168 & 159 & 327 & 179 & 159 & 338 & 198 & 176 & 373 \\
\hline & Lulucha & & & & & & & & & & \\
\hline Imantag & Piñán & 100353999001 & 105 & 78 & 183 & 105 & 84 & 189 & 116 & 93 & 209 \\
\hline \multicolumn{3}{|c|}{ Total } & 273 & 237 & 510 & 284 & 243 & 527 & 314 & 268 & 582 \\
\hline
\end{tabular}

El $83 \%$ de la población del área de estudio se considera indígena, el $26 \%$ mestizo y tan solo el $1 \%$ blanco. Esta distribución étnica es normal en la zona ya que la ocupación de los páramos por parte de los pueblos originarios del Ecuador inició desde la época prehispánica (Reyes, 1995), convirtiendo a estos espacios en refugios de la naturaleza y una fuente para la vida humana con un alto valor espiritual (Molano, 2010). El desarrollo cultural de estos pueblos hizo que generen una alta conciencia del valor ecosistémico del páramo, manejándolo con criterios que aseguraron sus servicios (González \& Cárdenas. 1995), a la vez que iban perfeccionando técnicas de agricultura y domesticación de animales (Hofstede, et. al., 2014). El perfeccionamiento de estas técnicas continúo con la llegada de los incas que introdujeron animales andinos como las llamas y alpacas y aumentaron las zonas agrícolas en altura con 
la implementación de terrazas (de Moreno, 1995). En estos espacios se desarrollaron las tradiciones, conocimientos y relaciones sociales en base a las características del ecosistema (León, 2011). Con la llegada de los españoles en el Ecuador se produjo un nuevo reordenamiento de la tierra, los colonizadores pasaron a ser propietarios de la mayor parte de las tierras productivas y a mano de obra de los indígenas de la región andina (Recharte \& Gearheard, 2001), de esta manera en gran parte de los páramos se establecieron grandes haciendas con un sistema de producción feudal (Korovkin, 1997), facilitado por la infraestructura dejada por los incas (Recharte \& Gearheard, 2001), durante este proceso mucha de la biodiversidad endémica se fue perdiendo por el ingreso de animales europeos que representaban una mayor producción para los hacendados (de Moreno, 1995). Paralelamente las poblaciones indígenas eran confinadas a las tierras más altas, tanto como mano de obra para abrir nuevos espacios a las haciendas o simplemente como refugio a las prácticas de los colonizadores (Hofstede, et. al., 2014).

La presencia de estos grupos étnicos en la actualidad es producto de los procesos de colonización, migración y mestizaje (Hofstede, et. al., 2014). Dentro de las comunidades los individuos realizan diferentes roles en donde existe gran diferencia entre las actividades realizada por los hombres y las mujeres, siendo las labores de la mujer esencialmente las del mantenimiento del hogar (Hofstede, et. al., 2014). En cuanto a la migración de la población en el sector es casi nula, sin embargo, en las familias económicamente dependientes de la actividad agropecuaria, han buscado otras alternativas de producción, lo que ha llevado a varios habitantes en especial jóvenes a migrar a centro urbanos (Segovia, 2013).

\subsubsection{Educación}

La oferta educativa en el área de estudio es muy reducida con tan solo dos instituciones cercanas a las poblaciones. En la parroquia de Apuela el centro educativo más cercano a los poblados dentro del área de estudio es la escuela de educación primaria María Esther Cevallos ubicada a $8 \mathrm{Km}$ en el poblado de Irubí; la institución cuenta tan solo con cuatro docentes (GAD Apuela, 2011) y oferta tan solo los seis primeros años de educación básica. En la parroquia de Imantag la escuela Abelardo Moran Muñoz está ubicada precisamente en el poblado Piñán, cuenta con tan solo dos docentes (GAD Imantag, 2012) y oferta tan solo los seis primeros años de educación básica. La baja oferta educativa y la composición étnica de la población, en la cual las labores en el campo empiezan desde temprana edad (Guerrero \& Ospina, 2003), ha contribuido a que el $62 \%$ de la población en el área de estudio no sepa leer ni escribir (INEC, 2010). Si bien en términos nacionales la tasa de analfabetismo en las 
comunidades indígenas de la sierra es tan solo del 20 \% (INEC, 2010) y que la inversión en infraestructura y equipamiento para instituciones educativas aumentó sustancialmente desde el año 2007 (Ocaña, 2015), las comunidades dentro del área de estudio no han podido beneficiarse por la dificultad de acceso a estos centros poblados.

\subsubsection{Salud}

La oferta de salud para los poblados de la subcuenca del río Pitura es escasa, los subcentros de salud más cercanos se encuentran en las cabeceras parroquiales de Apuela e Imantag. Los subcentros de salud atienden un promedio de 27 pacientes al día con problemas de salud menores como: infecciones intestinales, resfriados, dolor en diferentes partes del cuerpo, etc., provocados por mala alimentación e insalubridad; mientras que las emergencias médicas son menos frecuentes con un promedio de 38 al mes (GAD Imantag, 2012). En estos subcentros de salud la mayor parte del tiempo tan solo se encuentra un médico residente brindando los servicios hospitalarios y el hospital básico más cercano es el Asdrúbal de la Torre que se encuentra en la ciudad de Cotacachi, aproximadamente a 6 horas en vehículo de los poblados (GAD Apuela, 2011).

El dificil acceso a estos poblados genera gran dificultad en la construcción e implementación de espacios donde los profesionales de la salud puedan prestar sus servicios, por tal motivo desde el año 2008 el Ministerio de Salud Pública del Ecuador (MSP), implementa un sistema de salud familiar, comunitario e intercultural (Arteaga, et. al., 2012), a fin de fortalecer los conocimientos ancestrales de las comunidades indígenas en el manejo de plantas medicinales y la atención de salud primaria con parteras y medicos comunitarios (Ortega, 2015). Sin embargo se siguen presentando en las comunidades altoandinas del Ecuador disparidades provocadas por la falta de interes de los comuneros en su estado de salud y la resistencia a acudir a los servicios de salud por discriminación o por las limitaciones de lengua (Rodríguez, 2006).

\subsubsection{Servicios Básicos}

Los pobladores del poblado Piñán acceden mediante entubamiento de ríos y vertientes al agua para su consumo (INEC, 2010), mientras que en los poblados pertenecientes a la parroquia de Apuela el $41 \%$ obtiene el agua para consumo humano de ríos, vertientes o acequias, el $56 \%$ de los hogares tiene acceso a la red pública de agua potable, el restante la obtienen de otras fuentes como pozos o carros repartidores (INEC, 2010). En cuanto a la 
enrgía electrica el 93 \% de los hogares cuenta con este servicio dotado por la red de energía electrica publica, este es el servicio ha llegado a cubrir la moyor parte de los hogares de la sierra norte del Ecuador (INEC, 2010). La eliminación de los desechos por el $57 \%$ de los hogares se realiza mediante quemas, mientras que el $22 \%$ arroja los desechos directamente a terrenos valdios o quebradas, el $15 \%$ los entierra y el restante elimina sus desechos en ríos o acequias. Si bien en las parroquias existe el servicio del carro recolector de basura este llega tan solo a las cabeceras cantonales y a los poblados cercanos (GAD Imantag, 2011).

\subsection{CARACTERIZAZCIÓN ECONÓMICO - PRODUCTIVA}

\subsubsection{Principales Actividades Económicas}

El área en estudio al ser un territorio constituido en su mayoría por páramo, hace que la economía de los pobladores de la zona se base principalmente en la ganadería, mientras que la agricultura básicamente es de subsistencia (GAD Imantag, 2012). Las actividades productivas en las comunidades suelen tener diferencias en cuanto a las labores que realizan tanto hombres como mujeres, siendo los hombres los que se encargan de trabajar la tierra (Hofstede, et. al., 2014). La dinámica de comercialización en las parroquias de Imantag y Apuela se realiza en la misma zona. Los medianos propietarios venden sus productos a intermediarios quienes los transportan a otros lugares, especialmente a Otavalo e Ibarra donde consiguen mejores precios (GAD Apuela, 2011). Los productos de las haciendas son comercializados fuera de las propiedades, bien sea directamente o a través de intermediarios. (GAD Imantag, 2012).

El pastoreo extensivo en las tierras con páramo como es el caso del área de estudio empezó con la formación de las haciendas en el tiempo de la colonia (Basile, 1974), lo que trajo consigo la introducción de especies exóticas de animales y pastos, la destrucción de los pajonales para la formación de potreros y la formación de huasipungos (Hofstede, et. al., 2014). Desde ese entonces los páramos han sido cada vez más colonizados por las grandes haciendas y parte de las poblaciones que se encontraban sin tierras (Recharte \& Gearheard, 2001). En la actualidad algunas comunidades asentadas en los páramos han sido beneficiadas con proyectos de desarrollo rural (Llambi, et. al., 2013), originando sistemas socioecológicos sostenibles encaminados a la protección del páramo (Hofstede, et. al., 2014), un ejemplo de lo descrito en la zona de estudio es la organización comunitaria de Piñan, que han visto en el ecoturismo una alternativa para obtener ingresos, para llevar a cabo este proyecto la comunidad cuenta con un recinto para el albergue de visitantes, servicio de alimentación, espacios para acampar, pesca deportiva, guía por parte de los comuneros, 
caminatas alrededor de la laguna Tobar Donoso y cabalgatas (Araque, 2012). Pese a esto la mayor parte de comunidades desconoce leyes, estímulos y programas concernientes a la producción y el aprovechamiento de los recursos naturales.

\subsubsection{Tenencia de la Tierra}

La mayor parte de los terrenos de producción familiar encontrados en la zona de estudio, no superan los $1.000 \mathrm{~m}^{2}$, sin embargo datos oficiales muestran que algunas familias, tienen tierras de una extensión de 1, 5, 10 y 20 hectáreas (GAD Imantag, 2012). Con el pasar del tiempo estos terrenos se están convirtiendo en pequeños solares por el crecimiento familiar, lo que dificulta el desarrollo de las actividades agropecuarias, aumentando la frontera agrícola y obligando a los habitantes a buscar alternativas para generar ingresos económicos como la venta de mano de obra para la construcción o la migración, fenómenos que se presentan sobre todo en la población más joven. (GAD Imantag, 2012).

Si bien el minifundio es un fenómeno que se observa en los páramos, existen comunidades que son propietarias de una gran extensión de tierras dentro de estos ecosistemas, en las cuales cada miembro es propietario de una parte de esas tierras para la subsistencia de su familia (Hofstede, et. al., 2014), mientras que las tierras destinadas para el pastoreo son de propiedad comunitaria (Lasso, 2009).

\subsubsection{Organización}

Dentro de las parroquias se encuentran pequeños poblados denominados: caserío, anejo, barrio, partido o comunidad. Están sujetas a la jurisdicción de la parroquia y se rige por la Ley de Organizaciones de Régimen de las Comunas (GAD Apuela, 2011). Las comunidades aparecen como la forma de organización más importante en la sierra ecuatoriana, seguidas por la forma de organización cooperativista (Martínez, 1988).

Las comunidades están representadas por cabildos o directivas locales, cuyos miembros son elegidos democráticamente en asambleas comunitarias anuales en las que participan todos los pobladores (GAD Apuela, 2011). La organización social de las comunidades campesinas no ha experimentado cambios notorios en lo que tiene relación con la estructura, en general. Aunque se puede advertir una mayor participación dinámica de la mujer en diversas actividades productivas y en otras de promoción humana (GAD Apuela, 2011). 
Una de las organizaciones más importantes dentro de la subcuenca es la de la comuna de Piñán, la cual es una asociación indígena formada a mediados de los años 60 , la comuna realiza asambleas periódicas en las cuales se discuten temas de prioridad comunal y se informa de las actividades realizadas y a realizar (Monje \& Narváez-Mena, 2.006).

\subsection{EVALUACIÓN DE IMPACTOS DENTRO DE LA CUENCA}

El análisis de impactos dentro de la subcuenca del río Pitura mediante la matriz de Leopold adaptada se detalla en la tabla 24 :

TABLA 7: Impactos roducidos en la Subcuenca Mediante la Matriz de Leopold.

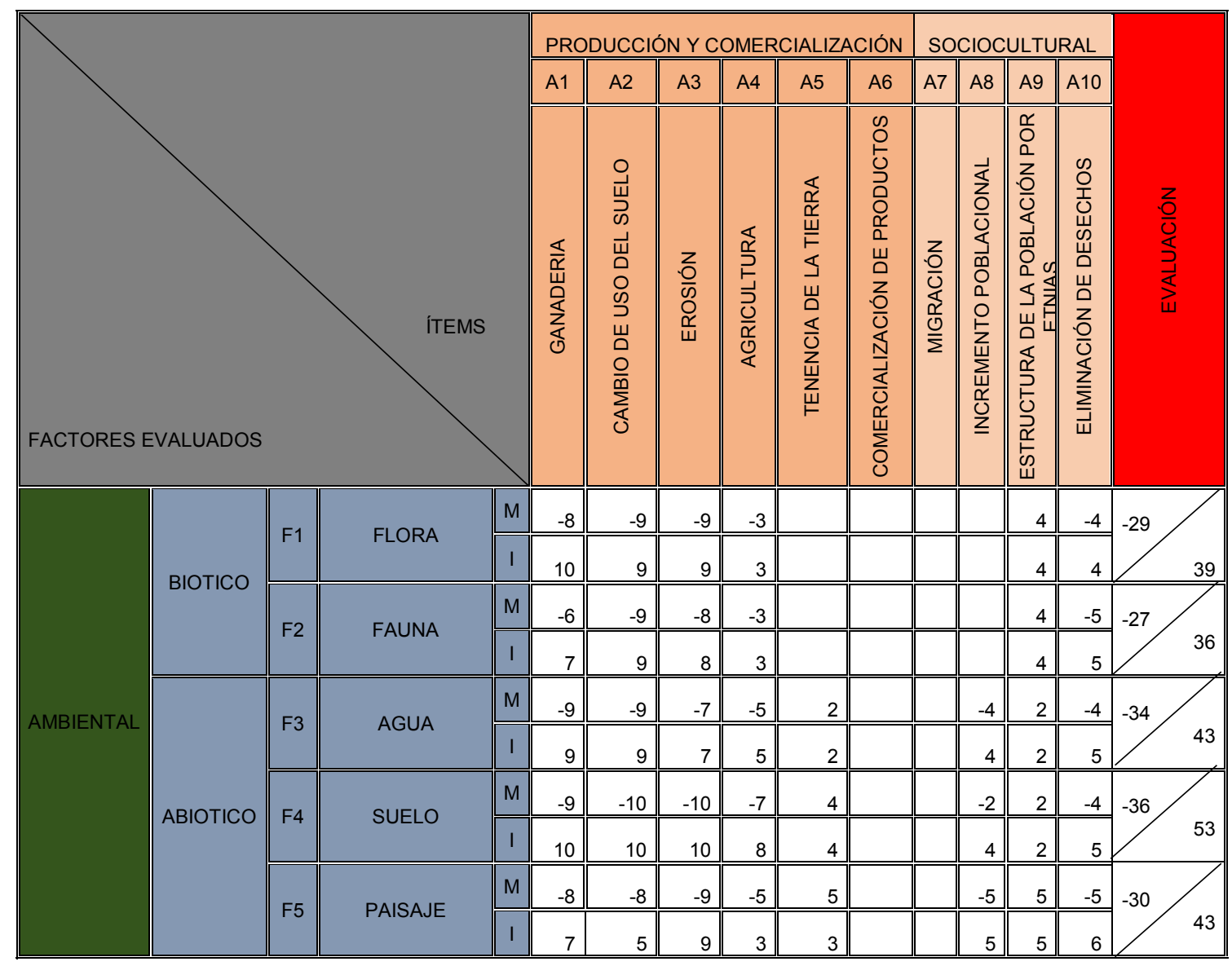

Continúa en la siguiente página 


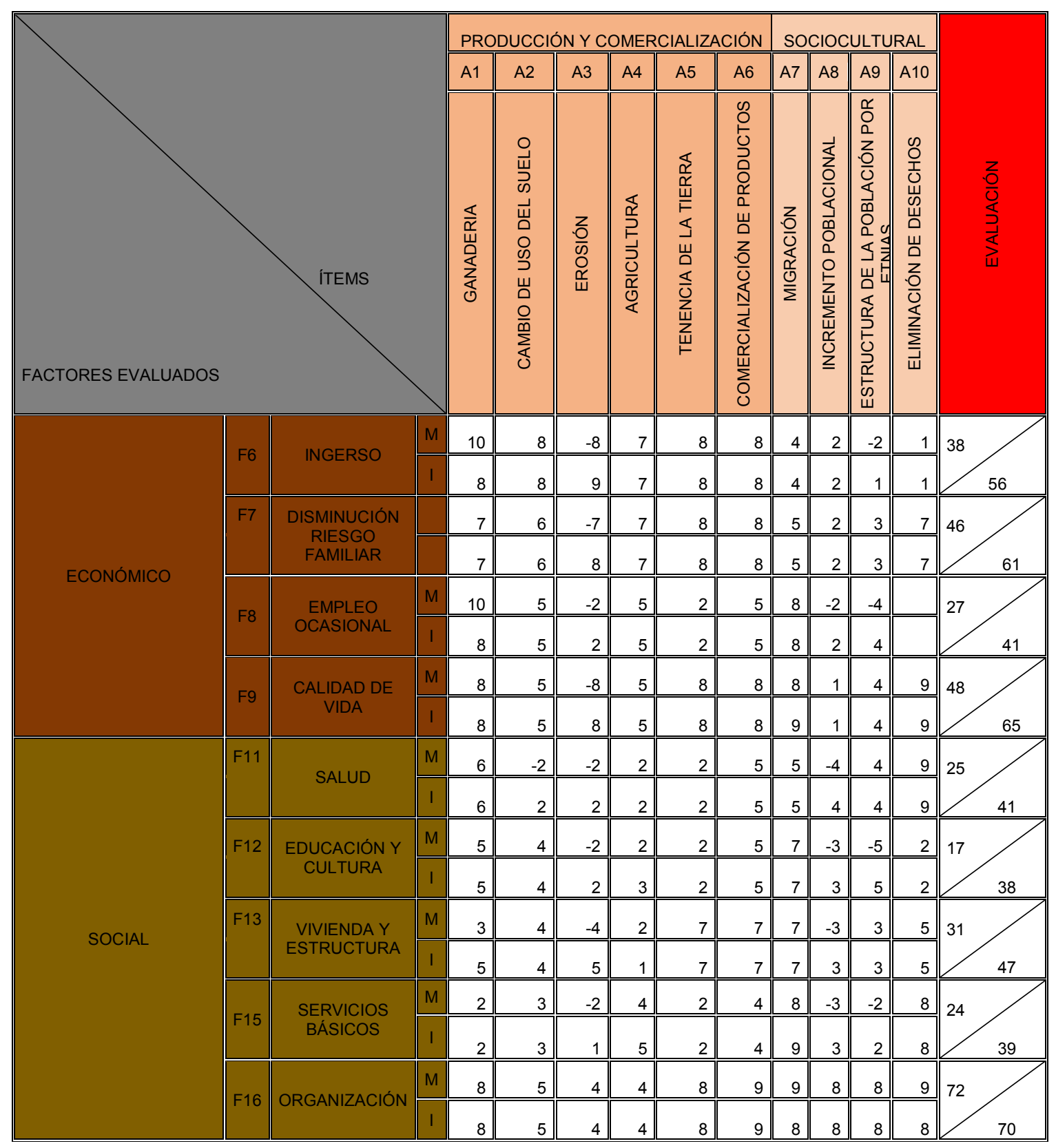

En la tabla anterior se observan los resultados de la aplicación de la matriz Leopold a las características productivas y socioculturales de la subcuenca; los datos del análisis muestran valores negativos en los elementos del componente ambiental, esto debido a que el área de estudio se encuentra cubierta en su gran mayoría por páramo, ecosistema frágil que es muy susceptible a los cambios producidos por la actividad antrópica (Hofstede, et. al., 2014). La ganadería es la principal actividad productiva realizada en la zona y la que mayor impacto genera al ambiente, la vegetación presente es muy susceptible al consumo y pisoteo de los animales, que necesitan de grandes extensiones para su desarrollo debido a la capacidad de carga relativamente baja del ecosistema (Buytaert, et. al., 2006). El suelo también es muy 
afectado por esta actividad como se observa en la tabla, al tener una estructura porosa y con gran cantidad de materia orgánica (Llambi, et. al., 2012), se compactan fácilmente con el peso de los animales, con lo que pierde su capacidad de regulación hídrica (Hofstede, et. al., 2014), afectando también el sistema hidrológico y el suministro de agua para los habitantes (Buytaert, et. al., 2006). La ganadería está acompañada de quemas, los campesinos buscan proveer de nuevos pastos nutritivos a los animales mediante esta práctica (Hofstede, et. al., 2014), con esto la flora y fauna nativa decrece dando paso a especies exóticas que presentan características invasoras (Lasso, 2009). Si bien la agricultura en la subcuenca es una actividad poco desarrollada, también genera impactos importantes sobre el ambiente, la estructura del suelo cambia con su preparación para el cultivo, la biodiversidad disminuye al introducir especies y los cursos de agua naturales son modificados por la necesidad de riego (Hofstede, et. al., 2014). Estas dos actividades generan impactos importantes en el paisaje, transformando el páramo en un mosaico compuesto por ecosistemas naturales y agroecosistemas dominados por especies exóticas (Monasterio \& Molinillo. 2003).

Los espacios en los que se generan las actividades productivas son sobre utilizados por los pobladores, por un lado se encuentran los comuneros que al ser propietarios individuales de pequeñas parcelas se ven obligados a incorporar técnicas que aumenten la productividad como el uso de agroquímicos, perdiendo gran parte de su identidad cultural y conocimiento ancestral (Hofstede, et. al., 2014) y por otro lado se encuentran las grandes haciendas que liberan a los animales en sus extensas propiedades sin ningún tipo de control, deteriorando de manera sistemática el pajonal e introduciendo especies de pastos con mayores rendimientos en los potreros (Lasso, 2009).

Las zonas con intervención antrópica aumentaron de forma acelerada en los últimos 15 años y los impactos negativos que tienen sobre el componente ambiental son evidentes, sin embargo, son las que más aportan a los componentes socioeconómicos, por lo que no se pueden ser eliminadas de la subcuenca, es necesario proponer un manejo que permita alcanzar la sostenibilidad de los ecosistemas, incluyendo un sistema eficiente de eliminación de desechos, que también amenazan los recursos naturales del área de estudio.

La tasa de incremento poblacional en la subcuenca es baja, por lo que no tiene un impacto significativo en el ambiente. Su composición étnica la hace culturalmente rica, pese a la introducción de costumbres y prácticas ajenas a las comunidades, producto de la presencia de las grandes haciendas y la migración de algunos de sus habitantes, que traen consigo nuevos conocimientos. Si bien el panorama de la subcuenca no es muy alentador, existen ya iniciativas de desarrollo sustentable, como el propuesto por la comunidad de Piñán, que ha 
visto en el ecoturismo una nueva alternativa económica y organizativa, que les permite conservar los recursos y fomentar su cultura como un atractivo más para los turistas nacionales y extranjeros.

\subsection{ZONIFICACIÓN DE LA CUENCA}

En la figura 30 se muestra el mapa de zonificación de la subcuenca de área de estudio.

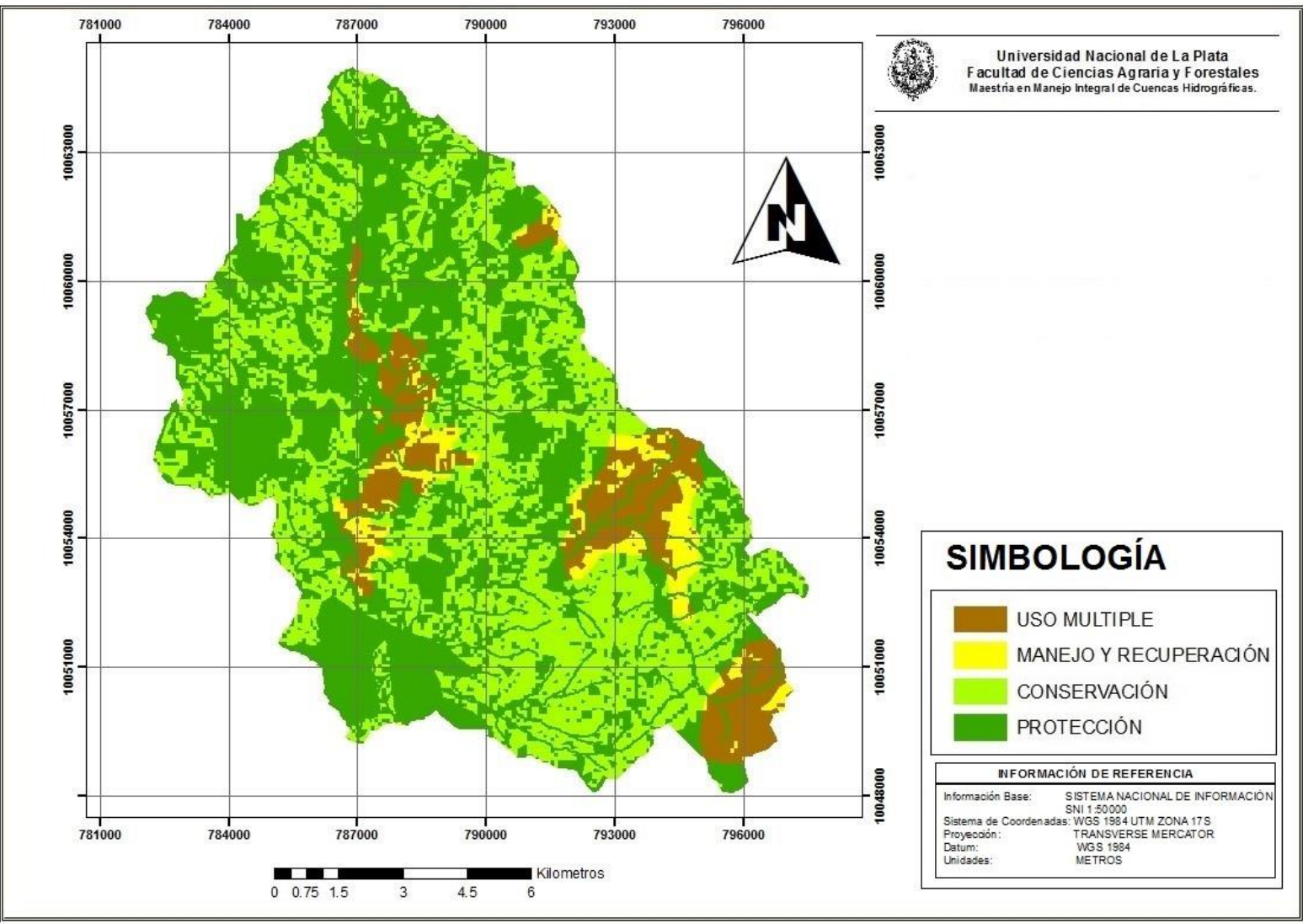

FIGURA 30: Zonificación de la subcuenca del río Pitura.

En la tabla 25 se muestra el resumen de las áreas y porcentajes de cada una de las zonas seleccionadas para realizar el plan de manejo de la subcuenca del río Pitura. 
TABLA 8: resumen de La zonificación de la subcuenca del río Pitura.

\begin{tabular}{lrr}
\hline \multicolumn{1}{c}{ ZONA } & \multicolumn{1}{c}{ ÁREA (ha) } & PORCENTAJE (\%) \\
\hline Uso Múltiple & $1.399,37$ & 9,61 \\
Manejo y Recuperación De Suelos & 578,61 & 3,97 \\
Conservación Y Ecoturismo & $5.378,15$ & 36,93 \\
Protección Permanente & $7.206,96$ & 49,49 \\
\hline
\end{tabular}

\subsubsection{Zona de Uso Multiple}

Son áreas cuyas características permiten el desarrollo de múltiples actividades como ganadería, agricultura y actividad forestal; así como también los sitios actualmente ocupados por asentamientos humanos y sus actividades productivas, además de sectores que mediante procesos de planificación sean destinados a infraestructura de diferente índole. Estas zonas fueron determinadas en áreas con pendientes menores al $25 \%$, que contaban con una clasificación agroecológica I, II y III, cubiertas por pastos y cultivos.

\subsubsection{Objetivos de la Zona}

- Promover el reordenamiento de las actividades productivas y el uso de la tierra basándose en la capacidad de uso del suelo.

- Mejorar el control de la degradación de los recursos de la subcuenca e incentivar la conservación de la vegetación natural.

- Colaborar con el mejoramiento de la estructura socioeconómica de los habitantes de la subcuenca, mediante la aplicación de prácticas agrosilvopastoriles para la zona.

\subsubsection{Actividades Permitidas}

- Construcción de infraestructura para uso comunitario, así como vías de acceso.

- Implementación de proyectos turísticos como alternativa de desarrollo familiar y comunitario.

- Manejo de residuos sólidos.

- Construcción de viviendas e instalación de cultivos.

- Establecimiento de microempresas de diferente índole. 
- Siembra y uso de especies productivas, así como actividades pecuarias.

- Establecimiento de zonas para la Investigación que incluyan a los pobladores locales.

\subsubsection{Zona de Manejo y Recuperación de Suelos}

Son áreas cuyas características permiten el desarrollo actividades agropecuarias y forestales, mediante la implementación de prácticas de conservación de suelos tales como: terrazas, zanjas de desviación, cercas vivas, cortinas rompe vientos, abonos verdes. Estas zonas fueron determinadas en áreas con pendientes mayores a $25 \%$, y menores a $50 \%$, que contaban con una clasificación agroecológica IV, y V, cubiertas por pastos y cultivos.

\subsubsection{Objetivos de la Zona}

- Promover la recuperación de áreas degradadas.

- Incentivar el uso del suelo basándose en su capacidad de uso.

- Controlar permanentemente el uso y aprovechamiento del suelo.

- Prevenir los procesos de degradación de los suelos.

\subsubsection{Actividades Permitidas}

- Realización de proyectos turísticos como alternativa de desarrollo familiar y comunitario.

- Planes de ordenamiento territorial por centros y/o hasta por predio.

- Manejo de residuos sólidos.

- Instalación de actividades agropecuarias, con la aplicación de técnicas de agrosilvopastoriles, que conlleven a la recuperación del recurso suelo

- Propiciar zonas para la Investigación (como estaciones de investigación), que incluyan a los pobladores locales.

- Implementación actividades de ecoturismo. 


\subsubsection{Zona de Conservación y Ecoturismo}

Son áreas que pos sus características permiten el desarrollo actividades de conservación, caracterizadas por la conservación de sus recursos naturales conjuntamente con sus procesos ecológicos. Estas zonas fueron determinadas en áreas con pendientes mayores a $25 \%$, y menores a $50 \%$, que contaban con una clasificación agroecológica $\mathrm{V}, \mathrm{y}$ VII, cubiertas por Páramo, vegetación arbustiva y combinaciones de páramos y arbustos.

\subsubsection{Objetivos de la Zona}

- Conservara los recursos naturales de la subcuenca, implantando la investigación científica y el monitoreo ambiental; encaminado al beneficio de las comunidades y el equilibrio ecológico de la subcuenca.

- Proporcionar espacios con fines ecoturísticos, promoviendo la generación de ingresos económicos como fuentes alternativas de subsistencia de las comunidades.

\subsubsection{Actividades Permitidas}

- Implementación de proyectos turísticos como alternativa de desarrollo familiar y comunitario.

- Manejo de residuos sólidos.

- Establecimiento de zonas para la investigación que incluyan a los pobladores locales.

- Establecimiento de plantaciones forestales de protección con especies nativas.

- Trabajos de investigación que se realicen en diferentes ámbitos.

\subsubsection{Zona de Protección Permanente}

Son áreas con ecosistemas frágiles que requieren protección absoluta, los cuales no permiten modificaciones; su localización es estratégica para la conservación de los recursos y la protección de ecosistemas importantes; incluye los sitios a lo largo de ríos o cualquier curso de agua permanente, considerando el nivel más alto de las aguas en época de crecientes, en faja paralela a cada margen. Estas zonas fueron determinadas en áreas con pendientes mayores a $50 \%$, que contaban con una clasificación agroecológica VII y VIII, cubiertas por bosque natural, así como también $30 \mathrm{~m}$. a los márgenes de los ríos y lagunas. 


\subsubsection{Objetivos de la Zona}

- Preservar las características naturales de los ecosistemas, asegurando la las vertientes hídricas.

\subsubsection{Actividades Permitidas}

- Implementación de zonas para la Investigación (como estaciones de investigación), que incluyan a los pobladores locales.

- Ejecución de actividades de ecoturismo de bajo impacto.

- Establecimiento de plantaciones forestales de protección con especies nativas.

La zonificación inició con el análisis de las características morfométricas de la subcuenca, mismo que mostró susceptibilidad a crecidas y procesos erosivos. Dadas estas características y el acelerado crecimiento del área de intervención; la protección, conservación y recuperación de la cobertura vegetal son fundamentales en los procesos de manejo y zonificación, los que no deben descuidar las necesidades sociales, económicas y culturales de los pobladores. Con estas consideraciones se establecieron cuatro zonas de manejo, de las cuales tres están destinadas al mantenimiento y recuperación de los ecosistemas naturales y la restante está destinada al desarrollo económico, social y cultural de las personas asentadas dentro del área de estudio.

Está zonificación es una herramienta de planificación que busca promover el desarrollo sustentable de las comunidades asentadas en la subcuenca, para lo cual cada una de las zonas establecidas están clasificadas en base a su composición ecológica y la potencialidad para soportar las actividades antrópicas, su objetivo es establecer el ordenamiento y gestión de los recursos naturales del territorio. 


\section{PROPUESTA DE PLAN DE MANEJO}

\subsection{OBJETIVOS}

\subsubsection{Objetivo General}

Formular programas y proyectos que contribuyan a la conservación, y recuperación de los recursos naturales, y al desarrollo socioeconómico de la subcuenca del río Pitura.

\subsubsection{Objetivos Específicos}

- Promover la protección y conservación de la biodiversidad e integridad biológica de los ecosistemas del área de estudio.

- Fortalecer las capacidades de los habitantes de la subcuenca, en el manejo y la administración de los recursos naturales.

- Implementar sistemas de producción y desarrollo con la participación de los actores locales, como una estrategia para minimizar las presiones antrópicas y contribuir al mejoramiento socioeconómico de las comunidades.

- Promover la conservación y recuperación de los recursos naturales de la subcuenca, controlando el proceso de cambio de uso del suelo, en zonas donde su impacto sea mínimo.

- Orientar un ordenamiento de uso de suelo, en base a la capacidad de uso de este recurso, el mismo que solo será posible con el trabajo mancomunado entre las instituciones públicas, la comunidad y la empresa privada.

- Incluir acciones de recuperación de la cobertura vegetal, las que deben contemplar los procesos de regeneración natural, reforestación con objetivos de protección.

- Adecuar áreas recreativas, que sirvan como un atractivo turístico, que generen un ingreso alternativo para las comunidades dentro de la subcuenca, así como un interés en los actores involucrados en su manejo y la conservación de los recursos; de la mano con este proceso es importante incentivar la investigación dentro de la cuenca complemente estas iniciativas que conllevan a la conservación de los recursos naturales.

- Implementar prácticas agroecológicas, que permitan elevar los niveles de producción de ciertos cultivos tradicionales, que en su mayoría son ocupados como autoconsumo, sin descuidar la diversificación de cultivos alternativos, en la búsqueda de generar un menor 
deterioro del entorno, así como también complementar la dieta de los integrantes de las familias de las comunidades.

- Determinar áreas para el desarrollo de actividades productivas e implementación de prácticas de bajo impacto que permitan mejorar la rentabilidad.

- Incentivar estímulos para los pobladores como: créditos productivos, programas gubernamentales, asistencia técnica y capacitación.

\subsection{PROGRAMA DE MANEJO AMBIENTAL}

El presente programa intenta implementar un modelo de integración que combine prácticas eficaces y armoniosas, a fin de alcanzar un equilibrio entre la protección del ambiente y el desarrollo productivo y social de la subcuenca del río Pitura.

\subsubsection{Justificación}

Del diagnóstico realizado se concluye que existe un progresivo deterioro de los ecosistemas de la subcuenca, constituyéndose en un grave problema en el mantenimiento de la biodiversidad de la zona, así como también, afectando las condiciones de vida de los pobladores. Además se puede apreciar perdida del conocimiento ancestral de las poblaciones aplicable a los sistemas productivos.

La necesidad de incrementar la producción, ha generado una significativa expansión de la frontera agropecuaria, que ha determinado en tasas elevadas de ocupación de espacios, deforestación de bosque natural, destrucción de grandes áreas de páramo y su reemplazo por potreros, ocasionando la degeneración de la estructura de los ecosistemas.

Pese a existir organización por parte de los pobladores, no se han generado espacios en los que puedan ser parte de la planificación y toma de decisiones a nivel parroquial o cantonal. La falta de ofertas de empleo genera condiciones de pobreza y un progresivo deterioro de la calidad de vida de la población, que junto con un sistema educativo que no valora las características ecológicas, sociales y culturales de la zona, han contribuido a una explotación indiscriminada de los recursos naturales de la zona.

Por otro lado no ha existido una difusión de conocimientos y tecnologías de producción apropiados para el tipo de ecosistemas presentes en la zona; acompañado por una estructura 
institucional y administrativa débil, en la que los organismos se encuentran centralizados en la capital de la provincia, impidiendo que se genere una intervención.

Por lo cual el presente programa busca contribuir a la solución de los problemas planteados, mediante la generación de una propuesta de conservación integral de los recursos y un desarrollo participativo de los pobladores, implementando proyectos de educación e investigación ambiental que fomenten un sustento técnico y participativo para la consecución del Plan de Manejo.

\subsubsection{Objetivo General}

Promover el desarrollo sustentable de la subcuenca del río Pitura, procurando un manejo de los recursos naturales presentes en la zona, mediante el mejoramiento de la administración, manejo y conservación de los ecosistemas, y la incorporación de prácticas y técnicas para la protección y aprovechamiento de los recursos naturales.

\subsubsection{Objetivos Específicos}

- Conservar los ecosistemas presentes en la subcuenca y su diversidad ecológica, incorporando zonas de conservación y protección permanente, para proteger los recursos genéticos y mantener poblaciones viables de especies nativas y endémicas.

- Proteger los ecosistemas de la zona, mediante el establecimiento de unidades de manejo para producción y protección, a fin de mantener abiertas las opciones de desarrollo, a través del manejo de las zonas de uso múltiple dentro de la subcuenca.

- Investigar tecnologías alternativas para el manejo y conservación de los recursos naturales de la zona, de forma que se apoye el mejoramiento de la calidad de vida de la población.

- Promover y fortalecer la participación de las diferentes organizaciones y grupos locales en la planificación y ejecución de actividades de manejo de los recursos naturales y protección ambiental, incluyendo a instituciones y organismos que manejan estos temas.

- Elaborar una estrategia de ecoturismo dentro de la subcuenca, desarrollando actividades dentro de las áreas de conservación y ecoturismo, determinadas en la zonificación de la subcuenca, generando un ingreso alternativo importante para los pobladores, que contribuye a la satisfacción de necesidades presentes. 
- Generar un proceso sistemático de información, investigación, formación y difusión, para una permanente concientización ambiental de los pobladores.

\subsubsection{Resultados Esperados}

- Actividades de manejo implementadas a los diferentes ecosistemas presentes en la subcuenca, los que en la actualidad no se encuentran atendidos, a través de unidades de manejo para la producción y protección.

- Áreas de protección permanente fortalecidas constituyéndose en fuentes importantes de recursos bilógicos, edáficos e hidrológicos.

- Sistemas de información, investigación, formación y difusión relacionado el manejo y protección de los recursos naturales implementado en la zona.

- Pobladores participativos en los procesos de conservación y preservación del equilibrio del ambiente.

\subsubsection{Estrategia del Programa}

Para cumplir con los objetivos planteados para el programa, se han diseñado lineamientos estratégicos los cuales se plantean a continuación:

- Fortalecimiento de la organización y promover la participación activa de la población en los procesos inherentes al cuidado del ambiente, la apropiación del conocimiento, la toma de decisiones y la institucionalización de los procesos.

- Formulación de responsabilidades a fin de fortalecer los procesos de manejo.

- Construcción de unidades de producción y protección, como instrumentos de desarrollo.

\subsubsection{Localización y Período}

Las actividades concernientes a la protección y conservación de los recursos naturales de la subcuenca del río Pitura, están concentradas en las áreas de Protección Permanente, Manejo y recuperación de suelos y de conservación y Ecoturismo, las cuales están determinadas en el mapa de zonificación (figura 46). 
Como propuesta, la duración del presente programa debería ser de 5 años, con un horizonte de intervención de 15 años. En la primera etapa se espera poner en marcha el programa, con sus mecanismos de verificación y réplica por parte de la población y las instituciones encargadas del manejo ambiental. Mientras que en la segunda etapa se buscará ampliar la cobertura y conseguir el enraizamiento óptimo en la subcuenca.

\subsubsection{Proyectos del Programa}

El programa de manejo ambiental está formado de tres proyectos los que se detallan a continuación:

- Proyecto de Conservación y Manejo de los recursos Naturales.

- Proyecto de Educación Ambiental.

- Proyecto de Investigación Ambiental.

\subsection{PROGRAMA DE GESTIÓN PRODUCTIVA}

Las actividades agropecuarias dentro de la subcuenca se desarrollan bajo numerosas restricciones y limitaciones, las cuales deben ser superadas para poder alcanzar un desarrollo sustentable, siendo necesario la planificación de actividades en concordancia con las potencialidades de los recursos y las necesidades de los pobladores.

Las acciones propuestas buscan que las actividades productivas tengan el menor impacto posible, por lo que se concibe este programa como una herramienta de generación de ingresos para las comunidades, en base a modelos productivos acorde a las potencialidades de los ecosistemas.

\subsubsection{Justificación}

El desarrollo de las actividades agropecuarias dentro la subcuenca del río Pitura muestran graves problemas en aspectos de productividad y su impacto en el ambiente; esta problemática causada por los siguientes factores:

- Prácticas y técnicas de alto impacto, acompañadas de la pérdida paulatina del conocimiento ancestral de los pobladores. 
- Explotación del páramo y el bosque nativo, generando erosión y conflictos entre la potencialidad y el uso del suelo.

- Falta de intervención técnica dentro de la zona, que permita a los pobladores de la subcuenca generar alternativas de manejo sustentable de los recursos naturales, mejorar su calidad de vida y disminuir la presión sobre los ecosistemas naturales.

- Desconocimiento de leyes y programas concernientes a la producción y el aprovechamiento de los recursos naturales.

Por lo que es necesaria la generación de un programa de gestión de la producción, que genere alternativas para un desarrollo productivo acorde al concepto de sustentabilidad, mediante la aplicación de sistemas productivos eficientes y rentables, mejorando los ingresos de las comunidades y contribuyendo con la seguridad y soberanía alimentaria, y el equilibrio con el ambiente. Es fundamental contemplar la integralidad de las acciones a ser llevadas a cabo, que permitan superar las restricciones y limitaciones biofísicas y socioeconómicas de la zona.

\subsubsection{Objetivo General}

Optimizar la producción de las actividades agropecuarias dentro de la subcuenca del río Pitura, bajo el concepto de desarrollo sustentable, a fin de que se genere un ordenamiento de las actividades en base al uso potencial del suelo, generando ingresos para los pobladores de la zona en equilibrio con el ambiente.

\subsubsection{Objetivos Específicos:}

- Determinar zonas aptas para la realización de actividades agropecuarias de la subcuenca del río Pitura, contribuyendo a la sostenibilidad de los recursos naturales, económicos, y talento humano.

- Aplicar modelos agrosilvopastoriles que aumenten la productividad de la zona.

- Mejorar las condiciones de comercialización de los productos, a fin de mejorar los ingresos de las comunidades.

- Contribuir con la seguridad y soberanía alimentaria de las familias dentro de la subcuenca del río Pitura. 
- Generar sistemas de investigación y aplicación de tecnologías, que recuperen el conocimiento ancestral de las comunidades, para alcanzar un desarrollo agropecuario de la zona.

- Fomentar la diversificación de cultivos y actividades, a fin de mejorar la salida de los productos y la seguridad alimentaria de las familias.

- Generar estímulos que conlleven a un manejo de los recursos, mediante asistencia técnica, capacitaciones, titulación de tierras, inserción a programas de producción nacional; a fin de llegar a un ordenamiento espacial de las actividades agropecuarias, dando viabilidad a las estrategias de aprovechamiento sustentable.

- Controlar el avance de la frontera agrícola y las invasiones a áreas con presencia de ecosistemas naturales.

\subsubsection{Resultados Esperados}

- Actividades agropecuarias realizadas por las comunidades optimizadas

- Técnicas y prácticas agrosilvopastoriles que permitan diversificar la producción implementadas en la zona.

- Organizaciones comunitarias fortalecidas mejorando la capacidad de autogestión y la generación de pequeñas empresas.

- Sistemas de autoabastecimiento que garanticen la seguridad y soberanía alimentaria implementados en la zona.

\subsubsection{Estrategia del Programa}

Para cumplir con los objetivos planteados para el programa, se han diseñado lineamientos estratégicos los cuales se plantean a continuación:

- Ordenamiento agropecuario dentro de la zona, concentrando las actividades productivas en las zonas aptas para las mismas.

- Modelos productivos que permitan aumentar y diversificar la producción, evitando la degradación de los ecosistemas naturales.

- Optimización de sistemas de producción y aprovechamiento. 
- Alternativas y mecanismos eficientes para la realización de actividades productivas por parte de los pobladores.

- Fortalecimiento las vías de comercialización para productos y servicios.

\subsubsection{Localización y Período para la Ejecución del Programa}

Las actividades del proyecto se concentrarán en las de Uso Múltiple y de Manejo y Recuperación de Suelos determinadas en la zonificación de la subcuenca del río Pitura (Figura 46), con la implementación de acciones orientadas a manejar la producción agropecuaria en equilibro con la conservación de los recursos naturales.

Como propuesta, la duración del presente programa debería ser de 5 años, con un horizonte de intervención de 10 años. En la primera etapa se espera poner en marcha el programa, con sus mecanismos de verificación y réplica por parte de la población y las instituciones encargadas del manejo ambiental. Mientras que en la segunda etapa se buscará ampliar la cobertura y conseguir el enraizamiento óptimo en la subcuenca.

\subsubsection{Proyectos del Programa}

Dentro del Programa de Gestión Productiva se han diseñado los siguientes proyectos:

- Proyecto de Mejoramiento de la Producción Agrícola.

- Proyecto de Mejoramiento de la Producción Ganadera.

- Proyecto de Capacitación y Asistencia Técnica

\subsection{PROGRAMA DE DESARROLLO COMUNITARIO}

El presente programa muestra una propuesta de atención para las comunidades presentes dentro de la subcuenca del río Pitura, contrarrestando las diferentes limitaciones y restricciones a las que se enfrentan, y aprovechando las potencialidades y oportunidades para alcanzar un desarrollo sustentable, a fin de mejorar su calidad de vida, en base al fortalecimiento de sus estructuras, respetando sus valores culturales. 


\subsubsection{Justificación}

En los últimos 15 años la zona de estudio ha sufrido cambios en la estructura de sus ecosistemas, a consecuencia de las actividades antrópicas. Las áreas de bosque natural y páramo han sido reemplazadas por sistemas productivos que degeneran el ambiente y la calidad de vida de los pobladores.

Los sistemas productivos implementados deterioran los recursos naturales y desplazan los sistemas de producción tradicionales. Pese a este fenómeno no se ha percibido una mejoría en cuanto su calidad de vida, por el contrario las comunidades han sido empujadas hasta territorios con muy poco potencial productivo, ubicándolos dentro de los estratos sociales más pobres.

Por lo que el programa busca brindar a las comunidades, la posibilidad de recuperar y fortalecer su conocimiento ancestral, generando una mejor estructura organizativa e impulsando prácticas sociales y productivas sostenibles para la zona. Además de fortalecer su identidad cultural se busca mejorar su calidad de vida mediante la implementación de proyectos productivos, educativos y de salud.

\subsubsection{Objetivo General}

Contribuir al mejoramiento de la calidad de vida de las comunidades presentes dentro de la subcuenca del río Pitura, respetando su cultura, conocimiento ancestral y formas de organización; fortaleciendo su bienestar colectivo en base a un desarrollo sustentable.

\subsubsection{Objetivos Específicos:}

- Fortalecer las formas de organización de las comunidades dentro de la cuenca.

- Generar métodos y proyectos prácticos encaminados a la protección de los territorios de las comunidades.

- Aprovechar de manera sustentable los recursos naturales de la subcuenca.

- Desarrollar mecanismos de apoyo a las actividades sociales y productivas.

- Establecer convenios con instituciones públicas y privadas a fin de generar servicios e infraestructura social básica. 
- Recuperar los conocimientos ancestrales de las comunidades, y aplicarlos en sistemas productivos sostenibles y en equilibrio con el ambiente, que permitan generar alternativas para mejorar su situación económica.

- Implementar proyectos de fortalecimiento de valores, prácticas culturales tradicionales, y recuperación de conocimiento ancestral.

- Generar insumos e instrumentos para que las comunidades puedan alcanzar su autogestión.

\subsubsection{Resultados Esperados}

- Principales necesidades de las comunidades atendidas.

- Manejo sostenido de los recursos naturales, generando alternativas para alcanzar la seguridad y soberanía alimentaria.

- Servicios de infraestructura social básica implementados.

\subsubsection{Estrategia del Programa}

Para cumplir con los objetivos planteados para el programa, se han diseñado lineamientos estratégicos los cuales se plantean a continuación:

- Fortalecimiento de las organizaciones existentes en la zona, incentivando su desarrollo, y autogestión.

- Diseño e implementación de alternativas para la solución a necesidades básicas.

- Capacitación de líderes comunitarios en mecanismos para identificación, formulación y administración de proyectos, como forma práctica de conseguir establecer pequeñas y medianas industrias.

- Generación de mecanismos de fortalecimiento y coordinación institucional entre las comunidades y las diferentes instituciones públicas y privadas dela región.

\subsubsection{Localización y Período para la Ejecución del Programa}

El programa muestra una propuesta para atender las principales necesidades de las comunidades presentes dentro de la subcuenca del río Pitura, respetando sus valores y 
prácticas culturales, e incentivado la recuperación y fortalecimiento de sus saberes ancestrales.

Las acciones programadas dentro de los diferentes proyectos del programa, están planificadas a ser realizadas en un periodo de cinco años; posteriormente se realizará una evaluación y verificación de resultados alcanzados, y de esta manera se podrá determinar un periodo de réplica de cinco años más.

\subsubsection{Proyectos del Programa}

Dentro del Programa de Gestión Productiva se han diseñado los siguientes proyectos:

- Proyecto de Fortalecimiento Cultural

- Proyecto de Salud Comunitaria

\subsection{PROGRAMA DE CAPACITACIÓN Y ORGANIZACIÓN COMUNITARIA}

Para llevar a cabo la ejecución de los programas anteriores es necesario generar un proceso de organización y capacitación, que permita a las comunidades crear herramientas para alcanzar la autogestión y poner en marcha los programas, proyectos y actividades planteados con un alto sentido de pertenencia. Por lo que es necesario formular el presente programa.

\subsubsection{Justificación}

La mayor parte de las actividades económicas que se realizan dentro del área de estudio son agropecuarias, sin embargo, estas actividades se concentran en pocos productos, implementados con sistemas que son muy deficientes en términos de producción y conservación. Aun con todos los esfuerzos que las comunidades imprimen dentro de estas actividades los resultados son bajos, debido a las características biofísicas del medio en el que se desenvuelven y al tipo de prácticas y tecnología empleadas. En este marco la producción no es suficiente para poder cubrir la totalidad de necesidades básicas de los habitantes.

De igual manera una falta de conocimiento sobre la fragilidad de los ecosistemas en los cuales se desarrollan, han impedido que se genere una planificación que lleve a alcanzar un desarrollo integral en armonía con el ambiente. No se cuenta con un sistema educativo que 
integre los conocimientos, prácticas y valores culturales con nuevas tecnologías, que permitan a los habitantes autogestionar sus recursos e impulsar la asociatividad y cooperativismo, que son fundamentales para poder llegar a un desarrollo comunitario.

Es por eso que se hace necesario la implementación de este programa, como una herramienta para introducir el concepto de desarrollo sustentable en las comunidades, mediante la implementación de sistemas educativos, de capacitación y de organización, adaptados a las condiciones particulares de las comunidades en términos económicos, sociales y ambientales, permitiéndoles generar y adquirir conocimientos, reflexionar sobre su situación y planificar activamente sus procesos de desarrollo.

\subsubsection{Objetivo General}

Promover el desarrollo sustentable dentro de la subcuenca del río Pitura, en respeto a los valores y prácticas culturales y el rescate de su conocimiento ancestral, generando herramientas que permitan a las comunidades fortalecer sus procesos organizativos de desarrollo, autogestión y mejorar su calidad de vida.

\subsubsection{Objetivos Específicos:}

- Generar una metodología que permita superar las limitaciones en términos de organización y capacitación para las comunidades; adaptadas a las condiciones socioeconómicas de la zona.

- Generar espacios de intercambio de experiencias y conocimientos, en los cuales los pobladores puedan replicar sus conocimientos en conjunto a instituciones involucradas en el desarrollo comunitario.

- Implementar un sistema de capacitación integral en la cual los líderes comunitarios repliquen e intercambien los conocimientos adquiridos, experiencias, conocimiento ancestral y valores y prácticas culturales.

- Reforzar y establecer organizaciones y asociaciones comunitarias, que permitan a las comunidades tener mayores oportunidades de desarrollo.

- Generar conciencia sobre el papel y la importancia que la mujer desempeña para alcanzar el bienestar de la familia y la comunidad; brindándole espacios de capacitación e 
incentivando su participación activa en la planificación y organización de los proyectos emprendidos.

\subsubsection{Resultados Esperados}

- Un sistema de capacitación integral implementado en la zona, a fin de dar respuesta a las principales problemáticas en los campos social, económico y ambiental a las que se enfrentan.

- Espacios de intercambio de experiencias entre las comunidades e instituciones involucradas en el desarrollo comunitario implementados.

- Organizaciones consolidadas, con el objetivo de incentivar el desarrollo de los pobladores.

\subsubsection{Estrategia del Programa}

Para cumplir con los objetivos planteados para el programa, se han diseñado lineamientos estratégicos los cuales se plantean a continuación:

- Ejecución de metodologías de intervención comunitaria y de desarrollo local, en base a las características socioculturales de las comunidades, con un amplio respeto a sus prácticas y tradiciones, a fin de poder desarrollar los diferentes procesos en búsqueda de un desarrollo sustentable de la zona.

- Construcción de un modelo pedagógico participativo, que permita la aceptación por parte de las comunidades y lleve a la apropiación de los objetivos del plan de manejo integral de la subcuenca.

- Realización de estrategias conjuntas, con las que los pobladores se sientan identificados y representados

- Implementación de espacios de reflexión que permitan fijar objetivos comunes para alcanzar una mejor calidad de vida de cada uno de los integrantes de las comunidades.

- Replicación de conocimientos adquiridos en las diferentes capacitaciones, por parte de los líderes comunitarios y las instituciones públicas y privadas con presencia dentro de la zona. 


\subsubsection{Localización y Período para la Ejecución del Programa}

El presente programa pretende actuar en todas las comunidades presentes dentro de la subcuenca del río Pitura, mediante un sistema que permita replicar los conocimientos adquiridos en las diferentes capacitaciones por parte de los líderes comunitario y las instituciones públicas y privadas que actúan dentro de la zona.

El Programa de Capacitación y Organización Comunitaria se debe iniciar desde el primer año de ejecución del Plan de Manejo Integral de la Subcuenca del río Pitura, y durará un periodo de cinco años, a fin de poder cumplir con el resto de programas planteados.

\subsubsection{Proyectos del Programa}

Dentro del Programa de Gestión Productiva se han diseñado los siguientes proyectos:

- Proyecto de Capacitación para el Fortalecimiento de Organizaciones.

- Proyecto de Desarrollo Integral de la Mujer Comunitaria. 


\section{CONCLUSIONES}

Varios sectores de la subcuenca muestran una alta susceptibilidad a crecidas y proceso erosivos; por lo que las actividades agropecuarias deben ser circunscritas a un $7 \%$ de su superficie, potencialmente apto para realizar actividades agropecuarias -clasificadas en las categorías agroecológicas I, II y III según la clasificación de la capacidad agrológica de los Suelos (USDA, 1.961) - Esta condición edáfica reduce significativamente el uso productivo agropecuario y limita la economía de la población. En el restante $93 \%$ es conveniente realizar únicamente actividades de manejo, recuperación y conservación de los recursos naturales.

La utilización de la matriz de Leopold fue una herramienta importante, en la determinación de los impactos, biofísicos y socioeconómicos presentes en la subcuenca del río Pitura. Permitió el análisis de las actividades sociales y económicas y su efecto en los parámetros ambientales; de donde se desprende la existencia de impactos negativos en el componente ambiental, especialmente en los factores agua, suelo y flora a causa del incremento de las actividades ganaderas; al expandir la frontera agropecuaria, esto aumentó los daños por erosión y el decremento de los ecosistemas naturales de la subcuenca con la consecuente pérdida de biodiversidad.

La estimación de la tasa anual de pérdida de suelos, determinó que un 47,14 \% del área de estudio presenta un grado de erosión hídrica moderado y un $13,41 \%$ muestra un grado de erosión alto. El análisis multitemporal realizado para el período de 1999 al 2014, muestra un incremento del área intervención antrópica del 62,22 \%, con énfasis en la ganadería que es la principal actividad económica de los pobladores; estos no cuentan con la capacitación y el apoyo para aplicar modelos de producción de bajo impacto, la superficie de la mayoría de las propiedades no permite el desarrollo de esta actividad, superando la capacidad productiva del suelo e invadiendo zonas cubiertas por vegetación nativa. Por lo cual, se acepta la hipótesis de trabajo propuesta la que menciona que: los ecosistemas encontrados dentro de la subcuenca del río Pitura, están degradados principalmente por las actividades agropecuarias, una planificación integradora en el manejo de los recursos de la subcuenca del río Pitura constituye una etapa inicial en su recuperación.

Por medio de la zonificación de la subcuenca del río Pitura, se identificó y agrupó a las diferentes áreas territoriales. Esto permitió un tratamiento diferenciado en base a sus características y potencialidades biofísicas, sin que éstas pierdan sus interrelaciones con el conjunto de actividades que se realizan dentro de la subcuenca. La zonificación se constituyó en un insumo en el diseño del Plan de Manejo y una herramienta de análisis de las variables 
en conjunto. Su implementación aportará a una acción eficiente y una participación local específica en la resolución de los conflictos de uso de los recursos naturales.

Los diferentes programas elaborados contribuirán a la solución de los problemas presentes en la subcuenca, con la generación de una propuesta de conservación integral basada en el manejo de los recursos, mejoramiento de la administración, manejo y conservación de los ecosistemas, y el desarrollo de las comunidades; mediante la ejecución de actividades de conservación, protección y producción, en las que se incorporan prácticas y técnicas de manejo alternativas, implementadas por una población capacitada y activa. 


\section{AGRADECIMIENTOS}

Al finalizar el presente trabajo tan arduo e intenso, quiero agradecer primeramente a la Secretaría Nacional de Educación Superior Ciencia y Tecnología del Ecuador (SENESCYT), por financiar mis estudios y permitirme embarcarme en esta experiencia de enriquecimiento profesional y personal, que será sin duda de utilidad para mi país, tal cual el objetivo del programa de becas.

A mi Director Gerardo Denegri, por su apoyo desinteresado, paciencia y confianza, por sus orientaciones y esclarecimiento en los temas que han sido invaluables en cada paso de este trayecto. A mis evaluadores Antonio Jaramillo, Jorge Sfeir y Juan Manuel Cellini, por el tiempo dedicado a la lectura minuciosa del trabajo y sus aportes para mejorar el producto final. A Fernanda Gaspari, Directora de la Maestría, por su colaboración y apoyo para poder concretar este proyecto. A Guillermo Beltrán y Oscar Rosales, docentes de la Universidad Técnica del Norte, por enriquecer la tesis con sus conocimientos y consejos.

A mi madre, pilar fundamental de mi vida, que con su dedicación y ejemplo ha sido la luz que ilumina mi camino. A mi hermana cuya fortaleza fue una inspiración para superar todos los obstáculos que se presentaron. A mis sobrinos cuya ternura y amor, me llenaron de energía para conseguir el objetivo trazado. Al resto de mi familia y amigos que jamás perdieron la fe en mi capacidad y fueron el sostén de cada momento de flaqueza. A la familia Asprella Moscoloni quienes me brindaron el amor y el calor de un hogar lejos de mi hogar, colmando de alegría cada día de mi estancia en la Argentina.

Finalmente agradecer a mi novia María José, por ser el motor de mi vida, quien con su dulzura, amor y confianza inspiro este trabajo; manteniéndome firme con sus consejos y entendiéndome en cada momento; es gracias a ella que me encuentro escribiendo estas líneas y quien sin duda es dueña del título que alcance. 


\section{BIBLIOGRAFÍA}

Aguilar, I. 2007. Las Cuencas y la Gestión del Riesgo. Serviprensa S.A. GuatemalaGuatemala. $45 \mathrm{p}$.

Aguirre, C. 2010. Diseño Experimental. Universidad Técnica del Norte. Ibarra-Ecuador. 260 p.

Aguirre, N. 2007. Manual para el Manejo Sustentable de Cuencas Hidrográficas. Universidad Nacional de Loja. Loja-Ecuador. 115 p.

Altvater, E. 2004. Globalización: la euforia llegó a su fin. Editorial Abya Yala. Quito-Ecuador. $265 \mathrm{p}$.

Antón, J. Saa, A. Grau, J. Gallardo, J. Díaz, M. Andina, D. \& Tarquis, A. 2014. Mathematical Decision Theory Applied to Land Capability: A Case Study in the Community of Madrid. Journal of Environmental Quality. Vol. 43 (2). Pp 763-774.

Año, C. Sánchez, J. \& Antolín, C. 1997. Análisis y Valoración de los Sistemas de Evaluación de Suelos en España: Evolución, Tendencias Actuales y Perspectivas Futuras. Estudios Geográficos. Vol. 228. Pp 331-353.

Araque L., 2.012. Diseño de un Producto Turístico para la Parroquia de Imantag, Cantón Cotacachi, Provincia de Imbabura. Escuela Superior Politécnica de Chimborazo. RiobambaEcuador. Tesis de grado (Inédito). Disponible en: http://dspace.espoch.edu.ec/handle/123456789/2179.

Argote, M. 2015. Análisis de Sensibilidad de Proyecciones de Población. Papeles de Población. Vol. 21 (84). Pp 45-47.

Artaraz, M. 2002. Teoría de las Tres Dimensiones de Desarrollo Sostenible. Revista Ecosistemas. Vol. 11(2). Pp 1-6.

Arteaga, E. San Sebastián, M. \& Amores, A. 2012. Construcción Participativa de Indicadores de la Implementación del Modelo de Salud Intercultural del Cantón Loreto, Ecuador. Saúde em Debate. Vol. 36 (94). Pp 402-413.

Bahamondes, R. 2007. Restauración Ambiental en Cuencas Hidrográficas. Recuperación de Suelos y de Recursos Hídricos en la Cuenca Alta del Río Purén. Chile Forestal. Vol. 329. Pp 17-18.

Basile, D.1974. Tillers of the Andes: Farmers and Farming in the Quito Basin. University of North Carolina Department of Geography. North Carolina-Estados Unidos. 174 p. 
Beltrán , G. \& Rosales, O. 2012. Manual de Trabajos de Hidrología. Universidad Técnica del Norte. Ibarra-Ecuador. $72 \mathrm{p}$.

Beltrán, G. 2007. Folleto de Manejo de Cuencas. Universidad Técnica del Norte. IbarraEcuador. Pp 85 p.

Beltrán, G. 2010. Apuntes Cuencas Hidrográficas SIG. Universidad Técnica del Norte. IbarraEcuador. Pp 76 p.

Beltrán, K. Salgado, S. Cuesta, F. León, S. Romoleroux, K. Ortiz, E. Cárdenas, A. \& Velastegui, A. 2009. Distribución Espacial, Sistemas Ecológicos y Caracterización Florística de los Páramos en el Ecuador. EcoCiencia, Proyecto Páramo Andino y Herbario QCA. QuitoEcuador. $75 \mathrm{p}$.

Bergkamp, G. 1995. A Hierarchical Approach for Desertification Assessment. In Desertification in Developed Countries. Pp 59-78.

Bosman, A. Van der Molen, P. Young, R. \& Cleef, A. 1993. Ecology of a Paramo Cushion Mire. Journal of Vegetation Science. Vol. 4. Pp. 633-640

Burbano, F. 1989. Notas de Hidrología Preparado para el $4^{\circ}$ Año de ingeniería Forestal. Universidad Técnica del Norte. Ibarra-Ecuador. 125 p.

Buytaert, W. Célleri, R. De Bievre, B \& Cisneros, F. 2012. Hidrología del Páramo Andino: Propiedades, Importancia Y Vulnerabilidad. Revista Colombia Tiene Páramos. Vol. 2. Pp. 827.

Buytaert, W. Celleri, R. Willems, P. De Bievre, B. \& Wyseure, G. 2006. Spatial and Temporal Rainfall Variability in Mountainous Areas: A Case Study from the South Ecuadorian Andes. Journal of Hydrology. Vol. 329 (3). Pp 413-421.

Buytaert, W. Cuesta, F. \& Tobon C. 2011. Potential Impacts of Climate Change on the Environmental Services of Humid Tropical Alpine Regions. Global Ecology and Biogeography. Vol. 20. Pp. 19-33.

Buytaert, W. de Bièvre, B. Wyseure, G. \& Deckers, J. 2005. The Effect of Land Use Changes on the Hydrological Behaviour of Histic Andosols in South Ecuador. Hydrological Processes. Vol. 19 (20). Pp 3985-3997.

Buytaert, W. Deckers, J. Dercon, G. De Biévre, B. Poesen, J. \& Govers, G. 2002. Impact of Land Use Changes on the Hydrological Properties of Volcanic Ash Soils in South Ecuador. Soil Use and Management. Vol. 18 (2). Pp 94-100. 
Buytaert, W. Iñiguez, V. \& De Bièvre, B. 2007. The Effects of Afforestation and Cultivation on Water Yield in the Andean Páramo. Forest Ecol Managazine. Vol. 251. Pp. 22-30.

Caballero, N. 2014. Revisión del Marco Conceptual sobre Servicios Ecosistémicos. Memoria de los Foros Técnicos sobre Servicios Ecosistémicos en Uruguay. Montevideo-Uruguay. Pp.815.

Cámara, L. Berzosa, B. \& Correa, E. 2005. Planificación Estratégica. Guía para Entidades sin Ánimo de Lucro que Prestan Servicios de Inserción Sociolaboral. CIDEAL. Madrid-España. $141 \mathrm{p}$.

Cando, M. 2014. Estudio de Impacto Ambiental del Proyecto Multipropósito Piñan Tumbabiro. Centro De Transferencia Y Desarrollo Tecnológico Espe-Cecai. Quito-Ecuador. Informe Preliminar. $852 \mathrm{p}$.

Carranza, C. 2000. Aplicación Metodológica a Estudios de Zonificación Ecológico-Económica en Áreas Litorales, Caso: Chimbote. Revista del Instituto de Investigación de la Facultad de Ingeniería Geológica, Minera, Metalurgica y Geográfica. Vol. 3 (5) Pp 51-55.

Castaño, C. 2002. Páramos y Ecosistemas Alto Andinos de Colombia en Condición Hotspot y Global Climatic Tensor. IDEAM. Bogotá-Colombia.387 p.

CATIE. 1986. Manejo Integral de Cuencas Hidrográficas. Seminario Taller de Manejo Integral de Cuencas Hidrográficas. San José-Costa Rica. 42 p.

Ceballos, A. Schnabel, S. Gómez, D. \& Cerdá, A. 1998. Relación entre la Escala Espacial y Escorrentía Superficial en una Pequeña Cuenca Hidrográfica Semiárida Ante Condiciones Contrastadas de Humedad del Suelo (Extremadura, suroeste de España). Cuaternario y Geomorfología. Vol. 12 (1-2). Pp 63-75.

CEMAT, 1983. Carta Europea de Ordenación del Territorio. Conferencia Europea de Ministros Responsables de la Ordenación del Territorio. Torremolinos-España. 7 p. Informe. Disponible en: www.ehu.eus/Jmoreno/ArchivosPOT/CartaEuropeaOT.pdf

Chinchilla, M. Mata, R. \& Alvarado, A. 2011. Andisoles, Inceptisoles y Entisoles de la Subcuenca del Río Pirrís, Región de Los Santos. Agronomía costarricense: Revista de Ciencias Agrícolas. Vol. 35 (1). Pp 83-107.

Cleef, A. \& Rangel, J.1984. La Vegetación del Páramo del Noreste de la Sierra Nevada de Santa Marta. La Sierra nevada de Santa Marta (Colombia), Transecto Buritaca-La Cumbre. En: T. Van der Hammen, P. Ruíz (eds). Estudios de Ecosistemas Tropandinos. Berlín. Pp. 203-266. 
Cleef, A. Rangel, J. Salamanca, S. Ariza, C. \& Van Reenen, G. 2005. La Vegetación del Páramo del Macizo de Tatamá, Cordillera Occidental, Colombia. En: J. Cramer (ed). Estudios de Ecosistemas Tropandinos. Berlín. Pp. 304-378.

Clérici, C. \& García, F. 2001. Aplicaciones del Modelo USLE/RUSLE para Estimar Pérdidas de Suelo por Erosión en Uruguay y la Región Sur de la Cuenca del Río de la Plata. Agrociencia. Vol. 5 (1). Pp 92-103.

Córdova, J. \& Novoa, V. 1997. Problematica, Experiencias y enfoque sobre la Erosión, Manejo and Conservación de Suelos de Ladera en Ecuador. Integral de Microcuencas. International Potato Center. Pp 123-133.

Cortez, C. 2015. Altitudinal Variation of the Wealth and Relative Abundance of Anuros of the National Park And Natural Area For Integrated Management Cotapata. Ecología en BoliviaRevista del Instituto de Ecología. Vol. 41 (1). Pp 777-780.

Crespo, P. Célleri, R. Buytaert, R. Ochoa B. Cárdenas, I Iñiguez, V. Borja, P. \& De Bièvre B. 2014. Impactos del Cambio de Uso de la Tierra sobre la Hidrología de los Páramos Húmedos Andinos. En: F. Cuesta, J. Sevink, L. Llambí, B. De Bièvre, \& J. Posner (eds.). Avances en Investigación para la Conservación de los Páramos Andinos, CONDESAN. Pp 288-304.

Cuello, M. 2003. Estimación de la Producción y Transporte de Sedimentos en la Cuenca Alta del río Yaque del Norte y del río Guanajuma República Dominicana. CATIE. Turrialba-Costa Rica. 68 p. Tesis Mag. Sc. (Inédito). Disponible en: http://orton.catie.ac.cr/repdoc/A0749e/ A0749e.pdf

Cuesta, F. Salgado, S. Báez, S. Medina, B. \& Josse, C. 2013. Herbazal Inundable del Páramo. En: Ministerio del Ambiente del Ecuador 2012. Sistema de Clasificación de los Ecosistemas del Ecuador Continental. Ministerio del Ambiente del Ecuador. Quito. Pp 143-145.

Custode, E. De Noni, G. Trujillo, G. \& Viennot, M. 1992. La Cangahua en el Ecuador: Caracterizacion Morfo-edafologica y Comportamiento Frente a la Erosión. Terra. Vol. 10. Pp 332-346.

De Moreno, C. 1995. Llamas y Ovejas: El Desarrollo del Ganado Lanar en la Audiencia de Quito. En: L. Escobari (ed.). Colonización Agrícola y Ganadera en América, Siglos XVI-XVIII: Su Impacto en la Población Aborigen. Pp. 153-190.

Díaz, M. Vanegas, E. García, N. \& Camacho, J. 2014. Comparación de Métodos para Determinar Capacidad de Uso de Tierras Agrícolas, con Fines de Ordenamiento Territorial Rural, en Guatemala. Revista Ciencias Técnicas Agropecuarias. Vol. 23 (2). Pp 45-49. 
EROS.USGS. 2015. USGS Global Visualization Viewer. GeoTIFF Ecuador, Perú. [en línea]: documenting electronic sources on the Internet. [fecha de consulta: 2 de febrero 2015] Disponible en: http:// eros.usgs.gov

ESRI. 2013. ArcGis Resources. Función NDVI. [en línea]: documenting electronic sources on the Internet. [fecha de consulta: 4 Abril 2014] Disponible en: http://resources.arcgis. com/es/help/main/10.1/index.html\#//009t00000052000000

Exhibición, V. \& del Río Bermejo, I. 1978. Calidad Ambiental y Desarrollo de Cuencas Hidrográficas: Un Modelo para Planificación y Análisis Integrados. Secretaría General Organización de los Estados Americanos. Washington D.C.-E.E.U.U. 112 p.

Fernández V. 2009. Guía metodológica para la evaluación del impacto ambiental. MundiPrensa Libros. Madrid-España. 409 p.

Ferrando, F. 2015. Alcances en Torno a la Gestión Ambiental a Nivel de Cuencas Hidrográficas. Tiempo y Espacio. Vol. 13. Pp175-184.

Fierro, D. \& Jiménez, L. 2011. Caracterización de la Microcuenca del río Manzano, Cantón Alausí, Provincia de Chimborazo y Propuesta de Plan de Manejo, Utilizando Herramientas SIG. Escuela Politécnica del Ejército. Sangolqui-Ecuador. Tesis de Grado, 237p. (Inédito). Disponible en: repositorio.espe.edu.ec/bitstream/21000/4531/1/T-ESPE-032673.pdf

Flores, F. 2010 .Manejo Integral de la Cuenca Hidrográfica del Río Ambi Ubicado en la Provincia de Imbabura entre las Poblaciones de Atuntaqui y Otavalo, sector Cantón Cotacachi. Universidad San Francisco de Quito. Quito-Ecuador. 154 p. Tesis de Grado (Inédito). Disponible en:http://repositorio.usfq.edu.ec/bitstream/23000/1005/1/96293.pdf.

Foley, J. DeFries, R. Asner, G. Barford, C. Bonan, G. Carpenter, S. Chapin, F. Coe, M. Daily, G. Gibbs, H. Helkowski, J. Holloway, T. Howard, E. Kucharik, C. Monfreda, C. Patz, J. Prentice, I. Namankutty, N. \& Snyder, P. 2005. Global Consequences of Land Use. Science. Vol. 22. Pp 570-574.

Forbes, F. \& Hodges, R. 1971. New Approaches to Comprehensive Planning in Canada. JAWRA Journal of the American Water Resources Association. Vol. 7(5). Pp 1059-1070.

Fraile, O. Sal, J. \& Neumann, R. 1993. El Agroecosistema Andino: Problemas, Limitaciones, Perspectivas. Anales del Taller Internacional sobre el Agroecosistema Andino. Lima-Peru. Pp 119-127.

Francke Campaña, S. 2001. Experiencias de restauración hidrológica forestal de cuencas hidrográficas degradadas de Chile. En: IICA (ed.) Agua, Vida y Desarrollo. Pp. 1-2 
Fries, A. Rollenbeck, R. Nauß, T. Peters, T. \& Bendix, J. 2012. Near Surface Air Humidity in a Megadiverse Andean Mountain Ecosystem of Southern Ecuador and its Regionalization. Agricultural and Forest Meteorology. Vol. 152. Pp 17-30.

GAD Apuela. 2011. Plan de Desarrollo y Ordenamiento Territorial de la Parroquia Apuela. SNISENPLADES. Cotacachi-Ecuador. 282 p.

GAD Imantag. 2012. Plan de Desarrollo y Ordenamiento Territorial de la Parroquia de Imantag. Cotacahi- Ecuador. 225 p.

Gallopín, G. 2003. Sostenibilidad y Desarrollo Sostenible: Un Enfoque Sistémico. CEPAL. Santiago-Chile. $44 \mathrm{p}$.

García, R. 2007. La Gestión de Permisos Ambientales. Residuos: Revista Técnica. Vol. 17 (98). Pp 80-89.

Gaspari, F., Senisterra , G., Delgado, M., Rodríguez , A., \& Besteiro, S. 2010. Manual de Manejo Integral de Cuencas Hidrográficas. Grupo de Manejo de Cuencas. La Plata Argentina. $321 \mathrm{p}$.

GLCF. 2015. Access Land Cover Change for Local to Global Systems. GeoTIFF Ecuador, Perú. [en línea]: documenting electronic sources on the Internet. [fecha de consulta: 2 de febrero 2015] Disponible en: http:// glcf.umd.edu

Gómez, C. 2001. Modelo de Evaluación, Seguimiento y Monitoreo de los Impactos ambientales en los Suelos Colombianos por la Agricultura Intensiva. Maestría en Gestión Ambiental. Universidad Nacional-IDEAM. Bogota-Colombia. Tesis de Grado. 176 p. (Inedito). Disponible en: https://www.siac.gov.co/documentos/DOC Portal/DOC Suelo/Oferta\% 20natural/081210 Mod eval mont seg imp amb act agric.doc.pdf

Gonzales, J. Pinto, P. \& Gonzáles, F. 2013. Memorias primera mesa de trabajo sobre manejo y gestión Integrada de Cuencas Hidrográficas. 22 p.

González, F., \& Cárdenas, T. 1995. El páramo un paisaje deshumanizado: El caso de las provincias del Norte y Gutiérrez (Boyacá-Colombia). ECOAN El Páramo. Ecosistema de alta montaña. Serie Montañas Tropoandinas. Vol. 1. Pp 64-81.

Guerrero, F. \& Ospina, P. 2003. El Poder de la Comunidad. Ajuste Estructural y Movimiento Indígena en los Andes Ecuatorianos. CLACSO. Buenos Aires-Argentina. 304 p.

Gutiérrez, C. 2014. Hidrología Básica y Aplicada. Abya-Yala. Quito-Ecuador. 371 p. 
Harden, C. Hartsig, J. Farley, K. Lee, J. \& Bremer, L. 2015. Effects of Land-Use Change on Water in Andean Páramo Grassland Soils. Annals of the Association of American Geographers. Vol. 103 (2). Pp 375-384.

Heinz, P. 2014. Gestión de Zonas de Recarga y Fuentes Hídricas. Banco del Estado. QuitoEcuador. 65 p.

Hernández, E. 1997. Estrategias para el Fortalecimiento del Manejo de Cuencas Hidrográficas de Montañas Tropicales. XI Congreso Forestal Mundial. Mérida-Venezuela. Pp 249-257.

Hofstede, R. Calles, J. Lopez, V. Polanco, R. Torres, F. Ulloa, J. Vásquez, A. \& Cerra, M. 2014. Los Paramos Andinos .Que Sabemos? Estado de Conocimiento sobre el Impacto del Cambio Climático en el Ecosistema Páramo. UICN. Quito-Ecuador. 154 p.

Hofstede, R. Jongsma, W. Lips, J. \& Sevink, Y. 1998. Geografía, Ecología y Forestación en la Sierra Alta del Ecuador. Editorial Abya Yala. Quito-Ecuador. 242 p.

Iglesias, J. \& Santiana, J. 2013. Bosque Siempreverde Montano Alto de Cordillera Occidental de los Andes. En: Ministerio del Ambiente del Ecuador 2012. Sistema de Clasificación de los Ecosistemas del Ecuador Continental. Ministerio del Ambiente del Ecuador. Quito. Pp 90-91.

IICA-PROCIANDINO, 1995. La erosión, manejo y conservación de los suelos de ladera en la Subregión Andina. PROCIANDINO. Quito-Ecuador. 60 p.

INAMHI. 2012. Anuario Meteorológico. Obtenido de Estudios e Investigaciones Meteorológicas. Disponible en: http://186.42.174.231/publicaciones/Anuarios/Meteoro/Am\% 202010.pdf

INEC. 2010. Censo de Población y Vivienda del Ecuador . Obtenido de Instituto Nacional de Estadistica y Censo. Disponible en: http://www.ecuadorencifras.gob.ec/wpcontent/descargas /Manu-lateral/Resultados-provinciales/imbabura.pdf

INEC. 2012. Proyecciones de la Población de la República del Ecuador 2010-2050. Dirección de Normativas y Metologías del SEN. Instituto Nacional de Estadísticas y Censos. Informe Técnico. 48 p. Disponible en: http://www.inec.gob.ec/proyecciones poblacionales/ metodologia.pdf.

INEGI. 2005. Guía para la Interpretación de Cartografía. Instituto Nacional de Estadística, Geografía e Informática. México-México. 21 p.

Innovativa-ESPE. 2014a. Informe de Factibilidad del Proyecto Multiproposito Tumbabiro. ESPE-UTN. Quito-Ecuador.(Correspondencia Personal). 
Innovativa-ESPE. 2014b. Estudio Impacto Ambiental del proyecto Multiproposito Tumbabiro. ESPE. Ibarra-Ecuador. (Correspondencia Personal).

IGM. 2013. Cartografía de Libre Acceso. Obtenido de Geoportal IGM. Disponible en: http://www.geoportaligm.gob.ec/portal/index.php/descargas/cartografia-delibre -acceso/

Jandl, R. Borsdorf, A. Van Miegroet, H. Lackner, R. \& Psenner, R. 2009. Global Change and Sustainable Development in Mountain Regions. Alpine Space-Man and Environment, Vol. 7. Innsbruck University Pres. Innsbruck-Austria. 164 p.

Josse, C. Cuesta, F. Navarro, G. Barrena, V. Cabrera, E. Chacón, E. \& Tovar, A. 2009. Ecosistemas de los Andes del Norte y Centro. Bolivia, Colombia, Ecuador, Perú y Venezuela. Secretaría General de la Comunidad Andina. Lima-Perú. 96 p.

Josse, C. Navarro, G. Comer, P. Evans, R. Faber-Langendoen, D. Fellows, M. Kittel, G. Menard, S. Pyne, M. Reid, M. Schulz, K. Snow, K. \& Teague J. 2003. Ecological Systems of Latin America and the Caribbean: A Working Classification of Terrestrial Systems. NatureServe. Arlington-Estados Unidos. 47 p.

Korovkin, T. 1997. Indigenous Peasant Struggles and the Capitalist Modernization of Agriculture: Chimborazo, 1964-1991. Latin American Perspectives. Vol. 24 (3). Pp 25-49.

Lægaard, S. 1992. Influence of Fire in the Grass Páramo Vegetation of Ecuador. En: H. Balslev \& J. Luteyn (eds). Páramo: An Andean Ecosystem Under Human Influence. Academic Press. Londres. Pp 151-170

Lasso, R. 2009. Zonas de Altura y Páramos. Espacios de Vida y Desarrollo. AVSF, CAMAREN, EcoCiencia. Quito-Ecuador. 126 p.

León, J. 2011. Particularidades culturales de la gente de montaña. En: P. Menan, A. Vásconez, S. Flores, R. Hofstede, C. Josse, G. Lasso \& A. Medina (eds). Páramo. Paisaje Estudiado, Habitado, Manejado e institucionalizado. EcoCiencia, Abya Yala, Ecobona. Quito. Pp 155-166.

Llambi, L. Werschitz, S. Alejandra, I. Célleri, R. De Bievre, B. Ochoa, B. \& Borja, P. 2012. Ecología, Hidrología y Suelos del Páramo. CONDESAN. Quito-Ecuador. 283 p.

Llambi, L. Sarmiento L \& Rada F. 2013, La Evolución de la Investigación Ecológica en los Páramos de Venezuela: Múltiples Visiones de un Ecosistema Único. En: J. Medina, O. Huber, J. Nassar \& P. Navarro (eds.). Un Recorrido por el Paisaje Vegetal Venezolano: Homenaje a Volkmar Vareschi. Ediciones IVIC. Pp 173-209. 
Luteyn, J. 2000. Páramos: A Checklist of Plant Diversity, Geographical Distribution, and Botanical Literature. En: M. William \& M. Eddie (eds.).Memoirs of the New York Botanical Garden. Pp. 269-271

Malagón, D. \& Pulido, C. 2000. Suelos del Páramo Colombiano. En: J. Rnagel. Colombia Diversidad Biótica III. La región de vida paramuna. Universidad Nacional de Colombia. Facultad de Ciencias, Instituto de Ciencias Naturales. Bogotá. Pp 629-644.

Mancilla, G. 2008. Uso de la Ecuación Universal de Pérdidas de Suelo (Usle) en el Campo Forestal. Universidad de Chile. Santiago-Chile. 64 p.

Martínez, L. 1998. Comunidades y Tierra en el Ecuador. Ecuador Debate. Vol. 45. Pp 173188.

Mena, P. \& Hofstede, R. 2006. Los Páramos Ecuatorianos. Botánica Económica de los Andes Centrales. Revista de la Universidad Mayor de San Andres. Pp 91-109.

Mena, P. 2001. Los Páramos del Ecuador. Particularidades, Problemas y Perspectivas. AbyaYala/Proyecto Páramo. Quito-Ecuador. 311 p.

Ministerio de Transporte y Comunicaciones del Perú. 2008. Manual de Hidrología, Hidráulica y Drenaje. DEE. Lima-Peru. 209 p.

Ministerio del Ambiente. 2013. Sistema de Clasificación de los Ecosistemas del Ecuador. Subsecretaria de Patrimonio Natural. Quito-Ecuador. 145 p.

Ministerio del Ambiente. 2012a. Línea Base de Deforestación del Ecuador Continental. Ministerio del Ambiente del Ecuador. Quito-Ecuador. 30 p.

Ministerio del Ambiente. 2012b. Sistema de clasificación de los Ecosistemas del Ecuador Continental. Ministerio del Ambiente del Ecuador. Quito-Ecuador. 136 p.

Ministerio del Ambiente. 2015. Texto Unificado de Legislación Ambiental Secundaria del Ministerio del Ambiente. Registro Oficial del Ecuador. Quito-Ecuador. 756 p.

Molano, J. 2010. Delimitaciones Diacrónicas de los Territorios de Páramo en Colombia. Límites, Fronteras y Territorialidades. En: A. Caro (ed.). Definición de Criterios para la Delimitación de Páramos. IAVH. Bogotá. Pp 42-53.

Monasterio, M. \& Molinillo, M. 2003. Venezuela. En: R. Hofstede, P. Segarra \& P. Mena (eds.). Los Páramos del Mundo. Global Peatland Initiative/NC-IUCN/EcoCiencia. Quito. Pp. 205-236 Monje, J. \& Narváez-Mena, H. 2006. Elaboración de un Plan de Manejo Participativo del Páramo de Contrahierba del Comité De Desarrollo Agrícola El Piñán. Pontificia Universidad 
Católica del Ecuador, Sede Ibarra. Ibarra-Ecuador. Tesis de Grado. 122 p. (Inédito). Disponible en: http://dspace.pucesi.edu.ec/bitstream/11010/264/1/T71603.pdf.

Mosquera, G. Lazo, P. Cárdenas I. \& Crespo, P. 2012. Identificación de las Principales Fuentes de Agua que Aportan a la Generación de Escorrentía en Zonas Andinas de Páramo Húmedo: Mediante el Uso de los Isótopos Estables Deuterio $(\delta 2 \mathrm{H})$ y Oxígeno-18 $(\delta 180)$. Maskana. Vol. 3 (2). Pp 87-105.

Ocaña, J. 2015. Impacto de la Inversión en Educación, Ciencia y Tecnología en El Desarrollo Económico de América Latina Y el Caribe Periodo: 2000-2012. Journal of Economics. Vol. 3 (1). Pp 107-132.

Ortega, F. 2015. Otras Opciones en la Atención de la Salud: Lo Tradicional y lo Alternativo. En: Organización Panamericana de la Salud (ed.). La Equidad en la Mira: La Salud pública en Ecuador Durante las Últimas Décadas. OPS/MSP/CONASA. Quito. Pp. 414-423

Podwojewski, P. \& Poulenard, J. 2000. La Degradación de los Suelos de los Páramos. Los Suelos del Páramo. Serie Páramo. Vol. 5. Pp 27-36.

Podwojewsky, P. 1999. Los Suelos de las Altas Tierras Andinas: Los Páramos del Ecuador. Boletín informativo-Sociedad Ecuatoriana de la Ciencia del Suelo. Vol. 18. Pp. 9-14.

Pourrut, P. 1983. Los climas del Ecuador-fundamentos Explicativos. CEDIG Documentos de Investigación. Vol. 4. Pp 8-40.

Quichimbo, P., Tenorio, G., Borja, P., Cárdenas, I., Crespo, P., \& Célleri, R. 2012. Efectos sobre las Propiedades Físicas y Químicas de los Suelos por el Cambio de la Cobertura Vegetal y Uso del Suelo: Páramo De Quimsacocha al Sur del Ecuador. Suelos Ecuatoriales. Vol. 42 (2). Pp 138-153.

Rada, D. 2000. La Gestión Integral del Agua en Cochabamba. Obtenido De Comisión Para La Gestión Integral Del Agua En Cochabamba.CONDESAN. Cochabamba-Bolivia. 252 p.

Ramakrishna, B. 1997. Estrategias de Extensión para el Manejo Integrado de Cuencas Hidrográficas: Conceptos y Experiencias. Editorial de IICA. San José-Costa Rica. 338 p.

Ramsay, P. \& Oxley, E. 2001. An Assessment of Aboveground Net Primary Productivity in Andean Grasslands of Central Ecuador. Mountain Research and Development. Vol. 21 (2). Pp. 161-167. 
Ramsay, P. 1999. Landscape Mosaics in the High Andes: The Role of Fire in Páramo Communities. En: P. Ková (ed.). Nature and Culture in Landscape Ecology: Experiences for the 3rd Millennium. The Karolinum Press. Praga. Pp 192-199.

Rangel, O. 2000. Colombia Diversidad Biótica III. La Región de Vida Paramuna de Colombia. Universidad Nacional de Colombia. Bogotá-Colombia. 843 p.

Recharte, H. \& Gearheard, J. 2001. Los Páramos Altamente Diversos: Ecología Política de una Región. En: V. Mena, G. Medina, \& R. Hofstede (eds.). Los Páramos del Ecuador. Particularidades, Problemas y Perspectivas. Abya/Yala. Pp.55-85.

Reyes, P. 1995. El Páramo: Un Ecosistema de Alta Montaña. Serie Montañas Tropoandinas. Fundación Ecosistemas Andinos; Gobernación de Boyacá. Bogota-Colombia. 168 p.

Rodríguez, F. 2003. Perú: Ordenamiento Territorial con base en la Zonificación Ecológica Económica en la Amazonia. Taller Experiencias de Ordenamiento Territorial en Latinoamérica. Cali-Colombia. $35 \mathrm{p}$.

Rodríguez, L. 2006. Enfoque Intercultural en Salud Sexual y Reproductiva en el Ecuador. En: Fondo de Población de las Naciones Unidas (ed.). Enfoque Intercultural y de Género en Salud Materna. UNFPA. Quito. Pp 17-30.

Rodríguez, M. \& Gordón, D. 2015. Análisis Automático de la Susceptibilidad de las Inestabilidades de Laderas Provocadas por Terremotos en un Sector de la Cordillera de los Andes, Ecuador. Revista de la Sociedad Geológica de España. Vol. 28 (1). Pp 91-104.

Rodríguez, M. 2009. Desarrollo y Retos de la Participación de la Sociedad Civil en los Procesos de Ordenación Territorial. Perspectiva Geográfica. Vol. 1 (13). Pp 127-142.

Rosero, N. 2014. Impacto Ambiental y Plan de Manejo Ambiental en la Descarga de Aguas Residuales Generada por la Operación y Mantenimiento de la Planta de Tratamiento del Barrio La Primavera, de la Parroquia Yanayacu, Cantón Quero, Provincia de Tungurahua. Universidad Técnica de Ambato. Ambato-Ecuador. Tesis de Grado. 247p. (Inédito). Disponible en: http://repositorio.uta.edu.ec/bitstream/123456789/6798/1/tesis007\%20Maestr\%C3\%Ada \%20en\%20Agroecolog\%C3\%ADa\%20y\%20Ambiente\%20-\%20CD\%20221.pdf

Salgado, S. Báez, S. Medina, B. \& Josse, C. 2013a. Herbazal Inundable del Páramo. En: Ministerio del Ambiente del Ecuador 2012. Sistema de Clasificación de los Ecosistemas del Ecuador Continental. Ministerio del Ambiente del Ecuador. Quito. Pp 139-141.

Salgado, S. Cuesta, F. Báez, S. Josse, C. \& Medina, B. 2013b. Arbustal Siempreverde y Herbazal del Páramo. En: Ministerio del Ambiente del Ecuador 2012. Sistema de Clasificación 
de los Ecosistemas del Ecuador Continental. Ministerio del Ambiente del Ecuador. Quito. Pp 134-155.

Santos, L. \& Gonzáles, C. 1999. Mapa de Indices de Erodabilidad en la Cuenca Alta del Río Bogotá Utilizando el Sistema de Información Geográfica ARC-INFO. Revista Ingeniería e Investigación. Vol. 43. Pp 30-33.

Sarandón, S. \& Folres, C. 2014. Agroecología: Bases Teóricas para el Diseño y Manejo de Agroecosistemas sustentables. Editorial de la Universidad de La Plata. La Plata-Argentina. $467 \mathrm{p}$.

Sarandón, S. 2002. El desarrollo y uso de indicadores para evaluar la sustentabilidad de los agroecosistemas. Agroecología: El camino para una agricultura sustentable. La PlataArgentina. Pp 393-414.

Segovia, F. 2013. El Clima Cambia, Cambia tú También: Adaptación al Cambio Climático en Comunidades Locales en Ecuador. SPDA, Ecociencia, UICN, AECID. Lima-Peru. 25 p.

Segura, L. \& Arriaga, J. 2003. Principios Básicos de Contaminación Ambiental. UAEM. TolucaMéxico. $217 \mathrm{p}$.

SENPLADES, 2014. Informe de Evaluación Plan Estratégico Institucional 2014-2017. Dirección de Planificación Integral. Quito-Ecuador. Informe. 37 p.

SENPLADES, Ministerio de Defensa Nacional, Instituto Espacial Ecuatoriano, \& Ministerio de Agricultura, Acuacultura y Pesca. 2012. Amenaza a Erosión Hídrica. Proyecto: Generación de Geoinformación para la Gestión del Territorio a Nivel Nacional. SENPLADES. Quito-Ecuador. $55 \mathrm{p}$.

SENPLADES. 2013. Plan Nacional para el Buen Vivir 2013-2017. Secretaria Nacional de Planificación y Desarrollo. Quito-Ecuador. 602 p.

Sklenar, P. 2005. Flora genérica de los páramos. Guía llustrada de las Plantas Vasculares. Memoirs of The New York Botanical Garden. New York- Estados Unidos. 499 p.

Smith, A. \& Young, T. 1987. Tropical Alpine Plant Ecology. Annual Review of Ecology and Systematics. Vol. 2. Pp 137-158.

SNI. 2014. Archivos de Información Geográfica, Coberturas Territorial. Obtenido de Sistema Nacional de Información. Disponible en: http://sni.gob.ec/coberturas 
Soria, A. \& Chebez, J. 2015. Plan General de Manejo del Parque Nacional Chaco: Versión Consensuada Mediante Taller Público. Secretaría de Turismo y Deporte - Presidencia de la Nación República Argentina. Chaco-Argentina. 208 p.

Suárez, D. 2008. Formación de un Corredor de Hábitat de un Bosque Montano Alto en un Mosaico de Páramo en el Norte del Ecuador. Ecología Aplicada. Vol. 7. Pp 9-15.

Tetreault, D. 2015. Una Taxonomía de Modelos de Desarrollo Sustentable. Espiral. Estudios sobre Estado y Sociedad. Vol. 10 (29). Pp 45-77.

Tibaldi, A. Ferrari, L. \& Pasquarè, G. 1995. Landslides Triggered by Earthquakes and Their Relations with Faults and Mountain Slope Geometry: An Example from Ecuador. Geomorphology. Vol. 11 (3). Pp 215-226.

Treviño, A., 2003. El Desarrollo Sustentable: Interpretación y Análisis.Revista del centro de investigación. Universidad La Salle. Vol. 6 (21), Pp 55-59

Valderrama Plata, L. 1985. Algunas Directrices para la Planificación y Ordenación de Cuencas Hidrográficas. Memorias Tercer Congreso Colombiano de Cuencas Hidrográficas. CaliColombia. Pp 608-632.

Valencia, P. 2013. Consideraciones Jurídicas sobre el Ordenamiento Territorial Ambiental. Espacio y Desarrollo. Vol. 21. Pp. 139-169.

Valencia, R. Cerón, C. Palacios, W. \& Sierra, R. 1999. Los Sistemas de Clasificación de la Vegetación Propuestos para el Ecuador. En: R. Sierra (ed.) Propuesta Preliminar de un Sistema de Clasificación de Vegetación para el Ecuador Continental. Proyecto INEFAN/GEFBIRF y EcoCiencia. Quito. pp. 19-28.

Vanacker, V. Bellin, N. Molina, A. \& Kubik, P. 2014. Erosion Regulation as a Function of Human Disturbances to Vegetation Cover: A Conceptual Model.Landscape Ecology. Vol. 29 (2). Pp 293-309.

Vargas, O. \& Velazco, P. 2011. Reviviendo Nuestros Páramos: Restauración Ecológica. CONDESAN. Quito-Ecuador. 183 p.

Vargas, O. Premauer, J \& Cardenas, C. 2002. Efecto del Pastoreo sobre la Estructura de la vegetación en un Páramo Húmedo de Colombia. Ecotrópicos 15 (1). Pp 35-50.

Vásconez, P. \& Hofstede, R. 2006. Los páramos ecuatorianos. En: M. Moraes, R. Øllgaard, L. Kvist, F. Borchsenius \& H. Balslev. Botánica económica de los Andes Centrales. Universidad Mayor de San Andres, La Paz. Pp 91-109 
Vega, D. 2008. Plan de Ordenamiento Territorial Participativo para la Microcuenca del Río Sesesmiles. Honduras. Centro Agronómico Tropical de Investigación y Enseñanza. TurrialbaCosta Rica, 248 p. (Inédito). Disponible en: http://orton.catie.ac.cr/REPDOC/A2382E IA2382E.PDF.

Vergara, S. Valencia, A. \& Torres, L. 2015. Modelos Espacio-Temporales de Factores de Deterioro del Recurso Hídrico: Caso Centros Poblados en la Cuenca del Río Mayo, San Martín. Revista Investigación y Amazonía. Vol. 3 (2). Pp 105-109.

Vuille, M. Bradley, R. \& Keimig, F. 2000. Climate Variability in the Andes of Ecuador and its Relation to Tropical Pacific and Atlantic Sea Surface Temperatura Anomalies. Journal of Climatology. Vol. 13 (2). Pp 2520-535.

Wilcox, B. Breshears, D. \& Allen, C. 2003. Ecohydrology of a Resource-Conserving Semiarid Woodland: Effects of Scale and Disturbance. Ecological Monographs. Vol. 73 (2). Pp 223-239. Winters, P. Espinosa, P. \& Crissman, C. 1998. Manejo de los Recursos en los Andes Ecuatorianos. Abya-Yala. Quito-Ecuador. $60 \mathrm{p}$.

Yaguachi, T. 2013. Diagnóstico Ambiental y Desarrollo del Plan de Manejo y Conservación de la Subcuenca del Río Chillayacu de la Cuenca Media del Río Jubones en la Provincia de el Oro. Universidad Central del Ecuador. Quito-Ecuador, 188 p. (Inédito). Disponible en: www.dspace.uce.edu.ec/handle/25000/1282

Yilmaz, K. Gupta, H. \& Wagener, T. 2015. A Multi-Criteria Penalty Function Approach for Evaluating a Priori Model Parameter Estimates. Journal of Hydrology. Vol. 525. Pp 165-177.

Zambrano, M. \& González, V. 2003. La Valoración en el Ordenamiento Territorial. Postgrado en Sistemas de Información Geográfica Aplicados a la Gestión Territorial y Ambiental. Programa de Modernización de los Servicios Agropecuarios (Promsa).Universidad del Azuay. Cuenca-Ecuador.37 p.

Zapata, R. 2002. Química de los Procesos Pedogenéticos del Suelo. UNAL-Medellín. Medellín-Colombia. 88 p. 


\section{NOTA DEL DIRECTOR}

La Plata, 19 de noviembre de 2015

Sra. Directora Adjunta de la Maestría en Manejo Integral de Cuencas Hidrográficas:

Dra. Fernanda Gaspari

FCAyF- UNLP

De mi consideración:

Tengo el agrado de dirigirme a Ud. para avalar la presentación de las correcciones realizadas, en función de las sugerencias realizada por los evaluadores, para la tesis de Jorge Luis Ramírez López titulada: "Alternativas de Manejo Sustentable para la subcuenca del Río Pitura, provincia de Imbabura, Ecuador".

Sin otro particular la saludo muy atte.

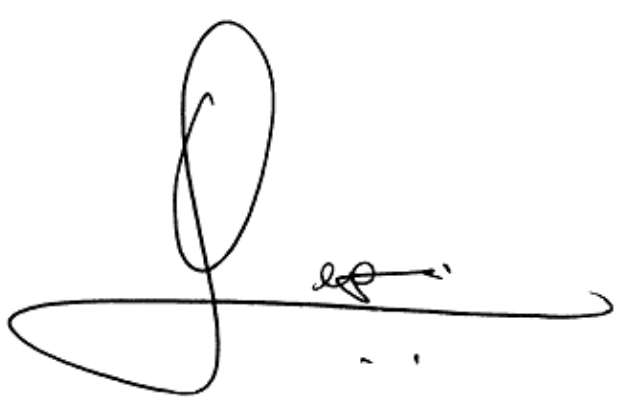

Ing.Ftal Mg Gerardo Denegri

FCAyF- UNLP 


\section{ANEXOS}

ANEXO 1

\section{PROYECTOS DEL PLAN DE MANEJO}

\section{PROGRAMA DE MANEJO AMBIENTAL}

El programa de manejo ambiental está formado de tres proyectos los que, a su vez, están subdivididos en componentes y actividades, a fin de su consecución y cumplimiento.

\subsection{Proyecto de Conservación y Manejo de los Recursos Naturales}

Para la aplicación de este proyecto se han escogido dos líneas de acción: la aplicación de actividades de manejo dentro de los ecosistemas que no están siendo atendidos y la aplicación de los criterios de protección permanente y conservación dentro de las zonas destinas para estos fines, con el objetivo de conservar la diversidad biológica y alcanzar un desarrollo sustentable de la subcuenca.

\subsubsection{Componente de Manejo de Recursos Naturales}

Este componente busca conseguir una producción sustentable dentro de la subcuenca y una conservación de los recursos de la misma, para lo cual se propone realizar las siguientes actividades:

- Capacitar a los habitantes de la subcuenca en el manejo de los recursos naturales.

- Inventariar y clasificar áreas de bosques naturales remanentes, páramos, y ecosistemas frágiles, a fin de determinar sus potenciales de manejo para producción y protección.

- Definir y delimitar unidades de manejo, y creación de responsabilidades de monitoreo y administración de las mismas.

- Elaboración y ejecución de planes y proyectos de manejo dentro de estas unidades.

- Establecimiento y fortalecimiento de proyectos de protección forestal en tierras comunitarias con aptitud forestal, a fin de proteger fuentes de agua.

- Establecimiento de proyectos de agrosilvopastoriles en tierras de uso agropecuario.

- Construcción de barreras vivas que pueden ser mejoradas con prácticas complementarias, como zanjas de infiltración, barreras muertas de piedras y ramas, una doble fila de árboles o una segunda barrera viva con gramíneas perennes 
- Construcción de cortinas rompe vientos para contrarrestar la erosión eólica su efectividad va a depender de su altura, del ángulo con relación a la dirección del viento, de su permeabilidad y de la distancia entre cortinas, por lo general la distancia entre las cortinas debe ser entre 10 y 15 veces la altura de los árboles, p.ej. 100 a 150 m., para arboles de $10 \mathrm{~m}$. , de altura.

- Realizar la plantación de especies nativas de la zona en lugares donde la erosión sea considerable para así disminuir este problema.

- Cercar las áreas consideradas con mayor erosión para evitar el pastoreo de ganado y el desprendimiento de la capa vegetal.

○ Evaluación y seguimiento del proyecto.

TABLA 1: Especies forestales recomendables para actividades de conservación y protección en la subcuenca del río Pitura.

\begin{tabular}{|c|c|c|}
\hline Nombre Común & Nombre Científico & Usos y beneficios no maderables \\
\hline Tara / guarango & Caesalpinia spinosa & Tanino, tintorería, medicinal. \\
\hline Yagual. & Polylepis spp & $\begin{array}{l}\text { Barreras contra vientos y heladas, sombra } \\
\text { para animales, medicinal }\end{array}$ \\
\hline Aliso & Alnus acuminata, & $\begin{array}{l}\text { Fijación de nitrógeno, protección de cuencas } \\
\text { hidrográficas, silvopastoril }\end{array}$ \\
\hline Porotón & Eritrina edulis & $\begin{array}{l}\text { Frutos para consumo humano, forraje, } \\
\text { fijación de nitrógeno }\end{array}$ \\
\hline Quishuar /Quiswara I. & Buddleja spp & $\begin{array}{l}\text { Barreras rompe vientos, ornamental, melífera } \\
\text { y medicinal. }\end{array}$ \\
\hline Guabo / Guamo & Inga spp & $\begin{array}{l}\text { Frutos para el consumo humano, fijación de } \\
\text { nitrógeno y aporte de materia orgánica al } \\
\text { suelo. }\end{array}$ \\
\hline Laurel de cera & Myrica spp & Cera, fijación de nitrógeno, silvopastoril. \\
\hline Nogal / tocte & Juglans neotropica & $\begin{array}{l}\text { Frutos para el consumo humano, tintorería, } \\
\text { medicinal, la semilla se utiliza para elaborar } \\
\text { botones. }\end{array}$ \\
\hline Sauco /tilo & Sambucus nigra & $\begin{array}{l}\text { Frutos para el consumo humano, ornamental } \\
\text { medicinal. }\end{array}$ \\
\hline Faique / espino & Acacia macracantha & $\begin{array}{l}\text { Semillas ricas en proteínas. Por lo cual se } \\
\text { utiliza para alimentar a los animales; sombra } \\
\text { para el ganado y forraje. }\end{array}$ \\
\hline Sacha capuli / cerezo & Vallea stipularis & $\begin{array}{l}\text { Cercas vivas, protección de riveras, } \\
\text { ornamental, melífera. }\end{array}$ \\
\hline Mutuy / Llin-Ilin. & Cassia spp & $\begin{array}{l}\text { Ornamental, cercos vivos, apto para dar } \\
\text { cobertura a suelos degradados, melífera. }\end{array}$ \\
\hline
\end{tabular}




\subsubsection{Componente de Fortalecimiento de las Zonas de Protección y Conservación}

Este componente busca fortalecer la protección de los recursos naturales dentro de la subcuenca del río Pitura, mediante la delimitación y manejo de las zonas de protección permanente; incorporando una planificación para el desarrollo de las actividades productivas y de conservación dentro de la subcuenca; las zonas de protección permanente dentro del plan de manejo son elementos claves en la consecución de la conservación del ambiente y el desarrollo socioeconómico de los pobladores, en equilibrio con el entorno.

Las principales actividades propuestas para este componente son las siguientes:

- Capacitar sobre tópicos de protección y conservación de ecosistemas a los habitantes de la subcuenca

- Establecimiento y difusión de las zonas de protección y conservación; a fin de que los pobladores de la subcuenca, conozcan en donde se encuentran las mismas, y la importancia que estas tienen para alcanzar un desarrollo sustentable de la zona.

- Realización de talleres de educación ambiental con las comunidades, a fin de capacitar a las mismas sobre los beneficios ambientales y económicos de la implementación de zonas de protección y conservación; así como las actividades permitidas dentro de las mismas.

- Participación de las comunidades en mancomunidad con las instituciones gubernamentales y no gubernamentales, para el establecimiento y manejo de estas zonas.

- Implementación de un sistema de monitoreo, vigilancia y protección dentro de las de las zonas de protección y conservación.

- Realizar convenios con Instituciones involucradas en el manejo de los recursos naturales, e instituciones de educación superior, a fin de generar investigación aplicada al manejo de los recursos naturales y a la implementación de prácticas de producción y protección de los ecosistemas.

- Incentivar fortalecimiento organizativo de las comunidades dentro de la subcuenca a fin de alcanzar una administración sostenible de los recursos.

- Fomentar el desarrollo de pequeñas obras de riego para diversificar la producción durante la época seca, promover cultivos anuales de alta rentabilidad para el consumo local, organizar y capacitar a los productores de la subcuenca en el uso y manejo de tecnologías sostenibles. 
- Diversificar las rotaciones de cultivo de acuerdo a la altitud, suelo, disponibilidad de riego y formas de propiedad, años de cultivo y periodo de descanso el mismo que dependerán de la fertilidad del suelo.

- Mantener el contenido de materia orgánica del suelo para lo que se deberá utilizar leguminosas de grano o cereales cuyos cultivos dejan gran cantidad de residuos (rastrojos, raíces) en el suelo.

- Aprovechar los recursos forrajeros en el momento en el que se producen realizando mezclas forrajeras (gramíneas/leguminosas) ayudando a la reconstitución de la fertilidad del suelo, no solamente debido a la fijación de nitrógeno por las leguminosas sino también por su efecto sobre la materia orgánica.

- Evaluación y monitoreo permanente del proyecto.

\subsubsection{Componente Fomento del Ecoturismo}

El desarrollo del ecoturismo dentro de la subcuenca del río Pitura, es fundamental para alcanzar el desarrollo sustentable de la zona; de igual manera esta se constituye en una alternativa importante para la diversificación y complementación de la economía de las comunidades; por lo cual para la consecución de este componente se plantean las siguientes actividades:

- Capación a los habitantes de la subcuenca sobre el ecoturismo y la oferta de diferentes actividades de recreación en ambientes naturales.

- Elaboración de una estrategia de ecoturismo para la subcuenca del río Pitura, con énfasis en el manejo de las áreas de protección y conservación, considerando las particularidades y potencialidades de las mismas.

- Creación de un sistema comunitario de prestación de servicios turísticos como: Hospedaje, alimentación, guía, etc.

- Establecer mecanismos para asegurar que un porcentaje significativo de los beneficios económicos generados por el turismo se inviertan en la conservación de los recursos.

- Involucrar a las operadoras de turismo y otras personas involucradas en la industria del ecoturismo, como parte de la promoción del proyecto.

- Promocionar los atractivos turísticos de la zona mediante la difusión de información interpretativa y educativa para turistas regionales, nacionales e internacionales; 
- Realización de estudios de mercado, a fin de complementar y mejorar los servicios que se oferta dentro de la subcuenca.

- Gestionar recursos provenientes de organismos nacionales e internacionales que promuevan la conservación de ecosistemas frágiles y apoyen a crear empresas de ecoturismo local.

- Mejorar la accesibilidad al área con mantenimiento anual de caminos a través de mingas.

- Realizar un estudio sobre la factibilidad de proyectos ecoturísticos.

- Realizar actividades como: caminatas, cabalgatas a través de senderos ecológicos que incluirían actividades recreativas como pesca deportiva. Los centros turísticos no se deben construir con materiales que alteren el paisaje, más bien deberían ser construcciones en las cuales se aprovechen los materiales, productos de la zona.

- Crear alternativas como el Agroturismo, que basa principalmente en la cosecha de productos típicos de la zona, por los propios turistas, quienes pueden encontrar en esta actividad una fuente de distracción y entretenimiento basados en la variedad de productos que la naturaleza nos brinda.

\subsection{Proyecto de Educación Ambiental}

Con la ejecución de este proyecto se busca incorporar conceptos de educación ambiental dentro de la cultura de las comunidades de la subcuenca del río Pitura, por medio del desarrollo de contenidos y capacitación ambiental específica para la zona; para lo cual se buscara generar información acorde a la realidad socioeconómica y la formación ambiental de las comunidades, a fin de que esta regenere sus contenidos y formas de aplicación en el campo, en función a la evolución y desarrollo de la subcuenca de una manera continua y permanente.

Con esto se intenta generar conciencia sobre el valor de los recursos naturales y la interacción que el ser humano genera con los ecosistemas, proveyendo a los pobladores de medios que les permitan generar un juicio que refuerce un desarrollo social basado en la concientización ambiental y en el rescate del conocimiento ancestral aplicado a la producción racional; además de incorporar conocimiento de tecnologías alternativas sobre el uso y la conservación de los recursos naturales, que conlleven cada vez más a una conciencia de protección del ambiente. 


\subsubsection{Componente de Formación Ambiental Comunitaria}

Mediante este componente se busca difundir e implementa tecnologías alternativas de producción, en base a criterios de conservación, que permitan alcanzar una culturización ambiental de los pobladores de la comunidad, para lo cual se propone realizar las siguientes actividades:

- Capacitación a los habitantes de la subcuenca sobre temas de conservación de los recursos naturales y mitigación de efectos ambientales.

- Convenios con autoridades de educación, a fin de alcanzar la introducción de temas ambientales en el currículo formal de las instituciones educativas.

- Construcción y equipamiento de unidades multiuso, para apoyar en la formación ambiental de los pobladores.

- Efectuar programas de información y capacitación referente a temas ambientales incluyendo videos, campañas de reciclaje, teatro, en las comunidades.

\subsection{Proyecto de Investigación Ambiental}

Este proyecto busca aumentar los conocimientos del componente natural de la subcuenca y la relación socioeconómica que se genera con las diferentes actividades realizadas por los habitantes y su potencial y limitaciones para alcanzar un desarrollo sustentable. La posibilidad de la implementación de tecnologías nuevas y tradicionales, como estrategias alternativas de manejo de los recursos naturales, proporcionando información necesaria para realizar el monitoreo y evaluación del plan de manejo de la subcuenca del río Pitura

Este proyecto también busca ser el enlace entre las diferentes instituciones que realizan investigación en la región y en el país, a fin de que se puedan generar investigaciones específicas dentro de la zona, así como capacitación y extensión especializada.

\subsubsection{Componente de Investigación Básica}

Dentro de este componente se propone realizar las siguientes actividades:

- Capación a los habitantes de la subcuenca sobre temas de investigación. 
- Levantamiento de información básica sobre las condiciones ecológicas y biológicas y sociales de la subcuenca.

- Realización de investigaciones sobre los sistemas de producción y aprovechamiento de los recursos naturales, a fin de evaluar el estado actual de la subcuenca.

- Generación de convenios con instituciones involucradas en el manejo de los recursos naturales e instituciones de educación superior a fin de poder contar con profesionales con conocimiento en técnicas prácticas efectivas de manejo y protección del ambiente.

\subsubsection{Componente Uso Apropiado de los Recursos}

Este componente busca generar información que permitan implementar acciones inmediatas dentro de la subcuenca, para lo cual se proponen las siguientes acciones:

- Integración sistemática de conocimientos ambientales, a las prácticas y técnicas de producción aplicadas en la zona.

- Realización de investigaciones sobre el uso actual y potencial del suelo, a fin de la consolidación del sector agropecuario en la zona y la satisfacción de necesidades de los habitantes.

- Proponer alternativas de manejo de los recursos hídricos de la zona.

- Implementar acciones de mitigación de impactos ambientales negativos generados por la actividad antrópica.

- Realizar investigaciones sobre los principales factores que afectan el desarrollo institucional en el campo de la conservación de los recursos naturales.

- Evaluación y monitoreo permanente del proyecto.

\subsection{Cronograma del Programa}

La tabla 2 muestra el cronograma de ejecución del Programa de Manejo Ambiental 
TABLA 2: Cronograma de ejecución del Programa de Manejo Ambiental.

\begin{tabular}{|c|c|c|c|c|c|c|c|c|c|c|c|c|c|}
\hline \multirow{2}{*}{ PROYECTO } & \multirow{2}{*}{ COMPONENTE } & \multirow{2}{*}{ ACTIVIDADES } & \multicolumn{11}{|c|}{ Semestre } \\
\hline & & & $\overline{11}$ & 2 & 3 & $\overline{44}$ & $\overline{5}$ & 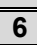 & 77 & 8 & & 9 & 10 \\
\hline \multirow{32}{*}{ 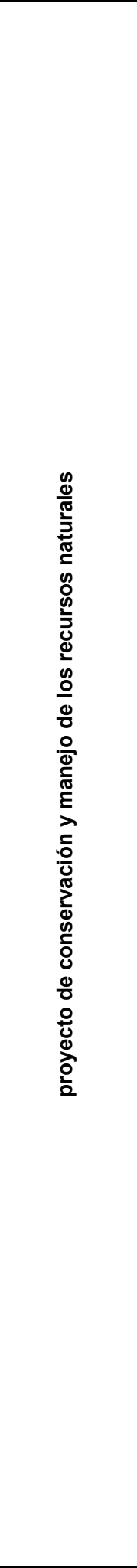 } & \multirow{11}{*}{ 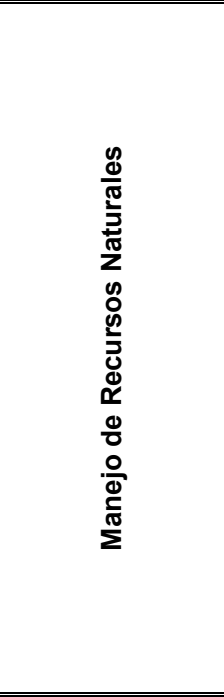 } & $\begin{array}{l}\text { Capacitar a los habitantes de la subcuenca en el manejo de } \\
\text { los recursos naturales }\end{array}$ & & & & & & & & & & & \\
\hline & & $\begin{array}{l}\text { Inventariar y clasificar áreas de bosques naturales } \\
\text { remanentes, páramos, y ecosistemas frágiles }\end{array}$ & & & & & & & & & & & \\
\hline & & Definir y delimitar unidades de manejo & & & & & & & & & & & \\
\hline & & Elaboración y ejecución de planes y proyectos de manejo & & & & & & & & & & & \\
\hline & & $\begin{array}{l}\text { Establecimiento y fortalecimiento de proyectos de protección } \\
\text { forestal }\end{array}$ & & & & & & & & & & & \\
\hline & & Establecimiento de proyectos de agrosilvopastoriles & & & & & & & & & & & \\
\hline & & Construcción de barreras vivas & & & & & & & & & & & \\
\hline & & $\begin{array}{l}\text { Construcción de cortinas rompe vientos para contrarrestar la } \\
\text { erosión eólica }\end{array}$ & & & & & & & & & & & \\
\hline & & $\begin{array}{l}\text { Realizar la plantación de especies endémicas de la zona en } \\
\text { lugares donde la erosión sea considerable para así disminuir } \\
\text { este problema }\end{array}$ & & & & & & & & & & & \\
\hline & & $\begin{array}{l}\text { Cercar las áreas consideradas con mayor erosión para evitar } \\
\text { el pastoreo de ganado y el desprendimiento de la capa } \\
\text { vegetal. }\end{array}$ & & & & & & & & & & & \\
\hline & & Evaluación y monitoreo permanente del proyecto & & & & & & & & & & & \\
\hline & : & $\begin{array}{l}\text { Capacitar sobre tópicos de protección y conservación de } \\
\text { ecosistemas a los habitantes de la subcuenca }\end{array}$ & & & & & & & & & & & \\
\hline & 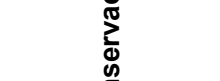 & $\begin{array}{l}\text { Establecimiento y difusión de las zonas de protección y } \\
\text { conservación }\end{array}$ & & & & & & & & & & & \\
\hline & $\stackrel{1}{0}$ & $\begin{array}{l}\text { Realización de talleres de educación ambiental con las } \\
\text { comunidades }\end{array}$ & & & & & & & & & & & \\
\hline & б. & $\begin{array}{l}\text { Participación de las comunidades en mancomunidad con las } \\
\text { instituciones gubernamentales }\end{array}$ & & & & & & & & & & & \\
\hline & むँ & Implementación de un sistema de monitoreo & & & & & & & & & & & \\
\hline & 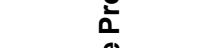 & Realizar convenios con Instituciones & & & & & & & & & & & \\
\hline & 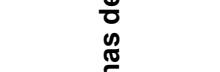 & $\begin{array}{l}\text { Fomentar el desarrollo de pequeñas obras de riego para } \\
\text { diversificar la producción durante la época seca }\end{array}$ & & & & & & & & & & & \\
\hline & 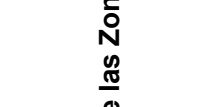 & $\begin{array}{l}\text { Diversificar las rotaciones de cultivo de acuerdo a la altitud, } \\
\text { suelo, disponibilidad de riego y formas de propiedad, años de } \\
\text { cultivo y periodo de descanso el mismo }\end{array}$ & & & & & & & & & & & \\
\hline & $\begin{array}{l}\stackrel{0}{0} \\
\stackrel{0}{\stackrel{2}{0}}\end{array}$ & $\begin{array}{l}\text { Mantener el contenido de materia orgánica del suelo para lo } \\
\text { que se deberá utilizar leguminosas de grano o cereales cuyos } \\
\text { cultivos dejan gran cantidad de residuos (rastrojos en el suelo }\end{array}$ & & & & & & & & & & & \\
\hline & $\overline{\bar{\varepsilon}}$ & $\begin{array}{l}\text { Aprovechar los recursos forrajeros en el momento en el que } \\
\text { se producen realizando mezclas forrajeras }\end{array}$ & & & & & & & & & & & \\
\hline & $\stackrel{\pi}{\frac{\pi}{0}}$ & Incentivar fortalecimiento organizativo & & & & & & & & & & & \\
\hline & 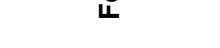 & Evaluación y monitoreo permanente del proyecto & & & & & & & & & & & \\
\hline & & $\begin{array}{l}\text { Capacitación a los habitantes de la subcuenca sobre el } \\
\text { ecoturismo }\end{array}$ & & & & & & & & & & & \\
\hline & & Elaboración de una estrategia de ecoturismo & & & & & & & & & & & \\
\hline & $\frac{c}{5}$ & $\begin{array}{l}\text { Creación de un sistema comunitario de prestación de } \\
\text { servicios turísticos }\end{array}$ & & & & & & & & & & & \\
\hline & 它 & $\begin{array}{l}\text { Capacitación a los habitantes de la subcuenca sobre el } \\
\text { ecoturismo }\end{array}$ & & & & & & & & & & & \\
\hline & $\frac{0}{0}$ & Establecer mecanismos de inversión ambiental & & & & & & & & & & & \\
\hline & $\underset{\frac{\pi}{0}}{0}$ & Involucrar a las operadoras de turismo & & & & & & & & & & & \\
\hline & કั & Promocionar los atractivos turísticos de la zona & & & & & & & & & & & \\
\hline & & Realización de estudios de mercado & & & & & & & & & & & \\
\hline & & Evaluación y monitoreo permanente del proyecto & & & & & & & & & & & \\
\hline
\end{tabular}




\begin{tabular}{|c|c|c|c|c|c|c|c|c|c|c|c|c|}
\hline \multirow{2}{*}{ PROYECTO } & \multirow{2}{*}{ COMPONENTE } & \multirow{2}{*}{ ACTIVIDADES } & \multicolumn{10}{|c|}{ Semestre } \\
\hline & & & 1 & 2 & 3 & 4 & 5 & 6 & 7 & 8 & 9 & 10 \\
\hline \multirow{6}{*}{ 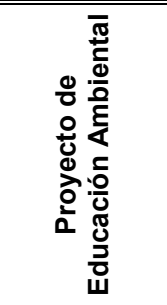 } & \multirow{6}{*}{ 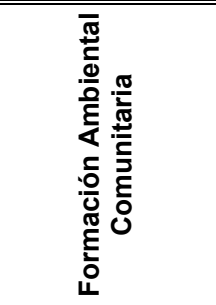 } & Capacitación a los habitantes de la subcuenca & & & & & & & & & & \\
\hline & & Convenios con autoridades de educación & & & & & & & & & & \\
\hline & & Construcción y equipamiento de unidades multiuso & & & & & & & & & & \\
\hline & & Efectuar programas de información y capacitación & & & & & & & & & & \\
\hline & & Levantamiento de información básica & & & & & & & & & & \\
\hline & & Evaluación y monitoreo permanente del proyecto & & & & & & & & & & \\
\hline \multirow{9}{*}{ 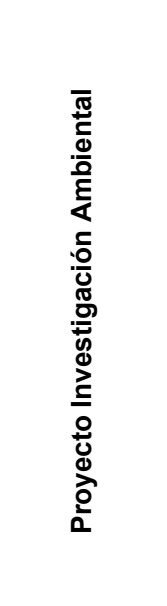 } & \multirow{5}{*}{ 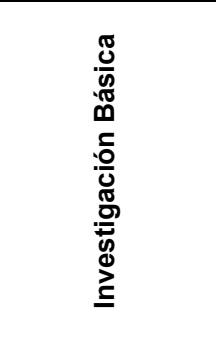 } & Capacitación de los habitantes de la subcuenca & & & & & & & & & & \\
\hline & & $\begin{array}{l}\text { Realización de investigaciones sobre los sistemas de } \\
\text { producción }\end{array}$ & & & & & & & & & & \\
\hline & & $\begin{array}{l}\text { Generación de convenios con instituciones involucradas en el } \\
\text { manejo de los recursos naturales }\end{array}$ & & & & & & & & & & \\
\hline & & Integración sistemática de conocimientos ambientales & & & & & & & & & & \\
\hline & & $\begin{array}{l}\text { Realización de investigaciones sobre el uso actual y potencial } \\
\text { del suelo }\end{array}$ & & & & & & & & & & \\
\hline & \multirow{4}{*}{ 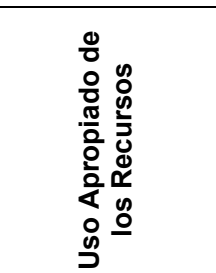 } & $\begin{array}{l}\text { Proponer alternativas de manejo de los recursos hídricos de } \\
\text { la zona }\end{array}$ & & & & & & & & & & \\
\hline & & $\begin{array}{l}\text { Implementar acciones de mitigación de impactos ambientales } \\
\text { negativos }\end{array}$ & & & & & & & & & & \\
\hline & & $\begin{array}{l}\text { Realizar investigaciones sobre los principales factores que } \\
\text { afectan el desarrollo institucional }\end{array}$ & & & & & & & & & & \\
\hline & & Evaluación y monitoreo permanente dl proyecto & & & & & & & & & & \\
\hline
\end{tabular}

\subsection{Costos del Programa}

En la tabla 3 se muestra que el programa tiene un costo de USD 238.200; valor dividido en costos operativos, que se refieren al personal contratado, los consultores y asesores, la operación los costos de movilización, hospedaje y alimentación; y los gastos de inversiones que incluyen infraestructura, material de trabajo y los estudios e inventarios que se realizarán, conjuntamente con su impresión y publicación.

TABLA 3: Costos del Programa de Manejo Ambiental

\begin{tabular}{|c|c|c|c|c|}
\hline PROYECTO & DESCRIPCIÓN & $\begin{array}{l}\text { COSTO UNITARIO } \\
\text { (USD) }\end{array}$ & TIEMPO EN MESES & $\begin{array}{l}\text { COSTO TOTAL } \\
\text { (USD) }\end{array}$ \\
\hline \multirow{6}{*}{ 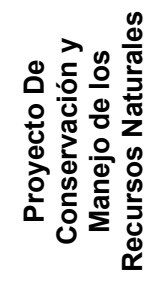 } & Asesor Forestal & 1.500 & 12 & 18.000 \\
\hline & Asesor Agropecuario & 1.500 & 12 & 18.000 \\
\hline & Asesor Ecoturismo & 1.500 & 12 & 18.000 \\
\hline & Técnico Forestal & 1.200 & 12 & 14.400 \\
\hline & Técnico Agropecuario & 1.200 & 12 & 14.400 \\
\hline & Técnico Ecoturismo & |1.200 & 12 & 14.400 \\
\hline
\end{tabular}

Continúa en la siguiente página 


\begin{tabular}{|c|c|c|c|c|}
\hline PROYECTO & DESCRIPCIÓN & $\begin{array}{l}\text { COSTO UNITARIO } \\
\text { (USD) }\end{array}$ & TIEMPO EN MESES & $\begin{array}{l}\text { COSTO TOTAL } \\
\text { (USD) }\end{array}$ \\
\hline \multirow{6}{*}{ 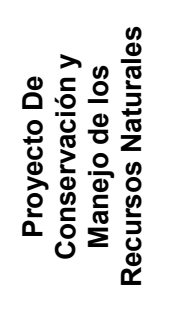 } & Movilización & 1.200 & 12 & 14.400 \\
\hline & Alimentación & 1.050 & 12 & 12.600 \\
\hline & Hospedaje & 1.350 & 12 & 16.200 \\
\hline & Capacitación & 1.500 & 6 & 9.000 \\
\hline & Material de trabajo & 1.000 & 12 & 12000 \\
\hline & \multicolumn{3}{|c|}{ SUBTOTAL } & 161.400 \\
\hline \multirow{8}{*}{ 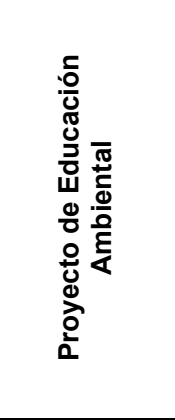 } & Técnico Ambiental & 1.200 & 12 & 14.400 \\
\hline & Movilización & 200 & 12 & 2.400 \\
\hline & Alimentación & 200 & 12 & 2.400 \\
\hline & Hospedaje & 200 & 12 & 2.400 \\
\hline & Capacitación & 1.000 & 6 & 6.000 \\
\hline & Infraestructura & 3.000 & - & 3.000 \\
\hline & Material de trabajo & 500 & 12 & 6.000 \\
\hline & \multicolumn{3}{|c|}{ SUBTOTAL } & 36.600 \\
\hline \multirow{8}{*}{ 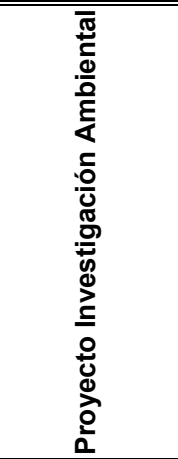 } & Coordinador & 1.500 & 12 & 18.000 \\
\hline & Movilización & 200 & 12 & 2.400 \\
\hline & Alimentación & 200 & 12 & 2.400 \\
\hline & Hospedaje & 200 & 12 & 2.400 \\
\hline & Capacitación & 1.000 & 6 & 6.000 \\
\hline & $\begin{array}{l}\text { Impresión y publicación } \\
\text { de información }\end{array}$ & 3.000 & - & 3.000 \\
\hline & Material de trabajo & 500 & 12 & 6.000 \\
\hline & \multicolumn{3}{|c|}{ SUBTOTAL } & 40.200 \\
\hline \multicolumn{4}{|c|}{ TOTAL } & 238200 \\
\hline
\end{tabular}

\subsection{Actores Clave}

Para poder ejecutar el programa es necesario contar con el apoyo de Instituciones Públicas y privadas relacionadas con el manejo de los recursos naturales, a fin de que estas puedan contribuir con los recursos económicos y el talento humano; esto sumado a la colaboración de la población; para este efecto se detallan los actores claves para la realización de este programa:

- Ministerio del Ambiente (Dirección Provincial de Imbabura)

- Ministerio de Turismo (Dirección Provincial de Imbabura)

- Ministerio de Agricultura, Ganadería, Acuacultura y Pesca (Dirección Provincial de Imabura). 
- Cámara Provincial de Turismo de Imbabura

- Universidades y/o centros de investigación

- Gobierno Autónomo Descentralizado Provincial de Imbabura

- Gobierno Autónomo Descentralizado del Cantón Cotacachi

- Gobiernos Autónomos Descentralizados de las Parroquias Apuela e Imantag

- ONG's y/o Entidades Cooperantes

\section{PROYECTOS DEL PROGRAMA DE GESTIÓN PRODUCTIVA}

Dentro del Programa de Gestión Productiva se han diseñado los siguientes proyectos:

\subsection{Proyecto de Mejoramiento de la Producción Agrícola}

El presente proyecto busca enlazar las prácticas de conservación ambiental con las prácticas de producción sostenibles, por lo que es necesario realizar capacitaciones a los habitantes de la subcuenca del río Pitura en diferentes áreas, con la finalidad de que las acciones propuestas en el proyecto sean aplicadas y monitoreadas.

Las acciones a desarrollarse en el proyecto se detallan a continuación:

- Capacitación de agricultores sobre métodos de control biológico y prácticas agroecológicas.

- Generación e implementación de módulos de producción, en base al establecimiento de unidades de producción adaptadas a las condiciones biofísicas y socioeconómicas de la zona.

- Incorporación de nuevas tecnologías, que permitan realizar un manejo de los recursos naturales y un incremento de los rendimientos y la rentabilidad de las actividades agrícolas.

- Definición de límites de producción sostenibles que aseguren su comercialización.

- Promover la comercialización asociativa y autogestionaria.

- Mejorar y tecnificar los diferentes cultivos, a fin de mejorar el autoabastecimiento.

- Manejo de especies nativas cuya producción puede tener algunas ventajas comparativas en la zona, a fin de superar las limitaciones de infraestructura y transportes. 
- Realizar investigaciones sobre sistemas de producción y especies particulares, que sean promisorios en la zona.

- Establecimiento de proyectos agroforestales en tierras de uso agrícola como cercos vivos, linderos, cortinas contra vientos y heladas, fajas en contorno, árboles dispersos en asocio con cultivos agrícolas o pastos, entre otras.

- Incentivar fortalecimiento organizativo de las comunidades dentro de la subcuenca a fin de alcanzar una administración sostenible de los recursos.

- Identificación y selección de materiales vegetativos para aptos las condiciones de la subcuenca.

- Fomentar en los pequeños y medianos productores de la subcuenca la producción diversificada de cultivos bajo manejo con especies forestales (maderables, energéticas y/o frutales propios de la zona), asociados con cultivos alimenticios (maíz, haba, cebada).

- Evaluación y monitoreo permanente del proyecto.

\subsection{Proyecto de Mejoramiento de la Producción Ganadera}

El presente proyecto busca consolidar la actividad ganadera dentro de la subcuenca del río Pitura, debido a que esta actividad se constituye una base económica de los pobladores. Por lo cual es fundamental integrar alternativas para el manejo del ganado, a fin de optimizar la producción lechera de la zona, mejorar los ingresos de la población y evitar la destrucción de los ecosistemas naturales presentes en el área.

Las acciones a ser implementadas en el proyecto son las siguientes:

- Capacitación de los habitantes de la subcuenca sobre el mejoramiento de producción ganadera

- Delimitación del área para fomento de la actividad pecuaria dentro de la subcuenca.

- Diseño de un Plan piloto de fomento de la producción pecuaria que incluya prácticas de producción sostenibles.

- Identificación de fincas piloto para implementación de la propuesta de plan piloto de producción pecuaria.

- Elaboración de programa de capacitación para comunidades que incluya los siguientes temas de producción: infraestructura necesaria, técnicas de crianza, control sanitario, 
silvopasturas, inseminación artificial, control de plagas y enfermedades y comercialización de productos.

- Visitas a instituciones públicas y privadas con experiencia en el manejo pecuario, con las que los pobladores puedan fortalecer sus conocimientos.

- Identificación y selección de especies de animales aptas para las condiciones de la subcuenca.

- Manejar la carga de ganado por unidad de área y pastoreo rotativo, complementar la alimentación del ganado con vainas y forrajes de los árboles de sombra (leguminosas).

- Implementar plantaciones de yagual (Polylepis incana), en linderos para la división de lotes asignados con ello conseguir mejores condiciones para los cultivos con la protección de vientos y heladas. Además, para obtener leña cultivada y disminuir la presión hacia vegetación boscosa existente en la zona, tomada debido a su resistencia a suelos pobres y a las condiciones de mayor altura

- Evaluación y monitoreo permanente del proyecto.

\subsection{Proyecto de Capacitación y Asistencia Técnica}

Este proyecto busca concienciar a los pobladores de la subcuenca, sobre las limitaciones que presentan las características biofísicas de la cuenca, y sepan como aprovechar de una manera sustentable los recursos naturales a su disposición. Además busca posibilitar el acceso a nuevas alternativas productivas y de comercialización a los pobladores Para la ejecución de este proyecto se han programado las siguientes acciones:

- Capacitación a las comunidades por parte de promotores y técnicos agropecuarios, que permitan lograr una organización y participación comunitaria, que viabilice la ejecución de los proyectos anteriores.

- Establecimiento de granjas integrales autosuficientes de carácter demostrativo.

- Implementación de una unidad de formulación y evaluación de proyectos que facilite a las comunidades la consecución de fondos para emprendimientos.

- Reforzar la cooperación entre los técnicos, investigadores e instituciones encargadas del sector agropecuario, con la comunidad. 
- Legalizar la tenencia de los predios que se encuentran ocupados en la zona, pero sin títulos de propiedad.

- Generación de un sistema de ahorro y crédito local, que permita una utilización más eficiente de los recursos generados en la zona.

- Financiación para el establecimiento de módulos de producción por áreas de potencial homogéneo, proyectos de comercialización y procesamiento comunitario, y la introducción de nuevas tecnologías.

\subsection{Cronograma del Programa}

En la tabla 4 se detalla el cronograma del Programa de Gestión Productiva.

TABLA 4: Cronograma del Programa de Gestión Productiva.

\begin{tabular}{|c|c|c|c|c|c|c|c|c|c|c|c|}
\hline \multirow{2}{*}{ PROYECTO } & \multirow{2}{*}{ ACTIVIDADES } & \multicolumn{10}{|c|}{ Semestre } \\
\hline & & 1 & 2 & 3 & 4 & 5 & 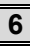 & 7 & 8 & 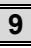 & 10 \\
\hline \multirow{14}{*}{ 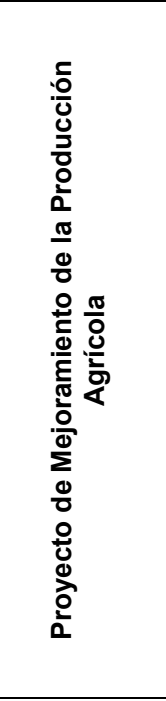 } & Capacitación de agricultores sobre métodos de control biológico y prácticas agroecológicas & & & & & & & & & & \\
\hline & Generación e implementación de módulos de producción & & & & & & & & & & \\
\hline & Incorporación de nuevas tecnologías & & & & & & & & & & \\
\hline & Elaboración y ejecución de planes y proyectos de manejo & & & & & & & & & & \\
\hline & Definición de límites de producción sostenibles que aseguren su comercialización & & & & & & & & & & \\
\hline & Promover la comercialización asociativa y autogestionaria. & & & & & & & & & & \\
\hline & Mejorar y tecnificar los diferentes cultivos & & & & & & & & & & \\
\hline & Manejo de especies nativas & & & & & & & & & & \\
\hline & Investigaciones sobre sistemas de producción y especies particulares & & & & & & & & & & \\
\hline & Establecimiento de proyectos agroforestales en tierras de uso agrícola & & & & & & & & & & \\
\hline & Incentivar fortalecimiento organizativo de las comunidades & & & & & & & & & & \\
\hline & $\begin{array}{l}\text { Identificación de los materiales vegetativos mejorados acorde a las condiciones de la } \\
\text { subcuenca. }\end{array}$ & & & & & & & & & & \\
\hline & $\begin{array}{l}\text { Fomentar en los pequeños y medianos productores de la subcuenca la producción } \\
\text { diversificada de cultivos bajo manejo con especies forestales }\end{array}$ & & & & & & & & & & \\
\hline & Evaluación y monitoreo permanente de la subcuenca & & & & & & & & & & \\
\hline \multirow{10}{*}{ 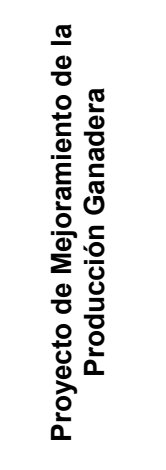 } & Capacitación de los habitantes de la subcuenca & & & & & & & & & & \\
\hline & Delimitación del área para fomento de la actividad pecuaria & & & & & & & & & & \\
\hline & Diseño de un Plan piloto de fomento de la producción pecuaria & & & & & & & & & & \\
\hline & $\begin{array}{l}\text { Identificación de fincas piloto para implementación de la propuesta de plan piloto de } \\
\text { producción pecuaria }\end{array}$ & & & & & & & & & & \\
\hline & Elaboración de programa de capacitación para comunidades & & & & & & & & & & \\
\hline & Visitas a instituciones públicas y privadas & & & & & & & & & & \\
\hline & Identificación de especies de animales mejorados acorde a las condiciones de la subcuenca & & & & & & & & & & \\
\hline & Manejar la carga de ganado por unidad de área y pastoreo rotativo & & & & & & & & & & \\
\hline & Implementar plantaciones de yagual, en linderos para la división de lotes & & & & & & & & & & \\
\hline & Evaluación y monitoreo del proyecto & & & & & & & & & & \\
\hline
\end{tabular}




\begin{tabular}{|c|c|c|c|c|c|c|c|c|c|c|c|}
\hline \multirow{2}{*}{ PROYECTO } & \multirow{2}{*}{ ACTIVIDADES } & \multicolumn{10}{|c|}{ Semestre } \\
\hline & & 1 & 2 & 3 & 4 & 5 & 6 & 7 & 8 & 9 & 10 \\
\hline \multirow{8}{*}{ 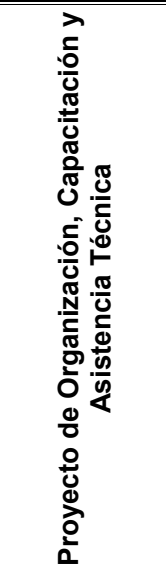 } & Capacitación a las comunidades por parte de promotores y técnicos agropecuarios & & & & & & & & & & \\
\hline & Establecimiento de granjas integrales autosuficientes de carácter demostrativo & & & & & & & & & & \\
\hline & Implementación de una unidad de formulación y evaluación de proyectos & & & & & & & & & & \\
\hline & $\begin{array}{l}\text { Reforzar la cooperación entre los técnicos, investigadores e instituciones encargadas del sector } \\
\text { agropecuario, con la comunidad }\end{array}$ & & & & & & & & & & \\
\hline & $\begin{array}{l}\text { Legalizar la tenencia de los predios que se encuentran ocupados en la zona, pero sin títulos de } \\
\text { propiedad }\end{array}$ & & & & & & & & & & \\
\hline & Generación de un sistema de ahorro y crédito local & & & & & & & & & & \\
\hline & $\begin{array}{l}\text { Financiación para el establecimiento de módulos de producción por áreas de potencial } \\
\text { homogéneo, proyectos de comercialización y procesamiento comunitario, y la introducción de } \\
\text { nuevas tecnologías }\end{array}$ & & & & & & & & & & \\
\hline & Evaluación y monitoreo permanente del proyecto & & & & & & & & & & \\
\hline
\end{tabular}

\subsection{Costos del Programa}

En la tabla 5 se muestra que el programa de Gestión Productiva tiene un costo de USD 151.800; valor dividido en costos operativos, que se refieren al personal contratado, los consultores y asesores, la operación los costos de movilización, hospedaje y alimentación; y los gastos de inversiones que incluyen infraestructura y material de trabajo.

TABLA 5: Costos del Programa de Gestión Productiva

\begin{tabular}{|c|c|c|c|c|}
\hline PROYECTO & DESCRIPCIÓN & $\begin{array}{c}\text { COSTO } \\
\text { (USD) } \\
\end{array}$ & $\begin{array}{l}\text { TIEMPO EN } \\
\text { MESES }\end{array}$ & $\begin{array}{l}\text { TOTAL } \\
\text { (USD) }\end{array}$ \\
\hline \multirow{8}{*}{ 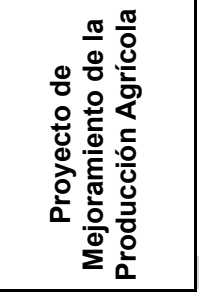 } & Asesor Agropecuario & 1.500 & 12 & 18.000 \\
\hline & Técnico Agropecuario & 1.200 & 12 & 14.400 \\
\hline & Movilización & 1.200 & 12 & 14.400 \\
\hline & Alimentación & 1.050 & 12 & 12.600 \\
\hline & Hospedaje & 1.350 & 12 & 16.200 \\
\hline & Capacitación & 1.500 & 6 & 9.000 \\
\hline & Material de trabajo & 1.000 & 12 & 12000 \\
\hline & \multicolumn{3}{|c|}{ SUBTOTAL } & 96.600 \\
\hline \multirow{4}{*}{ 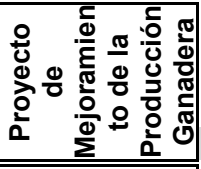 } & \begin{tabular}{|l|} 
Capacitación \\
\end{tabular} & 1.000 & 6 & 6.000 \\
\hline & Infraestructura & 3.000 & - & 3.000 \\
\hline & \begin{tabular}{|l|} 
Material de trabajo \\
\end{tabular} & 500 & 12 & 6.000 \\
\hline & \multicolumn{3}{|c|}{ SUBTOTAL } & 15.000 \\
\hline \multirow{8}{*}{ 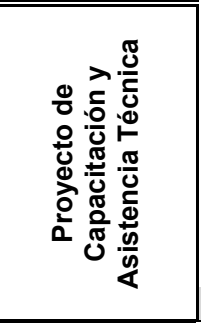 } & Coordinador & 1.500 & 12 & 18.000 \\
\hline & \begin{tabular}{|l|} 
Movilización \\
\end{tabular} & 200 & 12 & 2.400 \\
\hline & Alimentación & 200 & 12 & 2.400 \\
\hline & Hospedaje & 200 & 12 & 2.400 \\
\hline & Capacitación & 1.000 & 6 & 6.000 \\
\hline & Impresión y publicación de información & 3.000 & - & 3.000 \\
\hline & Material de trabajo & 500 & 12 & 6.000 \\
\hline & \multicolumn{3}{|c|}{ SUBTOTAL } & 40.200 \\
\hline TOTAL & & & & 151.800 \\
\hline
\end{tabular}




\subsection{Actores Clave}

Para poder ejecutar el programa es necesario contar con el apoyo de Instituciones Públicas y privadas relacionadas con el desarrollo agropecuario y el manejo de los recursos naturales, a fin de que estas puedan contribuir con los recursos económicos y el talento humano; esto sumado a la colaboración de la población; para este efecto se detallan los actores claves para la realización de este programa:

- Ministerio del Ambiente (Dirección Provincial de Imbabura)

- Ministerio de Agricultura, Ganadería, Acuacultura y Pesca (Dirección Provincial de Imabura).

- Ministerio de la Producción (Dirección Provincial de Imbabura).

- Universidades y/o centros de investigación

- Gobierno Autónomo Descentralizado Provincial de Imbabura

- Gobierno Autónomo Descentralizado del Cantón Cotacachi

- Gobiernos Autónomos Descentralizados de las Parroquias Apuela e Imantag

- ONG's y/o Entidades Cooperantes.

\section{PROYECTOS DEL PROGRAMA DE DESARROLLO COMUNITARIO.}

Dentro del Programa de Gestión Productiva se han diseñado los siguientes proyectos:

\subsection{Proyecto de Fortalecimiento Cultural}

El presente proyecto busca rescatar los valores, costumbres, actividades y conocimientos culturales y ancestrales, de las comunidades de la subcuenca del río Pitura; así como también el fortalecimiento de las organizaciones presentes dentro del área, a fin de desarrollar estrategias de autogestión y superación de limitaciones biofísicas y socioeconómicas.

Las acciones a desarrollarse en el proyecto se detallan a continuación:

- Generación de sistemas que permitan mejorar la relación, comunicación y representatividad de las comunidades. 
- Realización de proyectos de investigación que recuperen conocimiento ancestral de las comunidades, y los implementen en nuevas tecnologías de producción sustentable.

- Generación de centros de información, en donde se puedan documentar las investigaciones realizadas al servicio de las comunidades.

- Implementación de unidades operativas, que permitan viabilizar la ejecución de proyectos de las comunidades y sus necesidades organizativas.

- Implementación de sistemas de producción que adapten los sistemas de producción tradicionales a nuevas tecnologías con la finalidad de alcanzar la seguridad y soberanía alimentaria, así como también a proporcionarles los ingresos económicos indispensables para su desarrollo.

- Implementación de sistemas de crédito para fines productivos, sociales y de mejoramiento de viviendas.

- Implementación de sistemas de comercialización y transporte asociativo de los productos de las comunidades a fin de contrarrestar la poca infraestructura presente en la zona, intermediarios y la falta de atención por parte de autoridades competentes.

- Implementar sistemas de formación de líderes comunitarios, que encabecen los diferentes programas y proyectos dentro de las comunidades.

- Implementar actividades de alfabetización y profesionalización de los integrantes de las comunidades.

- Producción y distribución de material pedagógico en un marco de educación intercultural bilingüe.

- Evaluación y monitoreo permanente del proyecto.

\subsection{Proyecto de Salud Comunitaria}

La implementación de este proyecto nace con la finalidad de alcanzar el bienestar de la población, el cual depende de la satisfacción de las necesidades básicas, en términos económicos, sociales y ambientales, por lo a que a más de la implementación de los proyectos ambientales y productivos es necesario atender las necesidades sociales, entre ella la salud de las comunidades ubicadas dentro de la subcuenca, con énfasis en la prevención y saneamiento ambiental.

Las acciones a desarrollarse en el proyecto se detallan a continuación: 
- Capacitar a las comunidades y dotarlas de los elementos básicos para identificar, controlar, eliminar y manejar los factores de riesgo del ambiente, como parte fundamental de la prevención de enfermedades.

- Implementar campañas de vacunación, control y educación para la salud y nutrición a fin de mejorar las condiciones de salud de las comunidades.

- Adecuación de los sistemas administrativos de salud, a fin de reforzar el compromiso y la decisión política para con las comunidades ubicadas dentro de la subcuenca.

- Diseño y formulación de proyectos de salud y saneamiento pertinentes a las condiciones ambientales y socioeconómicas de la zona.

- Promover la participación activa de las familias en la gestión de servicios básicos de agua potable y eliminación de desechos sólidos y líquidos.

- Implementación de un proyecto de mejoramiento sanitario.

- Implantar y complementar la infraestructura física de agua potable y disposición sanitaria de desechos líquidos y sólidos, ajustado a las condiciones de la población y del medio ambiente.

- Conformación unidades de asistencia de primer nivel, que pueda brindar servicio de atención primaria en salud a la población, que estén conformadas cada una por: un médico general, del año rural o servicio social obligatorio; una enfermera licenciada, del año rural o servicio social obligatorio; dos auxiliares de enfermería; y, un tecnólogo en saneamiento básico.

- Realización de proyectos de barrido, con acciones promocionales, preventivas, educativas, asistenciales y de mantenimiento.

- Valoración nutricional, control periódico de la relación peso/talla, control del embarazo y estimulación de la lactancia materna, dentro de las comunidades.

- Elaboración y distribución de material educativo, acompañado de exposiciones informativas y educativas.

- Determinar la capacidad y el estado de funcionamiento de los diversos elementos que constituyen la infraestructura física sanitaria de la zona, a fin de poder solicitar mejoras a las autoridades competentes.

- Evaluación y monitoreo permanente del proyecto. 


\subsection{Cronograma del Programa}

En la tabla 6 se detalla el cronograma del Programa de Desarrollo Comunitario, especificando los semestres en los que se plantea realizar cada una de las acciones propuestas para los proyectos.

TABLA 9: Cronograma del Programa de Desarrollo Comunitario.

\begin{tabular}{|c|c|c|c|c|c|c|c|c|c|c|c|}
\hline \multirow{2}{*}{ PROYECTO } & \multirow{2}{*}{ ACTIVIDADES } & \multicolumn{10}{|c|}{ Semestre } \\
\hline & & 1 & 2 & 3 & 4 & 5 & 6 & 7 & 8 & 9 & 10 \\
\hline \multirow{11}{*}{ 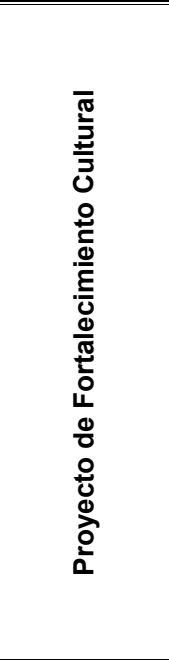 } & $\begin{array}{l}\text { Generación de sistemas que permitan mejorar la relación, } \\
\text { comunicación y representatividad de las comunidades. }\end{array}$ & & & & & & & & & & \\
\hline & Realización de proyectos de investigación & & & & & & & & & & \\
\hline & Generación de centros de información & & & & & & & & & & \\
\hline & Implementación de unidades operativas & & & & & & & & & & \\
\hline & $\begin{array}{l}\text { Implementación de sistemas de producción que adapten los } \\
\text { sistemas de producción tradicionales a nuevas tecnologías }\end{array}$ & & & & & & & & & & \\
\hline & Implementación de sistemas de crédito para fines productivos & & & & & & & & & & \\
\hline & $\begin{array}{l}\text { Implementación de sistemas de comercialización y transporte } \\
\text { asociativo de los productos de las comunidades }\end{array}$ & & & & & & & & & & \\
\hline & Implementar sistemas de formación de líderes comunitarios & & & & & & & & & & \\
\hline & $\begin{array}{l}\text { Implementar actividades de alfabetización y profesionalización de } \\
\text { los integrantes de las comunidades. }\end{array}$ & & & & & & & & & & \\
\hline & $\begin{array}{l}\text { Producción y distribución de material pedagógico en un marco de } \\
\text { educación intercultural bilingüe. }\end{array}$ & & & & & & & & & & \\
\hline & Evaluación y monitoreo permanente del proyecto. & & & & & & & & & & \\
\hline \multirow{14}{*}{ 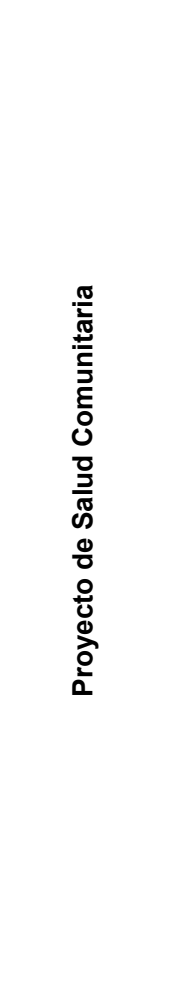 } & Incentivar fortalecimiento organizativo de las comunidades & & & & & & & & & & \\
\hline & $\begin{array}{l}\text { Implementar campañas de vacunación, control y educación para la } \\
\text { salud y nutrición }\end{array}$ & & & & & & & & & & \\
\hline & Adecuación de los sistemas administrativos de salud & & & & & & & & & & \\
\hline & Diseño y formulación de proyectos de salud y saneamiento & & & & & & & & & & \\
\hline & $\begin{array}{l}\text { Promover la participación activa de las familias en la gestión de } \\
\text { servicios básicos de agua potable y eliminación de desechos sólidos } \\
\text { y líquidos }\end{array}$ & & & & & & & & & & \\
\hline & Implementación de un proyecto de mejoramiento sanitario & & & & & & & & & & \\
\hline & $\begin{array}{l}\text { Capacitar a las comunidades y dotarlas de los elementos básicos } \\
\text { para identificar, controlar, eliminar y manejar los factores de riesgo } \\
\text { del ambiente }\end{array}$ & & & & & & & & & & \\
\hline & $\begin{array}{l}\text { Implantar y complementar la infraestructura física de agua potable y } \\
\text { disposición sanitaria de desechos líquidos y sólidos }\end{array}$ & & & & & & & & & & \\
\hline & Conformación unidades de asistencia de primer nivel & & & & & & & & & & \\
\hline & $\begin{array}{l}\text { Realización de proyectos de barrido, con acciones promocionales, } \\
\text { preventivas, educativas, asistenciales y de mantenimiento. }\end{array}$ & & & & & & & & & & \\
\hline & $\begin{array}{l}\text { Valoración nutricional, control periódico de la relación peso/talla, } \\
\text { control del embarazo y estimulación de la lactancia materna, dentro } \\
\text { de las comunidades. }\end{array}$ & & & & & & & & & & \\
\hline & $\begin{array}{l}\text { Elaboración y distribución de material educativo, acompañado de } \\
\text { exposiciones informativas y educativas }\end{array}$ & & & & & & & & & & \\
\hline & $\begin{array}{l}\text { Determinar la capacidad y el estado de funcionamiento de los } \\
\text { diversos elementos que constituyen la infraestructura física sanitaria } \\
\text { de la zona }\end{array}$ & & & & & & & & & & \\
\hline & Evaluación y monitoreo permanente del proyecto & & & & & & & & & & \\
\hline
\end{tabular}




\subsection{Costos del Programa}

En la tabla 7 se muestra que el programa de Desarrollo Comunitario tiene un costo de USD 591.400; este proyecto muestra un valor elevado para su realización debido a que es un proyecto social que al tener un componente de salud y saneamiento, necesita inversiones constantes en todo el periodo de aplicación del mismo; por esto es fundamental el apoyo de las instituciones públicas y privadas para poder alcanzar el proyecto.

TABLA 7: Costos del Programa de Desarrollo Comunitario.

\begin{tabular}{|c|c|c|c|c|}
\hline PROYECTO & DESCRIPCIÓN & $\begin{array}{c}\text { COSTO } \\
\text { UNITARIO } \\
\text { (USD) }\end{array}$ & $\begin{array}{l}\text { TIEMPO EN } \\
\text { MESES }\end{array}$ & $\begin{array}{c}\text { COSTO } \\
\text { TOTAL } \\
\text { (USD) }\end{array}$ \\
\hline \multirow{12}{*}{ 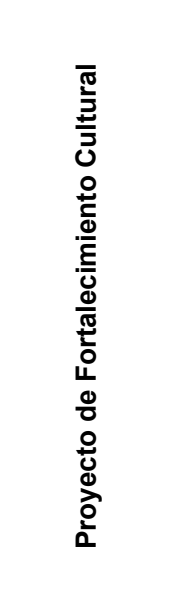 } & Coordinador & 1.500 & 12 & 18.000 \\
\hline & Asesor en Liderazgo & 1.200 & 12 & 14.400 \\
\hline & Asesor en Educación & 1.200 & 12 & 14.400 \\
\hline & Asesor Legal & 1.200 & 12 & 14.400 \\
\hline & Asesor en Organización Comunitaria & 1.200 & 12 & 14.400 \\
\hline & Movilización & 1.200 & 12 & 14.400 \\
\hline & Alimentación & 1.050 & 12 & 12.600 \\
\hline & Hospedaje & 1.350 & 12 & 16.200 \\
\hline & Capacitación & 1.500 & 6 & 9.000 \\
\hline & Infraestructura & 5.000 & 1 & 5.000 \\
\hline & Material de trabajo & 1.000 & 12 & 12000 \\
\hline & \multicolumn{3}{|c|}{ SUBTOTAL } & 144.800 \\
\hline \multirow{11}{*}{ 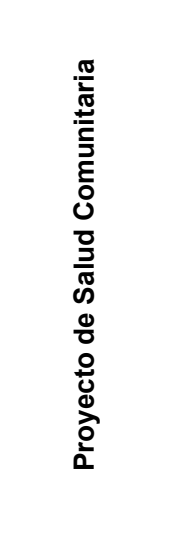 } & Médico general & 1.500 & 54 & 81.000 \\
\hline & Licenciada en Enfermería & 1.200 & 54 & 64.800 \\
\hline & 2 Auxiliares de enfermería & 1.600 & 54 & 86.400 \\
\hline & Movilización & 1.200 & 54 & 64.800 \\
\hline & Alimentación & 1.050 & 54 & 56.700 \\
\hline & Hospedaje & 1.350 & 54 & 72.900 \\
\hline & Campañas & 5.000 & 1 & 5.000 \\
\hline & Capacitación & 1.000 & 6 & 6.000 \\
\hline & Infraestructura & 3.000 & 1 & 3.000 \\
\hline & Material de trabajo & 500 & 12 & 6.000 \\
\hline & \multicolumn{3}{|c|}{ SUBTOTAL } & 446.600 \\
\hline \multicolumn{4}{|l|}{ TOTAL } & 591400 \\
\hline
\end{tabular}

\subsection{Actores Clave}

Para poder ejecutar el programa es necesario contar con el apoyo de Instituciones Públicas y privadas relacionadas con el desarrollo agropecuario y el manejo de los recursos naturales, a fin de que estas puedan contribuir con los recursos económicos y el talento 
humano; esto sumado a la colaboración de la población; para este efecto se detallan los actores claves para la realización de este programa:

- Ministerio del Ambiente (Dirección Provincial de Imbabura)

- Ministerio de Agricultura, Ganadería, Acuacultura y Pesca (Dirección Provincial de Imabura).

- Ministerio de la Producción (Dirección Provincial de Imbabura).

- Ministerio de Salud Pública (Dirección Provincial de Imbabura).

- Ministerio de Educación (Dirección Provincial de Imbabura).

- Secretaria Nacional de Educación Superior Ciencia y Tecnología (Dirección Provincial de Imbabura).

- Servicio Ecuatoriano de Capacitación Profesional.

- Universidades y/o centros de investigación

- Gobierno Autónomo Descentralizado Provincial de Imbabura

- Gobierno Autónomo Descentralizado del Cantón Cotacachi

- Gobiernos Autónomos Descentralizados de las Parroquias Apuela e Imantag

- ONG's y/o Entidades Cooperantes.

\section{PROYECTOS DEL PROGRAMA}

Dentro del Programa de Gestión Productiva se han diseñado los siguientes proyectos:

\subsection{Proyecto de Capacitación para el Fortalecimiento de Organizaciones}

El presente proyecto busca generar una metodología de capacitación para que las comunidades puedan atender las problemáticas y necesidades que se les presentan en los campos sociales, económicos y ambientales; es fundamental la participación de todos los integrantes de las comunidades encabezados por los líderes comunitarios que tomarán el papel de replicadores del conocimiento y facilitadores para el resto de los integrantes, a fin de consolidar el proceso organizativo en la zona.

Las acciones planteadas para el desarrollo del proyecto se muestran a continuación: 
- Capacitación de relaciones humanas para mejorar la comunicación entre organizaciones, comunidad y conocer la importancia del trabajo en grupo.

- Generar apoyo logístico, administrativo y de material de trabajo que se requieren para las diferentes capacitaciones y replicación del conocimiento.

- Generar convenios con instituciones públicas y privadas, a fin de que puedan ejecutar propuestas específicas de organización y capacitación

- Incentivar la creación de un fondo para financiar pequeños proyectos de comunidad que surjan de la aplicación del proceso de capacitación, y que no se encuentren contemplados dentro de los otros programas del Plan de Manejo Integral.

- Gestionar recursos para apoyar en el proceso de capacitación y cooperación comunitaria.

- Impulsar la investigación aplicada y participativa, el intercambio de experiencias y el acopio y sistematización de información mediante la creación de un sistema de documentación y proyectos para la subcuenca.

- Actualizar y difundir el reglamento interno a las comunidades.

- Intercambio de experiencias con comunidades que tengan iniciativas comunitarias de gestión.

- Evaluación y monitoreo permanente del proyecto

\subsection{Proyecto de Desarrollo Integral de la Mujer Comunitaria}

El presente proyecto nace de la necesidad de generar una conciencia sobre el papel primordial que la mujer desempeña en las actividades productivas, de seguridad y alimentaria y nutricional y sobre todo en el bienestar familiar y comunitario, a fin de reposicionarla como un actor fundamental para alcanzar el desarrollo; pese a la importancia que la mujer desempeña en la familia, la comunidad y la sociedad esta se enfrenta a grandes restricciones para poder desarrollarse personalmente y como ente de desarrollo, debido a que es víctima de una fuerte discriminación que no le permite tener total apertura en el manejo de los recursos como la tierra, créditos, insumos e infraestructura y a la vez no tiene total acceso a servicios de educación, salud, y capacitación. Es por eso que este proyecto es necesario como una herramienta que le permita eliminar las restricciones a las que se enfrenta y le permita aportar todo su potencial.

Para la realización del presente proyecto se plantean realizar las siguientes acciones: 
- Capacitación sobre temas de género a los habitantes de la subcuenca.

- Integración de una perspectiva de género en todas las estrategias y programas de desarrollo dentro de las comunidades.

- Generar un sistema de capacitación y asistencia técnica empresarial, constituyendo objetivos vinculantes al proceso de desarrollo de la mujer.

- Estimular la congregación, participación comunitaria, aprendizaje de nuevos conocimientos y técnicas productivas y manejo administrativo y empresarial.

- Brindar asistencia técnica, empresarial y financiera a las mujeres de las comunidades.

- Ejecutar proyectos de huertas caseras, cría de especies menores, talleres de artesanía, talleres de costura, madres comunitarias, panaderías, tiendas comunales, elaboración de dulces, conservas y lácteos, y ecología y turismo.

- Estimular su organización y autogestión, impulsando su organización y capacitación.

- Promover la inclusión de las necesidades específicas de las mujeres en planes y programas de desarrollo.

- Contribuir al reconocimiento de su aporte a la vida económica, social y cultural de las comunidades.

\subsection{Cronograma del Programa}

En la tabla 8 se detalla el cronograma del Programa de Atención Comunitaria, especificando los semestres en los que se plantea realizar cada una de las acciones propuestas para los proyectos.

TABLA 8: Cronograma del Programa de Capacitación y Organización Comunitaria.

\begin{tabular}{|c|c|c|c|c|c|c|c|c|c|c|c|}
\hline \multirow{2}{*}{ PROYECTO } & \multirow{2}{*}{ ACTIVIDADES } & \multicolumn{10}{|c|}{ Semestre } \\
\hline & & 1 & 2 & 3 & 4 & 5 & 6 & 7 & 8 & 9 & 10 \\
\hline \multirow{4}{*}{ 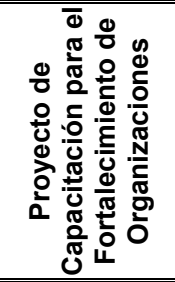 } & $\begin{array}{l}\text { Generar apoyo logístico, administrativo y de material de trabajo que se } \\
\text { requieren para las diferentes capacitaciones y replicación del conocimiento }\end{array}$ & & & & & & & & & & \\
\hline & Generar convenios con instituciones públicas y privadas & & & & & & & & & & \\
\hline & $\begin{array}{l}\text { Incentivar la creación de un fondo para financiar pequeños proyectos de } \\
\text { comunidad }\end{array}$ & & & & & & & & & & \\
\hline & $\begin{array}{l}\text { Gestionar recursos para apoyar en el proceso de capacitación y cooperación } \\
\text { comunitaria }\end{array}$ & & & & & & & & & & \\
\hline
\end{tabular}

Continúa en la siguiente página 


\begin{tabular}{|c|c|c|c|c|c|c|c|c|c|c|c|}
\hline \multirow{2}{*}{ PROYECTO } & \multirow{2}{*}{ ACTIVIDADES } & \multicolumn{10}{|c|}{ Semestre } \\
\hline & & 1 & 2 & 3 & 4 & 5 & 6 & 7 & 8 & 9 & 10 \\
\hline \multirow{6}{*}{ 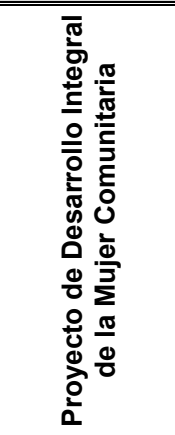 } & $\begin{array}{l}\text { Impulsar la investigación aplicada y participativa, el intercambio de experiencias } \\
\text { y el acopio y sistematización de información mediante la creación de un sistema } \\
\text { de documentación y proyectos para la subcuenca }\end{array}$ & & & & & & & & & & \\
\hline & $\begin{array}{l}\text { Capacitación de relaciones humanas para mejorar la comunicación entre } \\
\text { organizaciones }\end{array}$ & & & & & & & & & & \\
\hline & Actualizar y difundir el reglamento interno a las comunidades. & & & & & & & & & & \\
\hline & $\begin{array}{l}\text { Intercambio de experiencias con comunidades que tengan iniciativas } \\
\text { comunitarias de gestión }\end{array}$ & & & & & & & & & & \\
\hline & $\begin{array}{l}\text { Impulsar la investigación aplicada y participativa, el intercambio de experiencias } \\
\text { y el acopio y sistematización de información mediante la creación de un sistema } \\
\text { de documentación y proyectos para la subcuenca }\end{array}$ & & & & & & & & & & \\
\hline & Evaluación y monitoreo del proyecto & & & & & & & & & & \\
\hline \multirow{10}{*}{ 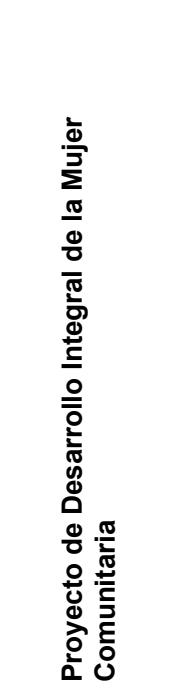 } & Capacitación de los habitantes de la subcuenca & & & & & & & & & & \\
\hline & $\begin{array}{l}\text { Integración de una perspectiva de género en todas las estrategias y programas } \\
\text { de desarrollo dentro de las comunidades }\end{array}$ & & & & & & & & & & \\
\hline & $\begin{array}{l}\text { Generar un sistema de capacitación y asistencia técnica empresarial, } \\
\text { constituyendo objetivos vinculantes al proceso de desarrollo de la mujer }\end{array}$ & & & & & & & & & & \\
\hline & $\begin{array}{l}\text { Estimular la congregación, participación comunitaria, aprendizaje de nuevos } \\
\text { conocimientos y técnicas productivas y manejo administrativo y empresarial. }\end{array}$ & & & & & & & & & & \\
\hline & $\begin{array}{l}\text { Brindar asistencia técnica, empresarial y financiera a las mujeres de las } \\
\text { comunidades }\end{array}$ & & & & & & & & & & \\
\hline & $\begin{array}{l}\text { Ejecutar proyectos de huertas caseras, cría de especies menores, talleres de } \\
\text { artesanía, talleres de costura, madres comunitarias, panaderías, tiendas } \\
\text { comunales, elaboración de dulces, conservas y lácteos, y ecología y turismo }\end{array}$ & & & & & & & & & & \\
\hline & $\begin{array}{l}\text { Estimular su organización y autogestión, impulsando su organización y } \\
\text { capacitación }\end{array}$ & & & & & & & & & & \\
\hline & $\begin{array}{l}\text { Promover la inclusión de las necesidades específicas de las mujeres en planes } \\
\text { y programas de desarrollo }\end{array}$ & & & & & & & & & & \\
\hline & $\begin{array}{l}\text { Contribuir al reconocimiento de su aporte a la vida económica, social y cultural } \\
\text { de las comunidades. }\end{array}$ & & & & & & & & & & \\
\hline & Evaluación y monitoreo permanente de la cuenca & & & & & & & & & & \\
\hline
\end{tabular}

\subsection{Costos del Programa}

En la tabla 9 se muestra que el programa de Capacitación y Organización Comunitaria tiene un costo de USD 172 200; al igual que el anterior proyecto este se muestra como un proyecto social, que necesita inversiones constantes en todo el periodo de aplicación del mismo; por esto es fundamental el apoyo de las instituciones públicas y privadas para poder alcanzar el proyecto. 
TABLA 9: Costos del Programa de Capacitación y Organización Comunitaria.

\begin{tabular}{|c|c|c|c|c|}
\hline PROYECTO & DESCRIPCIÓN & $\begin{array}{c}\text { COSTO } \\
\text { UNITARIO } \\
\text { (USD) }\end{array}$ & $\begin{array}{l}\text { TIEMPO EN } \\
\text { MESES }\end{array}$ & $\begin{array}{c}\text { COSTO } \\
\text { TOTAL } \\
\text { (USD) }\end{array}$ \\
\hline \multirow{13}{*}{ 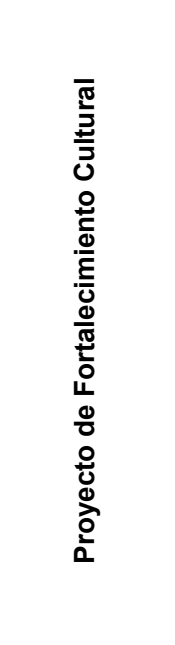 } & Coordinador & 1.500 & 12 & 18.000 \\
\hline & Asesor en Liderazgo & 1.200 & 12 & 14.400 \\
\hline & Asesor en Educación & 1.200 & 12 & 14.400 \\
\hline & Asesor Legal & 1.200 & 12 & 14.400 \\
\hline & Asesor en Organización Comunitaria & 1.200 & 12 & 14.400 \\
\hline & Asesor en manejo de conflictos & 1.200 & 12 & 14.400 \\
\hline & Movilización & 1.200 & 12 & 14.400 \\
\hline & Alimentación & 1.050 & 12 & 12.600 \\
\hline & Hospedaje & 1.350 & 12 & 16.200 \\
\hline & Capacitación & 1.500 & 6 & 9.000 \\
\hline & Infraestructura & 3.000 & 1 & 3.000 \\
\hline & \begin{tabular}{|l|} 
Material de trabajo \\
\end{tabular} & 1.000 & 12 & 12000 \\
\hline & \multicolumn{3}{|c|}{ SUBTOTAL } & 157.200 \\
\hline \multirow{4}{*}{ 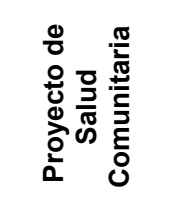 } & Capacitación & 1.000 & 6 & 6.000 \\
\hline & Infraestructura & 3.000 & 1 & 3.000 \\
\hline & Material de trabajo & 500 & 12 & 6.000 \\
\hline & \multicolumn{3}{|c|}{ SUBTOTAL } & 15.000 \\
\hline \multicolumn{4}{|l|}{ TOTAL } & 172.200 \\
\hline
\end{tabular}

\subsection{Actores Clave}

Para poder ejecutar el programa es necesario contar con el apoyo de Instituciones Públicas y privadas relacionadas con el desarrollo agropecuario y el manejo de los recursos naturales, a fin de que estas puedan contribuir con los recursos económicos y el talento humano; esto sumado a la colaboración de la población; para este efecto se detallan los actores claves para la realización de este programa:

- Ministerio del Ambiente (Dirección Provincial de Imbabura)

- Ministerio de Agricultura, Ganadería, Acuacultura y Pesca (Dirección Provincial de Imabura).

- Ministerio de la Producción (Dirección Provincial de Imbabura).

- Ministerio de Inclusión Económica y Social (Dirección Provincial de Imbabura).

- Ministerio de Salud Pública (Dirección Provincial de Imbabura).

- Ministerio de Educación (Dirección Provincial de Imbabura). 
- Secretaria Nacional de Educación Superior Ciencia y Tecnología (Dirección Provincial de Imbabura).

- Servicio Ecuatoriano de Capacitación Profesional.

- Universidades y/o centros de investigación

- Gobierno Autónomo Descentralizado Provincial de Imbabura

- Gobierno Autónomo Descentralizado del Cantón Cotacachi

- Gobiernos Autónomos Descentralizados de las Parroquias Apuela e Imantag

- ONG's y/o Entidades Cooperantes. 